Portland State University

PDXScholar

$5-12-2020$

\title{
Optimized Xanthene-based Probes for Pancreatic Cancer Imaging
}

Ian Ruramai Munhenzva

Portland State University

Follow this and additional works at: https://pdxscholar.library.pdx.edu/open_access_etds

Part of the Biomedical Engineering and Bioengineering Commons, and the Chemistry Commons Let us know how access to this document benefits you.

\section{Recommended Citation}

Munhenzva, Ian Ruramai, "Optimized Xanthene-based Probes for Pancreatic Cancer Imaging" (2020). Dissertations and Theses. Paper 5461.

https://doi.org/10.15760/etd.7333

This Dissertation is brought to you for free and open access. It has been accepted for inclusion in Dissertations and Theses by an authorized administrator of PDXScholar. Please contact us if we can make this document more accessible: pdxscholar@pdx.edu. 
Optimized Xanthene-based Probes for Pancreatic Cancer Imaging

$$
\text { by }
$$

Ian Ruramai Munhenzva

\begin{abstract}
A dissertation submitted in partial fulfillment of the requirements for the degree of
\end{abstract}

\author{
Doctor of Philosophy \\ in \\ Chemistry
}

Dissertation Committee:

Robert M. Strongin, Chair

Andrea Goforth

David R. Stuart

Daniel Ballhorn

Portland State University

2020 
(C) 2020 Ian Ruramai Munhenzva 


\begin{abstract}
Pancreatic Ductal Adenocarcinoma (PDAC) is one of the deadliest human malignancies with an extremely poor 5-year survival rate of below 5\%. Surgical resection is the most effective treatment of choice because chemotherapy and radiation therapy do not improve life expectancy. Residual tumor after PDAC surgery is common due to a lack of PDAC targeted intraoperative contrast agents to confirm clear margins.

Fluorescence imaging has the potential to improve surgery outcome and PDAC patients' survival rate via the use of highly PDAC-specific molecular probes to facilitate tumor identification. This thesis describes the application of a focused library of benzoxanthene fluorophores for PDAC margin assessment. This work shows the utility of fluorophore 12 in the ex vivo staining of human PDAC tissue. When 12 was used for ex vivo staining of healthy pancreas and PDAC tissue, it displayed visually higher localization in the PDAC-associated ductal epithelial cells compared to the healthy tissue. We optimized the ex vivo staining conditions such as fluorophore concentration, fluorophore incubation and washing time, for clinical translation. A receiver operator characteristic (ROC) curve analysis was used as a non-subjective evaluation for effective contrast between cancer and healthy tissue, confirming high throughput and efficient screening for the investigated parameters.
\end{abstract}

The need for dyes that are active in the near-infrared region (NIR) region $(>700$ $\mathrm{nm})$ and have large Stoke shifts led to the design and synthesis of a benzo[a]xanthene library. Among other advantages, imaging in the NIR results in reduced tissue damage and 
reduced photobleaching of the fluorophore. The benzo[a]xanthene library shows at least two-fold enhanced brightness compared to the benzo[c]xanthene library, along with no significant bathochromic shift, as predicted by density functional theory (DFT) calculations. Compound $\mathbf{8}$, a regioisomer of $\mathbf{1 2}$ with analogous physicochemical properties, showed selectivity for PDAC but was not as optimal as $\mathbf{1 2}$. The functionalization of the benzo[c]xanthene chromophore with a cyanine chromophore moiety was proposed towards developing NIR-active fluorophores. The synthesis of cyanine-xanthene hybrids was begun. Once the synthesis is optimized, the hybrid dyes will be screened for PDAC selectivity and subsequently used for PDAC margin assessment. 


\section{Acknowledgements}

First and foremost, I would like to express my deepest gratitude to Dr. Strongin for giving me the opportunity to work with him. Thank you Dr. Strongin for believing in me, encouraging me, and for always being supportive of me. I would not have done this work without your strong guidance and support.

I would like to strongly thank my dissertation committee Dr. Stuart, Dr. Goforth, Dr. Ballhorn and Dr. Simoyi for their precious time, constructive criticism and willingness to help. A huge thank you goes to Dr. Sibrian-Vazquez and Dr. Jorge Escobedo for their selflessness in helping me throughout this journey, I will always be indebted to you. A special thank you goes to Dr. Lei Wang for training me and for being a much need friend throughout this journey. I would like to thank our collaborators at Oregon Health and Science University, Dr. Summer Gibbs, Dr. Xiaolin Nan and Dr. Connor Barth for opening their labs to allow me to work with them and being trained on so many techniques important for this work.

I would like to thank the past and present members of Dr. Strongin research group for their constant peer support. To each and every undergraduate volunteer I had the greatest opportunity to work with, thank you so much for your contribution and your commitment, I really appreciate you. I also would like to thank the Department of Chemistry for giving me an opportunity to be an assistant in the BioAnalytical Mass Spectrometry Facility, a role I'm forever grateful for. Thank you Dr. Andrea Debarber for taking me under your wing and believing in me, I learned so much from working with you. 
Lastly, I would like to thank my family back in Zimbabwe for their love and prayers. Your support has made this happen and I'm forever grateful to have you in my life. My friends back home and here in the US, thank you so much for the love and encouragement in my pursuit. All I can sing is Ebenezer, thus far the Lord has brought us. 


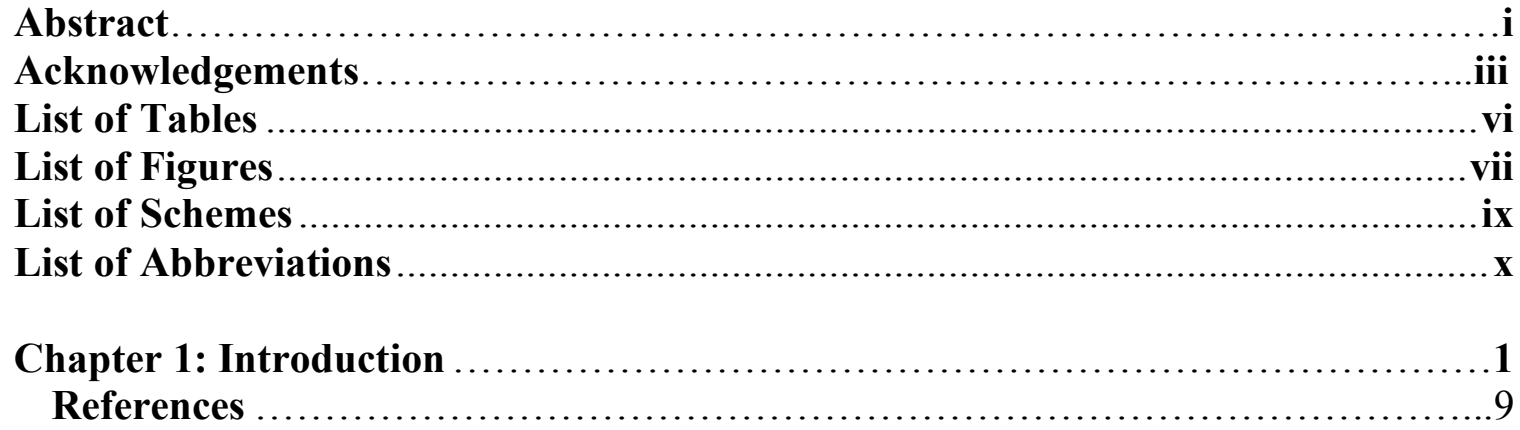

Chapter 2: Assessment of Human Pancreas Cancer Tissue and Precursor Lesions Via a Fluorophore with Inherent PDAC Selectivity ...........................12

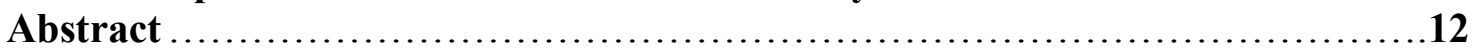

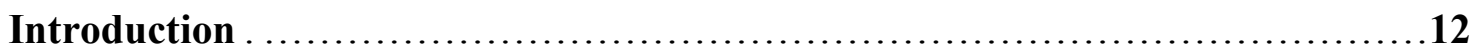

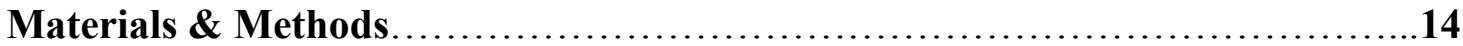

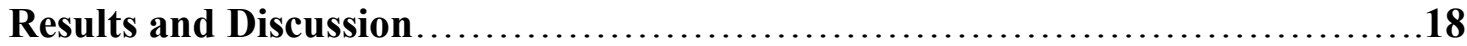

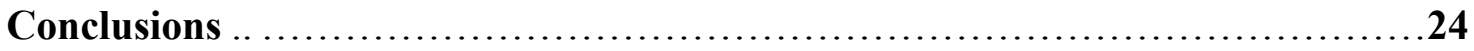

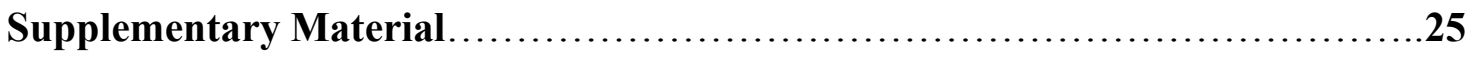

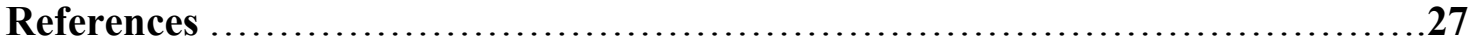

Chapter 3: Altering Fundamental Trends in the Emission of Xanthene Dyes .......29

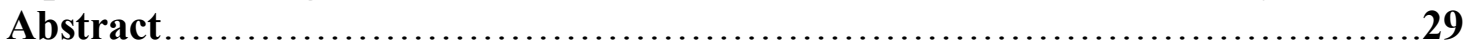

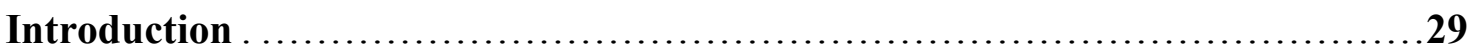

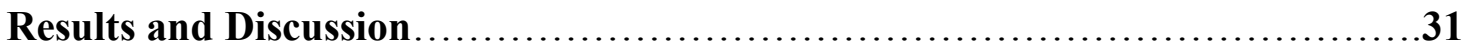

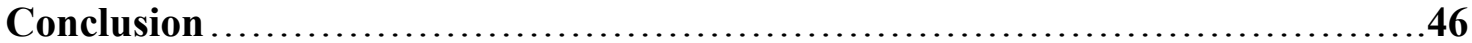

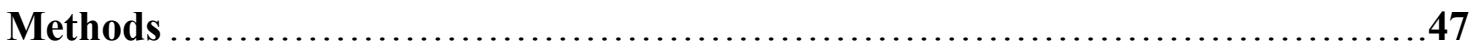

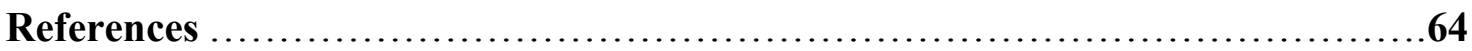

Chapter 4: Synthesis of Near Infrared Cyanine-Xanthene Hybrid Probes .........66

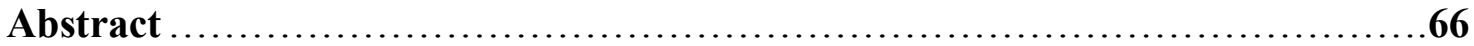

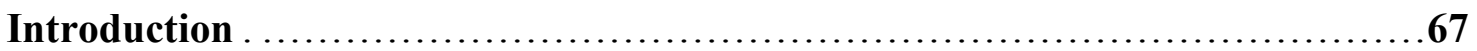

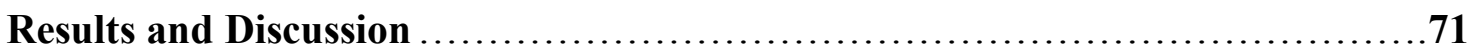

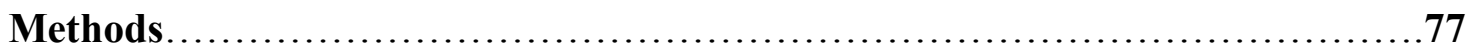

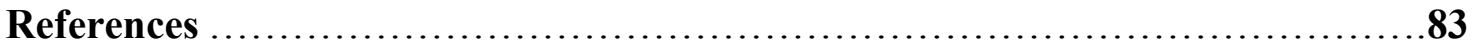

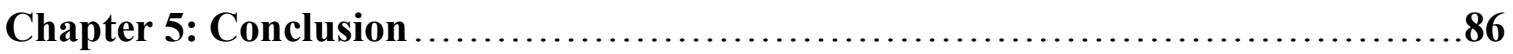

Appendix A: Supporting Information for Chapter 3 $\ldots \ldots \ldots \ldots \ldots \ldots \ldots \ldots \ldots \ldots \ldots$

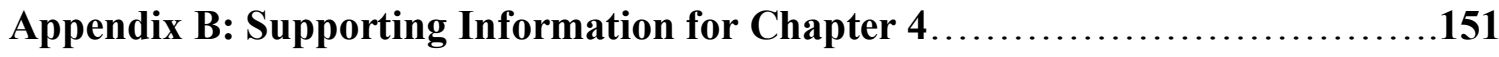




\section{Chapter 1 Tables}

\section{List of Tables}

Table 1. Guidelines for physicochemical properties described by Lipinski and Verber

Rules

\section{Chapter 2 Tables}

Table 1. Tissue staining optimization ROC analysis. AUC values are listed for fluorophore concentration and incubation time optimization studies with KMC mouse

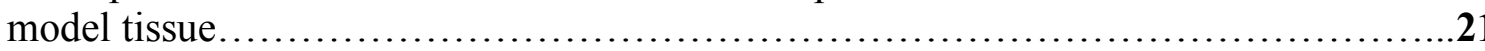

Table 2. ROC AUC values for human tissue staining with compound $12 \ldots \ldots \ldots \ldots \ldots .23$

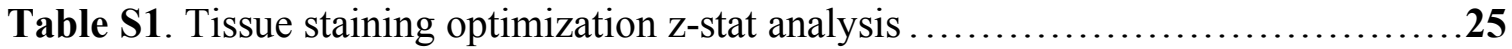

\section{Chapter 3 Tables}

Table 1. Spectral properties of compounds 1-9 in $\mathrm{MeOH}$

Table 2. Dihedral angles $\left(\mathrm{C}_{(7-10)}\right)$ and dipole moment for compounds $\mathbf{7 , 8}$ and 9 in their cationic and neutral forms from DFT-optimized geometries in the ground state.... 


\section{Chapter 1 Figures}

\section{List of Figures}

Figure 1. Hematoxylin \& Eosin stained normal, precancerous lesions (PanIN 1-3) and cancer tissue.

Figure 2. Altering angle of annulation and transposition of polar groups $\left(R_{2}\right.$ and $\left.R_{3}\right)$ to modulate physicochemical properties and photophysical properties.....................4

Figure 3. $\mathrm{R}_{2}$-substituted benzo[c]xanthene library of fluorophores $\ldots \ldots \ldots \ldots \ldots \ldots \ldots \ldots . .5$

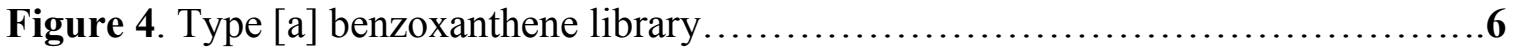

Figure 5. A library of cyanine-xanthene library .................................

\section{Chapter 2 Figures}

Figure 1. Compound 12 ....

Figure 2. Ex vivo images from frozen sections of resected human tissue stained with compound $\mathbf{1 2}$....

Figure 3. Whole tissue images of frozen sections (top panel) of healthy, PanIN, poorly moderately differentiated and moderately differentiated human normal and PDAC

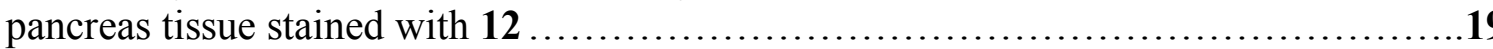

Figure 4. ROC curves for KMC mouse model ductal adenocarcinoma vs. stroma tissue differentiation following staining using $\mathbf{1 2}(125 \mu \mathrm{M})$.

Figure 5. Signal quantification from PDAC KMC mouse model tissue represented as pixel intensity histograms.

Figure 6 ROC curves for control (black), PanIN (green), high grade (brown) and low grade (red) human ductal adenocarcinoma vs. stroma tissue differentiation derived from staining with $\mathbf{1 2}$

Figure S1. Whole tissue images (in triplicate) of frozen sections (from top) of healthy, PanIN, poorly moderately differentiated and moderately differentiated human normal and PDAC pancreas tissue stained with $\mathbf{1 2}$ and unstained PDAC control tissue as the first image in each panel.

Figure S2. Whole tissue images of frozen sections from KMC mouse PDAC pancreas tissue stained with different concentrations of $\mathbf{1 2}$ for different incubation times and unstained PDAC control tissue as the first image in each panel.

\section{Chapter 3 Figures}

Figure 1. Annulation of the xanthene chromophore can lead to three types of benzoxanthenes. The benzo[a]xanthene framework is annulated on the side opposite to

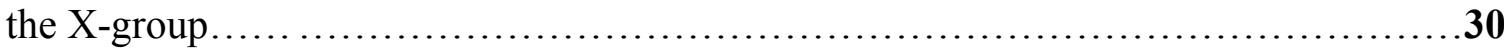

Figure 2. Seminaphthorhodafluors and seminaphthorhodamines...................31

Figure 3. Spectral properties of compounds 1-9 in aqueous media..................35

Figure 4. Comparison of the optical properties of compounds 7-9..................39

Figure 5. Figure 5. DFT-optimized geometries of the cationic (top) and the neutral forms (bottom) of compounds 7 (left) and 9 (right).

Figure 6. Calculated molecular electrostatic potential surfaces of DFT optimized geometries of the cationic and the neutral forms of compounds $\mathbf{7}$ and $\mathbf{9}$ in the groundstate 


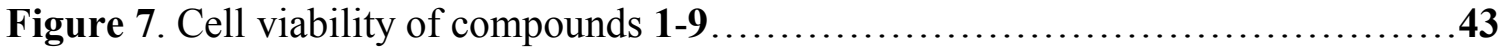

Figure 8. Subcellular localization of compound $8 \ldots \ldots \ldots \ldots \ldots \ldots \ldots \ldots \ldots \ldots \ldots \ldots \ldots 4$

Figure 9. A direct comparison of human PDAC tissue staining pattern of $\mathbf{8}$

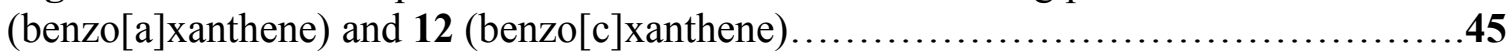

Figure 10. Immunofluorescence imaging of a microtubule network................46

\section{Chapter 4 Figures}

Figure 1. The xanthene core structure and common xanthene-based dyes showing possible sites for modification (blue numbers) ...............................67

Figure 2. The xanthene backbone and three possible sites for annulation..............68

Figure 3. Benzo[c]xanthene functionalized with a cyanine moiety to afford cyanine-

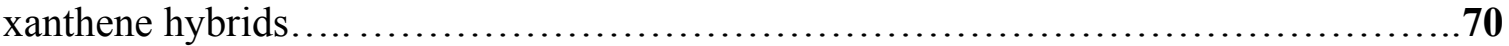

Figure 4. A library of cyanine-xanthene hybrid probes..........................71

Figure 5. Calculated absorption wavelength of proposed cyanine-xanthene hybrid

probes. 


\section{List of Schemes}

\section{Chapter 3 Schemes}

Scheme 1. Synthesis of seminaphthorhodafluors from the benzo[a]xanthenes series. 32

Scheme 2. Synthesis of 8-NHS.

\section{Chapter 4 Schemes}

Scheme 1. Synthesis of cyanine moiety first to form cyanine-xanthene dyes...........73

Scheme 2. First synthesize the $-\mathrm{C}-\mathrm{O}$ bridge of xanthene chromophore $\ldots \ldots \ldots \ldots \ldots \ldots . .75$

Scheme 3. First synthesize benzo[c]xanthene triflate followed by cross coupling with conjugated alkene........................................................ 


\section{List of Abbreviations}

\begin{tabular}{|c|c|}
\hline Ar & Argon \\
\hline Capan-1 & A human pancreatic ductal adenocarcinoma cell line \\
\hline DFT & Density Functional Theory \\
\hline $\mathrm{DMF}$ & Dimethylformamide \\
\hline DMSO & Dimethyl sulfoxide \\
\hline EEMs & Excitation emission matrices \\
\hline ER & Endoplasmic reticulum \\
\hline EtOAc & Ethyl acetate \\
\hline FDA & The Food and Drug Administration \\
\hline $\mathrm{H} \& \mathrm{E}$ & Hematoxylin and eosin \\
\hline $\mathrm{H}_{2} \mathrm{SO}_{4}$ & Sulfuric acid \\
\hline $\mathrm{HCl}$ & Hydrochloric acid \\
\hline HOAc & Acetic acid \\
\hline HOMO & Highest occupied molecular orbital \\
\hline HPLC & High-performance liquid chromatography \\
\hline HR ESI & High-resolution electrospray ionization \\
\hline $\mathrm{Hz}$ & Hertz \\
\hline IC50 & Half maximal inhibitory concentration \\
\hline ICG & Indocyanine green \\
\hline $\mathrm{K}_{2} \mathrm{CO}_{3}$ & Potassium carbonate \\
\hline $\log \mathrm{D}$ & Physicochemical partition coefficients \\
\hline LUMO & Lowest unoccupied molecular orbital \\
\hline$m / z$ & Mass to charge ratio \\
\hline MB & Methylene blue \\
\hline
\end{tabular}




$\begin{array}{ll}\mathrm{MeOH} & \text { Methanol } \\ \mathrm{MS} & \text { Mass spectrometry } \\ \mathrm{MW} & \text { Molecular weight } \\ \mathrm{N}_{2} & \text { Nitrogen } \\ \mathrm{NaOH} & \text { Sodium hydroxide } \\ \mathrm{NIR} & \text { Near infrared } \\ \mathrm{NMR} & \text { Nuclear magnetic resonance } \\ \text { OCT } & \text { Optimal cutting temperature } \\ \text { OHSU } & \text { Oregon Health and Science University } \\ \text { PanIN } & \text { Pancreatic intraepithelial neoplasia } \\ \text { PBS } & \text { Phosphate-buffered saline } \\ \text { PC } & \text { Pancreatic cancer } \\ \text { PDAC } & \text { Pancreatic ductal adenocarcinoma } \\ \text { PFA } & \text { Paraformaldehyde } \\ \text { pKa } & \text { The logarithmic acidity constant } \\ \text { rt } & \text { Room temperature } \\ \text { SBR } & \text { Signal to background ratio } \\ \text { SiO } & \text { Silicon dioxide } \\ \text { TFA } & \text { Trifluoroacetic acid } \\ \text { TLC } & \text { Thin layer chromatography } \\ \text { UV-Vis } & \text { Ultraviolet-visible } \\ \lambda_{\max } \text { abs } & \text { The wavelength of maximum absorption } \\ \lambda_{\max } \text { em } & \text { The wavelength of maximum emission } \\ \delta & \text { Chemical shifts } \\ & \end{array}$




\section{Chapter 1: Introduction}

\section{Pancreatic cancer}

Pancreatic Ductal Adenocarcinoma (PDAC) is the most prevalent form of pancreatic cancer, accounting for over $90 \%$ of all pancreatic cancer cases. ${ }^{1}$ Approximately 57,600 people will be diagnosed with pancreatic cancer and 47,050 of these patients will die. Pancreatic cancer accounts for $\sim 3 \%$ of all cancer cases in the US and $\sim 7 \%$ of all cancer deaths. ${ }^{2}$ Due to the late diagnosis of PDAC, conventional treatments such as chemotherapy and radiotherapy are ineffective, leaving surgery as the relatively most effective cure. ${ }^{3}$ White light visualization, palpation and rapid frozen section analysis (FSA) are some of the methods used during PDAC surgery to aid complete resection of the tumor. ${ }^{4}$ Due, in large part, to a lack of commercially available PDAC specific contrast agents, up to $75 \%$ of patients are left with residual disease after surgery. ${ }^{5}$ This high number highlights the current inability to detect the true delineation of the tumor extent during surgery. ${ }^{6}$ There is thus a need to develop PDAC contrast agents that can be used during surgery for margin assessment. Moreover, PDAC-specific probes may potentially be used for intraoperative FSA. ${ }^{7}$ Intraoperative frozen section examination is a common technique to assess tumor involvement (R1) during pancreatic cancer surgery. ${ }^{8}$ The goal is to achieve clear margins, where there is no tumor involvement (R0), after surgery. ${ }^{5}$

To develop such contrast agents it is important to understand the microenvironment

of PDAC that is characterized by high stromal tissue (Figure 1). The healthy acini cells are 
replaced by fibrous tissue in cancer. ${ }^{1}$ The stroma can act as a "fortress" blocking the entry of small molecules to the ducts with adenocarcinoma. ${ }^{4}$

The progression to cancer starts with precursor lesions called the pancreatic intraepithelial neoplasia (PanIN) which, by step-wise mutations, start from low-grade hyperplasia (PanIN-1 to PanIN-2) of the normal cells to high grade dysplasia/carcinoma in situ (PanIN-3). Once cancer evolves, the stroma comprises up to $90 \%$ of the mass (Figure 1). ${ }^{9}$ The components of the stroma include fibroblasts, leukocytes, endothelial cells and extracellular matrix proteins. ${ }^{10}$
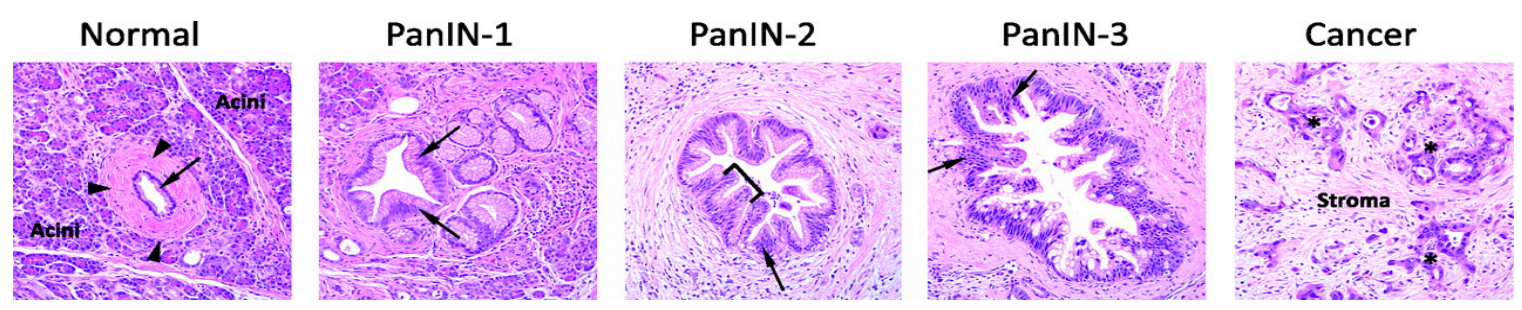

Figure 1. Hematoxylin \& Eosin stain of normal, precancerous lesions (PanIN 1-3) and cancer tissue.

Additionally, the mitochondrial membrane potential of cancer cells is relatively more negative compared to normal cells. ${ }^{11}$ This is due to mitochondrial DNA mutations. The differential membrane potential between cancer cells and normal cells has allowed for the use of cationic small molecules to study mitochondrial metabolism and also as potential anticancer drugs. ${ }^{12-17}$

In the work described herein, cationic probes are used as contrast imaging agents. The synthetic lipophilic cationic dyes selectively accumulate in the mitochondria of cancer cells compared to normal cells, enabling contrast between cancer and normal cells. Physicochemical properties including lipophilicity, charge, polar surface area, dipole 
moment are parameters for investigation towards the design and synthesis of inherent targeting contrast agents to achieve selectivity.

\section{Probe Design for PDAC Imaging}

To address the characteristic features of the PDAC microenvironment and the phenotypic properties of cancer cells (e.g., elevated mitochondrial membrane potential), a series of probes were systematically designed with a focus on their physicochemical properties of the dyes. ${ }^{4,11}$ Charge, lipophilicity, charge density, polar surface area and dipole moment are descriptors used in the drug development industry to achieve optimum biodistribution and tissue targeting. The descriptors as described by the Lipinski rule of five and the Verber rules (Figure 2) embody a starting framework to help understand optimal tissue targeting. Throughout the work herein, the physicochemical properties of the synthetic dyes served as a context to begin to understand optimal tissue targeting. ${ }^{18-20}$

Table 1. Guidelines for the physicochemical properties of drugs described by Lipinski and Verber Rules.

\begin{tabular}{|c|c|c|c|c|}
\hline $\begin{array}{c}\text { Lipinski } \\
\text { Rules }\end{array}$ & Log $\mathrm{D}<5$ & $\mathrm{MW}<500$ & $\begin{array}{c}\text { H-bond acceptors } \\
<5\end{array}$ & $\begin{array}{c}\text { H-bond donors } \\
<5\end{array}$ \\
\hline Verber & \multicolumn{2}{|c|}{ Polar surface area } & \multicolumn{2}{|c|}{ Rotatable bonds } \\
Rules & \multicolumn{2}{|c|}{$<140 \mathrm{~A}^{2}$} & \multicolumn{2}{|c}{$<$} \\
\hline
\end{tabular}

The Xanthene chromophore (Figure 2) acts a great platform to develop probes with diverse physicochemical properties, enabling structure-activity-relationship studies. Facile 
modifications to the chromophore that include changing the angle of annulation and changing the position of the polar groups $\left(\mathrm{R}_{2}\right.$ and $\left.\mathrm{R}_{3}\right)$ allows for the synthesis of xanthenebased probes with different lipophilicities, molecular sizes, charges (ionization states) and polar surface areas. ${ }^{21-25}$ These modifications not only alter the physicochemical properties of the dyes but the photophysical properties as well, which this work has also focused on.

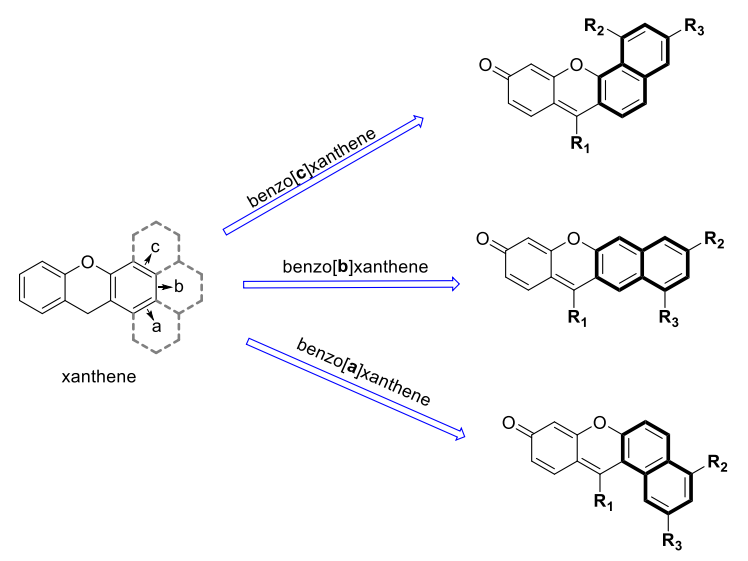

Figure 2. Altering angle of annulation and transposition of polar groups $\left(\mathrm{R}_{2}\right.$ and $\left.\mathrm{R}_{3}\right)$ to modulate physicochemical properties and photophysical properties.

\section{Research Focus}

The goals of this investigation are to i) design and synthesize libraries of xanthenebased fluorophores to be screened for PDAC specificity and evaluated for other properties, ii) develop a staining protocol for intraoperative PDAC margin assessment to ensure complete resection of cancer, and iii) develop a quantitative method to objectively measure PDAC selectivity. Previously, our group designed and synthesized a library of $\mathrm{R}_{2}$ substituted benzo[c]xanthene fluorophores (Figure 3) with physiochemical properties intended to promote inherent PDAC selectivity. ${ }^{23}$ 


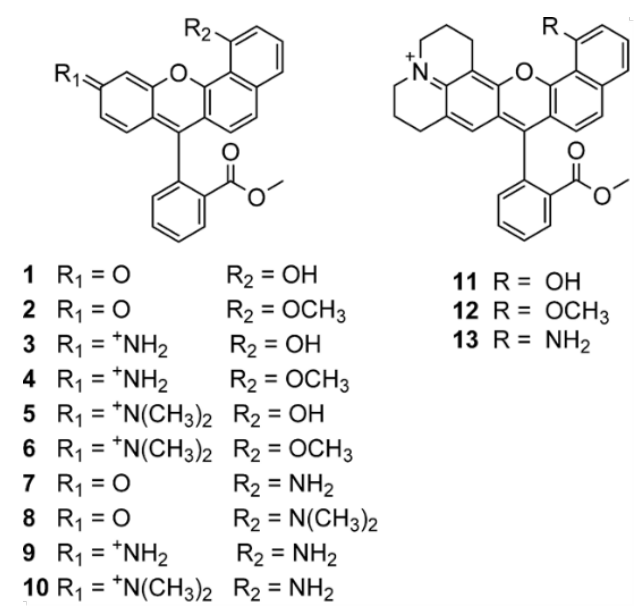

Figure 3. $\mathrm{R}_{2}$-substituted benzo[c]xanthene library of fluorophores.

Properties such as molecular weight, formal charge, lipophilicity, polar surface area and others, were used as descriptors to understand PDAC targeting. A unique characteristic of PDAC tissue compared to healthy pancreas tissue is the high fibrous tissue (stroma) surrounding ducts with adenocarcinoma, compared to normal ducts surrounded by acini cells. The "stromal fortress," serves as a barrier believed to promote resistance to chemotherapy. In a genetically-engineered PDAC murine model (KMC mice), compound 12 from the library shown in Figure 3 exhibited inherent localization in ductal adenocarcinoma versus the surrounding stroma tissue. Compound $\mathbf{1 2}$ showed the highest signal-to-background (S/B) ratio in both in vivo (tail vein injection) and ex vivo (frozen section tissue) staining of PDAC tissue compared to other candidates from the library. Importantly, compound $\mathbf{1 2}$ does not possess a conjugated targeting moiety/ligand therefore shows inherent PDAC-specificity. ${ }^{23}$

In this work, pre-staged human frozen tissue sections were purchased from Origene Inc., and $\mathbf{1 2}$ enabled the selective staining and quantification of signal intensity in PDAC as well as in the most common PDAC precursor lesions, PanIN. The quantification using 
a developed Matlab code allowed for an objective analysis of the staining in healthy human pancreas tissue versus the PDAC human tissue. The ability to selectively stain for PanIN has the potential to enable early monitoring and elucidation on PDAC progression. Moreover, the staining procedure was optimized to obtain a sample for quantitative imaging within $15 \mathrm{~min}$, in keeping with the timing of intraoperative H\&E staining (a gold standard for pathology) and the current clinical workflow. Utilizing the optimized staining protocol in conjunction with quantitative fluorescence using $\mathbf{1 2}$ has the potential to ensure clear margins after PDAC surgery to help address the current low survival rates from PDAC surgery. ${ }^{26}$

The need for dyes that are active in the near-infrared region (NIR) region $(>700$ $\mathrm{nm})$ and have large Stoke shifts led to the design and synthesis of a novel benzo[a]xanthene library (Figure 4). ${ }^{24}$ Among other advantages of imaging in the NIR include, reduced autofluorescence and reduced tissue damage due to the use of light with low energy to excite the fluorophore. ${ }^{27}$

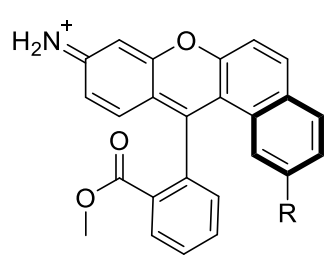

1. $\mathrm{R}=\mathrm{OH}$
2. $\mathrm{R}=\mathrm{OMe}$
3. $\mathrm{R}=\mathrm{NH}_{2}$

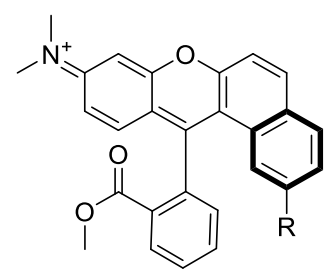

4. $\mathrm{R}=\mathrm{OH}$

5. $\mathrm{R}=\mathrm{OMe}$

6. $\mathrm{R}=\mathrm{NH}_{2}$

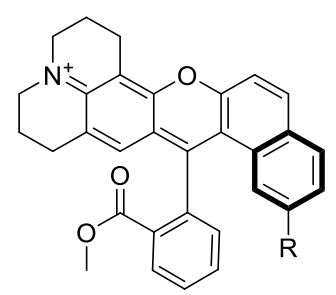

7. $\mathrm{R}=\mathrm{OH}$

8. $\mathrm{R}=\mathrm{OMe}$

9. $\mathrm{R}=\mathrm{NH}_{2}$

Figure 4. Type [a] benzoxanthene library.

The benzo[a]xanthene library displayed at least 2-fold enhanced brightness compared to the benzo[c]xanthene library, and no significant bathochromic shift, as was predicted by density functional theory calculations. ${ }^{24,28}$ Compound $\mathbf{8}$, a regioisomer of $\mathbf{1 2}$ 
with analogous physicochemical properties, also shows PDAC selectivity with compound 12 a more optimal candidate.

The functionalization of the benzo[c]xanthene chromophore with other chromophore moieties is another strategy that was used to develop NIR-active cyaninexanthene probes (Figure 5) in this work. Cyanine-xanthene hybrids are currently being synthesized and the preliminary synthesis is promising. These hybrid dyes will be screened for PDAC selectivity and subsequently used for PDAC margin assessment.
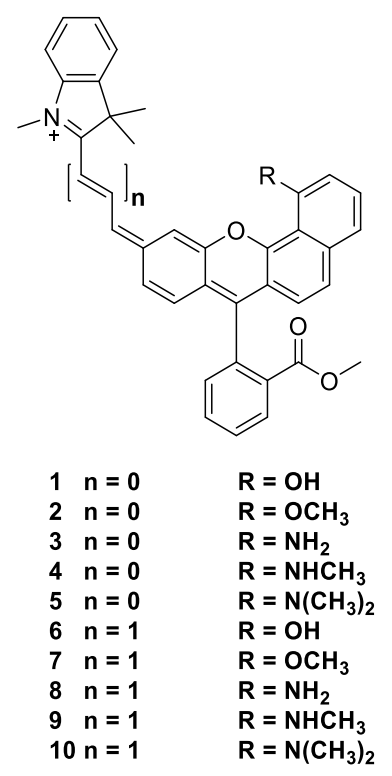

Figure 5. A library of cyanine-xanthene library.

\section{Research Value}

The outcome of this work will contribute to the field of inherent tissue targeting of PDAC, using probes without the need for any antibodies or related biomolecules conjugated as targeting ligands. The absence of a targeting ligand allows for attaining relatively much faster staining times required for intraoperative margin assessment during 
PDAC surgery. This intraoperative margin assessment could greatly improve the surgery outcome and in turn increase the survival rates of PDAC patients after surgery.

This work also led to a novel library of benzo[a]xanthene probes with atypical photophysical trends compared to all $\mathrm{pH}$-sensitive xanthene dyes reported thus far. The successful functionalization of a xanthene chromophore with cyanine dye moieties will address the inherent photophysical limitations of both classes by allowing for synergistic enhancement of photophysical properties. The ease of structure modifications will also allow for further structure-activity-relationship investigations of inherent tissue targeting. Lastly, the strategy utilized herein of inherent tissue targeting can be applied to the development of fluorescent analogs for other surgically treated cancer type, including breast, prostate and colon cancer.

\section{Specific Chapter Summaries}

Chapter 2 reports on the use of $\mathbf{1 2}$ to stain human PDAC tissue and the precursor PanIN lesions. I also show the development of an objective quantitative method based on Matlab code for measuring effective PDAC contrast. I show results of the optimization of an ex vivo staining protocol and its potential compatibility to the current PDAC surgery workflow.

Chapter 3 expands on the concept of inherent tissue targeting by reporting a novel library of benzo[a]xanthene dyes that are regioisomers of benzo[c]xanthenes. The goal of synthesizing the benzo[a]xanthene library was to study the effects of changing the angle of annulation on the photophysical and inherent tissue targeting properties. I also report on the atypical $\mathrm{pH}$ behavior of the benzo[a]xanthene library compared to other xanthene dyes. 
Also reported is an effective and efficient synthetic method I developed to allow for bioconjugation of the benzo[a]xanthene fluorophores to targeting ligands and the subsequent conjugation of compound $\mathbf{8}$ from the library to microtubule targeting antibody.

Chapter 4 focuses on the synthetic strategies employed to synthesize NIR-active cyanine-xanthene hybrid dyes. The cross-coupling between benzo[c]xanthene ditriflate and a conjugated alkene afforded the desired cyanine-xanthene hybrid probe.

Chapter 5 summarizes the results and discusses the direction for future work.

\section{REFERENCES}

(1) Haeberle, L.; Esposito, I. Pathology of pancreatic cancer. Transl. Gastroenterol. Hepatol. $2019,4$.

(2) Key Statistics for Pancreatic Cancer. The American Cancer Society; 2020. Available at: https://www.cancer.org/cancer/pancreatic-cancer/about/key-statistics.html. (Accessed 03-12-2020).

(3) Hoogstins, C. E. S.; Boogerd, L. S. F.; Sibinga Mulder, B. G.; Mieog, J. S. D.; Swijnenburg, R. J.; van de Velde, C. J. H.; Farina Sarasqueta, A.; Bonsing, B. A.; Framery, B.; Pèlegrin, A.; Gutowski, M.; Cailler, F.; Burggraaf, J.; Vahrmeijer, A. L. Image-guided surgery in patients with pancreatic cancer: first results of a clinical trial using SGM-101, a novel carcinoembryonic antigen-targeting, near-infrared fluorescent agent. Ann. Surg. Oncol. 2018, 25, 3350-3357.

(4) van der Vorst, J. R.; Vahrmeijer, A. L.; Hutteman, M.; Bosse, T.; Smit, V. T. H. B. M.; van de Velde, C. J. H.; Frangioni, J. V.; Bonsing, B. A. Near-infrared fluorescence imaging of a solitary fibrous tumor of the pancreas using methylene blue. World J. Gastrointest. Surg. 2012, 4, 180-184.

(5) Verbeke, C. S.; Menon, K. V. Redefining resection margin status in pancreatic cancer. HPB 2009, 11, 282-289.

(6) Gao, R. W.; Teraphongphom, N. T.; van den Berg, N. S.; Martin, B. A.; Oberhelman, N. J.; Divi, V.; Kaplan, M. J.; Hong, S. S.; Lu, G.; Ertsey, R.; Tummers, W. S. F. J.; Gomez, A. J.; Holsinger, F. C.; Kong, C. S.; Colevas, A. D.; Warram, J. M.; Rosenthal, E. L. Determination of tumor margins with surgical specimen mapping using near-infrared fluorescence. Cancer Res. 2018, 78, 5144-5154.

(7) Tummers, W. S.; Miller, S. E.; Teraphongphom, N. T.; Gomez, A.; Steinberg, I.; Huland, D. M.; Hong, S.; Kothapalli, S.-R.; Hasan, A.; Ertsey, R.; Bonsing, B. A.; Vahrmeijer, A. L.; Swijnenburg, R.-J.; Longacre, T. A.; Fisher, G. A.; Gambhir, S. S.; Poultsides, G. A.; Rosenthal, E. L. Intraoperative pancreatic cancer detection using tumor-specific multimodality molecular imaging. Ann. Surg. Oncol. 2018, 25, 18801888.

(8) Handgraaf, H. J.; Boonstra, M. C.; Van Erkel, A. R.; Bonsing, B. A.; Putter, H.; Van De Velde, C. J.; Vahrmeijer, A. L.; Mieog, J. S. D. Current and future intraoperative imaging strategies to increase radical resection rates in pancreatic cancer surgery. BioMed Res. Int. 2014, 2014.

(9) Iacobuzio-Donahue, C. A. Genetic evolution of pancreatic cancer: lessons learnt from the pancreatic cancer genome sequencing project. Gut 2012, 61, 1085-1094. 
(10) Westphalen, C. B.; Olive, K. P. Genetically engineered mouse models of pancreatic cancer. Cancer J. 2012, $18,502-510$.

(11) Chen, L. B. Mitochondrial membrane potential in living cells. Annu. Rev. Cell Biol. 1988, 4, 155-181.

(12) Trapp, S.; Horobin, R. W. A predictive model for the selective accumulation of chemicals in tumor cells. Eur. Biophys. J. 2005, 34, 959-966.

(13) Murphy, M. P. Selective targeting of bioactive compounds to mitochondria. Trends Biotechnol. 1997, 15, 326-330.

(14) Beckham, T. H.; Lu, P.; Jones, E. E.; Marrison, T.; Lewis, C. S.; Cheng, J. C.; Ramshesh, V. K.; Beeson, G.; Beeson, C. C.; Drake, R. R.; Bielawska, A.; Bielawski, J.; Szulc, Z. M.; Ogretmen, B.; Norris, J. S.; Liu, X. LCL124, a cationic analog of ceramide, selectively induces pancreatic cancer cell death by accumulating in mitochondria. J. Pharmacol. Exp. Ther. 2013, 344, 167-178.

(15) Davis, S.; Weiss, M.; Wong, J.; Lampidis, T. J.; Chen, L. B. Mitochondrial and plasma membrane potentials cause unusual accumulation and retention of rhodamine 123 by human breast adenocarcinomaderived MCF-7 cells. J. Biol. Chem. 1985, 260, 13844-13850.

(16) Ross, M. F.; Kelso, G.; Blaikie, F. H.; James, A. M.; Cocheme, H. M.; Filipovska, A.; Da Ros, T.; Hurd, T.; Smith, R. A.; Murphy, M. P. Lipophilic triphenylphosphonium cations as tools in mitochondrial bioenergetics and free radical biology. Biochemistry (Mosc.) 2005, 70, 222-230.

(17) Belostotsky, I.; da Silva, S. M.; Paez, M. G.; Indig, G. L. Mitochondrial targeting for photochemotherapy. Can selective tumor cell killing be predicted based on n-octanol/water distribution coefficients? Biotech. Histochem. 2011, 86, 302-314.

(18) Lipinski, C. A.; Lombardo, F.; Dominy, B. W.; Feeney, P. J. Experimental and computational approaches to estimate solubility and permeability in drug discovery and development settings. Adv. Drug Delivery. Rev. 2001, 46, 3-26.

(19) Veber, D. F.; Johnson, S. R.; Cheng, H.-Y.; Smith, B. R.; Ward, K. W.; Kopple, K. D. Molecular properties that influence the oral bioavailability of drug candidates. J. Med. Chem. 2002, 45, 2615-2623.

(20) Yoshida, F.; Topliss, J. G. QSAR model for drug human oral bioavailability. J. Med. Chem. 2000, 43, 2575 .

(21) Neckers, D. C.; Valdes-Aguilera, O. M. Photochemistry of the Xanthene Dyes. In Adv. Photochem.; Volman, D. H., Hammond, G. S., Neckers, D. C., Eds.; John Wiley \& Sons, Inc.: New York, NY, 1993; Vol. 18, p 315-394.

(22) Azuma, E.; Nakamura, N.; Kuramochi, K.; Sasamori, T.; Tokitoh, N.; Sagami, I.; Tsubaki, K. Exhaustive syntheses of naphthofluoresceins and their functions. J. Org. Chem. 2012, 77, 3492-3500.

(23) Wang, L.; Barth, C. W.; Sibrian-Vazquez, M.; Escobedo, J. O.; Lowry, M.; Muschler, J.; Li, H.; Gibbs, S. L.; Strongin, R. M. Far-red and near-infrared seminaphthofluorophores for targeted pancreatic cancer imaging. ACS Omega 2017, 2, 154-163.

(24) Wang, L. G.; Munhenzva, I.; Sibrian-Vazquez, M.; Escobedo, J. O.; Kitts, C. H.; Fronczek, F. R.; Strongin, R. M. Altering fundamental trends in the emission of xanthene dyes. J. Org. Chem. 2019, 84, 2585-2595.

(25) Yang, Y.; Lowry, M.; Xu, X.; Escobedo, J. O.; Sibrian-Vazquez, M.; Wong, L.; Schowalter, C. M.; Jensen, T. J.; Fronczek, F. R.; Warner, I. M.; Strongin, R. M. Seminaphthofluorones are a family of watersoluble, low molecular weight, NIR-emitting fluorophores. Proc. Natl. Acad. Sci. U. S. A. 2008, 105, 88298834. 
(26) Munhenzva, I. R.; Barth, C. W.; Sibrian-Vazquez, M.; Wang, L. G.; Escobedo, J. O.; Gibbs, S. L.; Strongin, R. M. Assessment of human pancreas cancer tissue and precursor lesions via a fluorophore with inherent PDAC selectivity. Methods 2019, 168, 35-39.

(27) Zhang, R. R.; Schroeder, A. B.; Grudzinski, J. J.; Rosenthal, E. L.; Warram, J. M.; Pinchuk, A. N.;

Eliceiri, K. W.; Kuo, J. S.; Weichert, J. P. Beyond the margins: real-time detection of cancer using targeted fluorophores. Nat. Rev. Clin. Oncol. 2017, 14, 347-364.

(28) Fabian, W. M. F.; Schuppler, S.; Wolfbeis, O. S. Effects of annulation on absorption and fluorescence characteristics of fluorescein derivatives: a computational study. J. Chem. Soc., Perkin Trans. 2 1996, 853856. 


\title{
Chapter 2: Assessment of Human Pancreas Cancer Tissue and Precursor Lesions Via a Fluorophore with Inherent PDAC Selectivity
}

Munhenzva, I. R.; Barth, C. W.; Sibrian-Vazquez, M.; Wang, L. G.; Escobedo, J. O.; Gibbs, S. L.; Strongin, R. M., Assessment of human pancreas cancer tissue and precursor lesions via a fluorophore with inherent PDAC selectivity. Methods 2019, 168, 35-39.

The above paper has been modified.

\begin{abstract}
Pancreatic ductal adenocarcinoma (PDAC) is the most prevalent and deadly form of pancreas cancer. Previously, utilizing compound 12, a fluorophore with inherent PDAC selectivity, PDAC was visualized both in vivo and ex vivo in a murine model. In the current study, human PDAC tissue is targeted. Compound 12 selectively stains ducts of the adenocarcinoma versus the surrounding stroma, enabling the imaging of PDAC in frozen tissue sections with high contrast. To enhance the potential of $\mathbf{1 2}$ for intraoperative applications, the ex vivo staining protocol was optimized for rapid margin assessment, with a final staining time of $\sim 15 \mathrm{~min}$. To measure diagnostic performance, the area under a receiver operating characteristic (ROC) curve was measured for the identification of ductal adenocarcinoma vs. stroma. The bright fluorescence contrast enabled quantitative determination of PDAC (or precancerous PanIN lesions) versus healthy pancreas tissue in human tissue array samples.
\end{abstract}

\section{INTRODUCTION}

Pancreatic ductal adenocarcinoma (PDAC) is the most prevalent form of pancreatic cancer, accounting for approximately $90 \%$ of all cases. ${ }^{1}$ With a five-year survival rate $<$ $5 \%$, PDAC is projected to be the second leading cause of cancer-related deaths by $2030 .^{2}$ 
Although $<20 \%$ of PDAC patients qualify for surgery, it remains the only effective treatment option. ${ }^{1}$ Resection margin $(\mathrm{RM})$ status is a key predictive factor in a patient's post-surgery survival. ${ }^{3}$ To assess margin clearance (R0) versus margin involvement (R1), surgeons currently rely on basic tools such as white light visualization and palpation for guidance during surgery. Intraoperative frozen section analysis (FSA) is also performed in many cases, wherein a tissue margin sample, stained with hematoxylin and eosin (H\&E), is assessed by a pathologist. ${ }^{4-6}$ However, H\&E staining is not quantifiable and is nonspecific for PDAC and does not adequately detect microscopic tumors. ${ }^{7}$ These techniques have resulted in high resection margin involvement ( $>50 \% \mathrm{R} 1)$ in PDAC patients. Patient prognosis is generally poor. ${ }^{8}$

Fluorescence imaging using PDAC-specific fluorophores offers an opportunity to improve current intraoperative margin assessment. ${ }^{9-11}$ It has the potential to provide rapid, accurate ex vivo confirmation of negative margin (R0) status during surgery. Our lab previously reported the synthesis of a library of xanthene fluorophores to investigate the targeted imaging of PDAC in a genetic-engineered PDAC murine model (KMC mice). Compound 12 from the library showed excellent selectivity and signal-to-background (S/B) ratio in both in vivo (tail vein injection) and ex vivo (FSA) staining of PDAC tissue. Compound 12 does not possess a conjugated targeting moiety. ${ }^{9}$ It was designed with physiochemical properties intended to promote its inherent selectivity for epithelial ductal adenocarcinoma versus the surrounding stroma tissue. ${ }^{12-14} \mathrm{~A}$ unique characteristic of PDAC is that most of the tumor volume does not consist of tumor cells, but rather is comprised of the stroma. The "stromal fortress," which is mainly collagen, serves as a 
barrier that, for instance, has been noted as a potential reason that PDAC is intrinsically resistant to chemotherapy. ${ }^{15}$

In the current study, we show that $\mathbf{1 2}$ enables the selective staining and quantification of PDAC in human frozen tissue samples, including the most common PDAC precursor lesions, pancreatic intraepithelial neoplasia (PanIN). Moreover, we optimized the procedure to obtain a sample for quantitative imaging within $15 \mathrm{~min}$, in keeping with intraoperative $\mathrm{H} \& \mathrm{E}$ staining and the current clinical workflow.

\section{MATERIALS \& METHODS}

\section{General Study Design}

The primary goal of this study was to identify a fluorescence staining protocol that provides the highest diagnostic performance within a clinically relevant time frame. These optimum conditions were applied to human PDAC specimen purchased from Origene Inc. Optimization was accomplished by fluorescence imaging with different staining concentrations $(125,250$ and $500 \mu \mathrm{M})$ and fluorophore incubation times $(1,5,10$ and 40 minutes), in triplicate (Figure S2, supplementary information). The performance was assessed using ROC curve analysis, with the area under the curve (AUC) as a metric for the contrast between PDAC versus surrounding stromal tissue. The mouse tissue for protocol optimization studies was from a genetically engineered mouse model of PDAC (KMC mouse model) used in a previous study by our group. ${ }^{9}$ The optimized conditions were used to stain human healthy and PDAC tissue specimens. The samples included (i) 
normal tissue, with $60 \%$ exocrine epithelium, $20 \%$ endocrine epithelium and $20 \%$ ducts; (ii) pancreatic intraepithelial neoplasia non-tumor structures (PanIN) comprised of $10 \%$ exocrine epithelium, 5\% endocrine epithelium and $85 \%$ ducts; (iii) moderately differentiated PDAC tissue with a tumor grade of G3, and; (iv) poorly differentiated tumor tissue with a tumor grade of G2. Compound $\mathbf{1 2}$ was used in all experiments (Figure 1). ${ }^{9}$

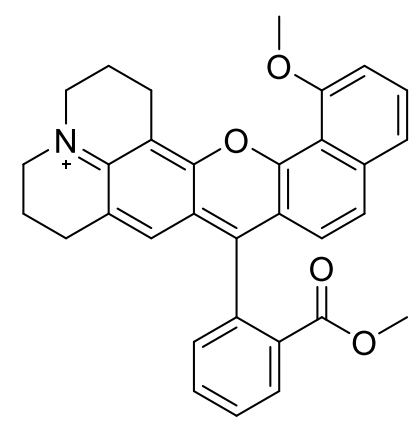

12

Figure 1. Compound 12.

\section{Ex vivo fluorescence microscopy}

The resected pancreas tissue from healthy control mice and the KMC mice models with PDAC tumor-bearing mice were fixed with $2 \%$ PFA for $12 \mathrm{~h}$, flash frozen in optimal cutting temperature (OCT) compound with liquid $\mathrm{N}_{2}$, and stored at $-80{ }^{\circ} \mathrm{C}$. Cryosections were cut at 10 microns onto Superfrost Plus slides (Fisherbrand, Fisher Scientific). Serial sections were obtained and used for ex vivo staining. Images were acquired on an Axio Observer inverted fluorescence microscope (Zeiss, Thornwood, NY) at 20× magnification. A PhotoFluor II was used and filtered using a $545 \pm 12.5$ bandpass excitation filter for $\mathbf{1 2}$. Fluorescence images were collected using an Axiocam 506 camera (Zeiss), were a $605 \pm$ 
35 bandpass emission filter. Whole tissue images were acquired using Zeiss Axioscan Z.1 slide scanner (Carl Zeiss) at 20× magnification. The fluorescence signal was optimized at the start of the study to not oversaturate the signal. For a standardized comparison, the power of Colibri 7 light source and integration times of the Hamamatsu ORCA Flash4 camera (Hamamatsu Photonics) were kept constant for all samples. The imaging on the slides was performed with identical image acquisition settings after staining overnight.

\section{Statistical Analysis}

Statistical analysis was performed using MatLab. To quantify tumor-to-stroma pancreas tissue diagnostic detection, ROC curves were generated for ductal adenocarcinoma versus stroma tissue. As a control, ROC curves were generated for healthy acinar tissue versus healthy acinar tissue. ROC curves and corresponding AUC measurements were calculated on a pixel-by-pixel basis by running a threshold value across individual pixel values for each tissue type and measuring the true-positive and false-negative fractions of adenocarcinoma ductal tissue over surrounding stromal tissue at each threshold increment. Histogram plots of the fluorescence image pixel values for ductal and stromal pixels were generated and plotted. Statistical significance between staining conditions was determined using the method described by Hanley and $\mathrm{McNeil}^{16}$ with standard error measurements and correlation coefficients for pixel intensity values for each condition used for z-score value calculations. Z-score values $>2$ were considered statistically significant. 


\section{Original ex vivo Direct Fluorophore Staining Protocol}

The initial wash to remove excess OCT was done by covering each tissue sample with PBS. After $2 \mathrm{~min}$, it was removed with vacuum. The tissue samples were fixed with 2\% PFA at rt. for 15 min and washed $3 \times$ using PBS with $0.1 \%$ Tween-20 for 5 min. Slides were incubated with fluorophore formulation, (10\% dimethyl sulfoxide DMSO (control) or 10\% DMSO fluorophore solution (dependent on specific concentration of fluorophore), $5 \%$ Kolliphor EL, $85 \%$ of $75 / 25$ serum/PBS) for $40 \mathrm{~min}$ at $\mathrm{rt}^{17}{ }^{17}$ Slides were covered to prevent photobleaching. Excess fluorophore was removed through two 5 min rinses with PBS. Fluorophore post-fixing was done using 2\% PFA for $15 \mathrm{~min}$ and washed $1 \times$ with PBS for 5 min. After removing excess PBS samples were mounted with fluoromount. The coverslip was placed onto tissue, making sure no air bubbles were present. The coverslips were sealed with colorless nail polish. The slides were stored at $20^{\circ} \mathrm{C}$. The total time for the staining protocol was $1 \mathrm{~h} 42 \mathrm{~min}$.

\section{Modified ex vivo direct fluorophore staining protocol}

The initial rinse was done by flash washing each tissue sample with PBS with rapid removal with vacuum. The tissue samples were fixed with $2 \%$ PFA at $\mathrm{rt}$ for $5 \mathrm{~min}$, rinsed rapidly $3 \times$ using PBS with $0.1 \%$ Tween-20. Slides were incubated with fluorophore formulation (5 min, rt). Slides were covered to prevent photobleaching. The excess fluorophore was removed by flash rinsing $2 \times$ with PBS. Fluorophore post-fixing was done 
using 2\% PFA for $5 \mathrm{~min}$ and with a $1 \times$ wash with PBS. Excess PBS was removed and samples were mounted with fluoromount. The coverslip was placed onto tissue, ensuring no air bubbles covered the samples. The coverslips were sealed with colorless nail polish. The slides were stored at $20^{\circ} \mathrm{C}$. The total time for the optimized protocol was $15 \mathrm{~min}$.

\section{RESULTS AND DISCUSSION}

\section{Staining of human PDAC tissue}

Our lab previously showed that $\mathbf{1 2}$ enabled the imaging of PDAC in a genetically engineered mouse model with high specificity both in vivo and ex vivo. Figure 2 shows the ex vivo efficacy of 12 in visualizing human PDAC, showing increased accumulation in the ductal adenocarcinoma epithelial tissue compared to the surrounding stroma tissue. In normal tissue, 12 shows a homogenous accumulation as also previously reported in our mouse model work. ${ }^{9}$

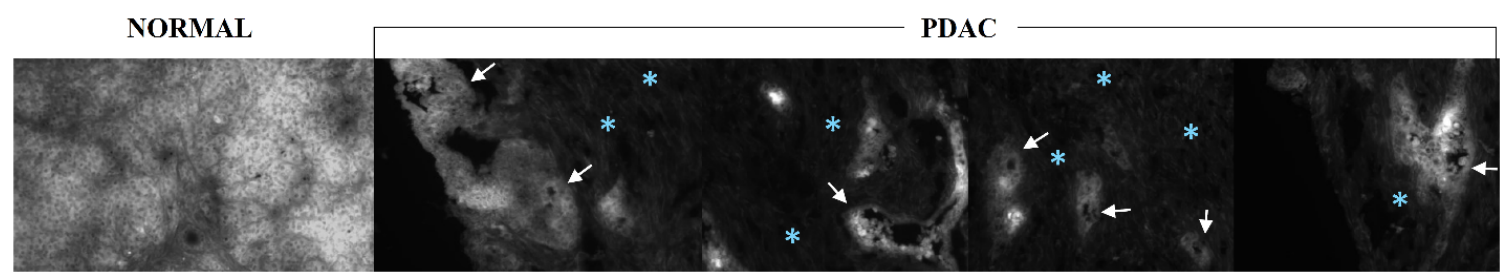

Figure 2. Ex vivo images from frozen sections of resected human tissue stained with compound 12. Normal tissue displayed homogeneous staining in acinar cells. PDAC tissue displayed high contrast between the ductal and stroma tissue. White arrows are pointing to the selectively stained ducts with adenocarcinoma surrounded by blue starred unstained stroma tissue regions of PDAC.

To obtain a more complete picture of the inherent accumulation of $\mathbf{1 2}$ in ductal adenocarcinoma versus the stroma tissue, whole tissue images were obtained using Zeiss Axioscan Z.1 slide scanner (Figure 3). The homogeneous staining of healthy human pancreas tissue can be readily observed. In addition, highly selective staining of the ductal 
adenocarcinoma versus stroma in the human PDAC pancreas tissue is clear. Two different grades of human PDAC pancreas tissue were examined. Figure 3 shows PanIN tissue, moderately differentiated tissue, and poorly differentiated PDAC pancreas tissue stained with 12. The selective accumulation in the ducts versus stroma is observed as the bright white spots (ducts with adenocarcinoma) and relatively dark regions (stroma tissue).

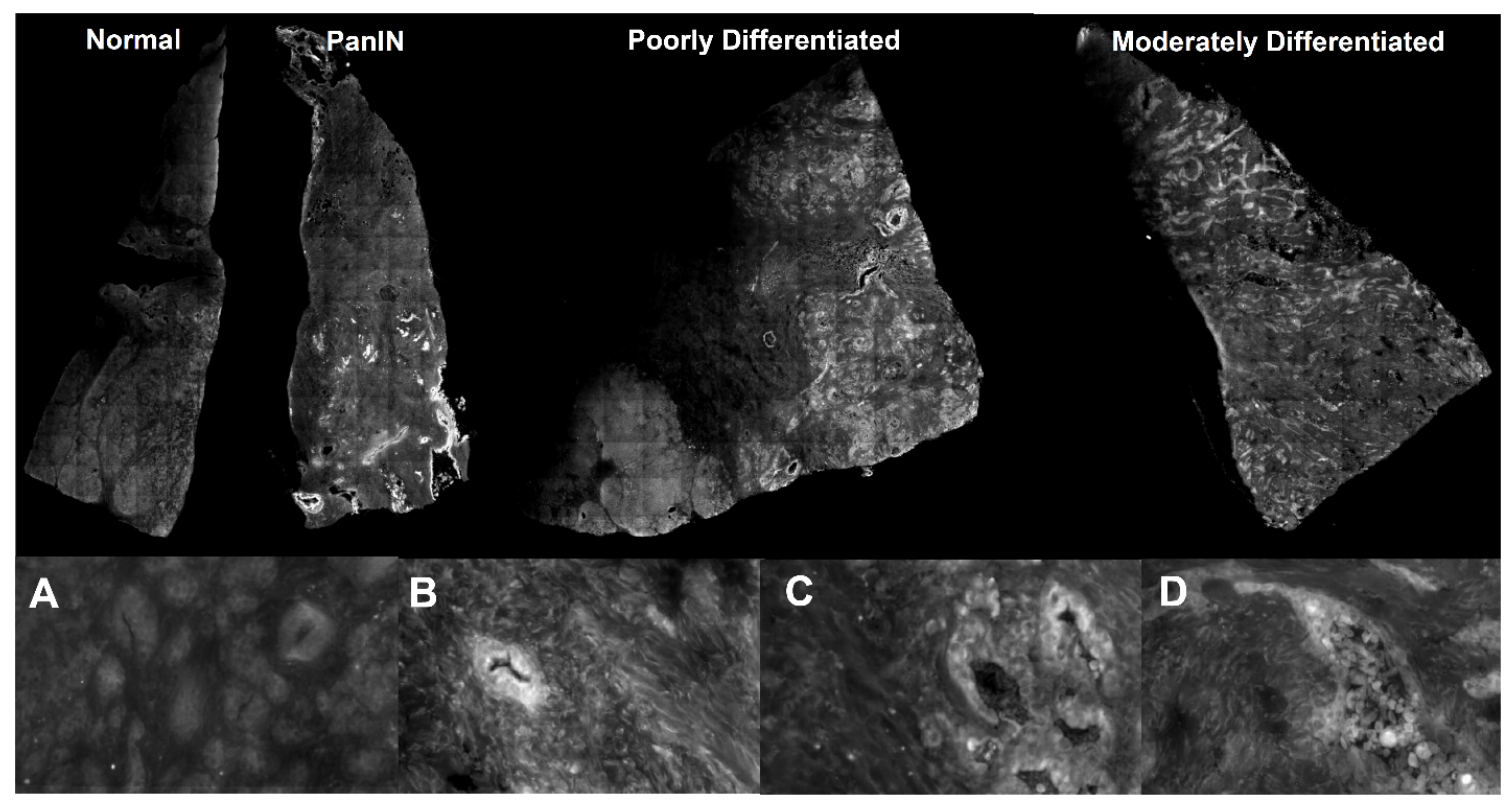

Figure 3. Whole tissue images of frozen sections (top panel) of healthy, PanIN, poorly differentiated and moderately differentiated human normal and PDAC pancreas tissue stained with 12. In the bottom panel shows magnified images of healthy ducts (A) and PDAC (B- PanIN (lesions), C- poorly differentiated and D- moderately differentiated).

\section{Staining protocol optimization using mouse tissue}

Since the results using human tissue were consistent with those obtained with the KMC mouse model, we utilized mouse frozen sections to optimize the staining procedure. Since H\&E staining, the gold standard for FSA pathology, requires $c a .12$ min to stain tissue, our aim was to shorten compound $\mathbf{1 2}$ processing time while maintaining PDAC selectivity and 
optical contrast. In order to evaluate $\mathrm{S} / \mathrm{B}$ (PDAC/stroma) during optimization, we employed a modified Matlab code used by Barth et al. $(2017)^{18}$ to generate the area under a receiver operating characteristic (ROC) curves, with the AUC used as a metric of diagnostic performance in differentiating PDAC from stroma. For the KMC tissue used, the ROC curves, the AUC values are reported in Figure 4 and Table 1, respectively. The zstat analysis reported the $125 \mu \mathrm{M}, 5$ min incubation time AUC value as significantly higher than all other staining conditions (Table S1, supplementary information).

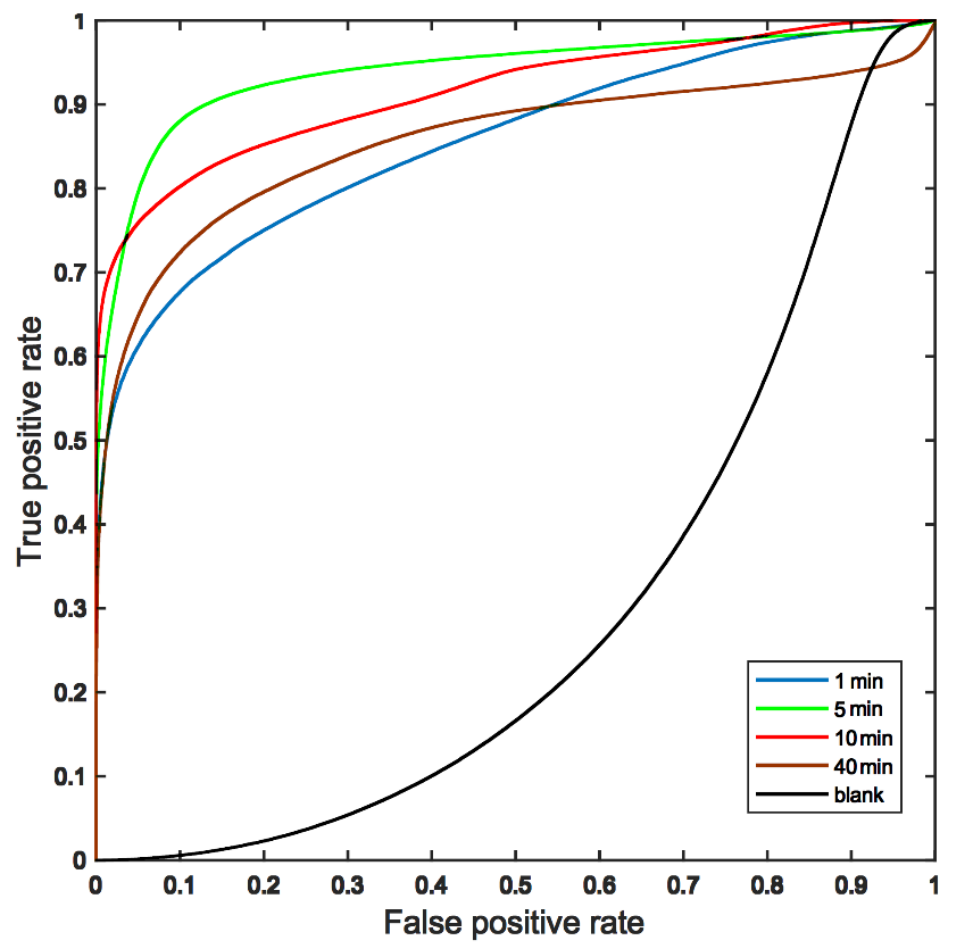

Figure 4. ROC curves for $\mathrm{KMC}$ mouse model ductal adenocarcinoma vs. stroma tissue differentiation following staining using $12(125 \mu \mathrm{M})$. 
Table 1. Tissue staining optimization ROC analysis. AUC values are listed for fluorophore concentration and incubation time optimization studies with KMC mouse model tissue.

ROC AUC values ${ }^{a}$

\begin{tabular}{ccccc}
\hline \multirow{2}{*}{$\begin{array}{c}\text { Fluorophore } \\
\text { concentration }(\mu \mathrm{M})\end{array}$} & $1 \mathrm{~min}$ & $5 \mathrm{~min}$ & $10 \mathrm{~min}$ & $40 \mathrm{~min}$ \\
\cline { 2 - 5 } & 0.8541 & 0.9390 & 0.9143 & 0.8556 \\
250 & 0.7307 & 0.8337 & 0.8751 & N/A \\
500 & 0.8691 & 0.8695 & 0.8810 & N/A \\
\hline
\end{tabular}
$\mathrm{N} / \mathrm{A}-$ not applicable
${ }^{a}$ ROC AUC values correspond to the area under the ROC curve for each incubation time
with $\mathbf{1 2}$.

The initial fluorophore concentration reported by Wang et al. (2017) ${ }^{9}$ of $125 \mu \mathrm{M}$ afforded the highest AUC with a fluorophore incubation time of 5 min (Table 1). A short rinse instead of 5 min washing, plus a shortened incubation with 2\% PFA (paraformaldehyde, 5 min compared to $15 \mathrm{~min}$ ) did not significantly change the AUC ( 0.9390 vs. 0.9376 for original vs. optimized protocols).
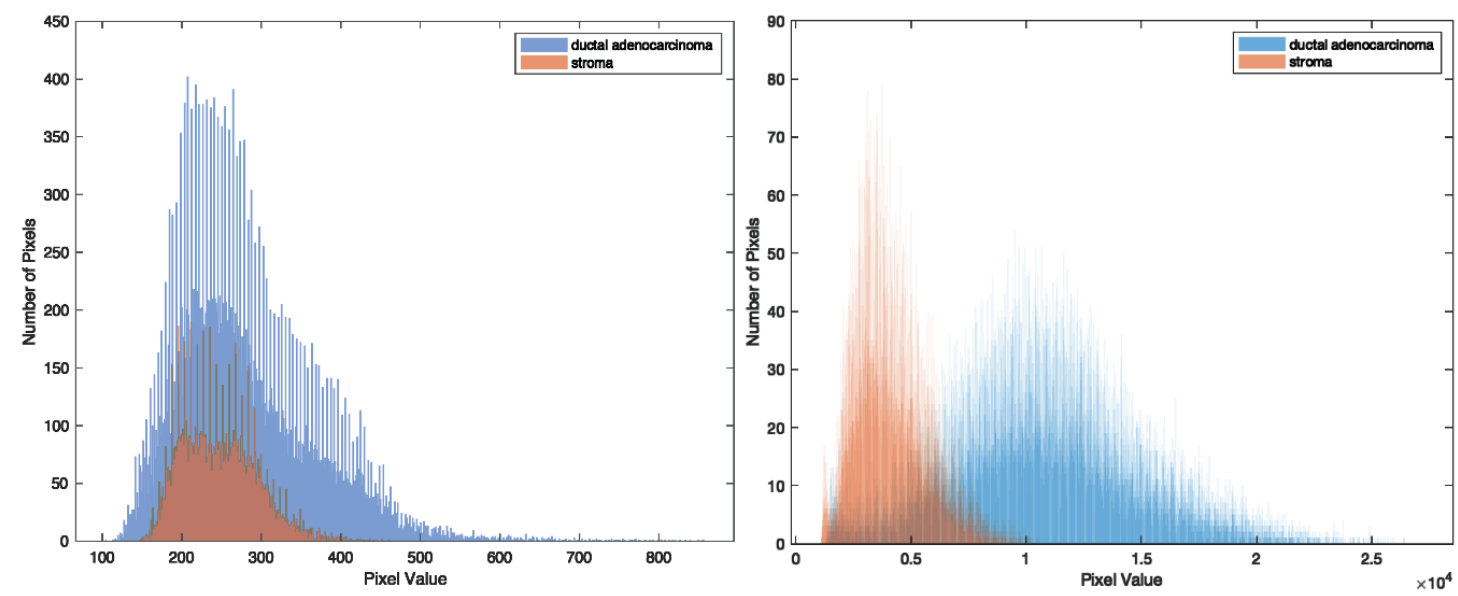

Figure 5. Signal quantification from PDAC KMC mouse model tissue represented as pixel intensity histograms. Unstained PDAC control tissue (left) and PDAC tissue stained with 12 (right) using the optimized protocol: $125 \mu \mathrm{M}$ with 5 min incubation, rinse and 5 min PFA incubation (total $15 \mathrm{~min}$ ). The separation of pixel values in stained tissue is evidence of its efficiency in selective PDAC targeting over surrounding stroma tissue. 
Optimized protocol (15 min processing) results are represented in Figure 5. The histogram of PDAC pancreas tissue stained with 12 displays a clear resolution of pixel values between the ductal adenocarcinoma and the stroma tissue. This is evidence that when 12 is used in the 15-min protocol it is effective in selectively targeting and imaging PDAC. Conversely, a PDAC negative control was subjected to the same conditions except for the addition of 12. It shows an unresolved pixel intensity overlay corresponding to PDAC and stroma (Figure 5, left).

Once the procedure was optimized with mouse tissue, it was applied to human frozen section samples. The optimized protocol was used to stain the four human pancreas tissue samples shown in Figure 3 (the Figure 2 images had been obtained using unoptimized conditions), including healthy and pancreatic intraepithelial neoplasia (PanIN, a PDAC precursor lesion of potential utility for early disease detection), as well as moderately- and poorly-differentiated PDAC tissue. ROC-calculated AUC values were used to monitor the PDAC vs. stroma diagnostic performance (Figure 6 and Table 2). 


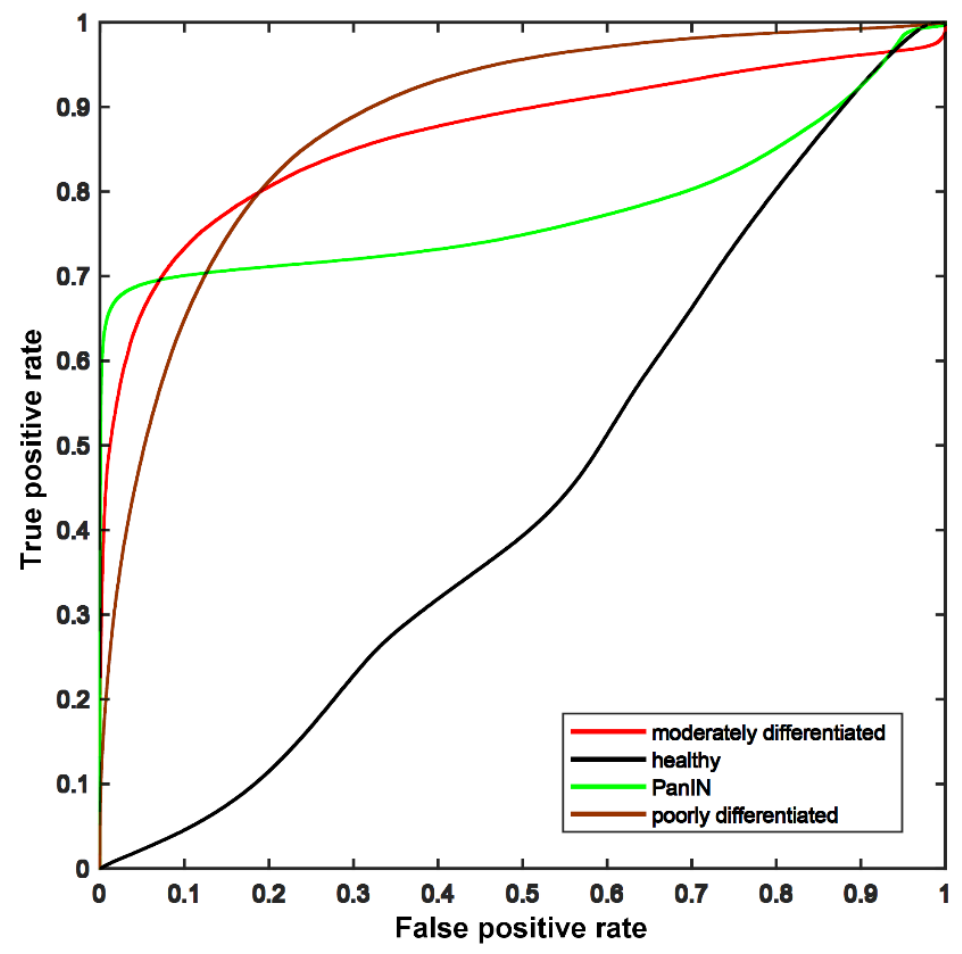

Figure 6. ROC curves for control (black), PanIN (green), high grade (brown) and low grade (red) human ductal adenocarcinoma vs. stroma tissue differentiation derived from staining with $\mathbf{1 2}$.

Table 2. ROC AUC values for human tissue staining with compound $\mathbf{1 2 .}$

\begin{tabular}{cc}
\hline Tissue type & ROC AUC \\
\hline Healthy $^{a}$ & 0.4508 \\
PanIN $^{b}$ & 0.7797 \\
Moderately differentiated $^{c}$ & 0.8821 \\
Poorly differentiated $^{d}$ & 0.8621 \\
\hline \multicolumn{2}{c}{$60 \%$ exocrine epithelium, 20\% endocrine } \\
epithelium, 20\% ducts; $^{b}$ pancreatic intraepithelial \\
neoplasia non-tumor structures with 10\% exocrine \\
epithelium, 5\% endocrine epithelium, $85 \%$ ducts; \\
${ }^{c}$ tumor grade G2 (moderately differentiated); ${ }^{d}$ tumor \\
grade G3 (poorly differentiated).
\end{tabular}




\section{CONCLUSIONS}

The primary aim of this study was to show the utility of an inherently-targeted fluorophore in the ex vivo staining of human PDAC tissue. Residual tumor during PDAC resection results in low survival rates from PDAC surgery due to locoregional recurrence or follow-up surgeries to ensure clear margins. Intraoperative fluorescence guidance using PDAC-specific contrast agents has the potential to aid the process of margin assessment. Typically, fluorophores are conjugated to targeting ligands to increase specificity. Ex vivo staining with fluorophore-antibody conjugates takes between 24 and 48 hours to obtain an image, which is not practical for surgery. In the previous study, $\mathbf{1 2}$ was shown to achieve specificity to PDAC in a PDAC mouse model without the need for conjugation to an antibody or any complex targeting ligands. Herein, we have shown that it can be used for analyzing human PDAC frozen tissue sections following a short 15-min staining protocol. It exhibits enhanced accumulation in the ducts of the adenocarcinoma versus the surrounding stroma tissue. In addition, it stains PanIN precancerous lesions which may be useful for investigating the progression of PDAC.

Unlike the current FSA stain (H\&E), 12 affords quantifiable images and PDAC specificity. The fluorescence in pancreas tissue was quantified using ROC curves. The high contrast between the stroma and the adenocarcinoma in $\mathbf{1 2}$ stained tissue can serve as marker for PDAC. For example, it may enable margin assessment both qualitatively and quantitatively since stained healthy pancreas tissue does not show appreciable contrast under the same processing conditions (e.g., Figures 3 and 5, Table 2). Moreover, ex vivo 
frozen section staining using $\mathbf{1 2}$ under the optimized conditions described herein takes place in nearly the same amount of time as H\&E staining. It is also promising that high contrast was also observed in the tissue sample containing the PanIN pancreatic cancer precursor lesions. This may potentially enable early monitoring and the investigation of PDAC progression.

\section{SUPPLEMENTARY MATERIAL}

Table S1. Tissue staining optimization z-stat analysis. Z-statistical values ${ }^{a}$

\begin{tabular}{ccccc}
\hline \multirow{2}{*}{$\begin{array}{c}\text { Fluorophore } \\
\text { concentration }(\mu \mathrm{M})\end{array}$} & $1 \mathrm{~min}$ & $5 \mathrm{~min}$ & $10 \mathrm{~min}$ & $40 \mathrm{~min}$ \\
\cline { 2 - 5 } Z-statistical values $^{a}$ \\
\hline 125 & 264.4 & N/A & 74.1 & 248.6 \\
250 & 307.3 & 197.1 & 219.8 & N/A \\
500 & 167.5 & 130.3 & 112.1 & N/A \\
\hline
\end{tabular}

${ }^{a} \mathrm{Z}$-statistical values for each staining condition and incubation time compared to the $125 \mu \mathrm{M}, 5 \mathrm{~min}$ incubation time ( $\mathrm{z}$-stat value $>2$ indicates significant AUC values). 

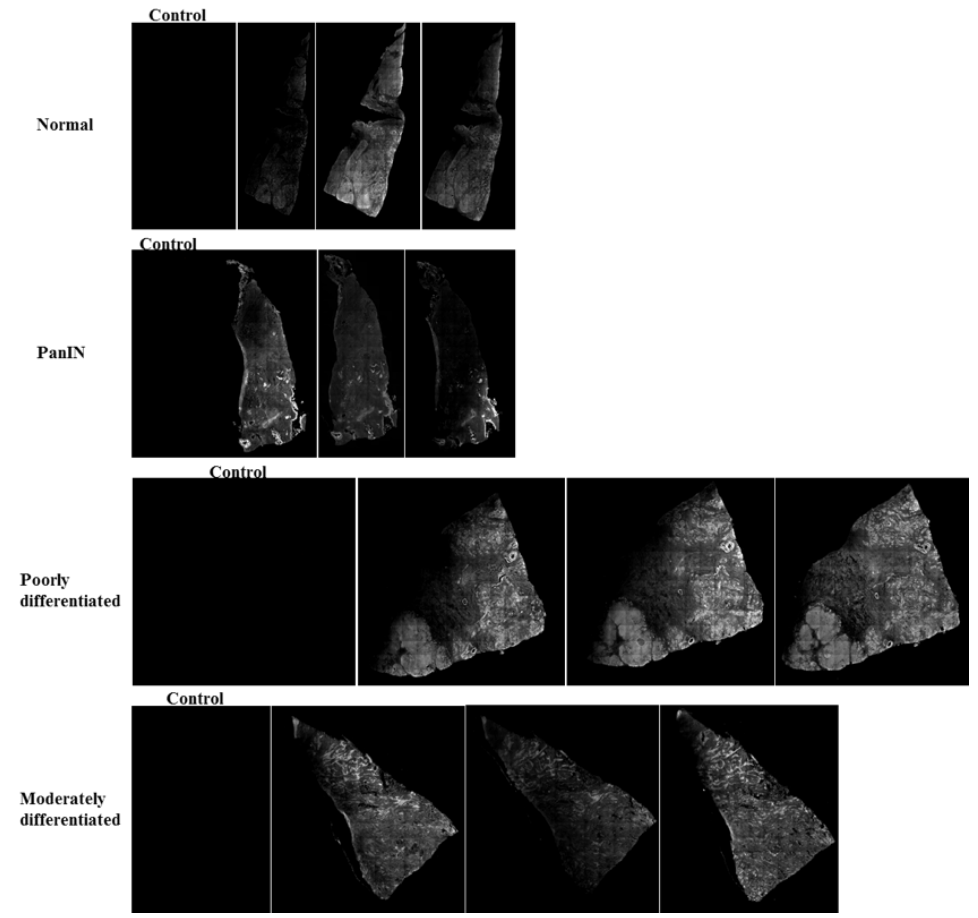

Figure S1. Whole tissue images (in triplicate) of frozen sections (from top) of healthy, PanIN, poorly moderately differentiated and moderately differentiated human normal and PDAC pancreas tissue stained with 12 and unstained PDAC control tissue as the first image in each panel. 


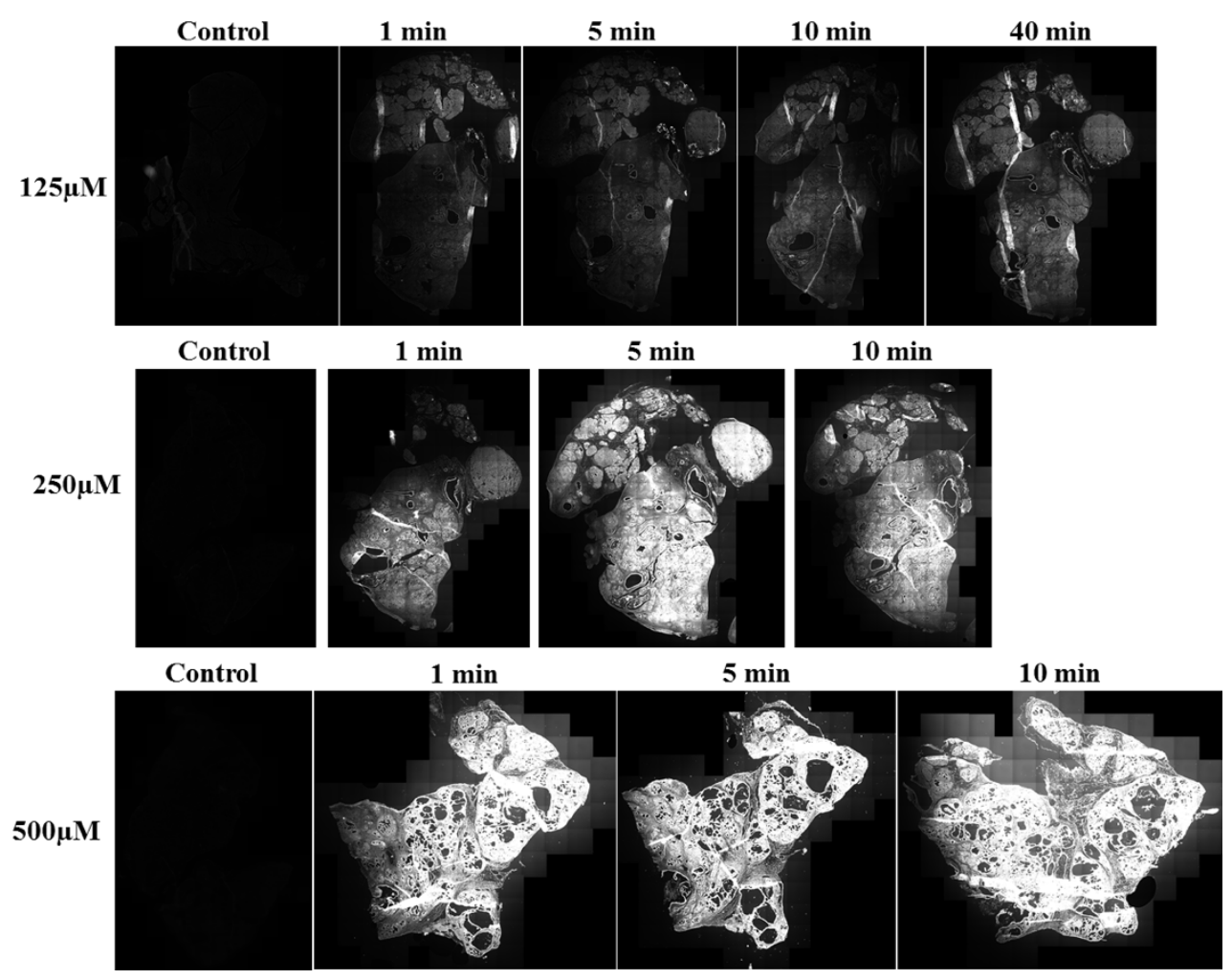

Figure S2. Whole tissue images of frozen sections from KMC mouse PDAC pancreas tissue stained with different concentrations of $\mathbf{1 2}$ for different incubation times and unstained PDAC control tissue as the first image in each panel.

\section{REFERENCES}

(1) Adamska, A.; Domenichini, A.; Falasca, M. Pancreatic ductal adenocarcinoma: Current and evolving therapies. Int. J. Mol. Sci. 2017, 18, 1338.

(2) He, C.; Zhang, Y.; Cai, Z.; Lin, X.; Li, S. Overall survival and cancer-specific survival in patients with surgically resected pancreatic head adenocarcinoma: A competing risk nomogram analysis. J. Cancer 2018, 9, 3156-3167.

(3) Osipov, A.; Nissen, N.; Rutgers, J.; Dhall, D.; Naziri, J.; Chopra, S.; Li, Q.; Hendifar, A. E.; Tuli, R. Redefining the positive margin in pancreatic cancer: impact on patterns of failure, long-term survival and adjuvant therapy. Ann. Surg. Oncol. 2017, 24, 3674-3682.

(4) Tao, Y. K.; Shen, D.; Sheikine, Y.; Ahsen, O. O.; Wang, H. H.; Schmolze, D. B.; Johnson, N. B.; Brooker, J. S.; Cable, A. E.; Connolly, J. L.; Fujimoto, J. G. Assessment of breast pathologies using nonlinear microscopy. Proc. Natl. Acad. Sci. U. S. A. 2014, 111, 15304. 
(5) Michalski, C. W.; Weitz, J.; Buechler, M. W. Surgery Insight: surgical management of pancreatic cancer. Nat. Clin. Pract. Oncol. 2007, 4, 526-535.

(6) Verbeke, C. S.; Menon, K. V. Redefining resection margin status in pancreatic cancer. $H P B$ 2009, 11, 282-289.

(7) Warren, B. F. Resection margins and R1 rates in pancreatic cancer - are we there yet? Histopathology 2008, 53, 599 .

(8) Kleeff, J.; Reiser, C.; Hinz, U.; Bachmann, J.; Debus, J.; Jaeger, D.; Friess, H.; Büchler, M. W. Surgery for recurrent pancreatic ductal adenocarcinoma. Ann. Surg. 2007, 245, 566-572.

(9) Wang, L.; Barth, C. W.; Sibrian-Vazquez, M.; Escobedo, J. O.; Lowry, M.; Muschler, J.; Li, H.; Gibbs, S. L.; Strongin, R. M. Far-red and near-infrared seminaphthofluorophores for targeted pancreatic cancer imaging. ACS Omega 2017, 2, 154-163.

(10) Lwin, T. M.; Miyake, K.; Murakami, T.; DeLong, J. C.; Amirfakhri, S.; Filemoni, F.; Yoon, S. N.; Yazaki, P. J.; Shivley, J. E.; Datnow, B. Fluorescent humanized anti-CEA antibody specifically labels metastatic pancreatic cancer in a patient-derived orthotopic xenograft (PDOX) mouse model. Oncotarget 2018, 9, 37333.

(11) Lwin, T. M.; Hoffman, R. M.; Bouvet, M. Advantages of patient-derived orthotopic mouse models and genetic reporters for developing fluorescence-guided surgery. J. Surg. Oncol. 2018, 118, 253-264.

(12) Owens, E. A.; Hyun, H.; Tawney, J. G.; Choi, H. S.; Henary, M. Correlating molecular character of NIR imaging agents with tissue-specific uptake. J. Med. Chem. 2015, 58, 4348-4356.

(13) Lipinski, C. A.; Lombardo, F.; Dominy, B. W.; Feeney, P. J. Experimental and computational approaches to estimate solubility and permeability in drug discovery and development settings. Adv. Drug Delivery. Rev. 1997, 23, 3-25.

(14) Veber, D. F.; Johnson, S. R.; Cheng, H.-Y.; Smith, B. R.; Ward, K. W.; Kopple, K. D. Molecular properties that influence the oral bioavailability of drug candidates. J. Med. Chem. 2002, 45, 2615-2623.

(15) Xu, J.; Chen, Y.; Chen, H.; Hong, Z.; Shi, Z.; Zhuo, S.; Zhu, X.; Chen, J. Identifying the neck margin status of ductal adenocarcinoma in the pancreatic head by multiphoton microscopy. Sci. Rep. 2017, 7, 4586.

(16) Hanley, J. A.; McNeil, B. J. A method of comparing the areas under receiver operating characteristic curves derived from the same cases. Radiology 1983, 148, 839-843.

(17) Gibbs, S. L.; Xie, Y.; Goodwill, H. L.; Nasr, K. A.; Ashitate, Y.; Madigan, V. J.; Siclovan, T. M.; Zavodszky, M.; Hehir, C. A. T.; Frangioni, J. V. Structure-activity relationship of nerve-highlighting fluorophores. PLOS ONE 2013, 8, e 73493.

(18) Barth, C. W.; Schaefer, J. M.; Rossi, V. M.; Davis, S. C.; Gibbs, S. L. Optimizing fresh specimen staining for rapid identification of tumor biomarkers during surgery. Theranostics 2017, 7, 4722. 


\title{
Chapter 3: Altering Fundamental Trends in the Emission of Xanthene Dyes
}

Wang, L. G.; Munhenzva, I.; Sibrian-Vazquez, M.; Escobedo, J. O.; Kitts, C. H.; Fronczek, F. R.; Strongin, R. M., Altering Fundamental Trends in the Emission of Xanthene Dyes. The Journal of Organic Chemistry 2019, 84 (5), 2585-2595.

The above paper has been modified.

\begin{abstract}
Fluorescent small molecules enable researchers and clinicians to visualize biological events in living cells, tissues, and organs in real time. Herein, the focus is on the structure and properties of the relatively rare benzo[a]xanthenes that exhibit enhanced steric and electronic interactions due to their annulated structures. Three types of fluorophores were synthesized: (i) $\mathrm{pH}$ and solvent dependent seminaphthorhodafluors, (ii) $\mathrm{pH}$ and solvent independent seminaphthorhodafluors, and (iii) $\mathrm{pH}$-independent but solvent sensitive seminaphthorhodamines. The probes exhibited promising far-red to near-infrared (NIR) emission, large Stokes shift, broad full width at half maximum (FWHM), relatively high quantum yields, utility in PDAC imaging and immunofluorescence staining. Deviation of the $\pi$-system from planarity due to changes in the fluorophore ionization state resulted in fluorescence properties that are atypical of common xanthene dyes.
\end{abstract}

\section{INTRODUCTION}

Xanthenes, including benzoxanthene derivatives (Figure 1), are of considerable interest in chemical biology. They are an important class of heterocyclic compounds in both photophysical and medicinal chemistry. ${ }^{1-6}$ Benzoxanthenes have been employed as fluorescent materials for the recognition of biologically important molecules. ${ }^{7,8}$ Their light conversion ability enables applications ranging from optical fibers to filters. ${ }^{9}$ Much 
attention has been paid to the structural design and modification of benzoxanthenes due to their attractive biological and antiproliferative properties. ${ }^{10-12}$ We have previously reported a family of water-soluble, low molecular weight, NIR-emitting seminaphthofluorones wherein modifications to the regiochemistry of the ionizable groups and annulation directions have led to significant modulation of spectral properties. ${ }^{13}$ Transposition of the ionizable moieties, as a design variable of benzo[c]xanthene analogs, resulted in unusually large Stokes shift $(\sim 200 \mathrm{~nm})$ and emissions in the NIR $(>750 \mathrm{~nm}) .{ }^{14,15}$ In our previous work, a seminaphthorhodafluor dye featured an inherent affinity for pancreatic ductal adenocarcinoma (PDAC) cells without the need for conjugation to any targeting agents. ${ }^{16}$ This was accomplished through a systematic modification of three classes of benzo[c]xanthene fluorophores with an emphasis on pharmacochemical properties. The study described herein focuses on a series of red-to-NIR emitting fluorescent benzo[a]xanthene annulated probes containing various polar groups (Y, on C-5, Figure 1), including their synthesis, spectral properties, computational modeling and in vitro imaging.

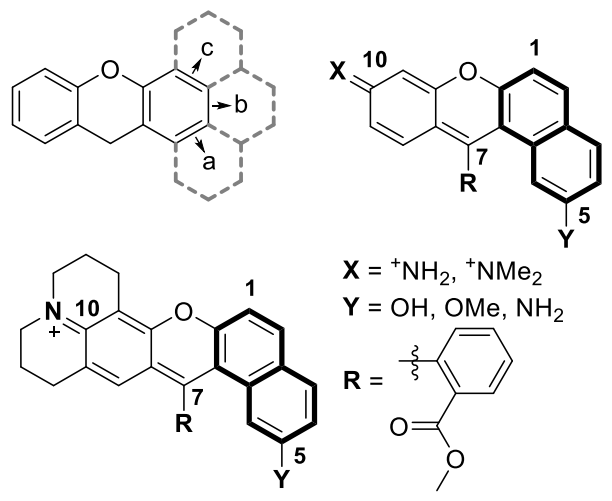

Figure 1. Annulation of the xanthene chromophore can lead to three types of benzoxanthenes. The benzo[a]xanthene framework is annulated on the side opposite to the $\mathrm{X}$-group. 
The design of a library of nine fluorophores was based on systematic functional group variation (Figure 2). At C-5, the hydroxyl, methoxy or amine functionality, as well as different levels of rigidity at the $\mathrm{C}-10$ iminium group were varied. All structures possess a methyl benzoate at C-7, allowing for eventual conjugation to biological molecules. Compounds 1, 4 and 7 are the only $\mathrm{pH}$ - and solvent-dependent fluorophores in the series. Substitution of the hydroxyl at C-5 with a methoxy group results in analogs $\mathbf{2}, \mathbf{5}$, and $\mathbf{8}$. The corresponding naphthylamine are compounds $\mathbf{3}, \mathbf{6}$, and $\mathbf{9}$.

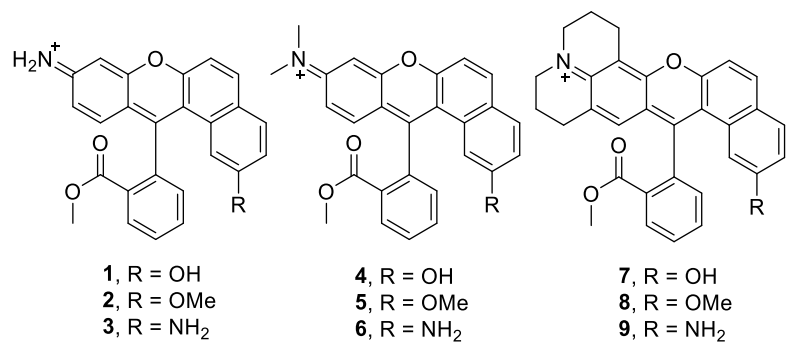

Figure 2. Seminaphthorhodafluors and seminaphthorhodamines.

\section{RESULTS AND DISCUSSION}

Fluorophore synthesis and characterization. Seminaphthorhodafluor analogs (Figure 2) were synthesized in three steps (Scheme 1). Briefly, condensation of the corresponding hydroxybenzophenone with the appropriate 2-naphthol derivative in a mixture of $\mathrm{CH}_{3} \mathrm{SO}_{3} \mathrm{H}$ :TFA $(1: 1)$ at $80{ }^{\circ} \mathrm{C}$ for $16-24 \mathrm{~h}$ produced a single isomer (benzoxanthene type a) as the major product. Single-crystal X-ray structure analysis and 2D NMR (COSY), confirmed the structure assignment. Subsequent Fischer esterification to produce the methyl ester derivatives was carried out under reflux conditions in anhydrous $\mathrm{MeOH}$ and catalyzed by $\mathrm{HCl}$. The required starting materials 2-(2,4dihydroxybenzoyl)benzoic acid, 2-(4-amino-2-hydroxybenzoyl)benzoic acid, 2-(8- 
hydroxy-1,2,3,5,6,7-hexahydropyrido[3,2,1-ij]quinoline-9-carbonyl)benzoic acid, and 2,7-naphthalene derivatives were synthesized according to published literature protocols. ${ }^{10,16,17}$ In the case of the seminaphthorhodamines (Figure 2), we followed a protocol developed recently by our group. ${ }^{18}$ All compounds were isolated by flash column chromatography on silica gel, preparative TLC or reversed phase chromatography, and characterized by 1D and 2D NMR as well as HR-ESI-MS. Detailed characterization data and procedures are described in the experimental section.

Scheme 1. Synthesis of seminaphthorhodafluors from the benzo[a]xanthenes series.

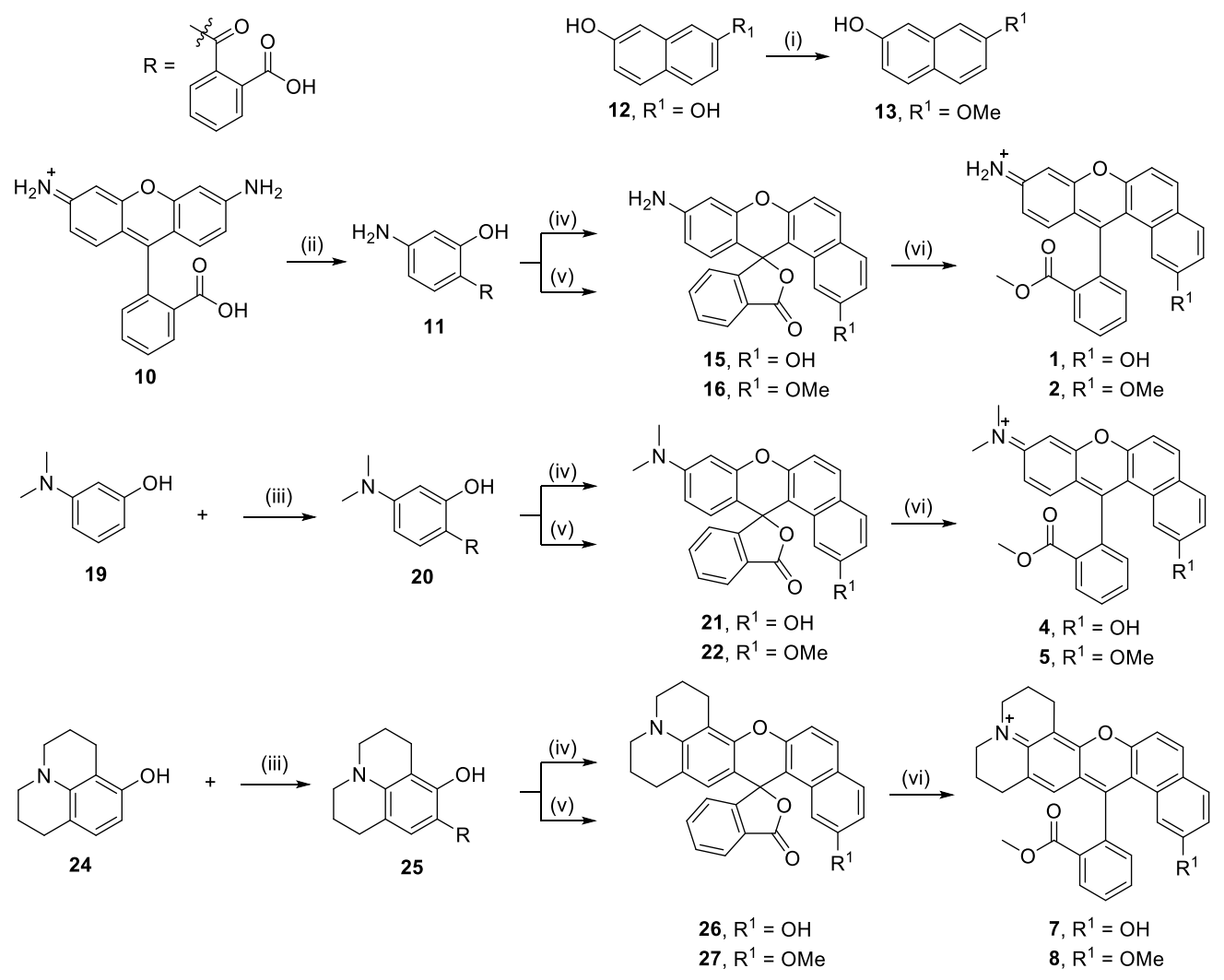

(i) $\mathrm{NaH}$, Mel, DMF $12 \mathrm{~h}$; (ii) $\mathrm{NaOH}, 160^{\circ} \mathrm{C} 3 \mathrm{~h}$; (iii) phthalic anhydride, toluene, reflux $12 \mathrm{~h}$; (iv) $\mathrm{MeSO}_{3} \mathrm{H}: \mathrm{TFA} 1: 1,12,80^{\circ} \mathrm{C} 24 \mathrm{~h}$; (v) $\mathrm{MeSO}_{3} \mathrm{H}: \mathrm{TFA} 1: 1,13,80^{\circ} \mathrm{C} 24 \mathrm{~h}$; (vi) $\mathrm{MeOH}, \mathrm{CH}_{3} \mathrm{COCl}, 50^{\circ} \mathrm{C} 72 \mathrm{~h}$ 
Spectroscopic studies of the pH-dependent seminaphthorhodafluors. The products were screened for $\mathrm{pH}$ and solvent dependence, relative quantum yields are reported as the average of multiple measurements using multiple references (Appendix A). ${ }^{19}$ Their optical properties in $\mathrm{MeOH}$ are summarized in Table 1 . The absorption and emission spectra of all fluorophores included in this series display broad, structured peaks, which enables efficient use over a wide range of wavelengths. All exhibit broad FWHM ranges from 101 to $182 \mathrm{~nm}$, covering a significant window of the NIR region (Figure 3). Stokes shifts range from 40 to $100 \mathrm{~nm}$.

Table 1. Spectral properties of compounds 1-9 in $\mathrm{MeOH}$.

\begin{tabular}{cccccccc}
\hline Compound & $\begin{array}{c}\lambda_{\max } \\
\text { abs } \\
(\mathrm{nm})\end{array}$ & $\begin{array}{c}\lambda_{\max } \\
\mathrm{em} \\
(\mathrm{nm})\end{array}$ & $\begin{array}{c}\text { Stokes } \\
\text { Shift } \\
(\mathrm{nm})\end{array}$ & $\begin{array}{c}\text { Extinction } \\
\text { Coefficient } \\
\left(\mathrm{M}^{-1} \cdot \mathrm{cm}^{-1}\right)\end{array}$ & $\begin{array}{c}\text { Quantum } \\
\text { Yield } \\
(\%)\end{array}$ & Brightness & FWHM \\
\hline $\mathbf{1}$ & 527 & 630 & 103 & 29,276 & 4.6 & 1347 & 151 \\
$\mathbf{2}$ & 520 & 590 & 70 & 26,261 & 41.99 & 11027 & 132 \\
$\mathbf{3}$ & 568 & 610 & 42 & 18,013 & 1.08 & 195 & 182 \\
$\mathbf{4}$ & 556 & 610 & 54 & 28,896 & 3.97 & 1147 & 110 \\
$\mathbf{5}$ & 520 & 610 & 90 & 27,549 & 11.65 & 3210 & 114 \\
$\mathbf{6}$ & 584 & 640 & 56 & 26,110 & 0.68 & 178 & 114 \\
$\mathbf{7}$ & 538 & 630 & 92 & 25,562 & 20.52 & 5245 & 114 \\
$\mathbf{8}$ & 535 & 630 & 95 & 26,275 & 18.36 & 4824 & 116 \\
$\mathbf{9}$ & 592 & 670 & 78 & 21,690 & 1.6 & 347 & 148 \\
\hline
\end{tabular}

At low pH, 1, 4 and 7 are red-to-NIR emitting (Figure 3). Their absorption spectra display structured peaks with maxima ranging from 520 to $540 \mathrm{~nm}$, large Stokes shifts (60 - $92 \mathrm{~nm}$ ), and emission maxima between 580 and $630 \mathrm{~nm}$ The absorption and fluorescence spectra (Figure 4a) of seminaphthorhodafluor naphthols 1, 4 and 7 exhibit $\mathrm{pH}$ dependence 
over the physiological range, as well as sensitivity to other solvent systems $(\mathrm{MeOH}$, DMSO). In aqueous solution, ratiometric absorption spectra with well-defined isosbestic points are observed (Figure 4a). At high $\mathrm{pH}$, the neutral forms (deprotonated naphthols) display red-shifted absorption peaks at ca. $600 \mathrm{~nm}$. Surprisingly, as the $\mathrm{pH}$ of the aqueous solutions of $\mathbf{1}, \mathbf{4}$ and $\mathbf{7}$ is increased further, the fluorescence intensity decreases to a nonfluorescent state $(\mathrm{pH}=12.1$, Figure $4 \mathrm{~g})$. Overall, the $\mathrm{p} K_{\mathrm{a}}$ values range from 8.07 for compound 1 to 8.39 for compound 7, embodying enhanced acidity as compared to 2naphthol $\left(\mathrm{p} K_{\mathrm{a}}=9.51\right)$. Although small differences in $\mathrm{p} K_{\mathrm{a}}$ for rhodols $\mathbf{1}, 4$ and 7 are observed, they follow the expected trend associated with $N$-substitution at C-10 $(7>\mathbf{4}>\mathbf{1})$. Solvent dependence can be at least partially attributed to the differences in the equilibria of the tautomers of the compounds. In organic solvents, absorptions from each tautomer are observed, with the shorter wavelength species predominating, similar to what is observed in the neutral buffer (Figure 4d). Quantum yields are generally about 3-27 times higher in organic solvents as compared to aqueous buffer. 

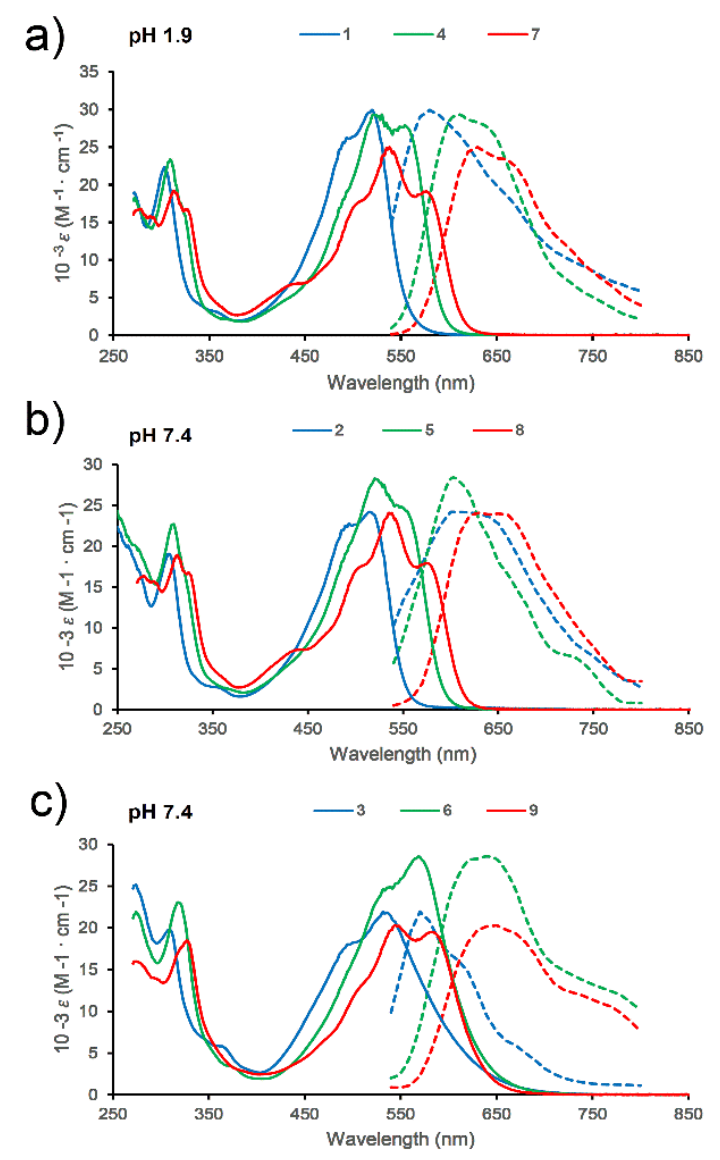

Figure 3. Spectral properties of compounds 1-9 in aqueous media. To ensure the cationic form, compounds $\mathbf{1}, \mathbf{4}$ and 7 were dissolved in $\mathrm{pH} 1.9$ aqueous solution with the remaining compounds dissolved in $\mathrm{pH} 7.4$ solution. (a) Absorption spectra (solid lines) and normalized fluorescence emission spectra (dash lines) of pH-dependent seminaphthorhodafluors $\left(\mathbf{1}, \mathbf{4}\right.$, and 7) in acidic solution 1:9 DMSO: $\mathrm{HCl}\left(12.5 \mathrm{mM}\right.$ in $\mathrm{H}_{2} \mathrm{O}, \mathrm{pH}$ 1.9) shows a red-shifted $\lambda_{\max }$ and emission maximum for 7 , which embody the extra ring system for rigidity (540 $\mathrm{nm}$ and $630 \mathrm{~nm}$ respectively) compared to $\mathbf{1}$ and $\mathbf{4}$. (b) $\mathrm{pH}$-independent seminaphthorhodafluors $(\mathbf{2}, \mathbf{5}$, and 8) in 1:9 DMSO:buffer (12.5 mM phosphate, $\mathrm{pH}$ 7.4) shows analogous absorption spectra of $\mathbf{2}, \mathbf{5}$ and $\mathbf{8}$ compared to 1, 4 and 7 with the emission spectra of 2,5 and 8 all in the red-to-NIR region. (c) pH-independent seminaphthorhodamines $(\mathbf{3}, \mathbf{6}$, and $\mathbf{9})$ in 1:9 DMSO:buffer $(12.5 \mathrm{mM}$ phosphate, $\mathrm{pH}$ 7.4) shows comparable $\lambda_{\max }$ and emission spectra between $\mathbf{6}$ and $\mathbf{9}$, with $\mathbf{6}$ showing high peak intensity for both absorption and emission spectra. Compound $\mathbf{3}$ absorption and emission spectra is blue-shifted, compared to $\mathbf{6}$ and $\mathbf{9}$. Emission spectra are normalized to their corresponding absorption peaks. Excitation Emission Matrices (EEMs) are provided in the Appendix A.

\section{Spectroscopic studies of pH-independent seminaphthorhodafluor methyl}

ethers. Replacing the hydroxyl moiety of 1, 4 and 7 with a methyl ether (compounds 2,5, 
and 8) eliminates both $\mathrm{pH}$ and solvent dependence (Figure 4b, and 4e). At $\mathrm{pH} 7.4$, compounds $\mathbf{2}, \mathbf{5}$, and $\mathbf{8}$ exist as single species, similar to what is observed for $\mathbf{1 ,} \mathbf{4}$ and $\mathbf{7}$ in acidic solution. Absorption spectra are nearly identical to the corresponding hydroxyl analogs. The emission wavelengths of the methyl ethers are also in the red-to-NIR region, (Figure 4g), including large Stokes shifts (90-105 nm). Quantum yields, ranging from about $12-42 \%$, are higher compared to $\mathbf{1}, 4$ and 7 ( $\sim 64$-fold higher for compound 2$)$. No spectral evidence for tautomeric equilibria is observed for the methyl ethers, with the absorption spectrum of compound 8 being the most stable over the $\mathrm{pH}$ range from 1.9 to 12.1 (Figure 4b), followed by compound 5, then 2 (SI). There is negligible change in the absorption spectrum upon changing solvents from DMSO to $\mathrm{MeOH}$ to neutral $\mathrm{pH}$ buffer (Figure 4e).

\section{Spectroscopic studies of pH-independent seminaphthorhodamines.}

Seminaphthorhodamines 3, 6 and 9 are $\mathrm{pH}$-insensitive, but exhibit greater solventdependent spectral changes compared to seminaphthorhodafluors $\mathbf{1 , 4}$, and 7. Compound 9 shows the highest stability over the $\mathrm{pH}$ range of 1.9 to 12.1 (Figure $4 \mathrm{c}$ ), followed by 6 , then 3 (SI). Their emission maxima range is from 610 to $670 \mathrm{~nm}$, with broad FWHM of up to $182 \mathrm{~nm}$ (in $\mathrm{MeOH}$ ), covering a significant portion of the NIR region. Stokes shifts range from 50 to $105 \mathrm{~nm}$ in aqueous media. Quantum yields are generally two times higher in $\mathrm{MeOH}$ compared to neutral buffer. Solvatochromic behavior (up to $60 \mathrm{~nm}$ ) is observed for the longest wavelengths in DMSO and for the shortest in aqueous media (Figure 4f).

Molecular simulations. Density functional theory (DFT) calculations were performed to further investigate the relationship between the structural and electronic properties of the benzo[a]xanthenes. The highest occupied molecular orbitals (HOMOs) 
and the lowest unoccupied molecular orbitals (LUMOs) were obtained from the optimized molecular geometries in the ground state at the B3LYP/6-31+G(d,p) level of theory using Gaussian 09 (see Table 2). ${ }^{20}$ Notably, electrons are preferentially localized on the naphthyl annulation region of the molecule within the HOMO, and more delocalized over the xanthene dye core of the molecule in the LUMO (Figure A9, Appendix A).

Table 2. Dihedral angles $\left(C_{(7-10)}\right)$ and dipole moment for compounds $\mathbf{7 , 8}$ and 9 in their cationic and neutral forms from DFT-optimized geometries in the ground state.

\begin{tabular}{ccccc}
\hline Compound & \multicolumn{2}{c}{$\begin{array}{c}\text { dihedral angle } \\
\left(\phi,{ }^{\circ}\right) \mathrm{C}_{(7-10)}\end{array}$} & \multicolumn{2}{c}{ dipole moment } \\
& & & & \\
& & & \\
& cation & neutral $)$ & cation & neutral \\
\hline $\mathbf{7}$ & -1.4 & -11.2 & 3.1 & 11.6 \\
$\mathbf{8}$ & -3.1 & $\mathrm{~N} / \mathrm{A}^{a}$ & 7.5 & $\mathrm{~N} / \mathrm{A}^{a}$ \\
$\mathbf{9}$ & -0.2 & -12.4 & 2.7 & 7.8 \\
\hline${ }^{a}$ Notapplicable. & & & & \\
\hline
\end{tabular}

${ }^{a}$ Not applicable. The neutral form cannot be produced.

To understand the effects of $\mathrm{pH}$ on the emission (as shown in Figure $4 \mathrm{~g}$ ) of compounds 7, 8, and 9 at the molecular level, we further examined geometries and electronic properties. DFT calculations revealed a distortion of the conjugated $\pi$-systems from planarity for the neutral forms of $\mathbf{7}$ and $\mathbf{9}$ (Figure 5). The dihedral angles $\left(C_{7-10}\right)$ are $>$ $-11^{\circ}$ (Table 2). In contrast, the dihedral angles in the cationic forms are closer to $0^{\circ}$, consistent with the more typical planar conformation. Similarly, compound $\mathbf{8}$, which exists only as a cation, has a relatively small dihedral angle of $-3.1^{\circ}$ (Table 2). Analogous 
relationships are observed for the other two $\mathrm{pH}$-dependent fluorohores, $\mathbf{1}$ and $\mathbf{4}$ (Table A11, Appendix A), wherein the neutral molecules exhibit greater dihedral angles compared to the corresponding cations.

It is not surprising that $\mathrm{pH}$-insensitive methoxy-functionalized $\mathbf{8}$ affords relatively consistent emission over the entire $\mathrm{pH}$ range studied. However, the emission from naphthol 7 is dim at $\mathrm{pH}$ ca. 9 and above as shown in the EEMs (Figure 4g). This is not typical for xanthenes such as fluorescein or even the type[c] benzoxanthenes, wherein higher $\mathrm{pH}$ enhances and red-shifts fluorescence emission. ${ }^{21}$ This unique effect is ascribed to the aforementioned increased dihedral angle distortion in the neutral form of $7\left(\mathrm{p} K_{\mathrm{a}}=8.39 \pm\right.$ $0.06)$.

Since the neutral and cationic forms of amino analog 9 have very similar dihedral angles compared to neutral and cationic 7, compound 9 should exhibit enhanced fluorescence at low $\mathrm{pH}$ levels, for instance at levels below the $\mathrm{p} K_{\mathrm{a}}$ of an ammonium cation. However, rhodamine and congeners are well-known to be relatively $\mathrm{pH}$-insensitive, and to display relatively bright emission over broad $\mathrm{pH}$ ranges. In the case of $\mathbf{9}$, however, the EEMs in Figure 4g show relatively bright fluorescence at only the lowest solution $\mathrm{pH}$ studied (1.9). The emission diminishes sharply as the equilibrium shifts towards the neutral form at higher $\mathrm{pH}$ values. This is in keeping with the emissive properties of neutral versus cationic 7, and serves as further evidence that fluorescence modulation in benzo[a]xanthenes is related to increases in the dihedral angle formed by carbons $7-10$ (Figure 5 and Table 2). 
a)

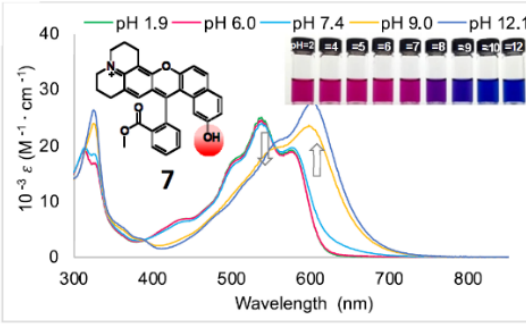

b)

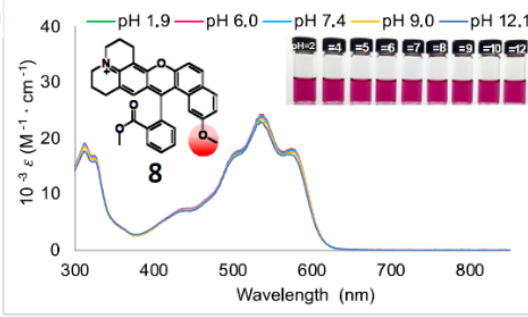

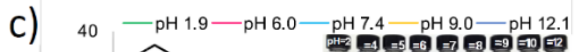

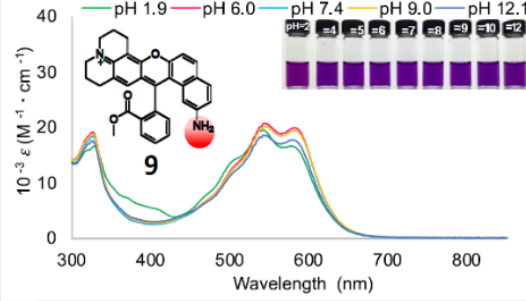

d)

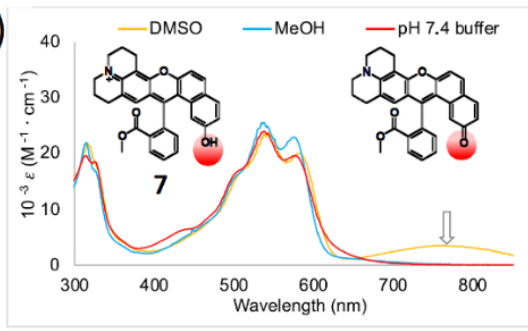

e)

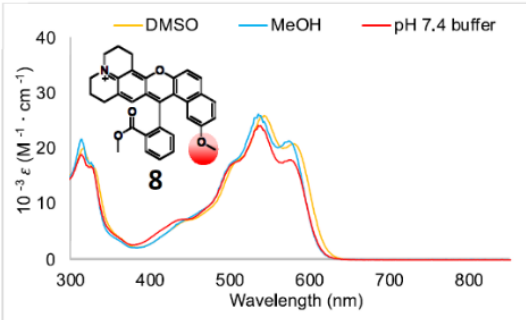

f)

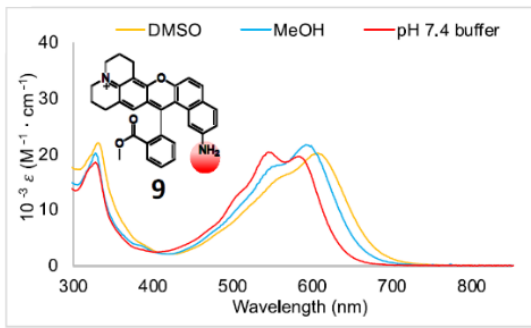

g)
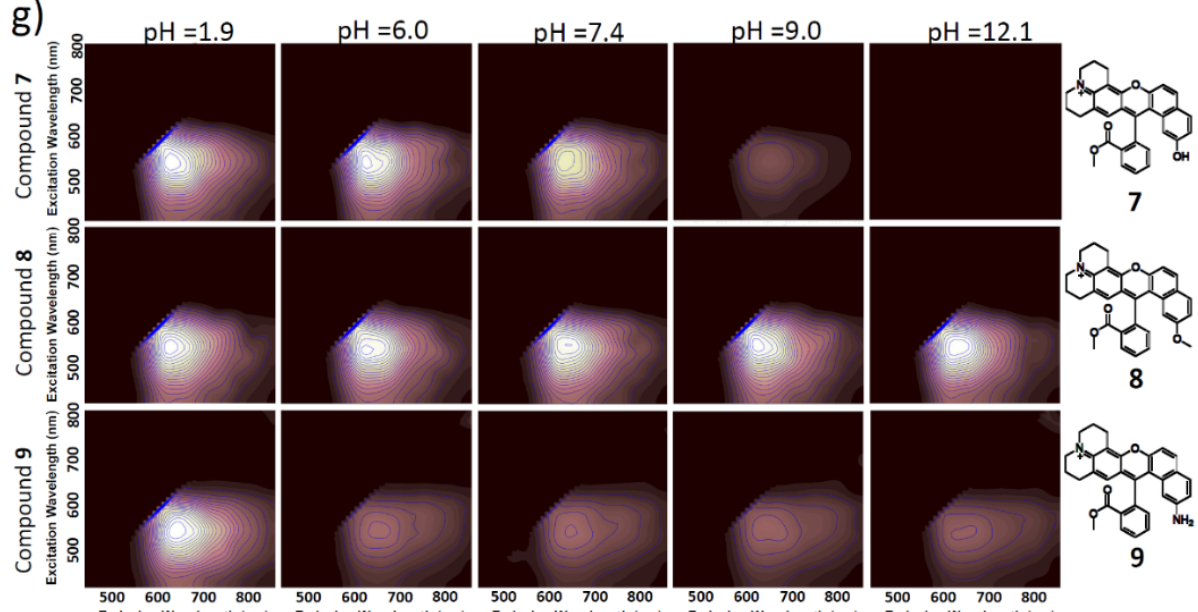

Figure 4. Comparison of the optical properties of compounds 7-9. (a) Absorption spectra of 7 (pH-sensitive) as a function of $\mathrm{pH}$ shows that above $\mathrm{pH} 9,7$ is red shifted and shows an isosbestic point $c a .550 \mathrm{~nm}$ across the $\mathrm{pH}$ range studied. (d) Absorption spectra of 7 as a function of solvents including DMSO, $\mathrm{MeOH}$, and 1:9 DMSO:buffer (12.5 mM phosphate, $\mathrm{pH}$ 7.4) shows minimal solvent dependence. In DMSO absorption of tautomer is observed $c a .750 \mathrm{~nm}$. (b) Absorption spectra of $\mathbf{8}$ (pH-insensitive) as a function of $\mathrm{pH}$ shows an overlay of absorption spectra across the $\mathrm{pH}$ range studied confirming the expected $\mathrm{pH}$ independence of $\mathbf{8}$. (e) Absorption spectra of $\mathbf{8}$ as a function of solvents shows minimal solvent dependence. (c) Absorption spectra of 9 ( $\mathrm{pH}$-insensitive) as a function of $\mathrm{pH}$ shows minimal $\mathrm{pH}$ dependency across the $\mathrm{pH}$ range studied. (e) Absorption spectra of $\mathbf{9}$ as a function of solvents shows solvent dependence compared to 7, due to stronger 
hydrogen bonding between solvent and $-\mathrm{NH}_{2}$ on 9 versus $-\mathrm{OH}$ on 7 . Inset figures are ambient light photographs of the compounds in solution. (g) Normalized excitation emission matrices (EEMs) as a function of $\mathrm{pH}$ for compounds $\mathbf{7 , 8}$, and $\mathbf{9}$. Fluorescence intensity of $\mathbf{7}$ reduced at $\mathrm{pH} 9$ and diminishes completely at $\mathrm{pH} 12$ due to twisting in the chromophore from the deprotonation of $-\mathrm{OH}\left(\mathrm{pK}_{\mathrm{a}} \sim 8.4\right)$. Fluorescence intensity of $\mathrm{pH}$ insensitive $\mathbf{8}$ remain consistent across $\mathrm{pH}$ range studied. Fluorescence intensity of $\mathbf{9}$ diminishes after $\mathrm{pH} 6$ due to the equilibria formed between cationic 9 and deprotonated $-\mathrm{NH}_{2}$ neutral 9 with twisted conformation similar to 7 . 
Our calculations also show an increased charge separation in the neutral $\mathbf{7}$ and $\mathbf{9 ,}$ with dipole moment values 3-4 times higher compared to the cationic forms (Table 2). Molecular electrostatic potential surfaces calculations using the natural bound order (NBO) display a significant charge repulsion between the centroid of the benzoate ring and the heteroatom at the edge of the [a] annulated ring system (Figure 6). The result of the charge repulsion of the naphthyl moiety is an increase in the dihedral angle formed by C7-C10.

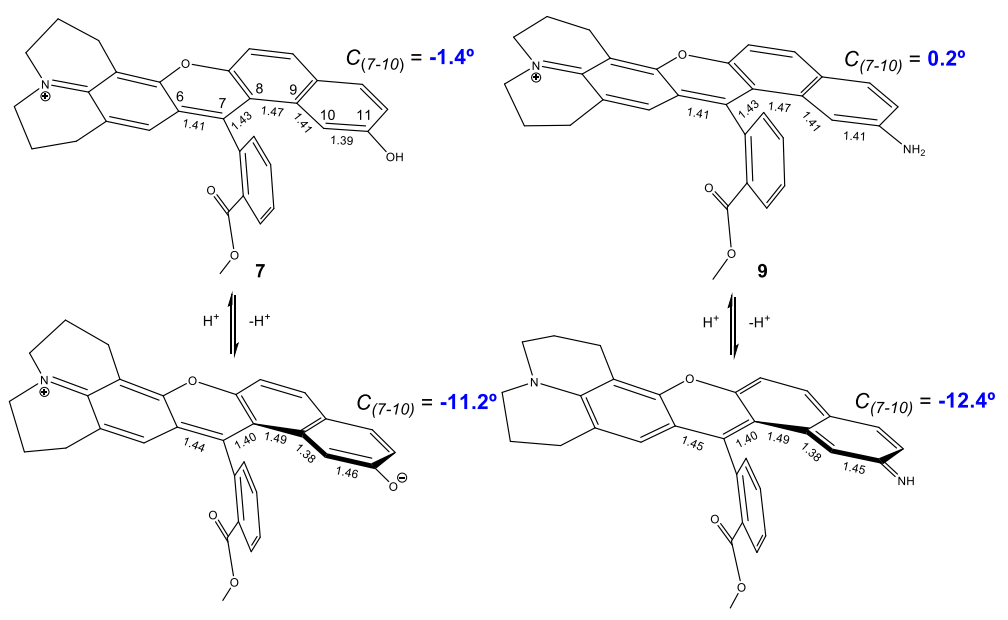

Figure 5. DFT-optimized geometries of the cationic (top) and the neutral forms (bottom) of compounds 7 (left) and 9 (right). The torsion in the naphthyl annulation region increases upon deprotonation of the hydroxyl and amino groups, respectively. The bond lengths in angstroms and dihedral angles $(\phi)$ for $C_{7}-C_{10}$ of the extended benzoxanthene region are shown for clarity. 


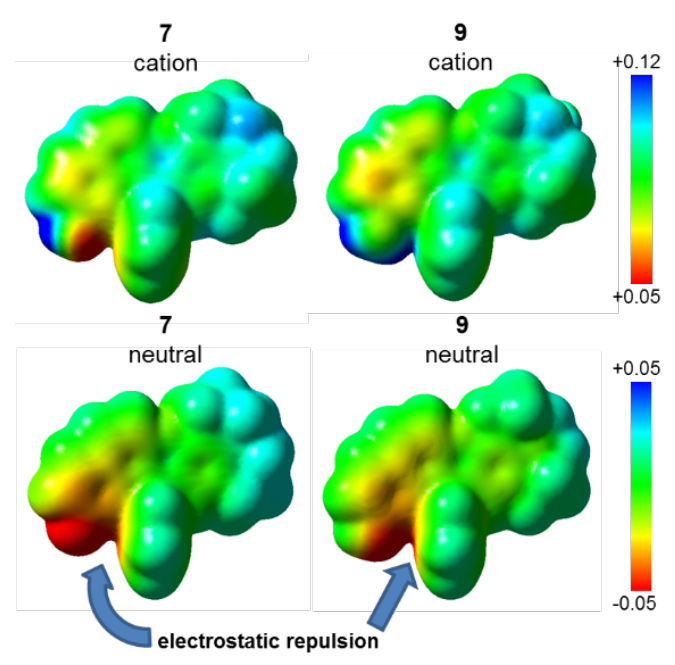

Figure 6. Calculated molecular electrostatic potential surfaces of DFT optimized geometries of the cationic and the neutral forms of compounds $\mathbf{7}$ and $\mathbf{9}$ in the ground-state.

In vitro studies. To investigate their biocompatibility and utility in live cell imaging, compounds 1 through $\mathbf{9}$ were screened for cytotoxicity in Capan-1 cells (a human PDAC cell line) (Figure 7). Cell viability is reported as the half maximal inhibitory concentration $\left(\mathrm{IC}_{50}\right)$ for each compound. Interestingly, methoxy analogs $(\mathbf{2}, \mathbf{5}$, and $\mathbf{8})$ exhibited higher cytotoxicity as compared to their corresponding hydroxyl analogs $(\mathbf{1}, \mathbf{4}$, and 7 ) and amine analogs $(\mathbf{3}, \mathbf{6}$, and 9). Moreover, alkylation at the $\mathrm{C}-10$ nitrogen seemed to result in increased cytotoxicity, with compound 1 the least toxic $\left(\mathrm{IC}_{50} 30.96 \mu \mathrm{M}\right)$, followed by compound $4\left(\mathrm{IC}_{50} 26.30 \mu \mathrm{M}\right)$, and then 7 ( $\left.\mathrm{IC}_{50} 13.45 \mu \mathrm{M}\right)$ among three $\mathrm{pH}$ dependent seminaphthorhodafluors. The same relationship was also observed for the other two sets of fluorophores, with $\mathrm{IC}_{50}$ value comparisons of $\mathbf{2}>\mathbf{5}>\mathbf{8}$ for $\mathrm{pH}$-independent seminaphthorhodafluors, and $\mathbf{3}>\mathbf{6}>\mathbf{9}$ for the $\mathrm{pH}$-independent seminaphthorhodamines. The evidence indicates that lipophilicity may play a role in the cytotoxicity of these compounds. 

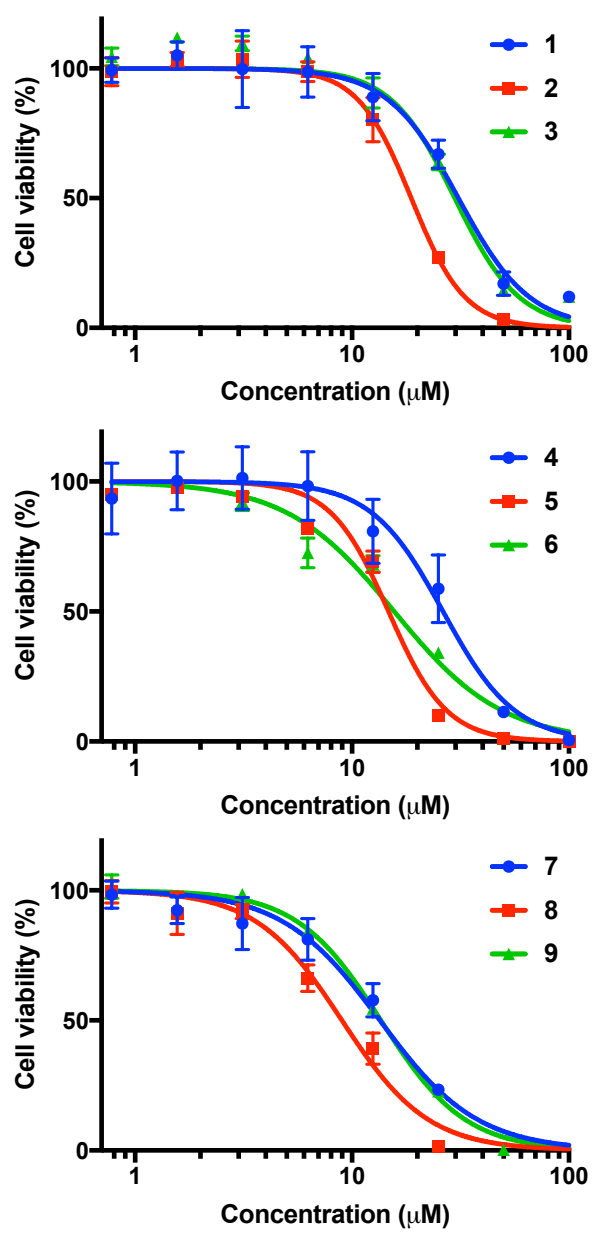

Figure 7. Cell viability of compounds 1-9. Cytotoxicity was determined by Cell Titer-Blue assay. Capan-1 cells were incubated with decreasing concentrations from $100 \mu \mathrm{M}$ of each compound in growth media. The half maximal inhibitory concentrations $\left(\mathrm{IC}_{50}\right)$ determined by interpolating values in the graph $(\%$ cell viability vs fluorophore concentration).

The subcellular localization (Figure 8) of compound $\mathbf{8}$ was investigated in Capan1 cells. Organelle-specific fluorescent probes for the nucleus (DAPI), endoplasmic reticulum (ER), lysosomes (Lyso), and mitochondria (Mito) were used to assess the sitespecific uptake. Compound $\mathbf{8}$ displays homogeneous distribution in the cytoplasm with 
limited accumulation in the nucleus, endoplasmic reticulum, and mitochondria, showing utility as a cell membrane permeable fluorescent probe for live cell imaging.

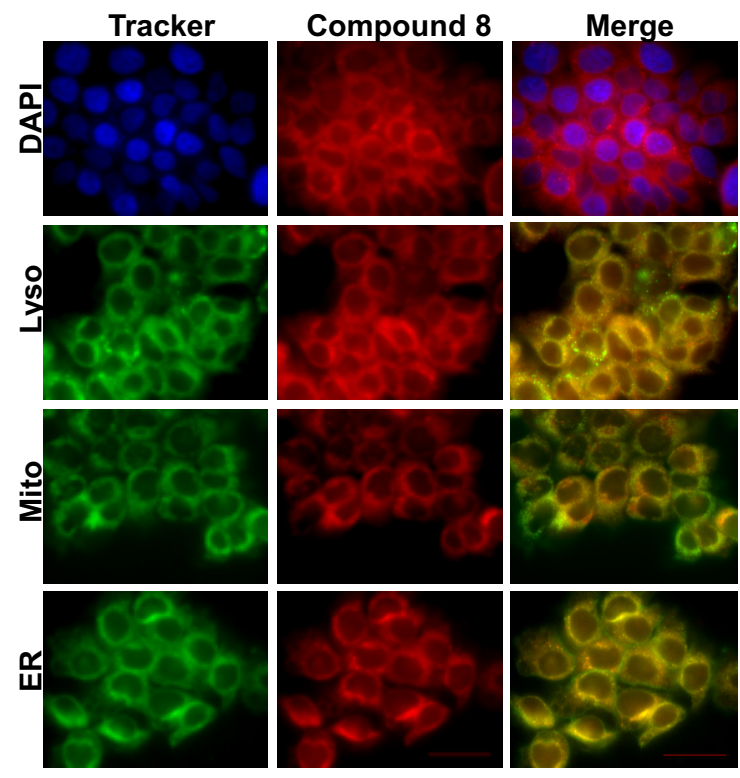

Figure 8. Subcellular localization of compound 8. Images of subcellular organelles stained with commercial fluorescent trackers are labeled as DAPI (blue), Lyso (green), Mito (green), ER (green). Mid-column shows the images of cells stained with compound $\mathbf{8}$ (red). The merge column shows images of (top) colocalization of DAPI $+\mathbf{8}$, followed successively below by, colocalization of Lyso $+\mathbf{8}$, colocalization of Mito $+\mathbf{8}$, and colocalization of ER $+\mathbf{8}$.

Compound $\mathbf{8}$ was used in the staining of a human PDAC tissue specimen, purchased from Origene, Inc. The goal was to compare the staining pattern of $\mathbf{8}$ to that of compound 12 from the benzo[c]xanthene library (Chapter 2). The physicochemical properties of 8 are close to those of 12, with the dipole moment of $\mathbf{8}$ an exception, nearly $2 \mathrm{x}$ that of $\mathbf{1 2}$ (Figure 9). Utilizing the area under the curve (AUC) as a measure of effective PDAC targeting, 8 displayed an AUC slightly < that of $\mathbf{1 2}$, but still high (AUC $>0.5$ ). This shows that maintaining physicochemical properties in the novel benzo[a]xanthene probes can preserve the inherent PDAC targeting properties. 

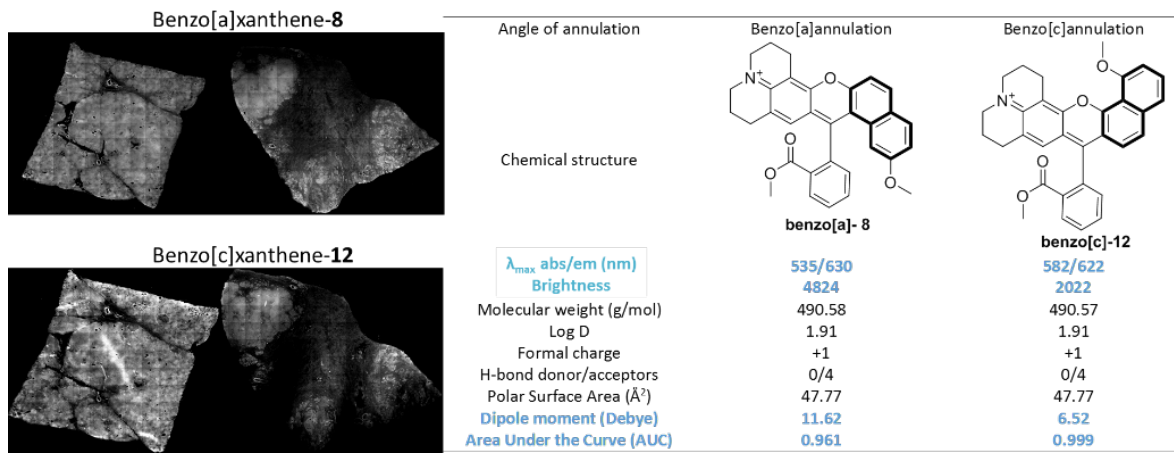

Figure 9. A direct comparison of the human PDAC tissue staining pattern of $\mathbf{8}$ (benzo[a]xanthene) and 12 (benzo[c]xanthene).

Since compound $\mathbf{8}$ exhibits a large Stokes shift, broad FWHM, appreciable brightness, and high stability across organic and aqueous buffer solutions, it was modified to produce the NHS activated probe 8-NHS (Scheme 2). Compound 8-NHS was conjugated to bovine alpha-tubulin mouse antibody as the primary and donkey anti-mouse antibody as the secondary antibody. The fluorophore to antibody-labeling conjugation ratio was $2.8: 1$, as determined by UV-Vis analysis. Immunoconjugates were used for indirect immunofluorescence staining in fixed U2OS cells at a $200 \mathrm{nM}$ concentration. Figure 10 shows high contrast and detailed microtubular network visualization, demonstrating benzo[a]xanthene's utility for specific staining applications. 
Scheme 2. Synthesis of 8-NHS.

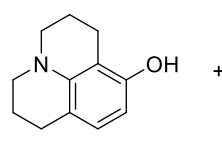

24

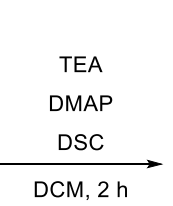

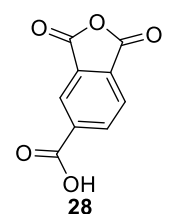

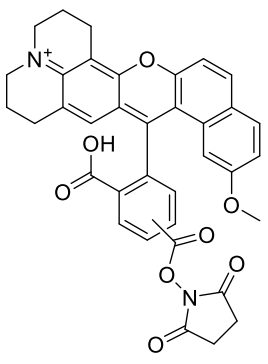

8-NHS
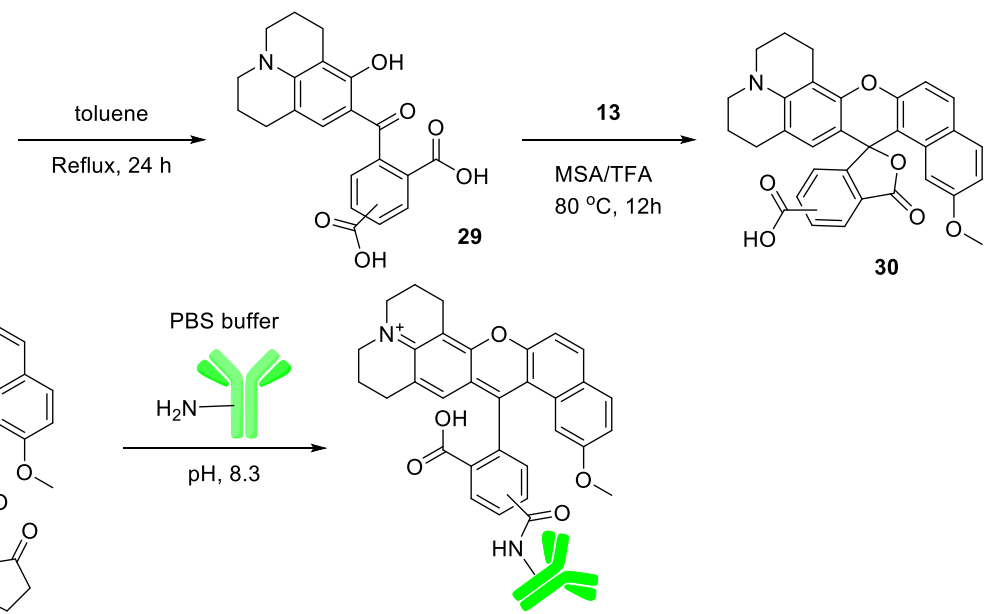

30
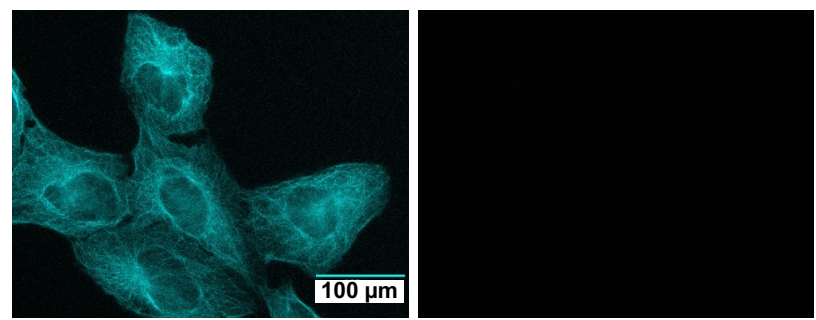

Figure 10. Immunofluorescence imaging of a microtubule network. Tubulin was labeled using indirect immunofluorescence with compound 8-NHS in fixed U2OS cell at $200 \mathrm{nM}$ concentration (left); negative control fluorescence image of fixed U2OS cells incubated with donkey, anti-mouse secondary antibody (preconjugated with compound 8-NHS) only (right). Scale bar $100 \mu \mathrm{m}$.

\section{CONCLUSION}

In summary, an efficient synthesis of red-to-NIR benzo[a]xanthene analogs has been developed. Spectral and physicochemical properties were tuned by varying the substituent at $\mathrm{C}-5\left(-\mathrm{OH},-\mathrm{OMe}\right.$ or $\left.-\mathrm{NH}_{2}\right)$. These changes afforded three types of fluorophores, based on their absorption spectra: (i) $\mathrm{pH}$ and solvent dependent 
seminaphthorhodafluors, (ii) $\mathrm{pH}$ and solvent independent seminaphthorhodafluors and (iii) $\mathrm{pH}$ independent but solvent dependent seminaphthorhodamines. Fluorescence properties observed included far red-to-NIR emission, large Stokes shifts (103 $\mathrm{nm}$ at neutral $\mathrm{pH})$, broad FWHM (182 nm in $\mathrm{MeOH})$ and relatively high quantum yields $(42 \%$ in $\mathrm{MeOH})$. Minimal cytotoxicity and relatively bright fluorescence rendered the dyes suitable for live cell imaging, as well as site-specific immunofluorescence imaging applications. Changes to the C-5 substituent led to significant modulation of fluorescence emission as a function of ionization state. This was ascribed to deviations from planarity in the chromophore.

This effect was associated with brighter fluorescence observed at lower solution $\mathrm{pH}$ values, which is opposite the trend typically exhibited by other xanthene and benzoxanthene dyes. The type [a] annulated fluorophores thus add architectural diversity and complementary fluorescent properties to the common xanthene dyes. Since they are analogs of the type [c] benzoxanthenes that have previously exhibited inherent cancer tissue targeting, ${ }^{16}$ the type [a] fluorophores enabled PDAC imaging providing insights into how structural changes modulate not only the optical but also the targeting and biological properties of the benzoxanthenes.

\section{METHODS}

General. Unless otherwise indicated, all commercially available starting materials were used directly without further purification. Silica gel Sorbent Technologies 32-63 $\mu \mathrm{m}$

was used for flash column chromatography. ${ }^{1} \mathrm{H}-\mathrm{NMR}$ was obtained on an ARX-400 
Advance Bruker spectrometer. Chemical shifts $(\delta)$ are given in ppm relative to DMSO- $d_{6}$ (2.50 ppm, ${ }^{1} \mathrm{H}, 39.52{ }^{13} \mathrm{C}$ ) unless otherwise indicated. MS (HRMS, ESI) spectra were obtained at the PSU Bioanalytical Mass Spectrometry Facility on a ThermoElectron LTQOrbitrap high resolution mass spectrometer with a dedicated Accela HPLC system, or an Agilent 6244 time-of-flight LCMS with diode array detector VL+.

Synthesis of 2-(4-amino-2-hydroxybenzoyl)benzoic acid (11). Rhodamine 110 hydrochloride $(1 \mathrm{~g}, 2.725 \mathrm{mmol})$ is mixed with $\mathrm{NaOH}(1.875 \mathrm{~g}, 4.635 \mathrm{~mol})$ and $1 \mathrm{~mL}$ of water. The mixture is stirred and heated in an oil bath at $160{ }^{\circ} \mathrm{C}$ for two hours, $3 \mathrm{~mL}$ of $50 \% \mathrm{NaOH}$ are added in one portion and the mixture heated and stirred at $160{ }^{\circ} \mathrm{C}$ for an additional one hour. The mixture is allowed to cool down to rt and diluted with $50 \mathrm{~mL}$ of water. The mixture is acidified to $\mathrm{pH} 1$ with concentrated $\mathrm{HCl}$. The resulting mixture is extracted with ethyl ether $(2 \times 50 \mathrm{~mL})$, the organic extracts combined, dried over anhydrous $\mathrm{Na}_{2} \mathrm{SO}_{4}$, filtered and the solvent evaporated under reduced pressure to leave a pale yellow solid. Yield $0.61 \mathrm{~g}, 87 \%$. ${ }^{1} \mathrm{H}$ NMR (400 MHz, DMSO-d $\left.d\right) \delta 13.01(\mathrm{~s}, 1 \mathrm{H}), 12.60(\mathrm{~s}, 1 \mathrm{H})$, $7.95(\mathrm{dd}, J=7.8,1.2 \mathrm{~Hz}, 1 \mathrm{H}), 7.67(\mathrm{td}, J=7.5,1.4 \mathrm{~Hz}, 1 \mathrm{H}), 7.60(\mathrm{td}, J=7.6,1.4 \mathrm{~Hz}, 1 \mathrm{H})$, $7.37(\mathrm{dd}, J=7.6,1.2 \mathrm{~Hz}, 1 \mathrm{H}), 6.71(\mathrm{~d}, J=8.5 \mathrm{~Hz}, 1 \mathrm{H}), 6.44(\mathrm{~s}, 2 \mathrm{H}), 6.04-5.97(\mathrm{~m}, 2 \mathrm{H})$. ${ }^{13} \mathrm{C}\left\{{ }^{1} \mathrm{H}\right\}$ NMR (101 MHz, DMSO- $\left.d_{6}\right) \delta 198.3,166.9,165.0,156.8,140.1,134.5,132.0$, 129.9, 129.7, 129.3, 127.7, 109.8, 106.5, 106.2, 98.2, 48.6. HRMS (ESI-Orbitrap) $m / z$ : [M - H] ${ }^{-}$Calcd for $\mathrm{C}_{14} \mathrm{H}_{10} \mathrm{NO}_{4} 256.0615$; Found 256.0627.

Synthesis of 2-(4-(dimethylamino)-2-hydroxybenzoyl)benzoic acid (20). Compound 18, 3-dimethyl amino phenol (5 g, $36.44 \mathrm{mmol})$ and 19, phthalic anhydride (5.39 g, 36.44 
$\mathrm{mmol}$ ) are dissolved in $30 \mathrm{~mL}$ of toluene and refluxed with an oil bath for $12 \mathrm{~h}$. The solvent is evaporated under vacuum to leave a purple residue. The residue is dissolved in ethyl acetate and the mixture passed through a plug of silica gel using EtOAc:Hexanes 1:1, EtOAc:Hexanes 3:1, and EtOAc for elution. Yield $4.32 \mathrm{~g}, 42 \% .{ }^{1} \mathrm{H}$ NMR (400 MHz, DMSO- $\left.d_{6}\right) \delta 13.07(\mathrm{~s}, 1 \mathrm{H}), 12.54(\mathrm{~s}, 1 \mathrm{H}), 7.97$ (dd, $\left.J=7.8,1.2 \mathrm{~Hz}, 1 \mathrm{H}\right), 7.69(\mathrm{td}, J=7.5$, $1.4 \mathrm{~Hz}, 1 \mathrm{H}), 7.61(\mathrm{td}, J=7.6,1.4 \mathrm{~Hz}, 1 \mathrm{H}), 7.38$ (dd, $J=7.6,1.1 \mathrm{~Hz}, 1 \mathrm{H}), 6.81(\mathrm{~d}, J=9.1$ $\mathrm{Hz}, 1 \mathrm{H}), 6.21(\mathrm{dd}, J=9.2,2.5 \mathrm{~Hz}, 1 \mathrm{H}), 6.10(\mathrm{~d}, J=2.5 \mathrm{~Hz}, 1 \mathrm{H}), 3.00(\mathrm{~s}, 6 \mathrm{H}) .{ }^{13} \mathrm{C}\left\{{ }^{1} \mathrm{H}\right\}$ NMR (101 MHz, DMSO-d 6 ) $\delta 198.7,166.9,164.3,155.7,140.0,133.9,132.1,129.9$, 129.7, 129.5, 127.6, 109.7, 104.3, 97.0, 39.6. HRMS (ESI-Orbitrap) $\mathrm{m} / z$ : [M - H] - Calcd for $\mathrm{C}_{16} \mathrm{H}_{14} \mathrm{NO}_{4} 284.0928$; Found 284.0938.

\section{Synthesis of 2-(8-hydroxy-1,2,3,5,6,7-hexahydropyrido[3,2,1-ij]quinoline-9-} carbonyl)benzoic acid (25). Phthalic anhydride (0.392 g 2.64 mmol) and 8hydroxyjulolidine $(0.5 \mathrm{~g}, 2.64 \mathrm{mmol})$ are dissolved in $12 \mathrm{~mL}$ of toluene. The mixture is refluxed in an oil bath for $24 \mathrm{~h}$, then the solvent evaporated under vacuum to leave a deep red residue. The target compound is isolated as a pale yellow solid by flash column chromatography on silica gel using $\mathrm{CH}_{2} \mathrm{Cl}_{2}: \mathrm{MeOH}$ 95:5 for elution. Yield: $622 \mathrm{mg}, 70 \%$. ${ }^{1} \mathrm{H}$ NMR (400 MHz, DMSO- $d_{6}$ ) $\delta 12.94$ (s, 2H), 7.94 (dd, $\left.J=7.8,1.3 \mathrm{~Hz}, 1 \mathrm{H}\right), 7.66$ (td, $J$ $=7.5,1.4 \mathrm{~Hz}, 1 \mathrm{H}), 7.58(\mathrm{td}, J=7.6,1.4 \mathrm{~Hz}, 1 \mathrm{H}), 7.33(\mathrm{dd}, J=7.5,1.3 \mathrm{~Hz}, 1 \mathrm{H}), 6.39(\mathrm{~s}$, $1 \mathrm{H}), 3.27-3.19(\mathrm{~m}, 4 \mathrm{H}), 2.59(\mathrm{t}, J=6.4 \mathrm{~Hz}, 2 \mathrm{H}), 2.40(\mathrm{t}, J=6.2 \mathrm{~Hz}, 2 \mathrm{H}), 1.90-1.80(\mathrm{~m}$, 2H), $1.80-1.70(\mathrm{~m}, 2 \mathrm{H}) .{ }^{13} \mathrm{C}\left\{{ }^{1} \mathrm{H}\right\}$ NMR (101 MHz, DMSO-d $\left.)\right) \delta$ 197.9, 167.0, 159.7, $148.8,140.1,131.7,129.9,129.8,129.6,129.2,127.7,112.4,108.3,104.6,49.4,48.9,26.6$, 
21.1, 20.1, 19.5. HRMS (ESI-Orbitrap) $m / z:[\mathrm{M}+\mathrm{H}]^{+}$Calcd for $\mathrm{C}_{20} \mathrm{H}_{20} \mathrm{NO}_{4} 338.1387$; found 338.1391; [M + Na] $]^{+}$Calcd for $\mathrm{C}_{20} \mathrm{H}_{19} \mathrm{NO}_{4} \mathrm{Na}$ 360.1206; Found 360.1210.

Synthesis of 7-methoxynaphthalen-2-ol (13). 2,7-naphthalenediol (1 g, 6.24 mmol, 1.0 equiv) was dissolved in dry THF $(14 \mathrm{~mL})$ and cooled to $0{ }^{\circ} \mathrm{C}$. $\mathrm{NaH}(60 \%$ dispersion in mineral oil, $250 \mathrm{mg}, 6.24 \mathrm{mmol}, 1.0$ equiv) was added portion-wise and the reaction contents were stirred at $0{ }^{\circ} \mathrm{C}$ for $10 \mathrm{~min} ; \mathrm{Me}_{2} \mathrm{SO}_{4}(886 \mu \mathrm{L}, 6.24 \mathrm{mmol}, 1.0$ equiv) was then added dropwise at $0{ }^{\circ} \mathrm{C}$. The reaction contents were stirred for $14 \mathrm{~h}$ with slow warming from $0{ }^{\circ} \mathrm{C}$ to $25{ }^{\circ} \mathrm{C}$. Upon completion, the contents were quenched by the addition of saturated $\mathrm{NH}_{4} \mathrm{Cl}(50 \mathrm{~mL})$. They were then poured into water $(50 \mathrm{~mL})$ and extracted with EtOAc $(3 \times 50 \mathrm{~mL})$. The combined organic extracts were washed with water $(50 \mathrm{~mL})$ and brine $(50 \mathrm{~mL})$, dried $\left(\mathrm{MgSO}_{4}\right)$, and concentrated. The resultant crude grey solid was purified by flash column chromatography (silica gel. hexanes/Et2O, 2/1). monomethylated product (334 mg. 30\%) as a purple solid. $\mathrm{Rf}=0.32($ silica gel, hexanes/EtOAc, $2 / 1) ;{ }^{1} \mathrm{H}$ NMR (400 MHz, DMSO-d $) \delta 9.63(\mathrm{~s}, 1 \mathrm{H}), 7.64(\mathrm{dd}, J=8.7,2.7 \mathrm{~Hz}, 2 \mathrm{H}), 7.07(\mathrm{~d}, J=2.6$ $\mathrm{Hz}, 1 \mathrm{H}), 7.03(\mathrm{~d}, J=2.4 \mathrm{~Hz}, 1 \mathrm{H}), 6.94-6.85(\mathrm{~m}, 2 \mathrm{H}), 3.83(\mathrm{~s}, 3 \mathrm{H}) .{ }^{13} \mathrm{C}\left\{{ }^{1} \mathrm{H}\right\}$ NMR $(101$ MHz, DMSO- $\left.d_{6}\right) \delta 157.6,155.8,136.0,129.0,129.0,123.1,115.9,115.1,108.1,104.5$, 55.0. HRMS (ESI-TOF) $m / z$ : $[\mathrm{M}+\mathrm{H}]^{+}$Calcd for $\mathrm{C}_{11} \mathrm{H}_{11} \mathrm{O}_{2}$ 175.0754; Found 175.0731.

Synthesis of 7-aminonaphthalen-2-ol (14). ${ }^{17}$ 2,7-dihydroxy naphthalene (5 g, 31.22 mmol), formamide $(1.37 \mathrm{~mL}, 34.34 \mathrm{mmol})$, and sodium sulfite $(8.26 \mathrm{~g}, 65.56 \mathrm{mmol})$ are suspended in $50 \mathrm{~mL}$ of DI water. The reaction mixture is refluxed in an oil bath overnight. The solid formed is collected by vacuum filtration and washed with $100 \mathrm{~mL}$ DI water. The 
collected solid is dissolved in $100 \mathrm{~mL}$ of diethyl ether, and washed with $100 \mathrm{~mL}$ of $6 \mathrm{~N}$ $\mathrm{HCl}$. The aqueous layer is basified to $\mathrm{pH} 13$ with $50 \% \mathrm{NaOH}$ solution, and washed with $100 \mathrm{~mL}$ of diethyl ether. The aqueous layer is then neutralized to $\mathrm{pH} 7$ with $2 \mathrm{~N} \mathrm{HCl}$ solution, and extracted with ethyl acetate $(3 \times 100 \mathrm{~mL})$. The organic extract is combined, dried over anhydrous $\mathrm{Na}_{2} \mathrm{SO}_{4}$, and the solvent evaporated under vacuum. Yield: $3.02 \mathrm{~g}$, 61\%. ${ }^{1} \mathrm{H}$ NMR (400 MHz, DMSO- $\left.d_{6}\right) \delta 9.30(\mathrm{~s}, 1 \mathrm{H}), 7.44(\mathrm{~d}, J=8.8 \mathrm{~Hz}, 1 \mathrm{H}), 7.42(\mathrm{~d}, J=$ $8.8 \mathrm{~Hz}, 1 \mathrm{H}), 6.72(\mathrm{~d}, J=2.3 \mathrm{~Hz}, 1 \mathrm{H}), 6.67(\mathrm{dd}, J=8.9,2.1 \mathrm{~Hz}, 1 \mathrm{H}), 6.65(\mathrm{dd}, J=9.0,2.2$ $\mathrm{Hz}, 1 \mathrm{H}), 6.59(\mathrm{~d}, J=2.1 \mathrm{~Hz}, 1 \mathrm{H}), 5.20(\mathrm{~s}, 2 \mathrm{H}) .{ }^{13} \mathrm{C}\left\{{ }^{1} \mathrm{H}\right\}$ NMR $\left(101 \mathrm{MHz}\right.$, DMSO- $\left.d_{6}\right) \delta$ 155.4, 146.8, 136.6, 128.9, 128.3, 121.2, 115.2, 113.4, 106.3, 104.6. HRMS (ESI-Orbitrap) $m / z:[\mathrm{M}+\mathrm{H}]^{+}$Calcd for $\mathrm{C}_{10} \mathrm{H}_{10} \mathrm{NO} 160.0757$; Found 160.0755 .

General condensation procedure. Hydroxybenzophenone (0.918 mol) and 1,8naphthalene derivative $(1.380 \mathrm{~mol})$ are dissolved in $1.5 \mathrm{~mL}$ of methanesulfonic acid, then $1.5 \mathrm{~mL}$ of TFA are added. The mixture is heated and stirred in an oil bath at $80^{\circ} \mathrm{C}$ for $16-$ $24 \mathrm{~h}$. The reaction mixture is allowed to warm to rt, then poured into $50 \mathrm{~mL}$ of DI water. If no precipitate is formed, the mixture is neutralized to $\mathrm{pH}$ 6-7 by portion wise addition of solid $\mathrm{NaHCO}_{3}$. The resulting precipitate is filtered, washed with DI water and air dried. The target compound isolated by flash column chromatography on silica gel, preparative TLC or medium pressure reversed chromatography as required.

General esterification procedure. Under Ar atm, compound $(0.131 \mathrm{mmol})$ is dissolved in $25 \mathrm{~mL}$ of anhydrous $\mathrm{MeOH}$. The solution is cooled to $0^{\circ} \mathrm{C}$ in an ice bath. Acetyl chloride $(750 \mu \mathrm{L})$ is added dropwise. The mixture is stirred and kept at $50{ }^{\circ} \mathrm{C}$ for $48 \mathrm{~h}$. Then acetyl 
chloride $(300 \mu \mathrm{L})$ is added dropwise and the mixture kept at $50{ }^{\circ} \mathrm{C}$ for additional $24 \mathrm{~h}$. The mixture is allowed to cool down to rt and the solvent is evaporated under vacuum.

\section{Synthesis of 9-amino-2-hydroxy-3' $H$-spiro[benzo[a]xanthene-12,1'-isobenzofuran]-} 3'-one (15). Following general condensation method, compound 11(100 mg, $0.389 \mathrm{mmol})$ and $12(62.3 \mathrm{mg}, 0.389 \mathrm{mmol})$ were condensed to provide compound 15, yield $93 \mathrm{mg}, 63 \%$. ${ }^{1} \mathrm{H}$ NMR $\left(400 \mathrm{MHz}, \mathrm{DMSO}-d_{6}\right) \delta 9.75(\mathrm{~s}, 1 \mathrm{H}), 8.13-8.06(\mathrm{~m}, 1 \mathrm{H}), 7.94(\mathrm{~d}, J=8.9 \mathrm{~Hz}$, 1H), $7.75(\mathrm{~d}, J=8.7 \mathrm{~Hz}, 1 \mathrm{H}), 7.72-7.63(\mathrm{~m}, 2 \mathrm{H}), 7.26(\mathrm{~d}, J=8.9 \mathrm{~Hz}, 1 \mathrm{H}), 7.16-7.10$ $(\mathrm{m}, 1 \mathrm{H}), 6.90(\mathrm{dd}, J=8.7,2.3 \mathrm{~Hz}, 1 \mathrm{H}), 6.42(\mathrm{~d}, J=2.2 \mathrm{~Hz}, 1 \mathrm{H}), 6.34(\mathrm{dd}, J=8.7,2.3 \mathrm{~Hz}$, $1 \mathrm{H}), 6.25(\mathrm{~d}, J=8.7 \mathrm{~Hz}, 1 \mathrm{H}), 6.22(\mathrm{~d}, J=2.2 \mathrm{~Hz}, 1 \mathrm{H}), 5.62(\mathrm{~s}, 2 \mathrm{H}) .{ }^{13} \mathrm{C}\left\{{ }^{1} \mathrm{H}\right\} \mathrm{NMR}(101$ MHz, DMSO-d $\left.d_{6}\right) \delta 169.4,156.4,154.6,150.9,150.7,149.8,135.7,132.8,132.5,130.9$, $129.7,127.7,126.4,125.3,125.0,123.2,116.1,114.6,111.7,106.6,106.5,106.4,98.4$, 83.9. HRMS (ESI-Orbitrap) $m / z:[\mathrm{M}+\mathrm{H}]^{+}$Calcd for $\mathrm{C}_{24} \mathrm{H}_{16} \mathrm{NO}_{4}$ 382.1074; Found 382.1068 .

\section{Synthesis of 9-amino-2-methoxy-3' $H$-spiro[benzo[a]xanthene-12,1'-isobenzofuran]-} 3'-one (16). Following general condensation method, compound 11(100 mg, $0.389 \mathrm{mmol})$ and $13(67.7 \mathrm{mg}, 0.389 \mathrm{mmol})$ were condensed to provide compound 16, yield $93 \mathrm{mg}, 61 \%$. ${ }^{1} \mathrm{H}$ NMR $\left(400 \mathrm{MHz}, \mathrm{DMSO}-d_{6}\right) \delta 8.20-8.10(\mathrm{~m}, 1 \mathrm{H}), 8.03(\mathrm{~d}, J=8.9 \mathrm{~Hz}, 1 \mathrm{H}), 7.86(\mathrm{~d}, J$ $=8.9 \mathrm{~Hz}, 1 \mathrm{H}), 7.77-7.70(\mathrm{~m}, 2 \mathrm{H}), 7.37(\mathrm{~d}, J=8.9 \mathrm{~Hz}, 1 \mathrm{H}), 7.27-7.20(\mathrm{~m}, 1 \mathrm{H}), 7.00(\mathrm{dd}$, $J=8.9,2.4 \mathrm{~Hz}, 1 \mathrm{H}), 6.45(\mathrm{~d}, J=2.1 \mathrm{~Hz}, 1 \mathrm{H}), 6.37(\mathrm{dd}, J=8.7,2.1 \mathrm{~Hz}, 1 \mathrm{H}), 6.33(\mathrm{~d}, J=$ 8.7 Hz, 1H), $6.27(\mathrm{~d}, J=2.4 \mathrm{~Hz}, 1 \mathrm{H}), 5.67(\mathrm{~s}, 2 \mathrm{H}), 3.26(\mathrm{~s}, 3 \mathrm{H}) .{ }^{13} \mathrm{C}\left\{{ }^{1} \mathrm{H}\right\} \mathrm{NMR}(101 \mathrm{MHz}$, DMSO-d6) $\delta 169.4,157.8,154.8,151.1,150.9,149.9,136.1,132.5,132.2,131.0,130.0$, 
$127.9,126.6,125.9,124.9,123.7,115.9,115.8,111.8,107.2,105.9,103.1,98.5,84.2,54.5$. HRMS (ESI-Orbitrap) m/z: [M+ H] ${ }^{+}$Calcd for $\mathrm{C}_{25} \mathrm{H}_{18} \mathrm{NO}_{4}$ 396.1230; Found 396.1228.

\section{Synthesis of 9-(dimethylamino)-2-hydroxy-3' $H$-spiro[benzo[a]xanthene-12,1'-} isobenzofuran]-3'-one (21). Following general condensation method, compound 20 (100 mg. $0.350 \mathrm{mmol})$ and $\mathbf{1 2}(56.1 \mathrm{mg}, 0.350 \mathrm{mmol})$ were condensed to provide compound $\mathbf{2 1}$, yield $67 \mathrm{mg}, 45 \% .{ }^{1} \mathrm{H}$ NMR (400 MHz, DMSO- $\left.d_{6}\right) \delta 9.76(\mathrm{~s}, 1 \mathrm{H}), 8.14-8.09(\mathrm{~m}, 1 \mathrm{H})$, $7.96(\mathrm{~d}, J=8.7 \mathrm{~Hz}, 1 \mathrm{H}), 7.76(\mathrm{~d}, J=8.8 \mathrm{~Hz}, 1 \mathrm{H}), 7.73-7.64(\mathrm{~m}, 2 \mathrm{H}), 7.27$ (d, $J=8.9 \mathrm{~Hz}$, 1H), $7.16-7.10(\mathrm{~m}, 1 \mathrm{H}), 6.91(\mathrm{dd}, J=8.8,2.2 \mathrm{~Hz}, 1 \mathrm{H}), 6.56-6.50(\mathrm{~m}, 2 \mathrm{H}), 6.39(\mathrm{~d}, J=$ $8.8 \mathrm{~Hz}, 1 \mathrm{H}), 6.25(\mathrm{~d}, J=2.2 \mathrm{~Hz}, 1 \mathrm{H}), 2.93(\mathrm{~s}, 6 \mathrm{H}) \cdot{ }^{13} \mathrm{C}\left\{{ }^{1} \mathrm{H}\right\}$ NMR (101 MHz, DMSO- $\left.d_{6}\right)$ $\delta 169.4,156.39,154.6,151.4,150.9,149.7,135.7,132.7,132.6,130.9,129.7,127.5,126.3$, $125.3,125.1,123.2,116.1,114.5,109.8,106.71,106.6,106.4,97.4,83.6,79.2$. HRMS (ESI-Orbitrap) $m / z$ : $[\mathrm{M}+\mathrm{H}]^{+}$Calcd for $\mathrm{C}_{26} \mathrm{H}_{20} \mathrm{NO}_{4} 410.1387$; Found 410.1386 .

\section{Synthesis of 9-(dimethylamino)-2-methoxy-3' $H$-spiro[benzo[a]xanthene-12,1'-} isobenzofuran]-3'-one (22). Following general condensation method, compound 20 (100 $\mathrm{mg}, 0.350 \mathrm{mmol})$ and $\mathbf{1 3}(61.0 \mathrm{mg}, 0.350 \mathrm{mmol})$ were condensed to provide compound $\mathbf{2 2}$, yield $104 \mathrm{mg}, 70 \% .{ }^{1} \mathrm{H}$ NMR (400 MHz, DMSO- $\left.d_{6}\right) \delta 8.21-8.13(\mathrm{~m}, 1 \mathrm{H}), 8.05(\mathrm{~d}, J=8.7$ Hz, 1H), $7.87(\mathrm{~d}, J=8.9 \mathrm{~Hz}, 1 \mathrm{H}), 7.76-7.71(\mathrm{~m}, 2 \mathrm{H}), 7.38$ (d, $J=8.9 \mathrm{~Hz}, 1 \mathrm{H}), 7.26-$ $7.20(\mathrm{~m}, 1 \mathrm{H}), 7.01(\mathrm{dd}, J=8.9,2.4 \mathrm{~Hz}, 1 \mathrm{H}), 6.58-6.53(\mathrm{~m}, 2 \mathrm{H}), 6.47$ (d, $J=8.2 \mathrm{~Hz}, 1 \mathrm{H})$, $6.29(\mathrm{~d}, J=2.4 \mathrm{~Hz}, 1 \mathrm{H}), 3.28$ (s, 3H), $2.94(\mathrm{~s}, 6 \mathrm{H}) \cdot{ }^{13} \mathrm{C}\left\{{ }^{1} \mathrm{H}\right\}$ NMR (101 MHz, DMSO-d 6 ) $\delta 169.4,157.9,154.7,151.6,151.2,149.8,136.2,132.6,132.2,131.0,130.1,127.8,126.5$, 
125.9, 124.9, 123.7, 115.9, 115.7, 109.9, 107.2, 106.2, 103.1, 97.4, 83.9, 54.49, 39.8. HRMS (ESI-Orbitrap) $m / z$ : [M+ H] ${ }^{+}$Calcd for $\mathrm{C}_{27} \mathrm{H}_{22} \mathrm{NO}_{4} 424.1543$; Found 424.1542 .

\section{Synthesis of 11-hydroxy-1,2,3,5,6,7-hexahydro-3' $H$-spiro[benzo[5,6]chromeno[2,3-} flpyrido[3,2,1-ij]quinoline-9,1'-isobenzofuran]-3'-one (26). Following general condensation method, compound $\mathbf{2 5}$ (100 mg, $0.296 \mathrm{mmol})$ and $\mathbf{1 2}(47.5 \mathrm{mg}, 0.296 \mathrm{mmol})$ were condensed to provide compound $\mathbf{2 6}$, yield $39 \mathrm{mg}, 29 \% .{ }^{1} \mathrm{H}$ NMR (400 MHz, DMSO$\left.d_{6}\right) \delta 9.71(\mathrm{~s}, 1 \mathrm{H}), 8.11-8.06(\mathrm{~m}, 1 \mathrm{H}), 7.93(\mathrm{~d}, J=8.6 \mathrm{~Hz}, 1 \mathrm{H}), 7.74(\mathrm{~d}, J=8.8 \mathrm{~Hz}, 1 \mathrm{H})$, $7.71-7.61(\mathrm{~m}, 2 \mathrm{H}), 7.28(\mathrm{~d}, J=8.9 \mathrm{~Hz}, 1 \mathrm{H}), 7.14-7.08(\mathrm{~m}, 1 \mathrm{H}), 6.90(\mathrm{dd}, J=8.7,2.2$ $\mathrm{Hz}, 1 \mathrm{H}), 6.20(\mathrm{~d}, J=2.2 \mathrm{~Hz}, 1 \mathrm{H}), 5.91(\mathrm{~s}, 1 \mathrm{H}), 3.16(\mathrm{t}, J=5.6 \mathrm{~Hz}, 2 \mathrm{H}), 3.10$ (ddd, $J=7.2$, 4.7, 3.0 Hz, 2H), 2.89 (t, $J=6.6 \mathrm{~Hz}, 2 \mathrm{H}), 2.58-2.34(\mathrm{~m}, 2 \mathrm{H}), 1.99-1.88(\mathrm{~m}, 2 \mathrm{H}), 1.82-$ $1.71(\mathrm{~m}, 2 \mathrm{H}) .{ }^{13} \mathrm{C}\left\{{ }^{1} \mathrm{H}\right\}$ NMR (101 MHz, DMSO-d 6 ) $\delta 169.4,156.3,154.6,150.9,145.1$, 143.7, 135.6, 132.7, 132.4, 130.9, 129.7, 126.4, 125.3, 125.0, 123.3, 123.2, 117.9, 116.0, $114.8,106.7,106.3,105.8,105.8,84.3,49.0,48.6,26.9,21.2,20.6,20.5$. HRMS (ESIOrbitrap) $m / z:[\mathrm{M}+\mathrm{H}]^{+}$Calcd for $\mathrm{C}_{30} \mathrm{H}_{24} \mathrm{NO}_{4} 462.1700$; Found 462.1702 .

Synthesis of 11-methoxy-1,2,3,5,6,7-hexahydro-3' $H$-spiro[benzo[5,6]chromeno[2,3flpyrido[3,2,1-ij]quinoline-9,1'-isobenzofuran]-3'-one $\quad$ (27). Following general condensation method, compound $\mathbf{2 5}(100 \mathrm{mg}, 0.296 \mathrm{mmol})$ and $\mathbf{1 3}(51.6 \mathrm{mg}, 0.296 \mathrm{mmol})$ were condensed to provide compound 27 , yield $45 \mathrm{mg}, 32 \% .{ }^{1} \mathrm{H}$ NMR (400 MHz, DMSOd6) $\delta 8.19-8.11(\mathrm{~m}, 1 \mathrm{H}), 8.02(\mathrm{~d}, J=8.9 \mathrm{~Hz}, 1 \mathrm{H}), 7.85(\mathrm{~d}, J=8.9 \mathrm{~Hz}, 1 \mathrm{H}), 7.76-7.69$ (m, 2H), 7.39 (d, $J=8.9 \mathrm{~Hz}, 1 \mathrm{H}), 7.25-7.18(\mathrm{~m}, 1 \mathrm{H}), 6.99(\mathrm{dd}, J=8.8,2.4 \mathrm{~Hz}, 1 \mathrm{H}), 6.26$ (d, $J=2.4 \mathrm{~Hz}, 1 \mathrm{H}), 5.99$ (s, 1H), 3.27 (s, 3H), 3.17 (t, $J=5.6 \mathrm{~Hz}, 2 \mathrm{H}), 3.12$ (ddd, 2H), 2.90 
$(\mathrm{t}, J=6.5 \mathrm{~Hz}, 2 \mathrm{H}), 2.59-2.36(\mathrm{~m}, 2 \mathrm{H}), 2.01-1.90(\mathrm{~m}, 2 \mathrm{H}), 1.83-1.70(\mathrm{~m}, 2 \mathrm{H}) .{ }^{13} \mathrm{C}\left\{{ }^{1} \mathrm{H}\right\}$ NMR (101 MHz, DMSO-d $\left.d_{6}\right) \delta 169.4,157.8,154.7,151.1,145.2,143.8,136.1,132.4$, $132.2,131.0,130.0,126.6,125.8,124.9,123.7,123.5,118.1,115.9,115.8,106.9,105.9$, 105.3, 103.1, 84.6, 54.5, 49.0, 48.6, 26.9, 21.2, 20.5, 20.5. HRMS (ESI-Orbitrap) $m / z$ : [M $+\mathrm{H}]^{+}$Calcd for $\mathrm{C}_{31} \mathrm{H}_{26} \mathrm{NO}_{4} 476.1856$; Found 476.1845 .

\section{Synthesis of 2-hydroxy-12-(2-(methoxycarbonyl)phenyl)-9H-benzo[a]xanthen-9-} iminium (1). Compound 1 was prepared following general esterification method, yield 92\%. ${ }^{1} \mathrm{H}$ NMR (400 MHz, DMSO-d 6$) \delta 10.38(\mathrm{~s}, 1 \mathrm{H}), 9.11(\mathrm{~d}, J=73.7 \mathrm{~Hz}, 2 \mathrm{H}), 8.55-$ $8.47(\mathrm{~m}, 1 \mathrm{H}), 8.40(\mathrm{dd}, J=7.2,2.0 \mathrm{~Hz}, 1 \mathrm{H}), 8.02(\mathrm{~d}, J=8.8 \mathrm{~Hz}, 1 \mathrm{H}), 8.00-7.92(\mathrm{~m}, 2 \mathrm{H})$, $7.81(\mathrm{~d}, J=8.9 \mathrm{~Hz}, 1 \mathrm{H}), 7.48(\mathrm{dd}, J=6.9,2.0 \mathrm{~Hz}, 1 \mathrm{H}), 7.23(\mathrm{dd}, J=8.7,2.0 \mathrm{~Hz}, 1 \mathrm{H}), 7.14$ (dd, $J=9.5,2.0 \mathrm{~Hz}, 1 \mathrm{H}), 7.07(\mathrm{~d}, J=2.0 \mathrm{~Hz}, 1 \mathrm{H}), 7.04(\mathrm{~d}, J=9.4 \mathrm{~Hz}, 1 \mathrm{H}), 6.31(\mathrm{~d}, J=$ $2.2 \mathrm{~Hz}, 1 \mathrm{H}), 3.56(\mathrm{~s}, 3 \mathrm{H}) \cdot{ }^{13} \mathrm{C}\left\{{ }^{1} \mathrm{H}\right\}$ NMR (101 MHz, DMSO- $\left.d_{6}\right) \delta 165.1,161.5,160.7$, $158.9,157.6,156.7,141.0,137.1,134.6,132.4,131.8,131.7,131.6,130.8,128.9,128.4$, 125.2, 121.2, 117.9, 117.9, 114.8, 113.8, 109.9, 96.0, 52.5. HRMS (ESI-Orbitrap) $\mathrm{m} / z$ : [M] ${ }^{+}$Calcd for $\mathrm{C}_{25} \mathrm{H}_{18} \mathrm{NO}_{4}$ 396.1230; Found 396.1229.

\section{Synthesis of 2-methoxy-12-(2-(methoxycarbonyl)phenyl)-9H-benzo[a]xanthen-9-} iminium (2). Compound 2 was prepared following general esterification method, yield $90 \% .{ }^{1} \mathrm{H}$ NMR (400 MHz, DMSO- $\left.d_{6}\right) \delta 9.39(\mathrm{~s}, 1 \mathrm{H}), 9.18(\mathrm{~s}, 1 \mathrm{H}), 8.59(\mathrm{~d}, J=9.0 \mathrm{~Hz}, 1 \mathrm{H})$, $8.42(\mathrm{dd}, J=7.9,1.3 \mathrm{~Hz}, 1 \mathrm{H}), 8.13(\mathrm{~d}, J=8.9 \mathrm{~Hz}, 1 \mathrm{H}), 8.05(\mathrm{td}, J=7.6,1.3 \mathrm{~Hz}, 1 \mathrm{H}), 7.94$ $(\mathrm{dd}, J=8.3,6.7 \mathrm{~Hz}, 2 \mathrm{H}), 7.58(\mathrm{dd}, J=7.6,1.2 \mathrm{~Hz}, 1 \mathrm{H}), 7.28(\mathrm{dd}, J=8.8,2.4 \mathrm{~Hz}, 1 \mathrm{H}), 7.17$ (dd, $J=9.5,2.1 \mathrm{~Hz}, 1 \mathrm{H}), 7.13-7.06(\mathrm{~m}, 2 \mathrm{H}), 6.61(\mathrm{~d}, J=2.4 \mathrm{~Hz}, 1 \mathrm{H}), 3.56(\mathrm{~s}, 3 \mathrm{H}), 3.26$ 
(s, $3 \mathrm{H}) .{ }^{13} \mathrm{C}\left\{{ }^{1} \mathrm{H}\right\}$ NMR (101 MHz, DMSO- $\left.d_{6}\right) \delta 165.5,162.3,160.5,160.2,158.2,156.8$, $140.8,137.7,135.3,132.8,132.4,132.1,131.6,131.4,129.7,129.0,126.6,122.0,118.9$, 118.3, 115.5, 115.4, 106.7, 96.6, 55.2, 53.1. HRMS (ESI-Orbitrap) $\mathrm{m} / z$ : $[\mathrm{M}]^{+}$Calcd for $\mathrm{C}_{26} \mathrm{H}_{20} \mathrm{NO}_{4} 410.1387$; Found 410.1395 .

\section{Synthesis of $N$-(2-hydroxy-12-(2-(methoxycarbonyl)phenyl)-9H-benzo[a]xanthen-9-} ylidene)- $N$-methylmethanaminium (4). Compound 4 was prepared following general esterification method, yield 85\%. ${ }^{1} \mathrm{H}$ NMR (400 MHz, DMSO- $\left.d_{6}\right) \delta 10.45(\mathrm{~s}, 1 \mathrm{H}), 8.54(\mathrm{~d}$, $J=8.9 \mathrm{~Hz}, 1 \mathrm{H}), 8.45-8.35(\mathrm{~m}, 1 \mathrm{H}), 8.04(\mathrm{~d}, J=8.8 \mathrm{~Hz}, 1 \mathrm{H}), 7.98(\mathrm{td}, J=7.2,1.6 \mathrm{~Hz}$, 2H), $7.78(\mathrm{~d}, \mathrm{~J}=8.9 \mathrm{~Hz}, 1 \mathrm{H}), 7.54-7.47(\mathrm{~m}, 1 \mathrm{H}), 7.39(\mathrm{dd}, J=9.8,2.5 \mathrm{~Hz}, 1 \mathrm{H}), 7.27(\mathrm{~d}$, $J=2.5 \mathrm{~Hz}, 1 \mathrm{H}), 7.26(\mathrm{dd}, J=9.2,2.4 \mathrm{~Hz}, 1 \mathrm{H}), 7.01(\mathrm{~d}, J=9.8 \mathrm{~Hz}, 1 \mathrm{H}), 6.36(\mathrm{~d}, J=2.1$ $\mathrm{Hz}, 1 \mathrm{H}), 3.56$ (s, 3H), 3.39 (s, 6H). ${ }^{13} \mathrm{C}\left\{{ }^{1} \mathrm{H}\right\}$ NMR (101 MHz, DMSO-d $) \delta$ 165.2, 160.6, $159.0,158.1,157.0,156.8,141.3,137.1,134.6,132.5,131.7,131.6,130.9,130.4,128.9$, $128.4,125.1,118.9,118.0,117.6,115.1,113.6,110.0,95.6,52.6,41.4,40.9$. HRMS (ESIOrbitrap) $m / z$ : $[\mathrm{M}]^{+}$Calcd for $\mathrm{C}_{27} \mathrm{H}_{22} \mathrm{NO}_{4} 424.1543$; Found 424.1547 .

\section{Synthesis of $\mathrm{N}$-(2-methoxy-12-(2-(methoxycarbonyl)phenyl)-9H-benzo[a]xanthen-9-} ylidene)- $N$-methylmethanaminium (5). Compound 5 was prepared following general esterification method, yield 95\%. ${ }^{1} \mathrm{H}$ NMR (400 MHz, DMSO-d 6$) \delta 8.61(\mathrm{~d}, J=9.0 \mathrm{~Hz}$, $1 \mathrm{H}), 8.44(\mathrm{dd}, J=8.0,1.2 \mathrm{~Hz}, 1 \mathrm{H}), 8.15(\mathrm{~d}, J=8.9 \mathrm{~Hz}, 1 \mathrm{H}), 8.06(\mathrm{td}, J=7.6,1.3 \mathrm{~Hz}, 1 \mathrm{H})$, $7.95(\mathrm{td}, J=7.7,1.3 \mathrm{~Hz}, 1 \mathrm{H}), 7.90(\mathrm{~d}, J=9.0 \mathrm{~Hz}, 1 \mathrm{H}), 7.61(\mathrm{dd}, J=7.8,1.2 \mathrm{~Hz}, 1 \mathrm{H}), 7.43$ (dd, $J=9.8,2.5 \mathrm{~Hz}, 1 \mathrm{H}), 7.31(\mathrm{~d}, 2.4 \mathrm{~Hz}, 1 \mathrm{H}), 7.30(\mathrm{dd}, J=8.8,2.4 \mathrm{~Hz}, 1 \mathrm{H}), 7.05(\mathrm{~d}, \mathrm{~J}=$ $9.9 \mathrm{~Hz}, 1 \mathrm{H}), 6.64$ (d, $J=2.4 \mathrm{~Hz}, 1 \mathrm{H}), 3.56(\mathrm{~s}, 3 \mathrm{H}), 3.41$ (d, $J=11.3 \mathrm{~Hz}, 6 \mathrm{H}), 3.27$ (s, 3H). 
${ }^{13} \mathrm{C}\left\{{ }^{1} \mathrm{H}\right\}$ NMR (101 MHz, DMSO- $\left.d_{6}\right) \delta 165.1,160.0,159.8,158.4,156.9,156.6,140.6$, 137.2, 134.9, 132.4, 131.6, 131.1, 131.0, 130.6, 129.2, 128.6, 126.1, 119.3, 118.2, 117.9, 115.2, 114.9, 106.3, 95.7, 54.7, 52.7, 41.5, 41.0. HRMS (ESI-Orbitrap) $m / z:[\mathrm{M}]^{+}$Calcd for $\mathrm{C}_{28} \mathrm{H}_{24} \mathrm{NO}_{4} 438.1700$; Found 438.1705.

Synthesis of 11-hydroxy-9-(2-(methoxycarbonyl)phenyl)-1,2,3,5,6,7hexahydrobenzo[5,6]chromeno[2,3-flpyrido[3,2,1-ij]quinolin-4-ium (7). Compound 7 was prepared following a general esterification method, yield $71 \%$. ${ }^{1} \mathrm{H}$ NMR (400 MHz, DMSO- $\left.d_{6}\right) \delta 10.24(\mathrm{~s}, 1 \mathrm{H}), 8.42(\mathrm{~d}, J=8.7 \mathrm{~Hz}, 1 \mathrm{H}), 8.40-8.34(\mathrm{~m}, 1 \mathrm{H}), 7.98(\mathrm{~d}, J=5.9$ Hz, 1H), $7.97-7.91(m, 2 H), 7.80(d, J=8.9$ Hz, 1H), $7.49-7.44$ (m, 1H), 7.19 (dd, J = 8.7, $2.3 \mathrm{~Hz}, 1 \mathrm{H}), 6.62(\mathrm{~s}, 1 \mathrm{H}), 6.23(\mathrm{~d}, \mathrm{~J}=2.2 \mathrm{~Hz}, 1 \mathrm{H}), 3.67(\mathrm{t}, J=5.7 \mathrm{~Hz}, 2 \mathrm{H}), 3.62(\mathrm{t}, J$ $=5.9 \mathrm{~Hz}, 2 \mathrm{H}), 3.55(\mathrm{~s}, 3 \mathrm{H}), 3.09(\mathrm{t}, J=6.0 \mathrm{~Hz}, 2 \mathrm{H}), 2.70(\mathrm{t}, J=6.5 \mathrm{~Hz}, 2 \mathrm{H}), 2.14-2.00$ (m, 2H), $1.93-1.81(\mathrm{~m}, 2 \mathrm{H}) .{ }^{13} \mathrm{C}\left\{{ }^{1} \mathrm{H}\right\}$ NMR (101 MHz, DMSO- $\left.d_{6}\right) \delta$ 165.1, 158.4, 157.0, $155.7,153.1,151.4,139.4,137.3,134.5,132.2,131.5,130.7,129.3,128.7,128.4,125.3$, $125.2,117.8,117.7,114.4,113.8,109.6,104.1,52.4,51.1,50.7,27.0,19.7,18.9,18.7$. HRMS (ESI-Orbitrap) $m / z$ : [M] ${ }^{+}$Calcd for $\mathrm{C}_{31} \mathrm{H}_{26} \mathrm{NO}_{4} 476.1856$; Found 476.1846 .

Synthesis of 11-methoxy-9-(2-(methoxycarbonyl)phenyl)-1,2,3,5,6,7hexahydrobenzo[5,6]chromeno[2,3-flpyrido[3,2,1-ij]quinolin-4-ium (8). Compound 8 was prepared following general esterification method, yield $81 \%$. ${ }^{1} \mathrm{H}$ NMR $(400 \mathrm{MHz}$, DMSO- $\left.d_{6}\right) \delta 8.50(\mathrm{~d}, J=8.9 \mathrm{~Hz}, 1 \mathrm{H}), 8.41(\mathrm{dd}, J=7.9,1.0 \mathrm{~Hz}, 1 \mathrm{H}), 8.09(\mathrm{~d}, J=8.9 \mathrm{~Hz}$, 1H), $8.06-8.00(\mathrm{~m}, 1 \mathrm{H}), 7.96-7.88(\mathrm{~m}, 1 \mathrm{H}), 7.92(\mathrm{~d}, J=8.9 \mathrm{~Hz}, 1 \mathrm{H}), 7.57$ (dd, $J=7.6$, $0.9 \mathrm{~Hz}, 1 \mathrm{H}), 7.24(\mathrm{dd}, J=8.9,2.4 \mathrm{~Hz}, 1 \mathrm{H}), 6.66(\mathrm{~s}, 1 \mathrm{H}), 6.55(\mathrm{~d}, J=2.3 \mathrm{~Hz}, 1 \mathrm{H}), 3.69$ (s, 
2H), $3.64(\mathrm{~s}, 2 \mathrm{H}), 3.55(\mathrm{~s}, 3 \mathrm{H}), 3.24(\mathrm{~s}, 3 \mathrm{H}), 3.10(\mathrm{~d}, J=5.9 \mathrm{~Hz}, 2 \mathrm{H}), 2.71(\mathrm{~s}, 2 \mathrm{H}), 2.14-$ $2.01(\mathrm{~m}, 2 \mathrm{H}), 1.96-1.82(\mathrm{~m}, 2 \mathrm{H}) .{ }^{13} \mathrm{C}\left\{{ }^{1} \mathrm{H}\right\} \mathrm{NMR}\left(101 \mathrm{MHz}, \mathrm{DMSO}-d_{6}\right) \delta$ 165.0, 159.4, 156.3, 155.4, 153.4, 151.4, 138.9, 137.5, 134.7, 132.1, 131.6, 131.0, 130.8, 129.6, 129.06, $128.7,126.1,125.4,118.3,117.6,115.1,114.6,105.9,104.3,54.7,52.6,51.3,50.8,27.0$, 19.7, 18.9, 18.7. HRMS (ESI-Orbitrap) $m / z$ : $[\mathrm{M}]^{+}$Calcd for $\mathrm{C}_{32} \mathrm{H}_{28} \mathrm{NO}_{4}$ 490.2013; Found 490.2005.

Compounds 3,6 , and 9 were synthesized according to a previous published protocol. ${ }^{18}$

Synthesis of isomers 4-(8-hydroxy-2,3,6,7-tetrahydro-1H,5H-pyrido[3,2,1ij]quinoline-9-carbonyl)isophthalic acid and 2-(8-hydroxy-2,3,6,7-tetrahydro-1H,5Hpyrido[3,2,1-ij]quinoline-9-carbonyl)terephthalic acid (29). 8-hydroxyjulolidine (3.00 $\mathrm{g}, 15.85 \mathrm{mmol}$ ) was dissolved in toluene $45 \mathrm{~mL}$, heated to $60{ }^{\circ} \mathrm{C}$ with an oil bath, and pounded trimellitic anhydride $(3.65 \mathrm{~g}, 19.02 \mathrm{mmol})$ was added with magnetic stirring. The mixture was refluxed for $24 \mathrm{~h}$ and cooled. The residue was filtered off, washed with toluene $(3 \times 7.5 \mathrm{~mL})$, dissolved in $\mathrm{MeOH}(45 \mathrm{~mL})$ refluxed for 10 minutes. Then acetic acid (15 $\mathrm{mL}$ ) was added and the mixture was evaporated to dryness. Crystalline solid was refluxed with $\mathrm{MeOH}(30 \mathrm{~mL})$ for $2 \mathrm{~h}$ and kept at $4{ }^{\circ} \mathrm{C}$ overnight. The crystals formed were filtered off and washed with $\mathrm{MeOH}(7.5 \mathrm{~mL})$ to give the product as a yellow crystalline solid (1.90 g, $20 \%$ yield). ${ }^{1} \mathrm{H}$ NMR (400 MHz, DMSO- $\left.d_{6}\right) \delta 13.40(\mathrm{~s}, 4 \mathrm{H}), 12.83(\mathrm{~d}, J=13.0,2.8 \mathrm{~Hz}$, 2H), $8.47(\mathrm{~s}, 1 \mathrm{H}), 8.19$ (d, $J=8.1 \mathrm{~Hz}, 1 \mathrm{H}), 8.15-8.09$ (dd, $1 \mathrm{H}), 8.04$ (dd, $J=8.7,2.8 \mathrm{~Hz}$, 1H), $7.79(\mathrm{~s}, 1 \mathrm{H}), 7.48(\mathrm{dd}, J=8.2,2.9 \mathrm{~Hz}, 1 \mathrm{H}), 6.40(\mathrm{dd}, J=12.8,2.7 \mathrm{~Hz}, 2 \mathrm{H}), 3.34(\mathrm{~s}$, 4H), 3.18 (s, 2H), 2.59 (m, $J=6.8 \mathrm{~Hz}, 5 \mathrm{H}), 2.46-2.38(\mathrm{~m}, 5 \mathrm{H}), 1.86(\mathrm{~s}, 4 \mathrm{H}), 1.77(\mathrm{~s}, 4 \mathrm{H})$. 
${ }^{13} \mathrm{C}\left\{{ }^{1} \mathrm{H}\right\}$ NMR (101 MHz, DMSO- $\left.d_{6}\right) \delta 197.3,197.1,167.0,166.7,166.6,166.6,160.3$, $160.2,149.5,149.5,144.3,140.6,134.2,133.9,133.0,131.9,131.2,130.8,130.6,130.4$, 130.0, 130.0, 128.8, 128.7, 113.2, 108.6, 108.6, 105.1, 105.1, 49.9, 49.4, 49.1, 27.1, 21.5, 20.5, 20.0. HRMS (ESI-TOF) $m / z$ : $[\mathrm{M}+\mathrm{H}]{ }^{+}$Calcd for $\mathrm{C}_{21} \mathrm{H}_{20} \mathrm{NO}_{6}$ 382.1285; Found 382.1286 and 382.1289 .

Synthesis of isomers 11-methoxy-3'-oxo-2,3,6,7-tetrahydro-1 $\mathrm{H,3}$ ' $\mathrm{H,5H}$ spiro[benzo[5,6] chromeno[2,3-f]pyrido[3,2,1-ij]quinoline-9,1'-isobenzofuran]-5'-

carboxylic acid and 11-methoxy-3'-oxo-2,3,6,7-tetrahydro-1 $\mathrm{H,3}$ ' $\mathrm{H,5H}$ spiro[benzo[5,6]chromeno[2,3-flpyrido[3,2,1-ij]quinoline-9, 1 '-isobenzofuran]-6'-

carboxylic acid (30). The direct condensation with 1:1 MSA/TFA gave $60 \%$ yield of $1: 1$ 5' and 6' carboxy isomers. Started with $100 \mathrm{mg}$ of the 8-hydroxybenzophenone resulted in $60 \mathrm{mg}$ of the dye. $\mathrm{R}_{\mathrm{f}} 0.35$ (9:1:0.5 MeOH/DCM/HCOOH). ${ }^{1} \mathrm{H}$ NMR (400 MHz, Methanol$\left.d_{4}\right) \delta 8.77(\mathrm{~s}, 1 \mathrm{H}), 8.19(\mathrm{~d}, J=6.9 \mathrm{~Hz}, 5 \mathrm{H}), 8.04(\mathrm{dd}, J=9.0,5.0 \mathrm{~Hz}, 2 \mathrm{H}), 7.72(\mathrm{~d}, J=8.9$ Hz, 2H), 7.65 (s, 1H), 7.46 (dd, $J=8.9,7.4 \mathrm{~Hz}, 2 \mathrm{H}), 7.11$ (d, $J=7.9 \mathrm{~Hz}, 1 \mathrm{H}), 6.94$ (ddd, $J$ $=8.9,2.4,0.9 \mathrm{~Hz}, 2 \mathrm{H}), 6.65(\mathrm{~d}, J=2.4 \mathrm{~Hz}, 1 \mathrm{H}), 6.57(\mathrm{~d}, J=2.3 \mathrm{~Hz}, 1 \mathrm{H}), 6.49(\mathrm{~s}, 1 \mathrm{H}), 6.43$ (s, 1H), $3.36(\mathrm{dq}, J=18.3,6.6 \mathrm{~Hz}, 8 \mathrm{H}), 3.16(\mathrm{~d}, J=6.9 \mathrm{~Hz}, 6 \mathrm{H}), 2.93(\mathrm{~m}, J=6.0 \mathrm{~Hz}, 4 \mathrm{H})$, 2.53 (ddt, $J=16.0,10.2,6.0 \mathrm{~Hz}, 4 \mathrm{H}), 1.98$ (q, $J=6.0 \mathrm{~Hz}, 4 \mathrm{H}), 1.82$ (q, $J=6.2 \mathrm{~Hz}, 4 \mathrm{H})$. ${ }^{13} \mathrm{C}\left\{{ }^{1} \mathrm{H}\right\}$ NMR (101 MHz, MeOD) $\delta 166.4,159.4,159.4,133.8,132.1,130.9,125.6,125.4$, $117.3,114.7,114.6,105.6,105.3,104.9,78.2,77.9,77.6,54.2,50.6,50.5,50.2,50.1,27.2$, 20.5, 20.5, 19.6, 19.5. HRMS (ESI-TOF) $m / z:[\mathrm{M}+\mathrm{H}]^{+}$Calcd for $\mathrm{C}_{32} \mathrm{H}_{26} \mathrm{NO}_{6} 520.1755$; Found 520.1747 and 520.1771. 
Synthesis of isomers 9-(2-carboxy-4-((2,5-dioxopyrrolidin-1yl)oxy)carbonyl)phenyl)-11-methoxy-1,2,3,5,6,7-hexahydrobenzo[5,6]chromeno[2,3f]pyrido[3,2,1-ij]quinolin-4-ium and 9-(2-carboxy-5-(((2,5-dioxopyrrolidin-1yl)oxy)carbonyl)phenyl)-11-methoxy-1,2,3,5,6,7-hexahydrobenzo[5,6]chromeno[2,3flpyrido[3,2,1-ij]quinolin-4-ium (8-NHS). Compound 30 (68 mg, $0.13 \mathrm{mmol}$ ), DMAP (79.95 $\mathrm{mg}, 0.65 \mathrm{mmol})$ and TEA $(0.091 \mathrm{~mL}, 0.65 \mathrm{mmol})$ were dissolved in dry DCM (5 $\mathrm{mL}$ ). DSC (67.06 $\mathrm{mg}, 0.26 \mathrm{mmol}$ ) was added and the reaction stirred for $2 \mathrm{~h}$. The reaction was quenched with $\mathrm{AcOH}(0.075 \mathrm{~mL}, 1.31 \mathrm{mmol})$ and the solution was directly loaded onto an equilibrated flash chromatography column and eluted with $0.5 \% \mathrm{HCOOH}$ in $\mathrm{CHCl}_{3} / \mathrm{MeOH} 98 / 2$ to afford the pure compound (54 mg, 80\%). Rf 0.22 (98:2:0.5 $\mathrm{MeOH} / \mathrm{DCM} / \mathrm{HCOOH}) .{ }^{1} \mathrm{H}$ NMR (400 MHz, DMSO-d $) \delta 8.58(\mathrm{dd}, J=1.5,0.7 \mathrm{~Hz}, 1 \mathrm{H})$, $8.30-8.25(\mathrm{~m}, 2 \mathrm{H}), 8.22(\mathrm{~s}, 2 \mathrm{H}), 8.11-8.04(\mathrm{~m}, 2 \mathrm{H}), 7.89(\mathrm{dd}, J=9.0,1.1 \mathrm{~Hz}, 2 \mathrm{H}), 7.59$ $(\mathrm{t}, J=1.0 \mathrm{~Hz}, 1 \mathrm{H}), 7.43(\mathrm{~d}, J=8.9 \mathrm{~Hz}, 2 \mathrm{H}), 7.35(\mathrm{dd}, J=8.0,0.7 \mathrm{~Hz}, 2 \mathrm{H}), 7.04(\mathrm{dt}, J=$ 8.9, $2.5 \mathrm{~Hz}, 2 \mathrm{H}), 6.27(\mathrm{dd}, J=6.0,2.4 \mathrm{~Hz}, 2 \mathrm{H}), 6.07(\mathrm{~d}, J=8.3 \mathrm{~Hz}, 2 \mathrm{H}), 3.32(\mathrm{~d}, J=5.9$ $\mathrm{Hz}, 4 \mathrm{H}), 3.20(\mathrm{t}, J=5.6 \mathrm{~Hz}, 4 \mathrm{H}), 3.17-3.09(\mathrm{~m}, 4 \mathrm{H}), 2.97-2.89(\mathrm{~m}, 4 \mathrm{H}), 2.63(\mathrm{~s}, 8 \mathrm{H})$, $2.03-1.94(\mathrm{~m}, 4 \mathrm{H}), 1.81(\mathrm{dd}, J=11.3,5.7 \mathrm{~Hz}, 4 \mathrm{H}), 1.18(\mathrm{~s}, 6 \mathrm{H}) .{ }^{13} \mathrm{C}\left\{{ }^{1} \mathrm{H}\right\} \mathrm{NMR}(101$ MHz, DMSO-d6) $\delta 208.8,174.4,173.5,173.3,169.3,166.7,166.6,163.7,158.4158 .3$, $155.4,155.3,151.6,151.5,145.6,145.6,144.4,144.4,137.1,134.2,133.0,133.0,132.5$, $132.5,131.5,131.3,127.5,126.3,125.9,125.7,124.2,124.0,123.9,118.8,118.7,116.4$ $116.4,116.2,106.9,106.9,106.4,106.4,106.3,105.1,105.0,103.5,103.5,85.4,69.0,56.3$ $55.0,54.9,49.5,49.0,40.6,40.4,40.2,40.0,39.8,39.5,39.3,32.6,30.2,30.1,29.5,27.3$, 
25.7, 21.6, 21.0. HRMS (ESI-TOF) $m / z:[\mathrm{M}+\mathrm{H}]^{+}$Calcd for $\mathrm{C}_{36} \mathrm{H}_{29} \mathrm{~N}_{2} \mathrm{O}_{8}$ 617.1918; Found 617.1922 and 617.1914.

UV-Vis Absorption and Fluorescence Spectroscopy. UV-vis spectra were collected using a Cary $50 \mathrm{UV}$-vis spectrophotometer at $\mathrm{rt}$ using a reduced- volume $1 \mathrm{~cm}$ quartz cuvette. Fluorescence spectra were collected on a Cary Eclipse fluorescence spectrophotometer (Agilent Technologies). All absorption spectra were reference corrected. Fluorescence spectra were corrected for the wavelength-dependent response of the R928 photomultiplier tube using a manufacturer-generated correction file. Quantum yields were reported as the average of multiple measurements using multiple references. EEMs were collected over various spectral regions, using 5 or $10 \mathrm{~nm}$ step sizes for emission and excitation. The band pass for excitation and emission was 5-10 $\mathrm{nm}$.

Cell Culture. The human PDAC cell line Capan-1 was obtained from Dr. Rosalie Sears's laboratory at Oregon Health and Science University (OHSU) and was maintained in RPMI medium (Gibco) in a humid atmosphere at $37{ }^{\circ} \mathrm{C}$ with $5 \% \mathrm{CO}_{2}$. All media were supplemented with $10 \% \quad(\mathrm{v} / \mathrm{v})$ fetal bovine serum (FBS) and $1 \%(\mathrm{v} / \mathrm{v})$ penicillin/streptomycin. Cell viability was determined by Cell Titer-Blue assay. Monolayers of $10^{4}$ Capan-1 cells were seeded in triplicate in 96-well plates and incubated with decreasing concentration from $100 \mu \mathrm{M}$ of each compound in growth media containing $10 \%$ FBS. After $24 \mathrm{~h}$ incubation time, $20 \mu \mathrm{L}$ of Cell Titer-Blue reagent was added into each well and culture cells were incubated for additional $2 \mathrm{~h}$. Fluorescence intensity in each well was recorded at 560/590 nm using a SpectraMax M5 Microplate Reader. The half- 
maximal inhibitory concentrations $\left(\mathrm{IC}_{50}\right.$ determined by interpolating values in the graph ( $\%$ cell viability vs fluorophore concentration).

In Vitro Live Cell Imaging. Monolayers of $10^{4}$ Capan-1 cells were seeded in triplicate in eight-well plates and incubated for $24 \mathrm{~h}$ in growth medium containing 10\% FBS and were allowed to attach. For subcellular colocalization experiments, the medium was extracted and cells were washed with phosphate-buffered saline (PBS), and phenol red-free growth medium was added to each well. Organelle trackers were added to each well, and incubated with the fluorophore of interest (final concentration $0.5 \mu \mathrm{M}$ ) for $1 \mathrm{~h}$. Cells were washed with PBS and fixed with $2 \%$ paraformaldehyde (PFA). Fluorescence microscopy was carried out using a Zeiss inverted microscope with an Axioscan fluorescence camera for imaging. The final concentration of organelle trackers used were as follows: DAPI $0.5 \mu \mathrm{M}$, Mito-tracker green $0.5 \mu \mathrm{M}$, and ER-tracker green $1 \mu \mathrm{M}$.

Fluorophore-labeled Antibodies. Compound $\mathbf{8}$ was conjugated to donkey anti-mouse antibody (Jackson ImmunoResearch) for immunofluorescence microtubule imaging. The antibody was buffer exchanged into $1 \times$ phosphate buffered saline (PBS) and $\mathrm{pH}$ adjusted to 8.3 with $35 \mathrm{mM}$ disodium phosphate. The conjugation reactions were set up with fluorophore and antibody mixed at a 10:1 molar ratio for immunofluorescence microtubule imaging measurements. The fluorophore-antibody conjugation reactions were rocked gently at $\mathrm{rt}$ protected from light for $3 \mathrm{hr}$ and were washed and concentrated in $10 \mathrm{kDa}$ MWCO spin filters. The fluorophore to antibody-labeling conjugation ratio was $2.8: 1$, 
which was determined using an absorbance spectrometer (SpectraMax M5 Microplate Reader).

Ex vivo Staining of PDAC tissue. The initial wash to remove excess OCT was done by covering each tissue sample with PBS. After 2 min, it was removed with vacuum. The tissue samples were fixed with $2 \%$ PFA at rt. for 15 min and washed $3 \times$ using PBS with $0.1 \%$ Tween-20 for $5 \mathrm{~min}$. Slides were incubated with fluorophore formulation, $(10 \%$ dimethyl sulfoxide DMSO (control) or 10\% DMSO fluorophore solution (dependent on specific concentration of fluorophore), $5 \%$ Kolliphor EL, $85 \%$ of $75 / 25$ serum/PBS) for 40 min at rt. Slides were covered to prevent photobleaching. Excess fluorophore was removed through two 5 min rinses with PBS. Fluorophore post-fixing was done using 2\% PFA for 15 min and washed $1 \times$ with PBS for 5 min. After removing excess PBS samples were mounted with fluoromount. The coverslip was placed onto tissue, making sure no air bubbles were present. The coverslips were sealed with colorless nail polish. The slides were stored at $20^{\circ} \mathrm{C}$. Images were acquired using Zeiss Axioscan Z.1 slide scanner (Carl Zeiss) at 20× magnification. The fluorescence signal was optimized at the start of the study to not oversaturate the signal. For a standardized comparison, the power of Colibri 7 light source and integration times of the Hamamatsu ORCA Flash4 camera (Hamamatsu Photonics) were kept constant for all samples. The imaging was performed on slides overnight after staining with identical image acquisition settings.

Immunofluorescence Labeling. U2OS Cells were pre-extracted with $0.5 \%$ Triton X-100 in PEM (100 mM PIPES buffer $\mathrm{pH} 7.0,1 \mathrm{mM}$ EGTA and $1 \mathrm{mM} \mathrm{MgCl}$ ) for $20 \mathrm{~s}$, fixed with $0.4 \%$ glutaraldehyde (Electron Microscopy Science) and $0.25 \%$ Triton X-100 in PEM 
for $90 \mathrm{~s}$, washed with PBS before fixing with 3\% glutaraldehyde in PEM 15 min. Cells were washed with PBS $(3 \times 5 \mathrm{~min})$, then reduced with $10 \mathrm{mM}$ sodium borohydride for 10 min, washed again with PBS $(3 \times 5 \mathrm{~min})$, and blocked with $5 \%$ bovine serum albumin (BSA) in PBS. Cells were incubated with bovine alpha-tubulin mouse primary antibody (Thermo Fisher Scientific) at $2 \mu \mathrm{gml}-1$ in BSA for $4 \mathrm{~h}$ at $\mathrm{rt}$ and washed with PBS $(3 \times 5$ min). Lastly, cells were incubated with fluorophore-labeled donkey anti-mouse secondary antibody at $0.2 \mu \mathrm{M}$ fluorophore concentration in PBS for $30 \mathrm{~min}$ at rt protected from light and washed with PBS $(3 \times 5$ mins $) .{ }^{22}$ Images were acquired on an Axio Observer inverted fluorescence microscope (Zeiss, Thornwood, NY) at 20× magnification. A PhotoFluor II was used and filtered using a $545 \pm 12.5$ bandpass excitation filter. Fluorescence images were collected using an Axiocam 506 camera (Zeiss), where a $605 \pm 35 \mathrm{~nm}$ bandpass emission filter was used for image collection.

\section{REFERENCES}

(1) Giri, R.; Goodell, J. R.; Xing, C.; Benoit, A.; Kaur, H.; Hiasa, H.; Ferguson, D. M. Synthesis and cancer cell cytotoxicity of substituted xanthenes. Bioorg. Med. Chem. 2010, 18, 1456-1463.

(2) Parkin, D. M.; Bray, F.; Ferlay, J.; Pisani, P. Global cancer statistics, 2002. CA. Cancer J. Clin. 2005, $55,74-108$.

(3) Asano, J.; Chiba, K.; Tada, M.; Yoshii, T. Cytotoxic xanthones from Garcinia hanburyi. Phytochemistry 1996, 41, 815-820.

(4) Pouli, N.; Marakos, P. Fused xanthone derivatives as antiproliferative agents. Anticancer Agents Med. Chem. 2009, 9, 77-98.

(5) Akao, Y.; Nakagawa, Y.; Nozawa, Y. Anti-cancer effects of xanthones from pericarps of mangosteen. Int. J. Mol. Sci. 2008, 9, 355-370.

(6) Chen, W.; Xu, S.; Day, J. J.; Wang, D.; Xian, M. A general strategy for development of near-infrared fluorescent probes for bioimaging. Angew. Chem., Int. Ed. 2017, 56, 16611-16615.

(7) Ilangovan, A.; Anandhan, K.; Prasad, K. M.; Vijayakumar, P.; Renganathan, R.; Ananth, D. A.; Sivasudha, T. Synthesis, DNA-binding study, and antioxidant activity of 14-aryl-14H-dibenzo a,j xanthene derivatives. Med. Chem. Res. 2015, 24, 344-355. 
(8) Wang, L.; Sibrian-Vazquez, M.; Escobedo, J. O.; Wang, J.; Moore, R. G.; Strongin, R. M. Spiroguanidine rhodamines as fluorogenic probes for lysophosphatidic acid. Chem. Commun. 2015, 51, 1697-1700.

(9) Nakamura, H.; Shirakawa, Y.; Kitamura, H.; Sato, N.; Shinji, O.; Saito, K.; Takahashi, S. Mechanism of wavelength conversion in polystyrene doped with benzoxanthene: emergence of a complex. Sci. Rep. 2013, 3, 2502.

(10) Sibrian-Vazquez, M.; Escobedo, J. O.; Lowry, M.; Strongin, R. M. Progress toward red and nearinfrared (NIR) emitting saccharide sensors. Pure Appl. Chem. 2012, 84, 2443-2456.

(11) Chu, Y.-H.; Escobedo, J. O.; Jiang, M.; Steyger, P. S.; Strongin, R. M. Rhodamine analogs for molecular ruler applications. Dyes Pigm. 2016, 126, 46-53.

(12) Spatafora, C.; Barresi, V.; Bhusainahalli, V. M.; Di Micco, S.; Musso, N.; Riccio, R.; Bifulco, G.; Condorelli, D.; Tringali, C. Bio-inspired benzo[k,l]xanthene lignans: synthesis, DNA-interaction and antiproliferative properties. Org. Biomol. Chem. 2014, 12, 2686-2701.

(13) Lipinski, C. A.; Lombardo, F.; Dominy, B. W.; Feeney, P. J. Experimental and computational approaches to estimate solubility and permeability in drug discovery and development settings. $A d v$. Drug Delivery. Rev. 2001, 46, 3-26.

(14) Sibrian-Vazquez, M.; Escobedo, J. O.; Lowry, M.; Fronczek, F. R.; Strongin, R. M. Field effects induce bathochromic shifts in xanthene dyes. J. Am. Chem. Soc. 2012, 134, 10502-10508.

(15) Yang, Y.; Lowry, M.; Schowalter, C. M.; Fakayode, S. O.; Escobedo, J. O.; Xu, X.; Zhang, H.; Jensen, T. J.; Fronczek, F. R.; Warner, I. M.; Strongin, R. M. An organic white light-emitting fluorophore. J. Am. Chem. Soc. 2006, 128, 14081-14092.

(16) Wang, L.; Barth, C. W.; Sibrian-Vazquez, M.; Escobedo, J. O.; Lowry, M.; Muschler, J.; Li, H.; Gibbs, S. L.; Strongin, R. M. Far-red and near-infrared seminaphthofluorophores for targeted pancreatic cancer imaging. ACS Omega 2017, 2, 154-163.

(17) Drake, B. V.; Thomas, D. W. Mild amination process for the preparation of aminohydroxynaphthalenes and derivatives from dihydroxynaphthalenes and carboxamides or amine salts using sulfites or bisulfites. GB Patent GB2359303A, August 22, 2001.

(18) Schweizer, C. "Three novel seminaphthorhodamines: synthesis, structure, and spectral properties." Portland State University, Portland, Oregon, June, 2016. Available at:

https://pdxscholar.library.pdx.edu/honorstheses/271 (accessed April 17, 2018).

(19) Rurack, K.; Spieles, M. Fluorescence quantum yields of a series of red and near-infrared dyes emitting at 600-1000 nm. Anal. Chem. 2011, 83, 1232-1242.

(20) Frisch, M. J.; Trucks, G. W.; Schlegel, H. B.; Scuseria, G. E.; Robb, M. A.; Cheeseman, J. R.; Scalmani, G.; Barone, V.; Mennucci, B.; Petersson, G. A.; Nakatsuji, H.; Caricato, M.; Li, X.; Hratchian, H. P.; Izmaylov, A. F.; Bloino, J.; Zheng, G.; Sonnenberg, J. L.; Hada, M.; Ehara, M.; Toyota, K.; Fukuda, R.; Hasegawa, J.; Ishida, M.; Nakajima, T.; Honda, Y.; Rev D.01 ed.; Gaussian, Inc.: Wallingford, CT. USA, 2009; Vol. Rev. D.01.

(21) Whitaker, J. E.; Haugland, R. P.; Prendergast, F. G. Spectral and photophysical studies of benzo[c]xanthene dyes: Dual emission pH sensors. Anal. Biochem. 1991, 194, 330-344.

(22) Whelan, D. R.; Bell, T. D. M. Image artifacts in single molecule localization microscopy: why optimization of sample preparation protocols matters. Sci. Rep. 2015, 5, 7924. 


\title{
Chapter 4: Synthesis of Near Infrared Cyanine-Xanthene Hybrid Probes
}

\begin{abstract}
Dyes that are active in the near infrared region (NIR, $>700 \mathrm{~nm}$ ) have been of great interest in various fields, including superresolution imaging and biomedical imaging as contrast agents. The xanthene dyes comprise some of the most common fluorophores such as fluorescein and rhodamine; however, they are not active in the NIR region. Owing to their favorable photophysical properties such as high molar absorbance, good water solubility and excellent quantum yields, xanthene scaffolds are among the most common labeling agents used in biological applications. Cyanine dyes are one type of the widely employed fluorophores for NIR fluorescent probe design. Xanthene chromophore functionalized with cyanine groups containing different lengths of their polymethine chain can be used to create a cyanine-xanthene based library of NIR fluorescent probes with enhanced photophysical properties for biological applications. There have been few studies that have explored the systematic chemical modification of members of a class of fluorophores for selective uptake by specific tissue or cell types using physiochemical predictors. Thus, the synthesis of the cyanine-xanthene hybrids will provide an understanding of structure activity relationship profiles for tissue and cellular specific uptake. The ability to correlate molecular structure of imaging agents and tissue-specific uptake could solve unmet clinical needs of NIR imaging agents that are inherently tissuespecific for diagnostics and therapeutic purposes.
\end{abstract}




\section{INTRODUCTION}

Xanthene dyes exhibit $\lambda_{\max }$ absorption and emission in the visible spectral region despite their relatively small molecular size (Figure 1$).{ }^{1}$ This is achieved by small bond length alternation (BLA) originating from the contributions of resonance structures. ${ }^{1}$ Xanthene dyes are among the most commonly used class of fluorescent dyes in bioimaging. Fluorescein is a particularly useful dye for biological purposes for several reasons: the dye is very soluble in water, it has a high extinction coefficient $\left(8 \times 10^{4} \mathrm{M}^{-1} \mathrm{~cm}^{-1}\right)$ and high quantum yield (0.92). ${ }^{2}$ Derivatives of fluorescein are readily synthesized and that allow for the utilization of the dye in many applications including $\mathrm{pH}$ sensing, tracer agents, laser dyes, labeling agents in biology. ${ }^{2-7}$

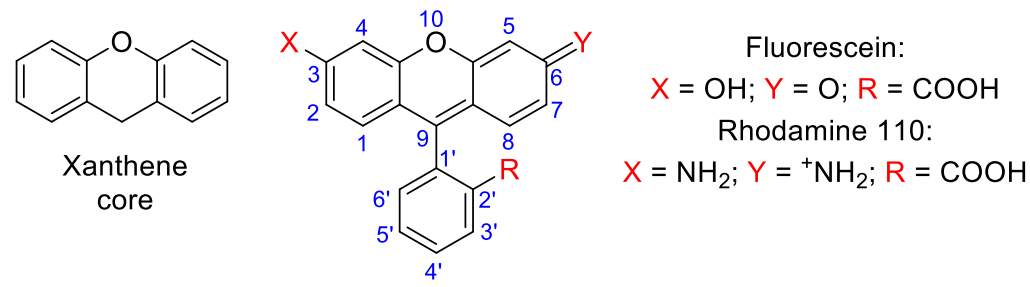

Figure 1. The xanthene core structure and common xanthene-based dyes showing possible sites for modification (blue numbers).

However, xanthene dyes typically possess small Stokes shifts and are not active in the near infrared (NIR) region. Strategies for red-shifting xanthene dyes for biodiagnostics and imaging applications have been an active area of investigation for many years. ${ }^{8}$ Strategies employed so far include replacement of the phenyl ring with electron 
withdrawing groups such as cyano ${ }^{9}$ or trifluoromethyl, ${ }^{10}$ extending annulation, extending $\pi$-conjugation, replacement of the bridging oxygen-atom by carbon, ${ }^{11}$ phosphorus, ${ }^{6}$ sulfur, ${ }^{7}$ or silicon, ${ }^{12}$ tellurium, ${ }^{13}$ selenium, ${ }^{14}$ and annulation (Figure 2). ${ }^{5,8,15,16}$ Our group has been focused on annulation as one strategy to red-shift the xanthene dyes. ${ }^{3,8,15-17}$

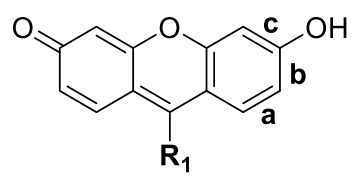

xanthene<smiles>[R]c1cc([R3])c2cc3c([R])c4ccc(=O)cc-4oc3cc2c1</smiles>

benzo[b]xanthene

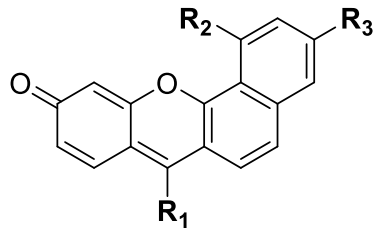

benzo[c]xanthene

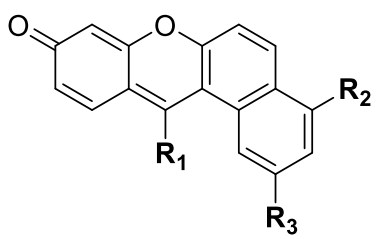

benzo[a]xanthene

Figure 2. The xanthene backbone and three possible sites for annulation.

The annulation of xanthene is advantageous due to the low synthesis cost, high optical sensitivity, and excellent physicochemical properties for application in cell and tissue biological studies. These benzo-annulated xanthene (Figure 2) exhibit various sites for potential modification to generate new series of fluorescent dyes with different molecular sizes, lipophilicities, and ionization states. This enables systematic structure 
changes for the optimization of optical and/or biological properties such as inherent tissuespecific in vivo targeting and malignant cell-specific ex vivo imaging. ${ }^{16,18}$

An alternative strategy to synthesize NIR-active xanthene fluorophores employed in this project is the extension of the $\pi$-conjugated system on the xanthene backbone by attaching a cyanine moiety (Figure 3 ).${ }^{19}$ Cyanine dyes are considered as a main source of organic long-wavelength fluorophores, providing excitation bands in the range 600-900 $\mathrm{nm} .{ }^{20}$ The red shifting of cyanine dyes is easily achieved by addition of a vinyl group ($\mathrm{CH}=\mathrm{CH}-)$ to the polymethine chain. ${ }^{21}$ The ease of tuning the photophysical properties, sharp near infrared absorption and emission bands and large molar absorptivity have led to the much interest of using the cyanine moiety. ${ }^{22}$ Indocyanine green (ICG) is the first Food and Drug Administration (FDA) approved cyanine-based fluorophore for clinical use. ${ }^{22}$ Despite great advances in the development of cyanine-based fluorescent probes as imaging fluorophores, improvement in the photophysical properties of cyanine fluorophores remains necessary. ${ }^{23}$ Some drawbacks of cyanine dyes are known, and these include limited stability in the presence of strong nucleophiles, photooxidation, and aggregation in aqueous media. There is a need to address such limit limitations of the cyanine-based fluorophores. 


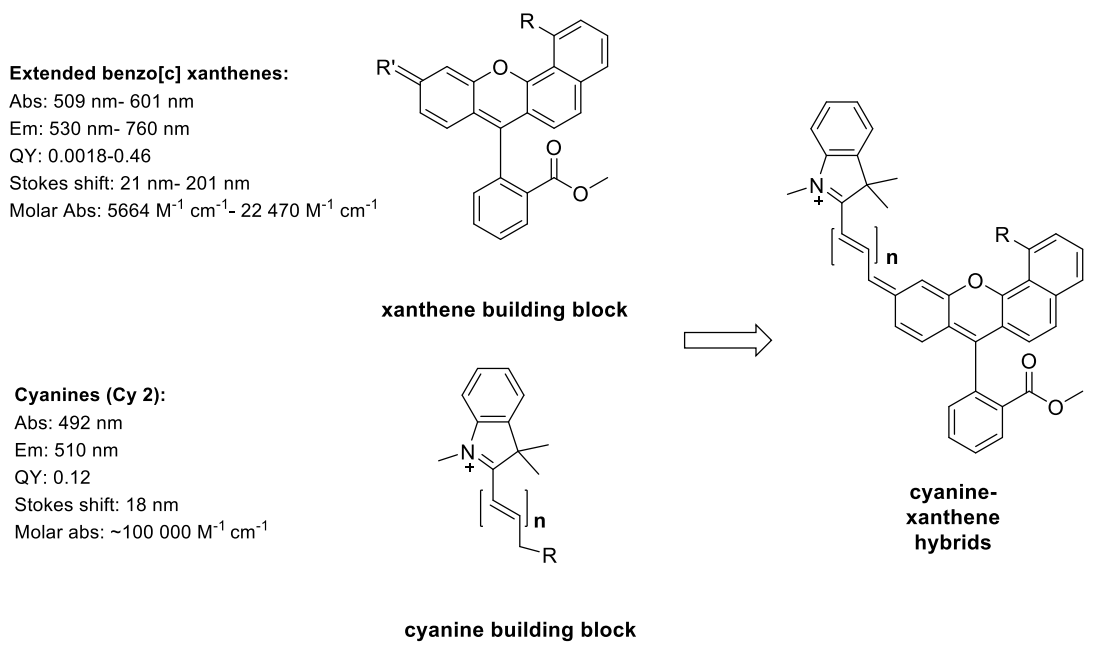

Figure 3. Benzo[c]xanthene functionalized with a cyanine moiety to afford cyanine-xanthene hybrids.

Rhodamine dyes functionalized with cyanine dyes have shown NIR absorption and emission spectral properties, as well as increased quantum yields and molar absorption coefficient values when compared to the classical rhodamine dyes. ${ }^{23}$ It has been hypothesized that the xanthene moiety could preserve far red optical properties, relatively high quantum yields and large Stokes shift where the cyanine moiety could enhance and achieve the desired NIR optical properties. Based on this design strategy, a library of ten compounds (Figure 4) will be synthesized that are expected to show synergistic photophysical properties compared to the individual xanthene and cyanine scaffolds. 


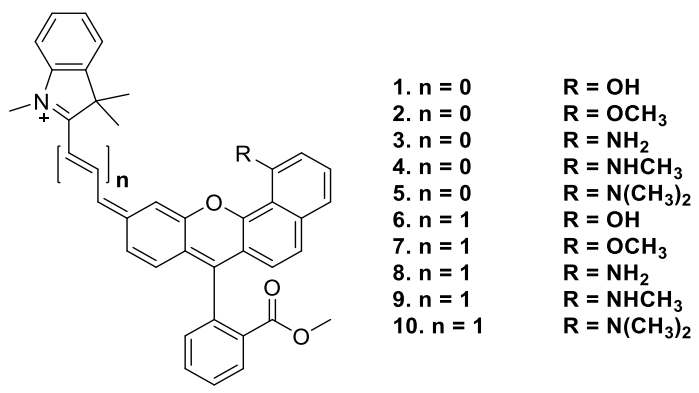

Figure 4. A library of cyanine-xanthene hybrid probes.

\section{RESULTS AND DISCUSSION}

\section{Density Functional Theory (DFT) calculations}

Molecular orbital calculations were performed using Time Dependent Density Functional Theory (TD-DFT) at B3LYP/6-31G level the Gaussian 09 software package. These calculations were done in order to predict the photophysical properties of the proposed cyanine-xanthene hybrid dyes. These predictions were useful in the preliminary selection to synthesize a focused library of compounds. The preliminary calculations from selected representative showed that when $n=1$ on the polymethine chain (Figure 5 ) the absorption of the probe is $\sim 660 \mathrm{~nm}$ which is much closer to desired NIR region (typically experimental absorption wavelength $>50 \mathrm{~nm}$ than calculated). Based on DFT calculations, the first compound targeted for synthesis was 6 because its calculated absorption maximum is $\sim 660$ $\mathrm{nm}$ and the naphthalene substrate is commercially available. 


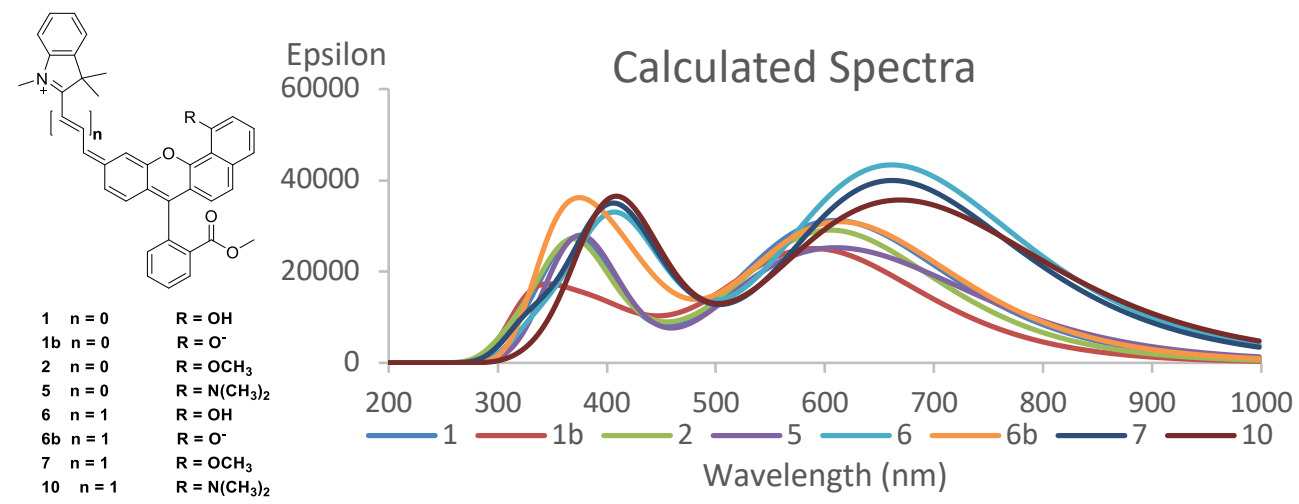

Figure 5. Calculated absorption wavelength of proposed cyanine-xanthene hybrid probes.

\section{Strategy 1: First synthesize the cyanine moiety.}

The cyanine-xanthene hybrids would be synthesized in 5 to 6 steps (Scheme 1). The initial step involved the formation of a phosphonium salt of 3-methoxybenzylbromide (12) from 3-methoxybenzylbromide (11) which was used as a crude product in the subsequent Wittig reaction with aldehyde 13, followed by demethylation of methoxy 14 with $\mathrm{HBr}$. Ortho acylation of phenol 15 with phthalic anhydride (16) afforded the functionalized cyanine hydroxybenzophenone hybrid building block 17 that could be condensed with 1,8dihydroxynaphthalene derivatives based on 18. This would give the desired cyaninexanthene hybrid dye in the lactone or carboxylate form such as 19. Subsequent Fisher esterification with $\mathrm{MeOH}$ catalyzed by either $\mathrm{H}_{2} \mathrm{SO}_{4}$ or $\mathrm{HCl}$, would afford the methyl ester

derivatives, $\mathbf{6}$. The acid condensation to synthesize 19, showed the hydrolysis products 15 and $\mathbf{1 6}$ instead suggesting hydrolysis of $\mathbf{1 7}$. 
Scheme 1. Synthesis of cyanine moiety first to form cyanine-xanthene hybrid dyes.
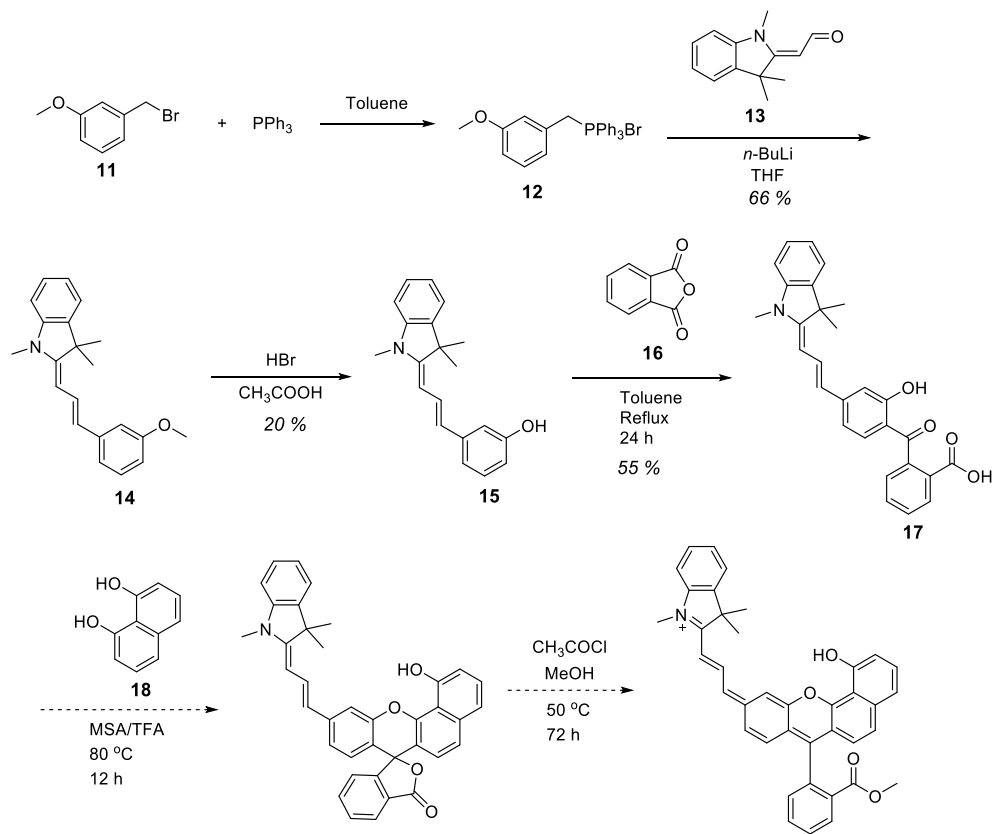

19

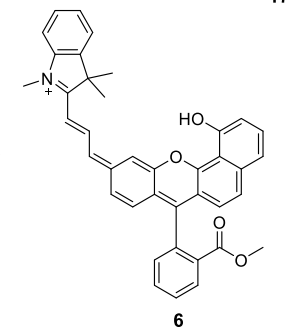

Strategy 2. Synthesize the xanthene bridge first. 
To address the acid hydrolysis problem from the first synthetic strategy (Scheme 1), an alternative was proposed to first synthesize the $-\mathrm{C}-\mathrm{O}$ bridge of the xanthene chromophore. The cyanine-xanthene hybrid probes would be synthesized in 7-8 steps. First, the -C-O bond bridge was formed from a copper catalyzed Ullmann type reaction between methyl 3-iodobenzoate (20) and 3-dimethylaminophenol (21) to afford 22. The methyl ester on one of diaryl ether derivative, was reduced using $\mathrm{NaBH}_{4}$ to afford 23. The bromination of phenol 23 using $\mathrm{PBr}_{3}$ would resulted in 24. Oxidation of 24 using DMSO and $\mathrm{Na}_{2} \mathrm{CO}_{3}$ yielded aldehyde $\mathbf{2 5}$. The nucleophilic addition of $\mathbf{2 6}$ gave the extended $-\mathrm{C}-\mathrm{O}$ xanthene bridge framework. Direct acylation with $\mathbf{1 6}$ would result in the benzophenone framework 28 with subsequent ring closing step catalyzed by a Lewis acid $\mathrm{ZnCl}_{2}$ to give the final product 28. The acylation reaction with phthalic anhydride to synthesize $\mathbf{2 0}$ showed only starting materials 18 and $\mathbf{6}$ without product. 
Scheme 2. First synthesize the $-\mathrm{C}-\mathrm{O}$ bridge of xanthene chromophore.

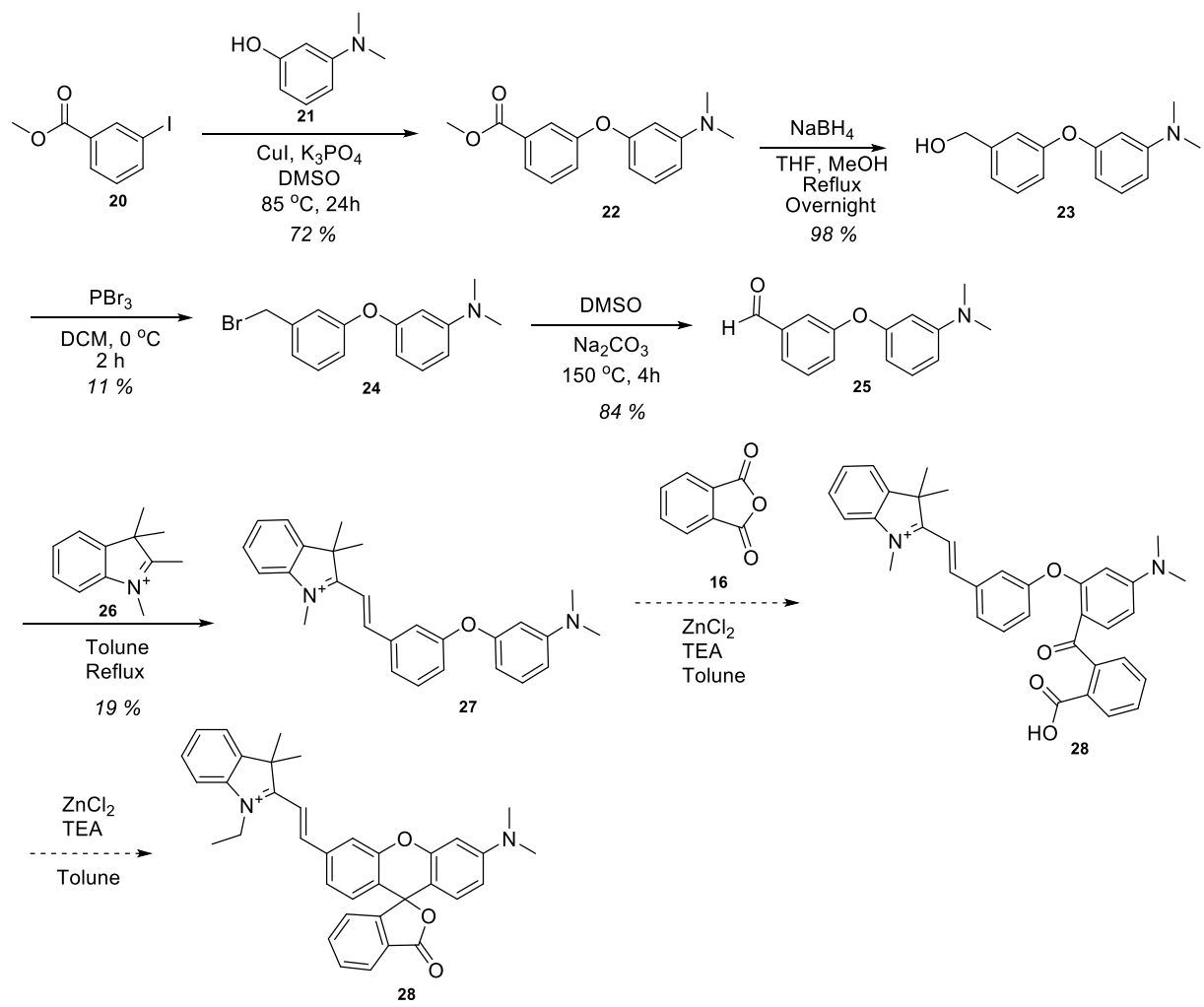

Strategy 3. Functionalizing benzo[c]xanthene with triflate for Mizoroki-Heck coupling reaction. 
The cyanine-xanthene hybrid fluorophore would be synthesized in 4-5 steps by starting with an intact xanthene chromophore to address challenges from Schemes 1 and 2. First, the resorcinol benzophenone (30) was synthesized from basic hydrolysis of fluorescein (29). The direct condensation between $\mathbf{3 0}$ and $\mathbf{1 8}$ afforded a benzo[c]xanthene dye $\mathbf{3 1}$. The benzo[c]xanthene 31 was functionalized with triflate to give (32) for subsequent crosscoupling reaction with a conjugated alkene $\mathbf{3 3}$, to give the final cyanine-xanthene hybrid probe, 34. The coupling reaction afforded the cyanine-xanthene hybrid dye as a mixture. There is need for reaction optimization.

Scheme 3. First synthesize benzo[c]xanthene triflate followed by cross coupling with conjugated alkene.
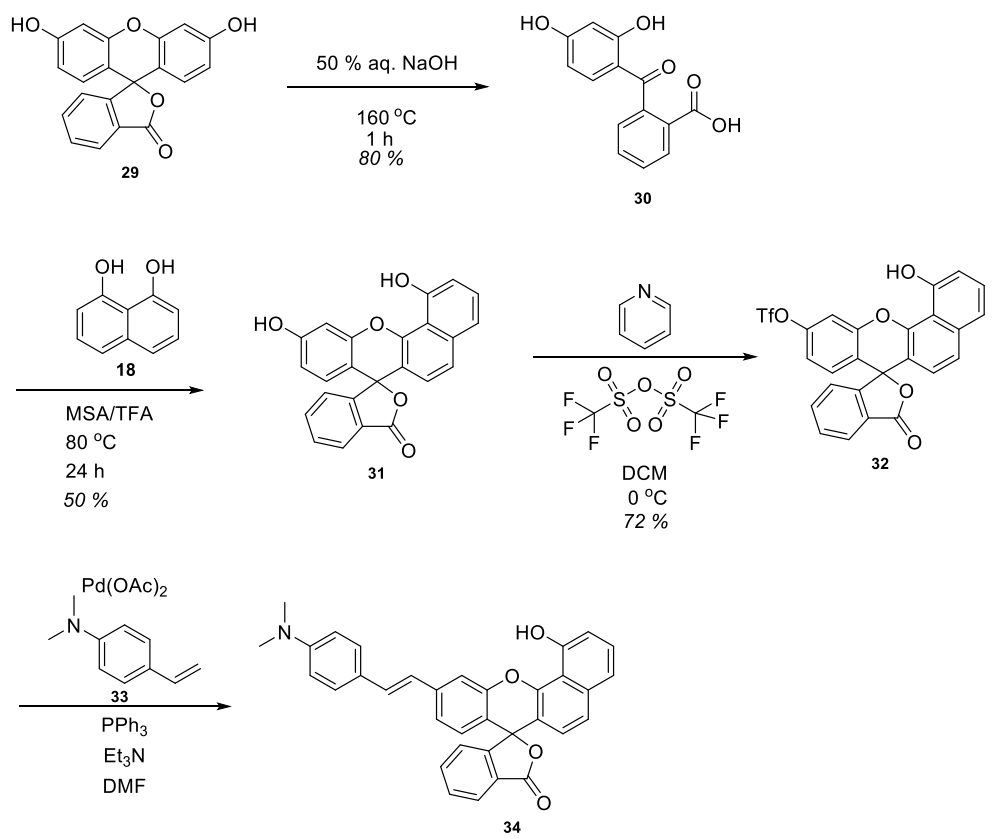


\section{METHODS}

General. Unless otherwise indicated, all commercially available starting materials were used directly without further purification. Silica gel Sorbent Technologies 32-63 $\mu \mathrm{m}$ was used for flash column chromatography. MS (HRMS, ESI) spectra were collected using Agilent 6244 time-of-flight LCMS with diode array detector VL+. All the LC-MS chromatograms and spectra are in Appendix B.

Synthesis of bromo(3-methoxybenzyl)triphenyl-15-phosphane (12). To a solution of 1-(bromomethyl)-3-methoxybenzene in toluene was added a solution of $\mathrm{PPh}_{3}$ in toluene. After being heated at reflux for $5 \mathrm{~h}$, the reaction mixture was cooled at $\mathrm{rt}$ and a first crop of product was collected by filtration. The filtrate was refluxed for additional $5 \mathrm{~h}$ and a second crop of product precipitated. The collected crops were used in the next reaction without any further purification.

Synthesis of $\quad$ (E)-2-((E)-3-(3-methoxyphenyl)allylidene)-1,3,3trimethylindoline (14). Under Ar atmosphere, $n$-BuLi (1.6 M, 6.18 mL, $10.47 \mathrm{mmol})$ was slowly added to a solution of $12(5.0 \mathrm{~g}, 10.79 \mathrm{mmol})$ in THF $(23 \mathrm{~mL})$ at $78^{\circ} \mathrm{C}$. The resulting reddish solution was allowed to warm at rt. Fisher's aldehyde in THF (13) $(2.17 \mathrm{~g}, 10.79$ mmol) was added dropwise and the reaction mixture was stirred for overnight, diluted with ice-cold $\mathrm{H}_{2} \mathrm{O}(200 \mathrm{~mL})$ and stirred for an additional hour. The aqueous layer was extracted with EtOAc; the combined organic layers were washed with $\mathrm{H}_{2} \mathrm{O}$ and dried. The product was separated by flash column chromatography on $\mathrm{SiO}_{2}$ using hexanes/ethyl acetate 95/5 (3.30 g, 66\%). HRMS (ESI-TOF) m/z: $[\mathrm{M}+\mathrm{H}]^{+}$Calcd for $\mathrm{C}_{21} \mathrm{H}_{23} \mathrm{NO}$ 306.1852; Found 306.1870. 


\section{Synthesis of 3-((E)-3-((E)-1,3,3-trimethylindolin-2-ylidene)prop-1-en-1-}

yl)phenol (15). Hydrogen bromide ( $\mathrm{HBr})(57.99 \mathrm{~mL}, 501.93 \mathrm{mmol})$ was added to 14 (16.73 mmol) in glacial acetic acid (same volume as $\mathrm{HBr}$ ). The solution was heated to reflux for $15 \mathrm{~h}$ and allowed to cool to rt. The mixture was diluted with $\mathrm{H}_{2} \mathrm{O}$ (same volume as $\mathrm{HBr}$ ) and concentrated under reduced pressure. After cooling the solution was neutralized to about $\mathrm{pH} 5-6$ with $30 \%$ aq. $\mathrm{NaOH}$. The aqueous phase was extracted with $\operatorname{DCM}(3 \times 50 \mathrm{~mL})$ and the organic layers were washed with brine and dried over $\mathrm{Na}_{2} \mathrm{SO}_{4}$. The solvent was evaporated under reduced pressure. The product was separated by flash column chromatography on $\mathrm{SiO}_{2}$ using hexanes/ethyl acetate 5/1 (0.67 g, 20\%). HRMS (ESI-TOF) m/z: $[\mathrm{M}+\mathrm{H}]^{+}$Calcd for $\mathrm{C}_{20} \mathrm{H}_{21} \mathrm{NO} 292.1696$; Found 292.1623.

\section{Synthesis of 2-(2-hydroxy-4-((E)-3-((E)-1,3,3-trimethylindolin-2-} ylidene)prop-1-en-1-yl)benzoyl)benzoic acid (17). Under Ar atmosphere anhydrous MeCN was added to $15(200 \mathrm{mg}, 686.36 \mu \mathrm{mol})$. Triethylamine $(95.67 \mu \mathrm{L}, 686.36 \mu \mathrm{mol})$ and $\mathrm{ZnCl}_{2}(93.54 \mathrm{mg}, 686.36 \mu \mathrm{mol})$ were added to the solution. The solution was let to stir for $1 \mathrm{~h}$ at $\mathrm{rt}$. phthalic anhydride $(111.83 \mathrm{mg}, 754.99 \mu \mathrm{mol})$ was added to the stirring solution. The reaction was allowed to stir overnight under reflux. The $\mathrm{MeCN}$ was removed under reduced pressure. The product was isolated by crystallization using chilled $\mathrm{MeOH}$ (200 mg, 55\%). HRMS (ESI-TOF) m/z: $[\mathrm{M}+\mathrm{H}]^{+}$Calcd for $\mathrm{C}_{28} \mathrm{H}_{25} \mathrm{NO}_{4}$; Found 440.1856 and 440.1921. 
Synthesis of 1-hydroxy-10-((E)-3-((E)-1,3,3-trimethylindolin-2-ylidene)prop1-en-1-yl)-3'H-spiro[benzo[c]xanthene-7,1'-isobenzofuran]-3'-one (19). Compound 17 (200 mg, $45.51 \mu \mathrm{mol})$ and 1,8-dihydroxynaphthalene (7.29 mg, $45.51 \mu \mathrm{mol})$ were combined and $150 \mu \mathrm{L}$ of 1:1 methanesulfonic acid : trifluoroacetic acid was added. The reaction was stirred overnight at $80{ }^{\circ} \mathrm{C}$. After the reaction was cooled, the reaction was poured on $500 \mu \mathrm{L}$ of iced distilled $\mathrm{H}_{2} \mathrm{O}$. The crude reaction was filtered by vacuum filtration. No product was observed, instead $\mathbf{1 5}$ was the main product peak in liquid chromatography- mass spectrometer.

Synthesis of methyl 3-(3-(dimethylamino)phenoxy)benzoate (22). In an oven dried microwave tube add CuI (138.83 mg, $728.93 \mu \mathrm{mol}), 2$-Picolinic acid (179.49 mg, $1.46 \mathrm{mmol}), 20(1.91 \mathrm{~g}, 7.29 \mathrm{mmol}), 21(1.0 \mathrm{~g}, 7.29 \mathrm{mmol})$ and $\mathrm{K}_{3} \mathrm{PO}_{4}(3.09 \mathrm{~g}, 14.58$ mmol). The reaction was vacuumed and back filled with dry $\mathrm{N}_{2}$ for 3 to 5 times, and sealed immediately with a Teflon cap. Anhydrous DMSO was added $(7 \mathrm{~mL})$. The reaction was stirred at $85{ }^{\circ} \mathrm{C}$ for $24 \mathrm{~h}$. After reaction had cooled down to rt, $50 \mathrm{~mL}$ distilled $\mathrm{H}_{2} \mathrm{O}$ was added and the product was extracted with DCM three times ( $50 \mathrm{~mL}$ each). The product was isolated by flash chromatography on $\mathrm{SiO}_{2}$ using hexanes/ethyl acetate 95/5 (1.37 g $69 \%$ ). HRMS (ESI-TOF) m/z: [M+ H] Calcd for $\mathrm{C}_{16} \mathrm{H}_{17} \mathrm{NO}_{3}$ 272.1281; Found 272.1276.

Synthesis of (3-(3-(dimethylamino)phenoxy)phenyl)methanol (23). Anhydrous THF was added to $22(1.0 \mathrm{~g}, 3.69 \mathrm{mmol})$ under dry $\mathrm{N}_{2} . \mathrm{NaBH}_{4}(766.91 \mathrm{mg}, 20.27 \mathrm{mmol})$ was added, as the reaction was stirring $3 \mathrm{~mL}$ of $\mathrm{MeOH}$ was added dropwise under reflux over $1 \mathrm{~h}$. The solution refluxed for an additional $40 \mathrm{~min}$. After the solution had cooled 
down to $\mathrm{rt}$ the $\mathrm{pH}$ was adjusted to 7 by using $1 \mathrm{M} \mathrm{HCl}$. The solution was extracted four times with EtOAc, dried with $\mathrm{Na}_{2} \mathrm{SO}_{4}$, filtered and evaporated under reduced pressure to give a clean product $\left(980 \mathrm{mg}, 98 \%\right.$ ). HRMS (ESI-TOF) $\mathrm{m} / \mathrm{z}:[\mathrm{M}+\mathrm{H}]^{+} \mathrm{Calcd}$ for $\mathrm{C}_{15} \mathrm{H}_{17} \mathrm{NO}_{2} 244.1332$; Found 244.1277.

\section{Synthesis of 3-(3-(bromomethyl)phenoxy)-N,N-dimethylaniline}

Compound 23 (1.20 g, $4.93 \mathrm{mmol}$ ) was dissolved in $20 \mathrm{~mL}$ anhydrous DCM under $\mathrm{N}_{2}$. The solution was chilled in an ice bath for 30 mins before adding $\operatorname{PBr}_{3}(0.42 \mathrm{~mL}, 4.48 \mathrm{mmol})$ and the reaction was stirred for an additional 10 mins before removing ice bath. The reaction was left to stir for two hours and quenched by adding saturated $\mathrm{Na}_{2} \mathrm{CO}_{3}(20 \mathrm{~mL})$ with slow addition. The product was extracted by ethyl ether three times ( $40 \mathrm{~mL}$ each). The combined organic fractions were washed with $\mathrm{Na}_{2} \mathrm{~S}_{2} \mathrm{O}_{3}(20 \mathrm{~mL})$ and saturated brine (20 $\mathrm{mL}$ ). The solution was dried with $\mathrm{Na}_{2} \mathrm{SO}_{4}$, filtered and concentrated under reduced pressure to give the crude product which was used without further purification (130 mg, 9.47\%). HRMS (ESI-TOF) m/z: [M + H] $]^{+}$Calcd for $\mathrm{C}_{15} \mathrm{H}_{16} \mathrm{BrNO} 306.0488$; Found 306.0403.

Synthesis of 3-(3-(dimethylamino)phenoxy)benzaldehyde (25). Compound 24 (130 mg, $424.55 \mu \mathrm{mol})$ and $\mathrm{NaHCO}_{3}(154.43 \mathrm{mg}, 1.84 \mathrm{mmol})$ were combined in $30 \mathrm{~mL}$ of DMSO and heated to $150^{\circ} \mathrm{C}$ for $4 \mathrm{~h}$. The dark red solution was cooled and diluted into 105 $\mathrm{mL}$ of $2 \mathrm{M} \mathrm{HCl}$ and stirred for $2 \mathrm{~h}$. The aqueous material was extracted thoroughly with DCM eight times (15 mL each) and the solvents were removed to isolate the crude product which was used in the next reaction without further purification (109 mg, $84 \%$ ). HRMS (ESI-TOF) m/z: [M+ H] $]^{+}$Calcd for $\mathrm{C}_{15} \mathrm{H}_{15} \mathrm{NO}_{2}$ 242.1176; Found 242.1210. 
Synthesis of (E)-2-(3-(3-(dimethylamino)phenoxy)styryl)-1,3,3-trimethyl-3Hindol-1-ium (27). To a solution of the $\mathbf{2 5}(84.50 \mathrm{mg}, 348.74 \mu \mathrm{mol})$ and the $\mathbf{2 6}(1.2 \mathrm{mmol})$ in anhydrous $\mathrm{EtOH}(10 \mathrm{~mL})$ under a dry $\mathrm{N}_{2}$ atmosphere was added four drops of pyridine. After being stirred for $4 \mathrm{~h}$ at $78^{\circ} \mathrm{C}$, the mixture was cooled to rt. The removal of solvent under reduced pressure and purification by flash column chromatography on $\mathrm{SiO}_{2}$ yielded a 1:1 mixture of 25 and 26. HRMS (ESI-TOF) m/z: [M $+\mathrm{H}]^{+}$Calcd for $\mathrm{C}_{27} \mathrm{H}_{29} \mathrm{~N}_{2} \mathrm{O}^{+}$ 397.2274; Found 397.2275.

Synthesis of $\quad$ (E)-2-(3-(2-(2-carboxybenzoyl)-5(dimethylamino)phenoxy)styryl)-1,3,3-trimethyl-3H-indol-1-ium (28). Under $\mathrm{Ar}$ atmosphere anhydrous $\mathrm{MeCN}$ was added to $27(26 \mathrm{mg}, 65.40 \mu \mathrm{mol})$. Triethylamine $(9.12$ $\mu \mathrm{L}, 65.40 \mu \mathrm{mol})$ and $\mathrm{ZnCl}_{2}(8.91 \mathrm{mg}, 65.40 \mu \mathrm{mol})$ were added to the solution. The solution was let to stir for $1 \mathrm{~h}$ at $\mathrm{rt}$. Phthalic anhydride $(10.66 \mathrm{mg}, 71.94 \mu \mathrm{mol})$ was added to the stirring solution. The reaction was allowed to stir overnight under reflux. The MeCN was removed under reduced pressure. There was no product peak in liquid chromatographymass spectrometer (only starting material observed).

Synthesis of 2-(2,4-dihydroxybenzoyl)benzoic acid (30). Fluorescein (29) (1.7 g, $5.12 \mathrm{mmol})$ was dissolved in $12 \mathrm{~mL}$ of $50 \% \mathrm{NaOH}$ solution $(\mathrm{w} / \mathrm{v})$ and heated at $160{ }^{\circ} \mathrm{C}$ in an oil bath for $1 \mathrm{~h}$. After cooling to $\mathrm{rt}$, the mixture was poured into $80 \mathrm{~mL}$ of ice $\mathrm{H}_{2} \mathrm{O}$, acidified with concentrated $\mathrm{HCl}$, and allowed to stand at $\mathrm{rt}$ for $2 \mathrm{~h}$. The precipitate was filtered and dried to afford the desired product as a beige powder (1.06 g, 80.3 \%). HRMS (ESI-TOF) m/z: $[\mathrm{M}+\mathrm{H}]^{-}$Calcd for $\mathrm{C}_{14} \mathrm{H}_{10} \mathrm{O}_{5}$ 257.0455; Found 257.1269. 


\section{Synthesis of 1,10-dihydroxy-3'H-spiro[benzo[c]xanthene-7,1'-isobenzofuran]-}

3'-one (31). Compound $30(2.0 \mathrm{~g}, 7.75 \mathrm{mmol})$ and 1,8-dihydroxynaphthalene (1.96 g, $12.24 \mathrm{mmol}$ ) were dissolved in $5 \mathrm{~mL}$ of methanesulfonic acid and $5 \mathrm{~mL}$ trifluoroacetic acid was added. The mixture was heated and stirred in an oil bath at $80^{\circ} \mathrm{C}$ for $24 \mathrm{~h}$. The reaction mixture was allowed to warm to rt, poured into $50 \mathrm{~mL}$ of iced cold distilled $\mathrm{H}_{2} \mathrm{O}$. The resulting precipitate was filtered, washed with $\mathrm{DI} \mathrm{H}_{2} \mathrm{O}$ and air dried. The compound was isolated by flash column chromatography on $\mathrm{SiO}_{2}$ using $\mathrm{CH}_{2} \mathrm{Cl}_{2} / \mathrm{MeOH}$ 9/1 (991 mg, 50 \%). HRMS (ESI-TOF) m/z: [M + H] Calcd for $\mathrm{C}_{24} \mathrm{H}_{14} \mathrm{O}_{5}$ 383.0914; Found 383.1616.

\section{Synthesis of 3'-oxo-3'H-spiro[benzo[c]xanthene-7,1'-isobenzofuran]-1,10-diyl} bis(trifluoromethanesulfonate) (32). Compound 31 (1.0 g, $2.62 \mathrm{mmol})$ was suspended in DCM $(30 \mathrm{~mL})$ and cooled to $0{ }^{\circ} \mathrm{C}$. Pyridine (1.69 $\left.\mathrm{mL}, 20.92 \mathrm{mmol}\right)$ and trifluoromethanesulfonic anhydride $(1.76 \mathrm{~mL}, 10.46 \mathrm{mmol})$ were added, and the ice bath was removed. The reaction was stirred at $\mathrm{rt}$ for $4 \mathrm{~h}$. The crude product was subsequently diluted with $\mathrm{H}_{2} \mathrm{O}$ and extracted with DCM. The combined organic extracts were washed with (saturated $\mathrm{CuSO}_{4}$, brine), dried $\left(\mathrm{Na}_{2} \mathrm{SO}_{4}\right)$, filtered, and concentrated under reduced pressure. The product was isolated by flash column chromatography on $\mathrm{SiO}_{2}$ using hexanes/ethyl acetate 8/2 (717 mg, $72 \%$ ). HRMS (ESI-TOF) m/z: $[\mathrm{M}+\mathrm{H}]^{+}$Calcd for $\mathrm{C}_{25} \mathrm{H}_{13} \mathrm{~F}_{3} \mathrm{O}_{7} \mathrm{~S}$ 515.0407; Found 515.0463.

Synthesis of $N, N$-dimethyl-4-vinylaniline (33). An oven-dried round bottom flask was charged with methyltriphenylphosphonium bromide $(8.62 \mathrm{~g}, 24.13 \mathrm{mmol})$ and $60 \mathrm{~mL}$ anhydrous THF and stirred under nitrogen. A $1.6 \mathrm{M}$ solution of $n$-BuLi in hexanes was added via syringe $(13.41 \mathrm{~mL}, 21.45 \mathrm{mmol})$ at rt. After stirring for $15 \mathrm{~min}, 4-\mathrm{N}, \mathrm{N}-$ 
dimethylbenzaldehyde $(2.0 \mathrm{~g}, 13.41 \mathrm{mmol})$ was added. After stirring overnight, the reaction was poured into $200 \mathrm{~mL}$ of hexanes. The suspension was filtered through Celite and concentrated under reduced pressure. The residue was taken up in EtOAc and filtered through a thin pad $(2 \mathrm{~cm})$ of alumina. Removal of solvents under reduced pressure provided $1.68 \mathrm{~g}$ of 33 (1.68 g, $84 \%$ ) which was judged to be pure by ${ }^{1} \mathrm{H}$ NMR. HRMS (ESI-TOF) m/z: $[\mathrm{M}+\mathrm{H}]^{+}$Calcd for $\mathrm{C}_{10} \mathrm{H}_{13} \mathrm{~N}$ 148.1121; Found 148.1170.

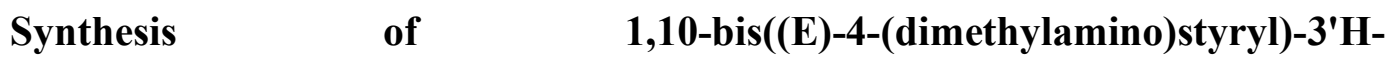
spiro[benzo[c]xanthene-7,1'-isobenzofuran]-3'-one (34). In $25 \mathrm{~mL}$ round-bottomed flask; added successively was compound $\mathbf{3 2}$ (100 mg, $194.39 \mu \mathrm{mol}$ ), compound $\mathbf{3 3}$ (28.62 mg $194.39 \mu \mathrm{mol}), 1 \mathrm{~mL}$ DMF, $1 \mathrm{~mL}$ TEA, $\mathrm{PPh}_{3}(10.20 \mathrm{mg}, 38.88 \mu \mathrm{mol})$ and palladium (4.36 mg, $19.44 \mu \mathrm{mol}$ ); under $\mathrm{N}_{2}$ protection. The reaction was heated to $120^{\circ} \mathrm{C}$ overnight. Removal of solvent under reduced pressure showed the product peak in liquid chromatography-mass spectrometer with other side products. HRMS (ESI-TOF) m/z: [M $+\mathrm{H}]^{+}$Calcd for $\mathrm{C}_{34} \mathrm{H}_{25} \mathrm{NO}_{4}$ 512.1856; Found 512.1912.

\section{REFERENCES}

(1) Sezukuri, K.; Suzuki, M.; Hayashi, H.; Kuzuhara, D.; Aratani, N.; Yamada, H. A laterally $\pi$-expanded fluorone dye as an efficient near infrared fluorophore. Chem. Commun. 2016, 52, 4872-4875.

(2) Lee, L. G.; Berry, G. M.; Chen, C. H. Vita blue: A new 633-nm excitable fluorescent dye for cell analysis. Cytometry $A$ 1989, 10, 151-164.

(3) Yang, Y.; Lowry, M.; Schowalter, C. M.; Fakayode, S. O.; Escobedo, J. O.; Xu, X.; Zhang, H.; Jensen, T. J.; Fronczek, F. R.; Warner, I. M. An organic white light-emitting fluorophore. J. Am. Chem. Soc. 2006, $128,14081$.

(4) Sun, W.-C.; Gee, K. R.; Klaubert, D. H.; Haugland, R. P. Synthesis of Fluorinated Fluoresceins. J. Org. Chem. 1997, 62, 6469-6475.

(5) Azuma, E.; Nakamura, N.; Kuramochi, K.; Sasamori, T.; Tokitoh, N.; Sagami, I.; Tsubaki, K.

Exhaustive syntheses of naphthofluoresceins and their functions. J. Org. Chem. 2012, 77, 3492-3500. 
(6) Fukazawa, A.; Suda, S.; Taki, M.; Yamaguchi, E.; Grzybowski, M.; Sato, Y.; Higashiyama, T.; Yamaguchi, S. Phospha-fluorescein: a red-emissive fluorescein analogue with high photobleaching resistance. Chem. Commun. 2016, 52, 1120-1123.

(7) Liu, J.; Sun, Y.-Q.; Zhang, H.; Shi, H.; Shi, Y.; Guo, W. Sulfone-Rhodamines: A new class of nearinfrared fluorescent dyes for bioimaging. ACS Appl. Mater. Interfaces 2016, 8, 22953-22962.

(8) Sibrian-Vazquez, M.; Escobedo, J. O.; Lowry, M.; Fronczek, F. R.; Strongin, R. M. Field Effects Induce Bathochromic Shifts in Xanthene Dyes. J. Am. Chem. Soc. 2012, 134, 10502-10508.

(9) Shi, J.; Zhang, X.-P.; Neckers, D. C. Xanthenes: flourone derivatives II. Tetrahedron Lett. 1993, 34, 6013-6016.

(10) Haley, L. N. A simple synthesis of 8-(trifluoromethyl)-2, 3, 5, 6, 11, 12, 14, 15-octahydro-1H, 4H, 10H, 13H-diquinolizino [9, 9a, 1-bc: 9', 9a', 1-hi] xanthylium perchlorate, an efficient dye. J. Heterocycl. Chem. 1977, 14, 683-683.

(11) Liu, J.; Diwu, Z.; Leung, W.-Y.; Lu, Y.; Patch, B.; Haugland, R. P. Rational design and synthesis of a novel class of highly fluorescent rhodamine dyes that have strong absorption at long wavelengths.

Tetrahedron Lett. 2003, 44, 4355-4359.

(12) Koide, Y.; Urano, Y.; Hanaoka, K.; Piao, W.; Kusakabe, M.; Saito, N.; Terai, T.; Okabe, T.; Nagano, T. Development of NIR fluorescent dyes based on Si-rhodamine for in vivo imaging. J. Am. Chem. Soc. 2012, 134, 5029-5031.

(13) Calitree, B.; Donnelly, D. J.; Holt, J. J.; Gannon, M. K.; Nygren, C. L.; Sukumaran, D. K.; Autschbach, J.; Detty, M. R. Tellurium analogues of rosamine and rhodamine dyes: synthesis, structure, 125Te NMR, and heteroatom contributions to excitation energies. Organometallics 2007, 26, 6248-6257.

(14) Detty, M. R.; Prasad, P. N.; Donnelly, D. J.; Ohulchanskyy, T.; Gibson, S. L.; Hilf, R. Synthesis, properties, and photodynamic properties in vitro of heavy-chalcogen analogues of tetramethylrosamine. Bioorg. Med. Chem. 2004, 12, 2537-2544.

(15) Yang, Y.; Lowry, M.; Xu, X.; Escobedo, J. O.; Sibrian-Vazquez, M.; Wong, L.; Schowalter, C. M.; Jensen, T. J.; Fronczek, F. R.; Warner, I. M.; Strongin, R. M. Seminaphthofluorones are a family of watersoluble, low molecular weight, NIR-emitting fluorophores. Proc. Natl. Acad. Sci. U. S. A. 2008, 105, 88298834.

(16) Wang, L.; Barth, C. W.; Sibrian-Vazquez, M.; Escobedo, J. O.; Lowry, M.; Muschler, J.; Li, H.; Gibbs, S. L.; Strongin, R. M. Far-red and near-infrared seminaphthofluorophores for targeted pancreatic cancer imaging. ACS Omega 2017, 2, 154-163.

(17) Wang, L. G.; Munhenzva, I.; Sibrian-Vazquez, M.; Escobedo, J. O.; Kitts, C. H.; Fronczek, F. R.; Strongin, R. M. Altering fundamental trends in the emission of xanthene dyes. J. Org. Chem. 2019, 84, 2585-2595.

(18) Munhenzva, I. R.; Barth, C. W.; Sibrian-Vazquez, M.; Wang, L. G.; Escobedo, J. O.; Gibbs, S. L.; Strongin, R. M. Assessment of human pancreas cancer tissue and precursor lesions via a fluorophore with inherent PDAC selectivity. Methods 2019, 168, 35-39.

(19) Wei, Y.; Cheng, D.; Ren, T.; Li, Y.; Zeng, Z.; Yuan, L. Design of NIR chromenylium-cyanine fluorophore library for "switch-on" and ratiometric detection of bio-active species in vivo. Anal. Chem. 2016, $88,1842-1849$.

(20) Vahrmeijer, A. L.; Hutteman, M.; Van Der Vorst, J. R.; Van De Velde, C. J.; Frangioni, J. V. Imageguided cancer surgery using near-infrared fluorescence. Nat. Rev. Clin. Oncol. 2013, 10, 507-518.

(21) Saccone, D.; Galliano, S.; Barbero, N.; Quagliotto, P.; Viscardi, G.; Barolo, C. Polymethine dyes in hybrid photovoltaics: Structure-properties relationships. Eur. J. Org. Chem. 2016, 2016, 2244-2259. 
(22) Chen, H.; Lin, W.; Cui, H.; Jiang, W. Development of unique xanthene-cyanine fused near-infrared fluorescent fluorophores with superior chemical stability for biological fluorescence imaging. Chem.--Eur. J. 2015, 21, 733-745.

(23) Yuan, L.; Lin, W. Y.; Yang, Y. T.; Chen, H. A unique class of near-infrared functional fluorescent dyes with carboxylic-acid-modulated fluorescence on/off switching: rational design, synthesis, optical properties, theoretical calculations, and applications for fluorescence imaging in living animals. $\mathrm{J}$. Am. Chem. Soc. 2012, 134, 1200-1211. 


\section{Chapter 5: Conclusion and Future Work}

Surgery remains the most effective cure for PDAC, whose survival rate is still very low $(<5 \%)$. Moreover, despite the curative nature of surgery most PDAC patients are left with residual tumor ( $>75 \%$ of patients) due to the lack of contrast agents that can help to inform surgeons if they need to remove more tissue. Intraoperative margin assessment has the potential to improve the outlook of PDAC patients after surgery by confirming clear margins (RO) with no microscopic tumor involvement. Microscopic tumor involvement (R1) after surgery increases the chances of locoregional recurrence of the disease thereby lowering the survival rate of patients after a curative PDAC surgery.

In this work compound 12, with no targeting ligand, allowed for the visualization of PDAC in human tissue and the common precancer lesions of PDAC, PanIN. A streamlined procedure was developed enabling staining within $15 \mathrm{~min}$ as required by the intraoperative workflow. A Matlab code was developed to enable objective quantification of the effective contrast of $\mathbf{1 2}$ in PDAC tissue. The staining protocol optimization rendered the potential use of $\mathbf{1 2}$ during PDAC surgery for margin assessment to ensure complete resection of tumor. A regioisomer of $\mathbf{1 2}$ maintained PDAC selectivity. This strategy provides an assortment of PDAC selective probes with distinct photophysical properties.

The motivation to synthesize benzoxanthenes functionalized with cyanines was to address the photophysical limitations of benzoxanthene mainly their absorption in the visible region where biomolecules like hemoglobin have strong absorption as well. The successful synthesis of the cyanine-xanthene hybrid dye using the coupling reaction, 
revealed the challenge of using conventional acid condensation reaction conditions typically used in the synthesis of benzoxanthene, due to the possible hydrolysis of the cyanine moiety.

Following the complete synthesis of the cyanine-xanthene hybrid library using the coupling method, the photophysical and chemical characterization $\left({ }^{1} \mathrm{H}-\mathrm{NMR},{ }^{13} \mathrm{C}-\mathrm{NMR}\right.$ and HR-MS) will be performed. The hybrid library will be used for in vivo biodistribution study, the fluorophore with the highest pancreas tumor tissue signal-to-noise ratio (SBR) will be identified. Ex vivo screening to investigate the staining pattern of the hybrid dyes will be carried out on human PDAC tissue specimens from Origene Inc.

Longer term goals of this study are to contribute to the visualization of PDAC and early precancer lesions during surgery to ensure complete removal of cancer. The cyaninexanthene hybrids will also allow for quantitative structure-activity relationship (QSAR) to understand the inherent tissue targeting. 
Appendix A: Supporting Information for Chapter 3

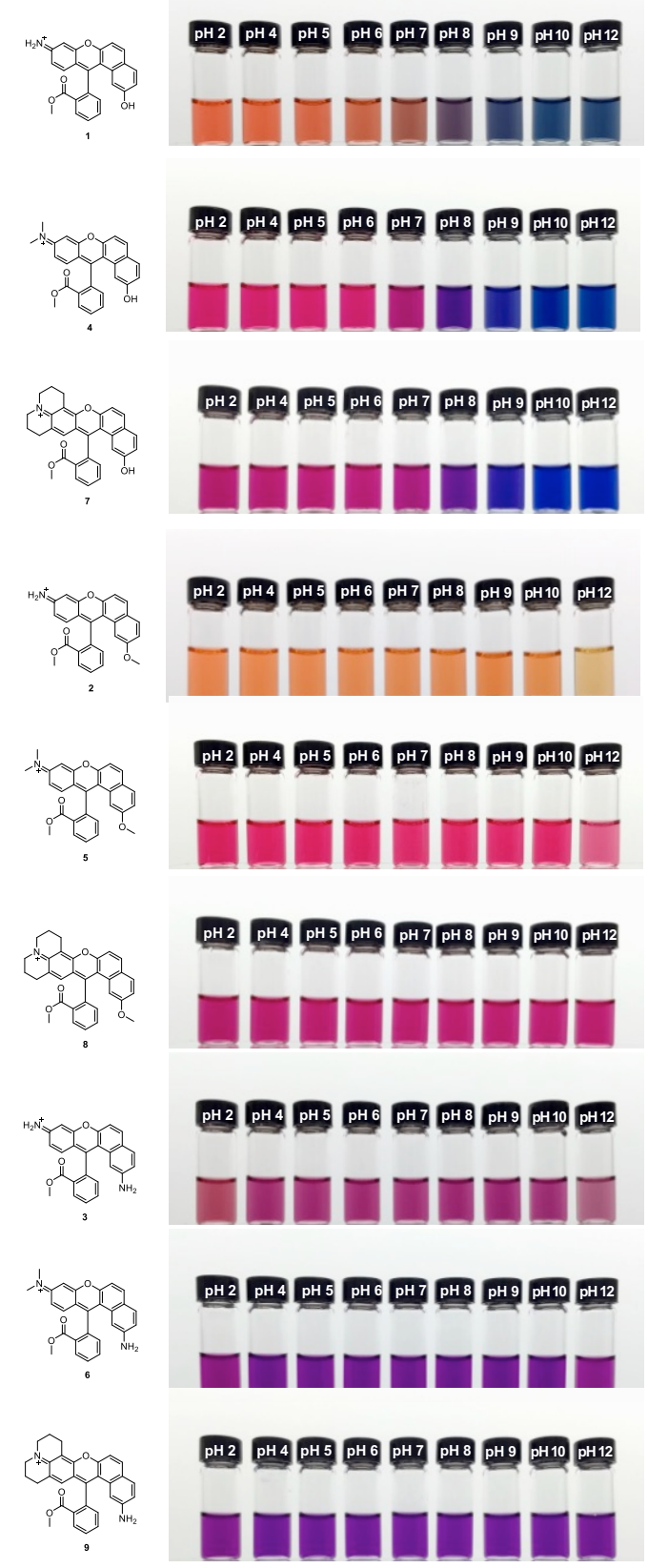

Figure A1. Solutions of compounds 1-9 under various $\mathrm{pH}$ conditions. Sample concentration: $50 \mu \mathrm{M}$. Aqueous solutions contains $10 \%$ DMSO. 
a)

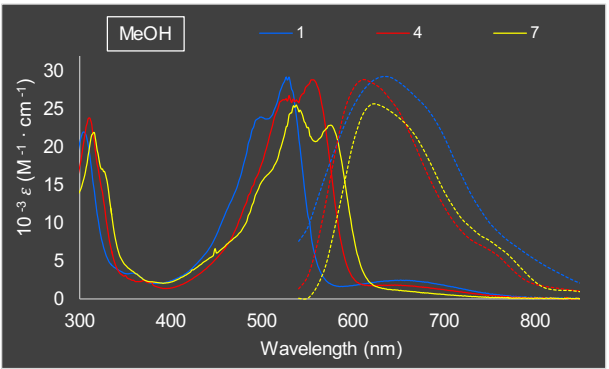

b)

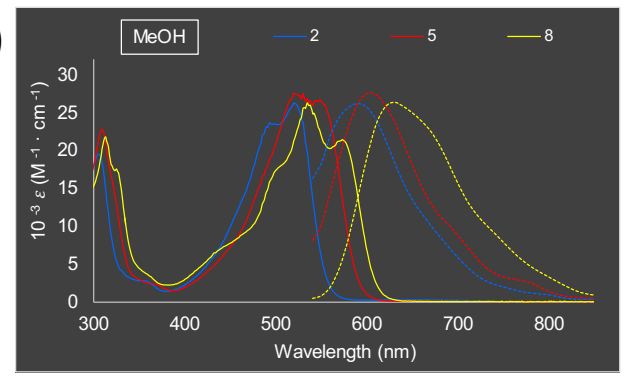

c)

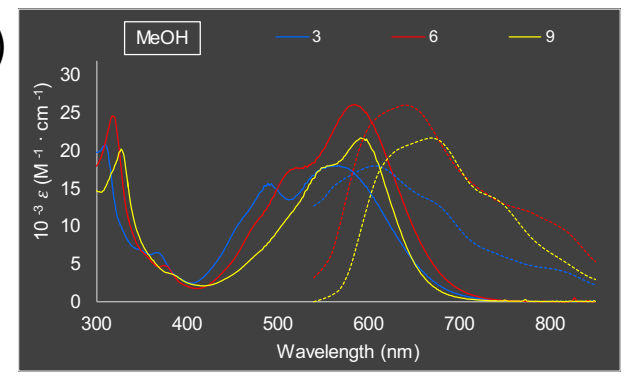

Figure A2. Absorption and normalized emission spectra of compounds 1-9 in $\mathrm{MeOH}$. 
Table A1. Tabulated spectral properties of compounds 1-9 in aqueous buffer at $\mathrm{pH}$ 7.4.

\begin{tabular}{|c|c|c|c|c|c|c|c|c|}
\hline Compound & $\begin{array}{c}\lambda_{\max } \text { abs } \\
(\mathrm{nm})\end{array}$ & $\begin{array}{c}\lambda_{\max } \mathrm{em} \\
(\mathrm{nm})\end{array}$ & $\begin{array}{c}\text { Stokes Shift } \\
\qquad(\mathrm{nm})\end{array}$ & $\begin{array}{c}\text { Extinction Coefficient } \\
\left(\mathrm{M}^{-1} \cdot \mathrm{cm}^{-1}\right)\end{array}$ & \begin{tabular}{|c|} 
Quantum Yield \\
$(\%)$ \\
\end{tabular} & Brightness & $\begin{array}{c}\text { FWHM } \\
(\mathrm{nm})\end{array}$ & $p \mathrm{~K}_{\mathrm{a}}$ \\
\hline 1 & 520 & 580 & 60 & 29,927 & 0.17 & 51 & 163 & $8.07 \pm 0.05$ \\
\hline 2 & 515 & 620 & 105 & 24,200 & 10.86 & 2628 & 161 & - \\
\hline 3 & 530 & 580 & 50 & 22,084 & 0.73 & 161 & 116 & - \\
\hline 4 & 530 & 610 & 80 & 29,327 & 1.56 & 458 & 104 & $8.14 \pm 0.04$ \\
\hline 5 & 520 & 610 & 90 & 28,258 & 7.86 & 2221 & 118 & - \\
\hline 6 & 567 & 640 & 73 & 28,615 & 0.29 & 83 & 101 & - \\
\hline 7 & 538 & 630 & 92 & 24,978 & 6.26 & 1564 & 115 & $8.39 \pm 0.06$ \\
\hline 8 & 535 & 640 & 105 & 24,075 & 8.18 & 1969 & 117 & - \\
\hline 9 & 545 & 650 & 105 & 20,276 & 0.56 & 114 & 140 & - \\
\hline
\end{tabular}


a)

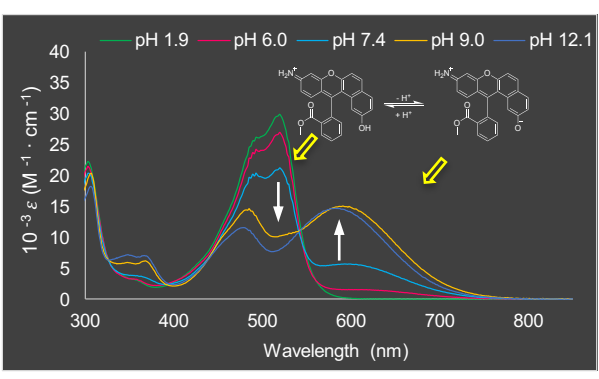

b)

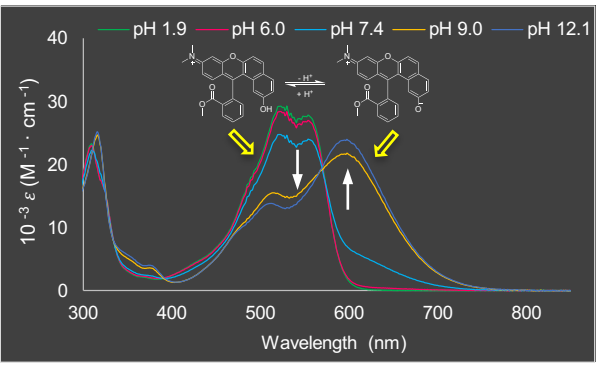

c)

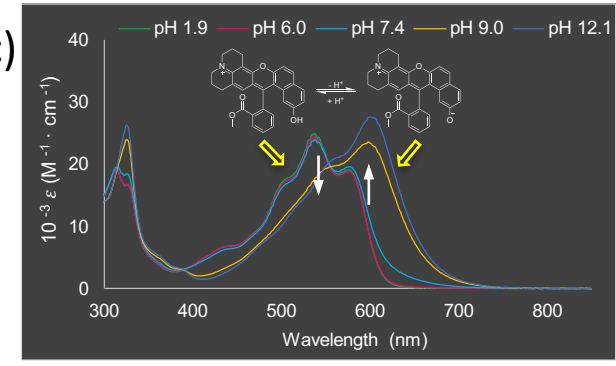

d)

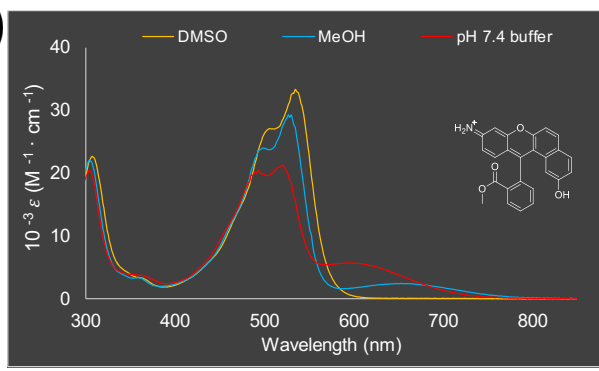

e)

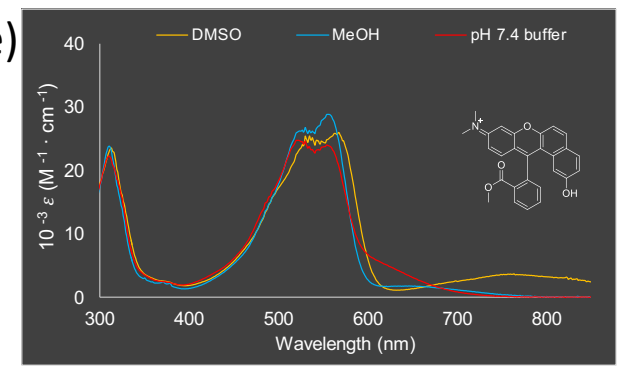

f)

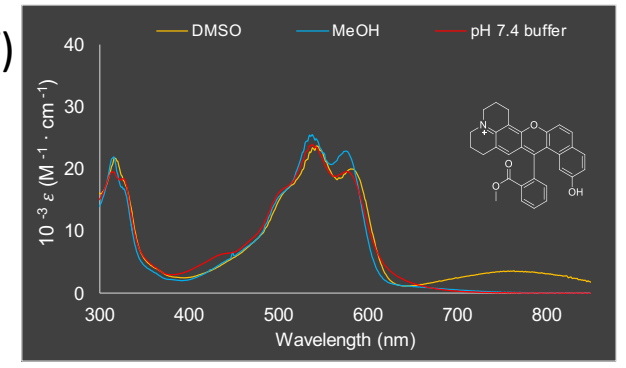

Figure A3. Absorption spectra of $\mathbf{p H}$ - and solvent-dependent seminaphthorhodafluors $(1,4$, and 7$)$. (ac) Absorption spectra as a function of $\mathrm{pH}$ for $\mathbf{1}$ (a), 4 (b), and 7 (c). (d-f) Absorption spectra as a function of solvents including DMSO, MeOH, and phosphate $\mathrm{pH} 7.4$ buffer for $\mathbf{1}$ (d), 4 (e), and 7 (f). Aqueous buffer solutions contain $10 \%$ DMSO and $12.5 \mathrm{mM} \mathrm{HCl}$, phosphate buffer, or $\mathrm{NaOH}$. Ratiometric absorption spectra were observed for $\mathbf{1}, \mathbf{4}$, and $\mathbf{7}$. Well defined isosbestic points indicate spectral changes result from acid-base equilibria between two species. 

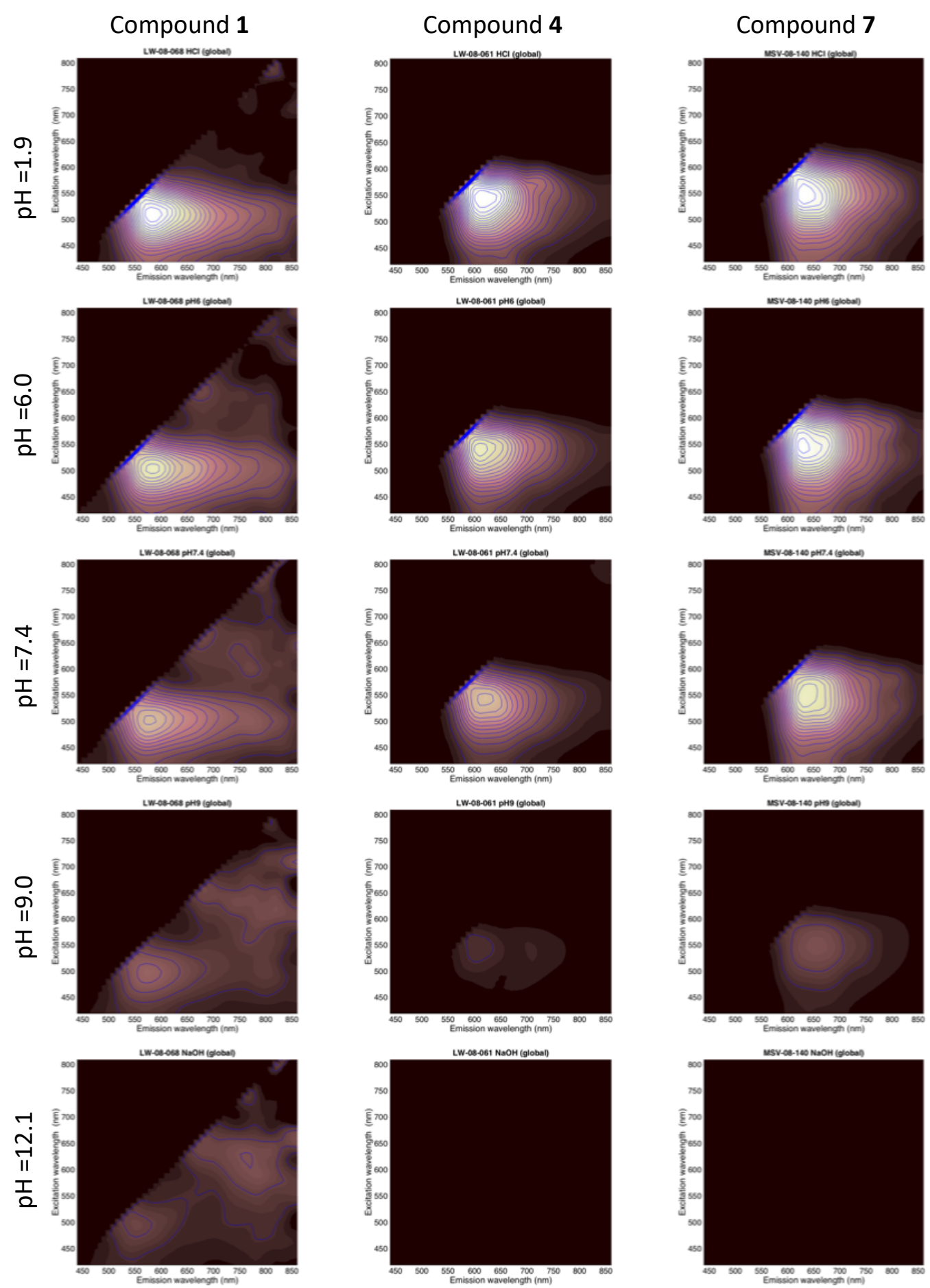

Figure A4. Excitation Emission Matrices (EEMs) of pH dependent seminaphthorhodafluors (1, 4, and 7). Aqueous buffer solutions contain $10 \% \mathrm{DMSO}$ and $12.5 \mathrm{mM} \mathrm{HCl}$, phosphate buffer, or $\mathrm{NaOH}$. 
a)

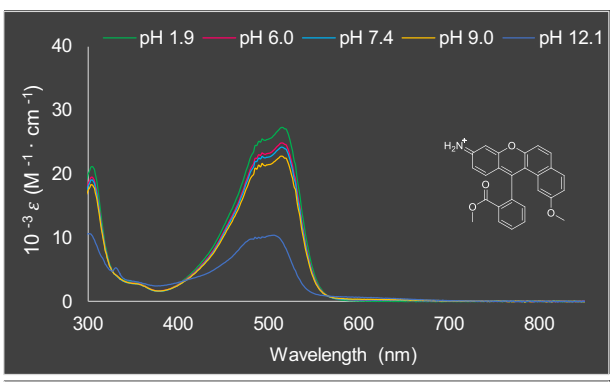

b)

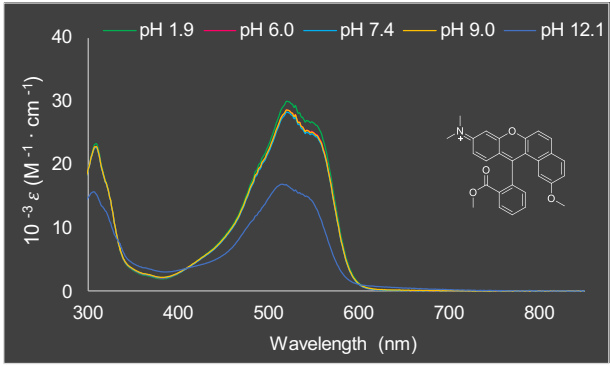

c)

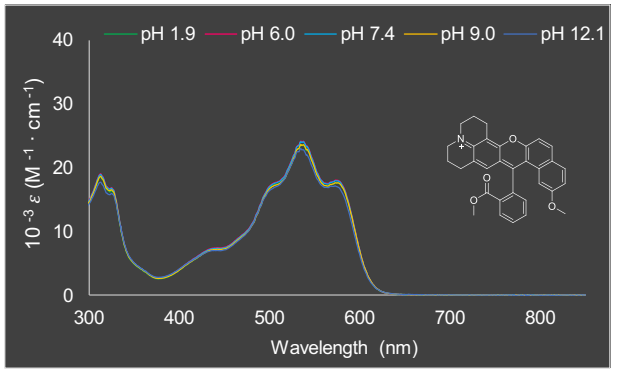

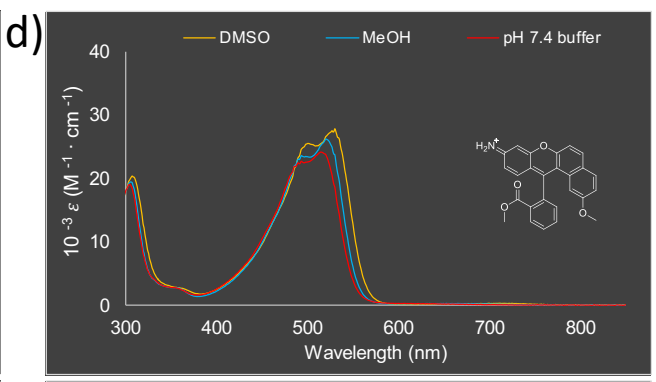

e)

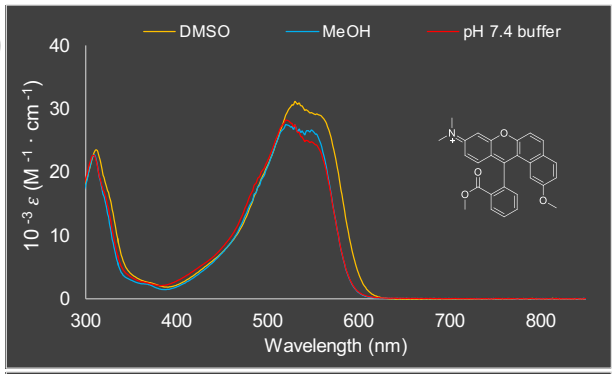

f)

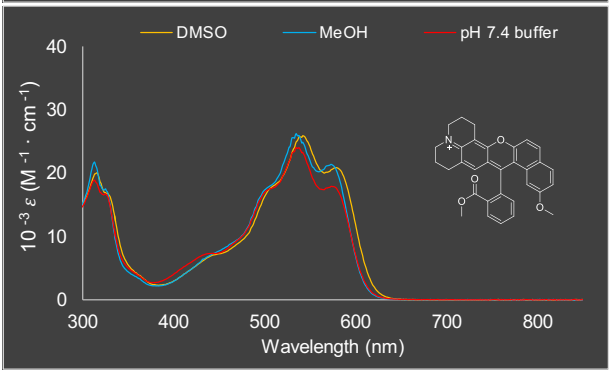

Figure A5. Absorption spectra of $\mathbf{p H}$ - and solvent-independent seminaphthorhodafluors $(2,5$, and 8$)$. (a-c) Absorption spectra as a function of $\mathrm{pH}$ for $\mathbf{2}$ (a), $\mathbf{5}$ (b), and $\mathbf{8}$ (c). (d-f) Absorption spectra as a function of solvents including DMSO, MeOH, and phosphate $\mathrm{pH} 7.4$ buffer for $\mathbf{2}$ (d), $\mathbf{5}$ (e), and $\mathbf{8}$ (f). Aqueous buffer solutions contain $10 \%$ DMSO and $12.5 \mathrm{mM} \mathrm{HCl}$, phosphate buffer, or $\mathrm{NaOH}$. No pH equilibria or solvatochromism behavior were observed for $\mathbf{2}, \mathbf{5}$, and $\mathbf{8}$. 

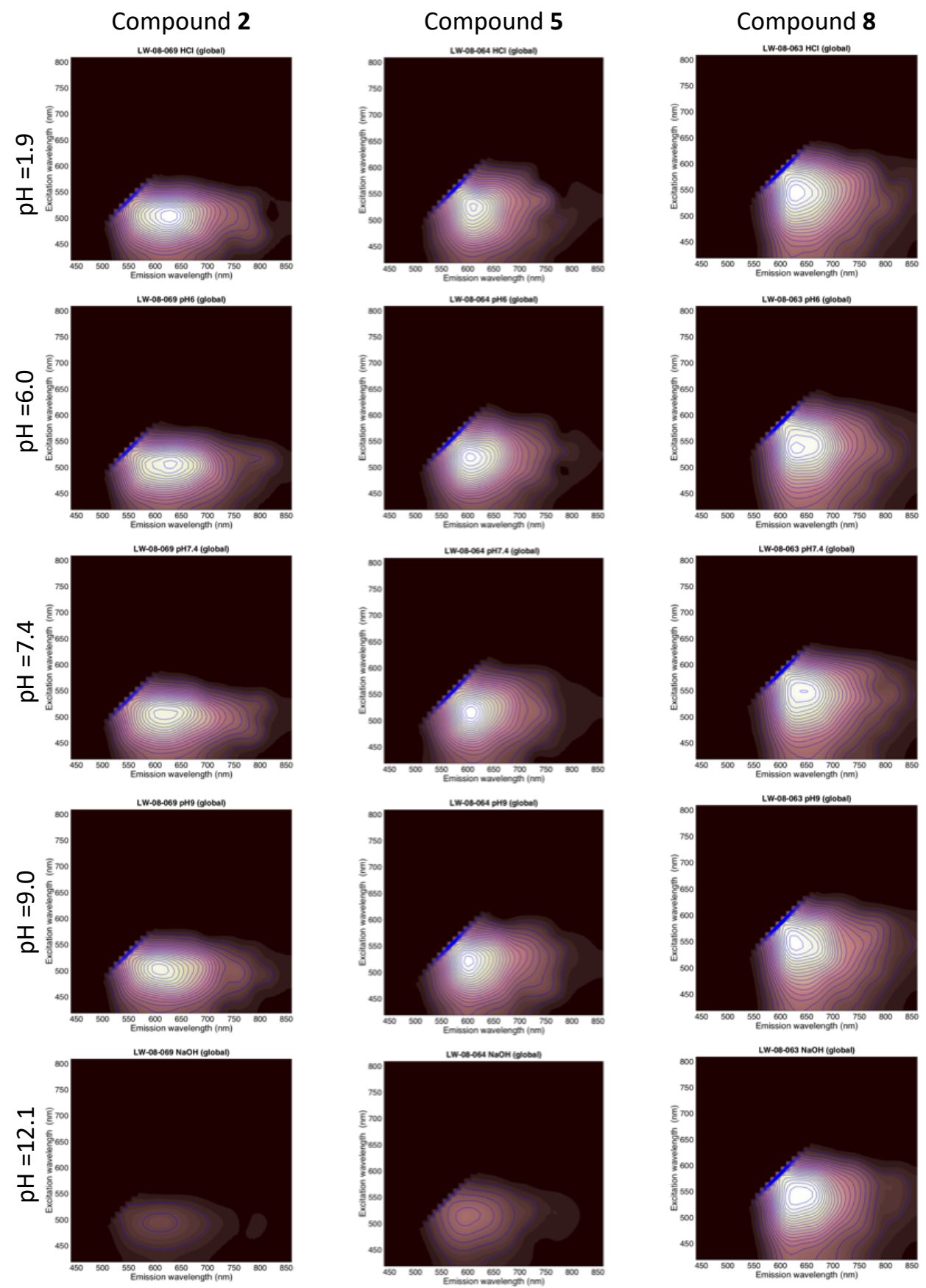

Figure A6. Excitation Emission Matrices (EEMs) of pH independent seminaphthorhodafluors (2, 5, and 8). Aqueous buffer solutions contain $10 \% \mathrm{DMSO}$ and $12.5 \mathrm{mM} \mathrm{HCl}$, phosphate buffer, or $\mathrm{NaOH}$. 
a)

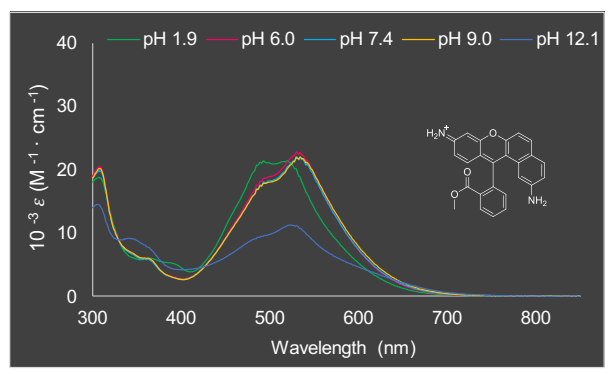

b)

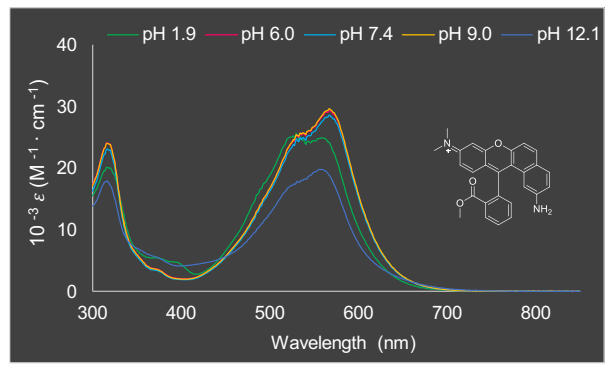

c)

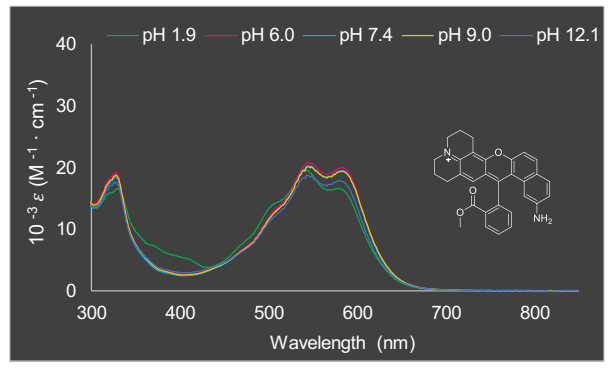

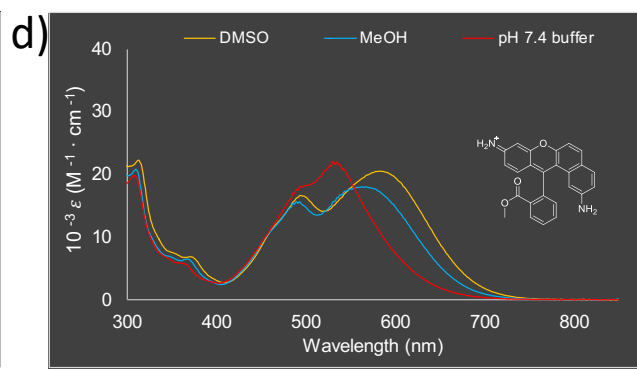

e)

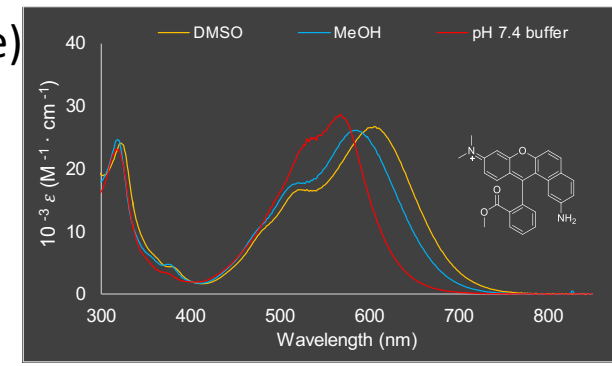

f)

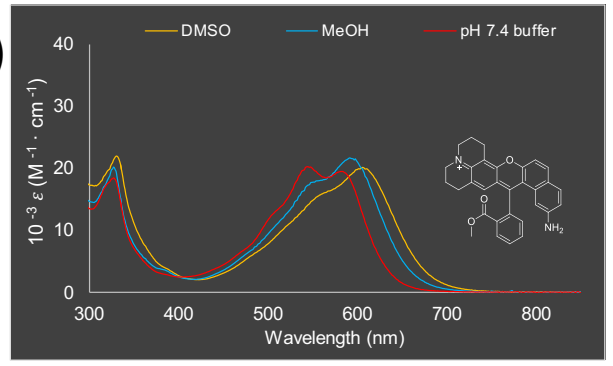

Figure A7. Absorption spectra of $\mathrm{pH}$-independent but solvent modest sensitive seminaphthorhodamines(3, 6, and 9). (a-c) Absorption spectra as a function of $\mathrm{pH}$ for 3 (a), 6 (b), and 9 (c). (d-f) Absorption spectra as a function of solvents including DMSO, MeOH, and phosphate $\mathrm{pH} 7.4$ buffer for 3 (d), 6 (e), and 9 (f). Aqueous buffer solutions contain $10 \%$ DMSO and $12.5 \mathrm{mM} \mathrm{HCl}$, phosphate buffer, or $\mathrm{NaOH}$. No $\mathrm{pH}$ equilibria behavior were observed for $\mathbf{3}, \mathbf{6}$, and $\mathbf{9}$, with moderate sensitivity to polarity with the longest wavelengths in DMSO and shortest in aqueous solution. 

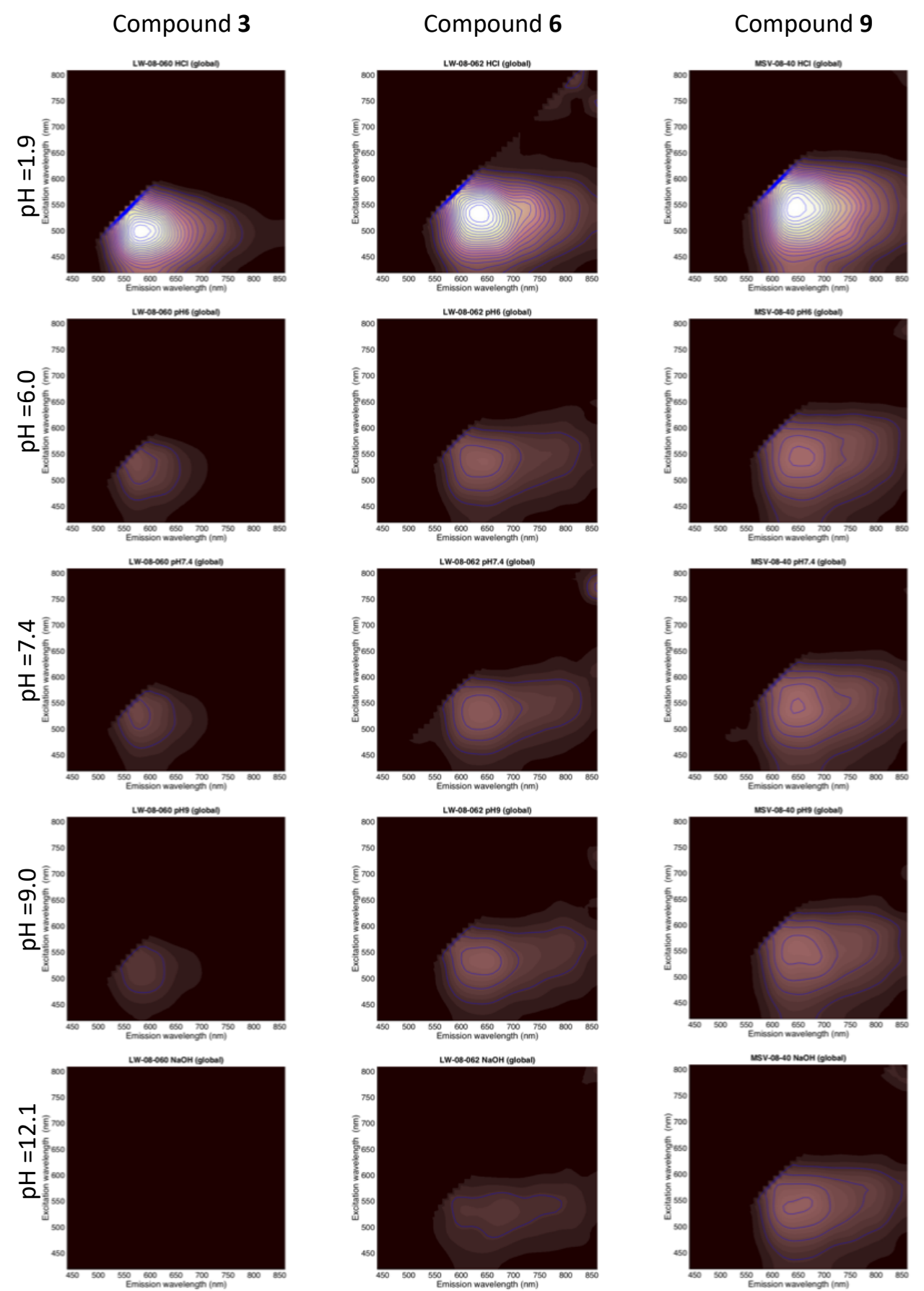

Figure A8. Excitation Emission Matrices (EEMs) of pH independent seminaphthorhodamines (3, 6, and 9). Aqueous buffer solutions contain 10\% DMSO and $12.5 \mathrm{mM} \mathrm{HCl}$, phosphate buffer, or $\mathrm{NaOH}$. 
HOMO
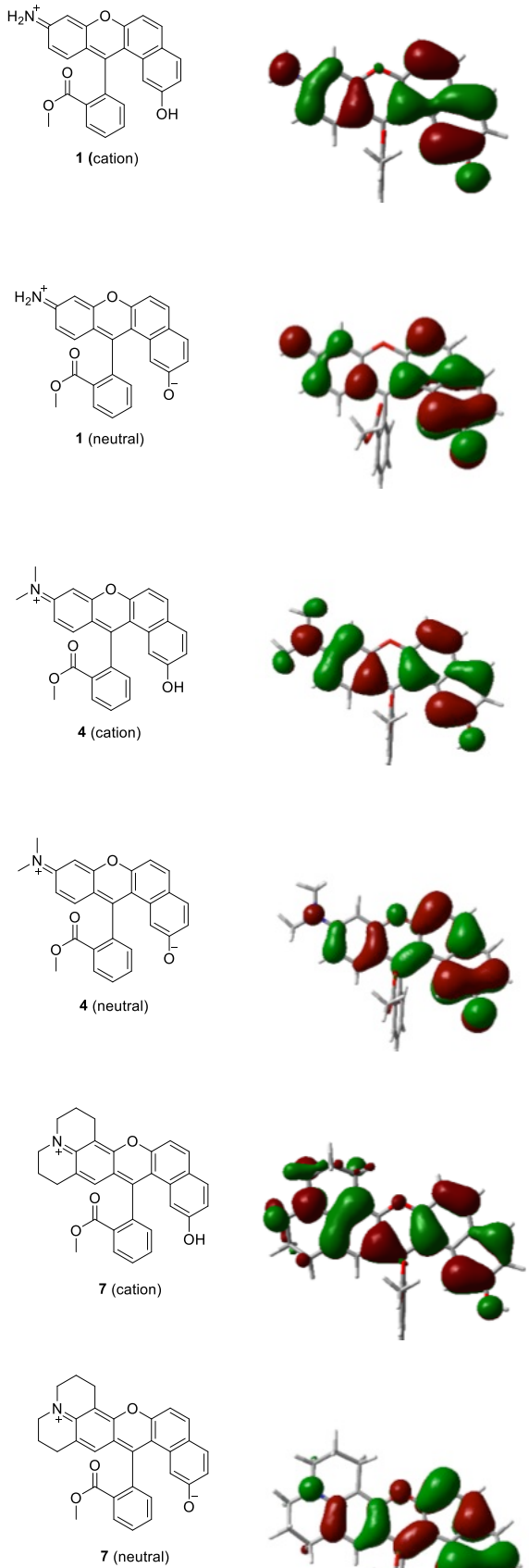

LUMO
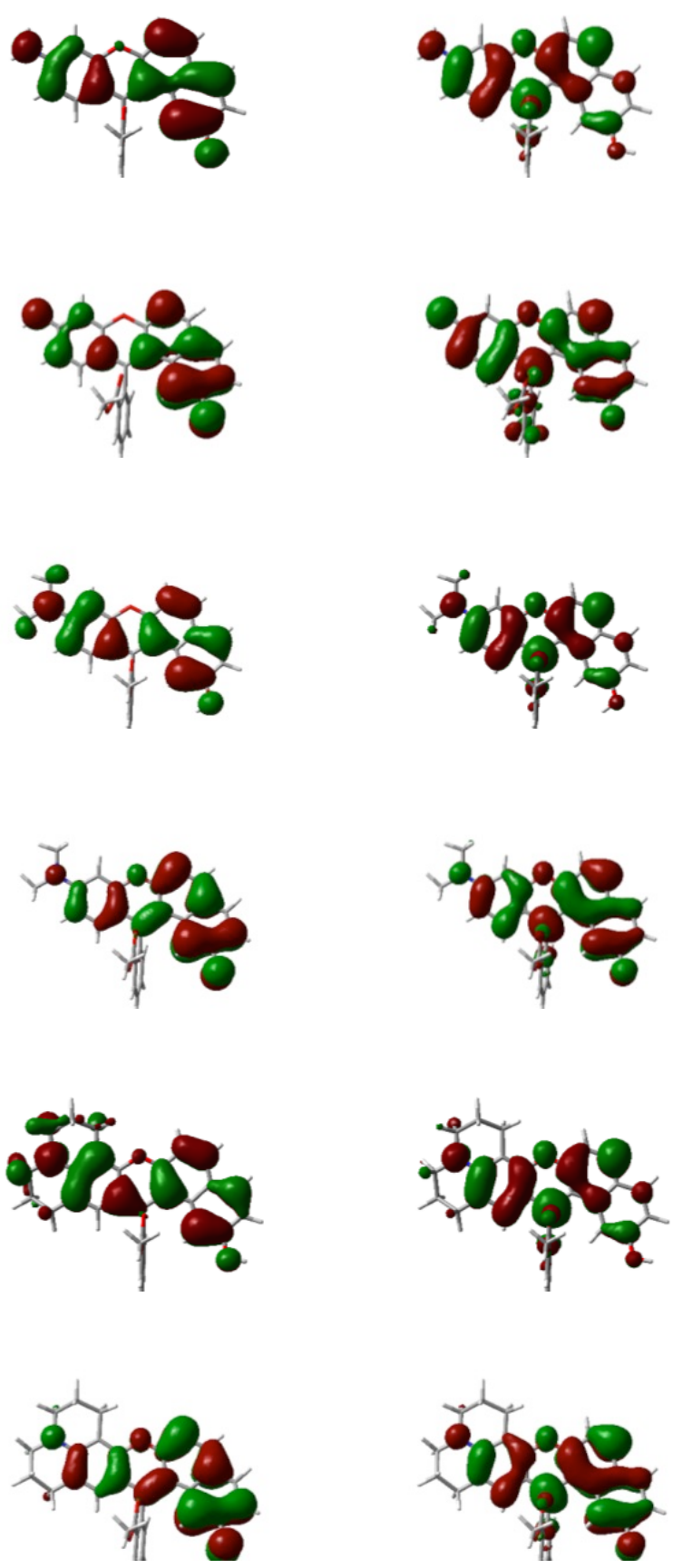

Figure A9. Calculated frontier molecular orbitals (HOMO and LUMO) for $\mathrm{pH}$-dependent seminaphthorhodafluors $(1,4$, and 7$)$ and their conjugate bases. 
HOMO
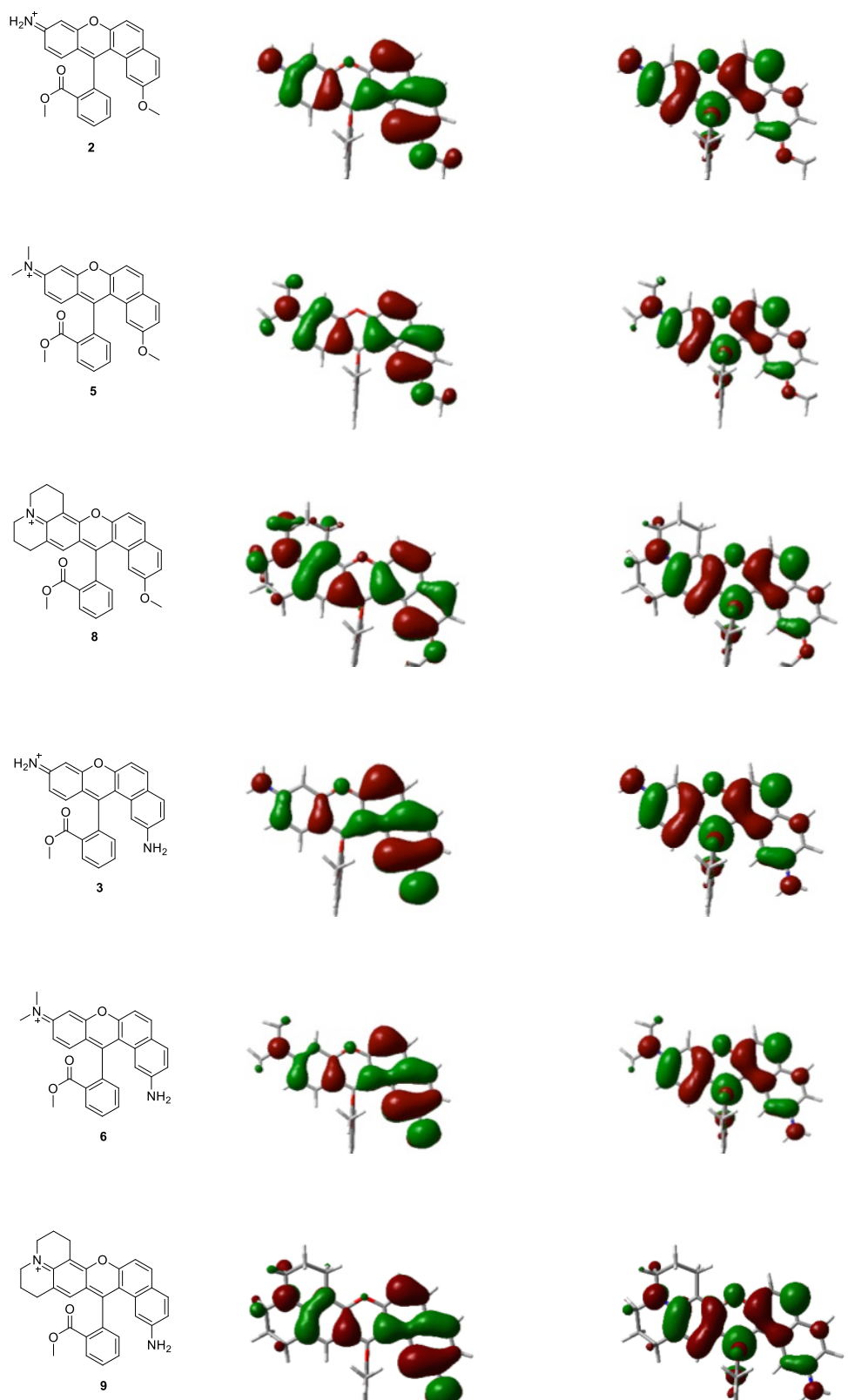

Figure A8. Calculated frontier molecular orbitals (HOMO and LUMO) for $\mathrm{pH}$-independent seminaphthorhodafluors $(2,5$, and 8$)$ and seminaphthorhodamines $(3,6$, and 9$)$. 
Table A2. Calculated HOMO and LUMO energies and their energy gaps for compounds 1-9 cations and 1, 4 and 7 neutral forms in the ground state.

\begin{tabular}{|c|c|c|c|}
\hline \multirow[t]{2}{*}{ Compound } & \multicolumn{3}{|c|}{ Energy (eV) } \\
\hline & НОМО & LUMO & Gap \\
\hline 1 cation & -8.8678 & -5.9445 & 2.9234 \\
\hline 1 neutral & -4.8924 & -2.7190 & 2.1734 \\
\hline 4 cation & -8.7242 & -5.8726 & 2.8515 \\
\hline 4 neutral & -4.7844 & -2.6249 & 2.1595 \\
\hline 7 cation & -8.3682 & -5.5703 & 2.7979 \\
\hline 7 neutral & -4.6982 & -2.5626 & 2.1356 \\
\hline 2 cation & -8.7005 & -5.8775 & 2.8230 \\
\hline 5 cation & -8.5152 & -5.7349 & 2.7803 \\
\hline 8 cation & -8.3818 & -5.5932 & 2.7887 \\
\hline 3 cation & -8.3974 & -5.8013 & 2.5960 \\
\hline 6 cation & -8.2648 & -5.6669 & 2.5979 \\
\hline 9 cation & -8.0757 & -5.4557 & 2.6200 \\
\hline
\end{tabular}


Table A3. Calculated dihedral angles for cations 1-9 and for the neutral forms of 1, 4, and 7 at $C_{(18-7-8-9)}$ and $C_{(7-8-9-10) \text {. }}$

\begin{tabular}{lll}
\hline Compound & \multicolumn{2}{c}{$\left(\phi,{ }^{\circ}\right)$} \\
\cline { 2 - 3 } & $\boldsymbol{C}_{(18-7-8-9)}$ & $\boldsymbol{C}_{(7-8-9-10)}$ \\
\hline 1 cation & -5.2 & -0.9 \\
4 cation & -4.2 & -0.4 \\
7 cation & -4.9 & -1.4 \\
2 cation & -5.2 & -1.2 \\
5 cation & -4.6 & -0.4 \\
8 cation & -5.6 & -3.1 \\
3 cation & -5.5 & -2.0 \\
6 cation & -5.6 & -1.9 \\
9 cation & -4.5 & 0.2 \\
1 neutral & -7.1 & -10.4 \\
4 neutral & -7.0 & -10.5 \\
7 neutral & -7.2 & -11.2 \\
\hline
\end{tabular}


Table A4. Calculated bond lengths for cations and neutral forms of compounds 1, 4, and 7 from carbon atoms (6-7-8-9-10-11).

\begin{tabular}{|c|c|c|c|}
\hline \multirow[t]{2}{*}{ Compound } & \multirow[t]{2}{*}{ Bond } & \multicolumn{2}{|c|}{ Bond Length } \\
\hline & & $\begin{array}{c}\text { cation } \\
(\mathbf{p m})\end{array}$ & $\begin{array}{c}\text { neutral } \\
\text { (pm) }\end{array}$ \\
\hline \multirow[t]{5}{*}{1} & C6-C7 & 142 & 145 \\
\hline & C7-C8 & 143 & 140 \\
\hline & C8-C9 & 147 & 149 \\
\hline & C9-C10 & 141 & 138 \\
\hline & $\mathrm{C} 10-\mathrm{C} 11$ & 139 & 146 \\
\hline \multirow[t]{5}{*}{4} & C6-C7 & 141 & 144 \\
\hline & $\mathrm{C} 7-\mathrm{C} 8$ & 143 & 140 \\
\hline & C8-C9 & 147 & 149 \\
\hline & C9-C10 & 141 & 138 \\
\hline & $\mathrm{C} 10-\mathrm{C} 11$ & 139 & 146 \\
\hline \multirow[t]{5}{*}{7} & C6-C7 & 141 & 144 \\
\hline & $\mathrm{C} 7-\mathrm{C} 8$ & 143 & 140 \\
\hline & C8-C9 & 147 & 149 \\
\hline & C9-C10 & 141 & 138 \\
\hline & C10-C11 & 139 & 146 \\
\hline
\end{tabular}



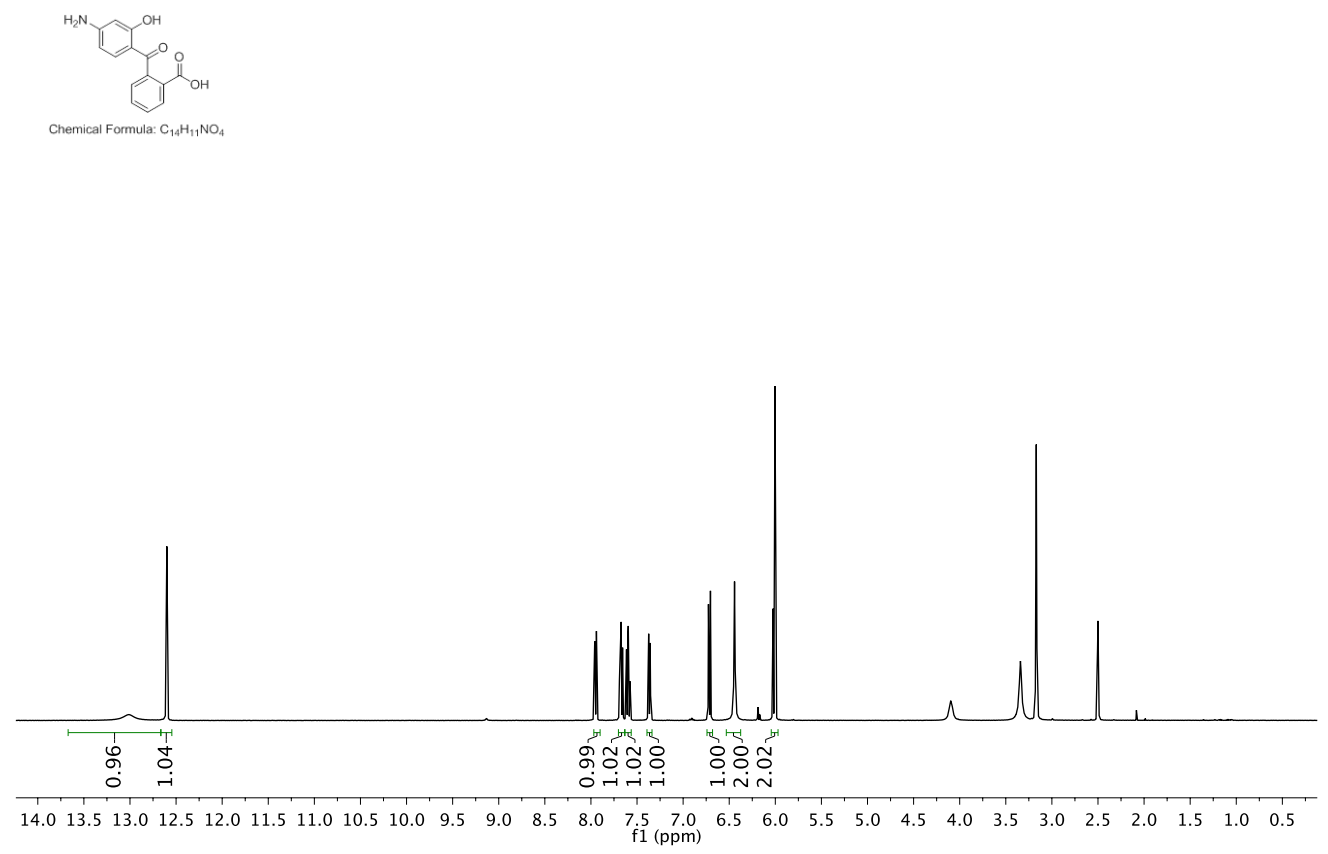

Figure A9. ${ }^{1} \mathrm{H}$ NMR spectrum of compound 11.
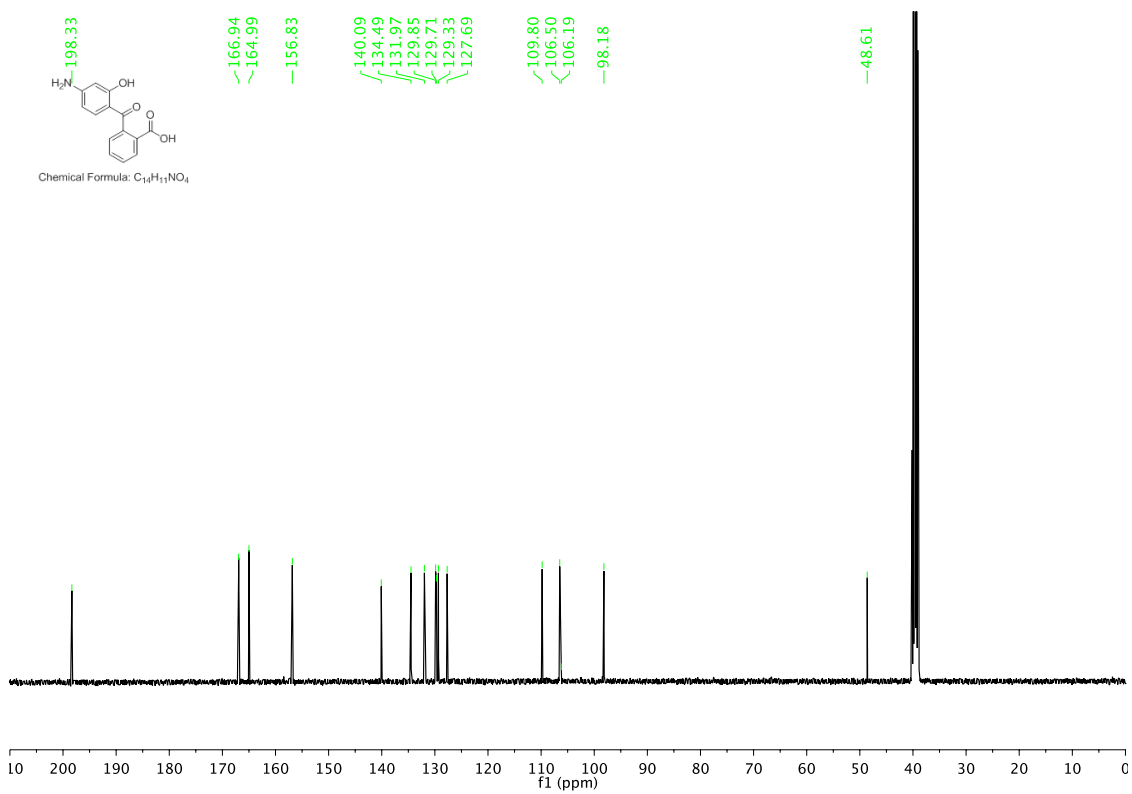

Figure A10. ${ }^{13} \mathrm{C}$ NMR spectrum of compound 11. 


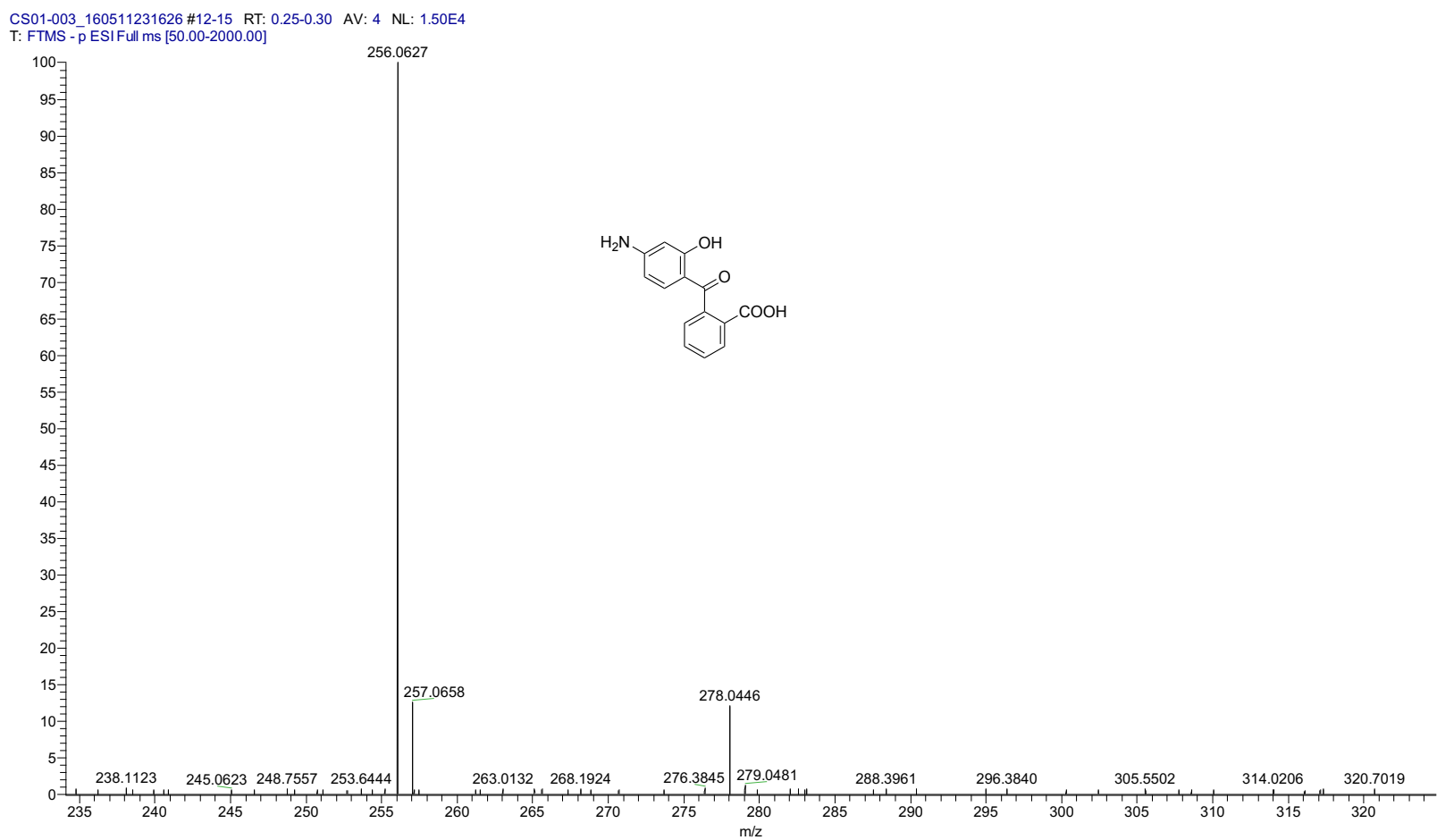

Figure A11. HR ESI positive mode spectrum of compound 11.

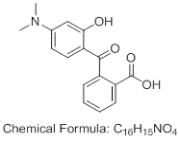

Chemical Formula: $\mathrm{C}_{13} \mathrm{H}_{15} \mathrm{NO}$

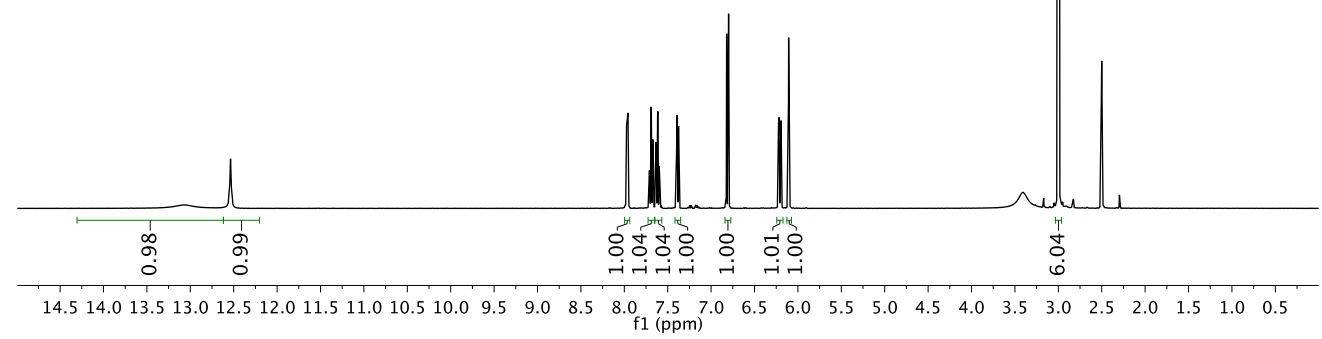

Figure A12. ${ }^{1} \mathrm{H}$ NMR spectrum of compound 20. 


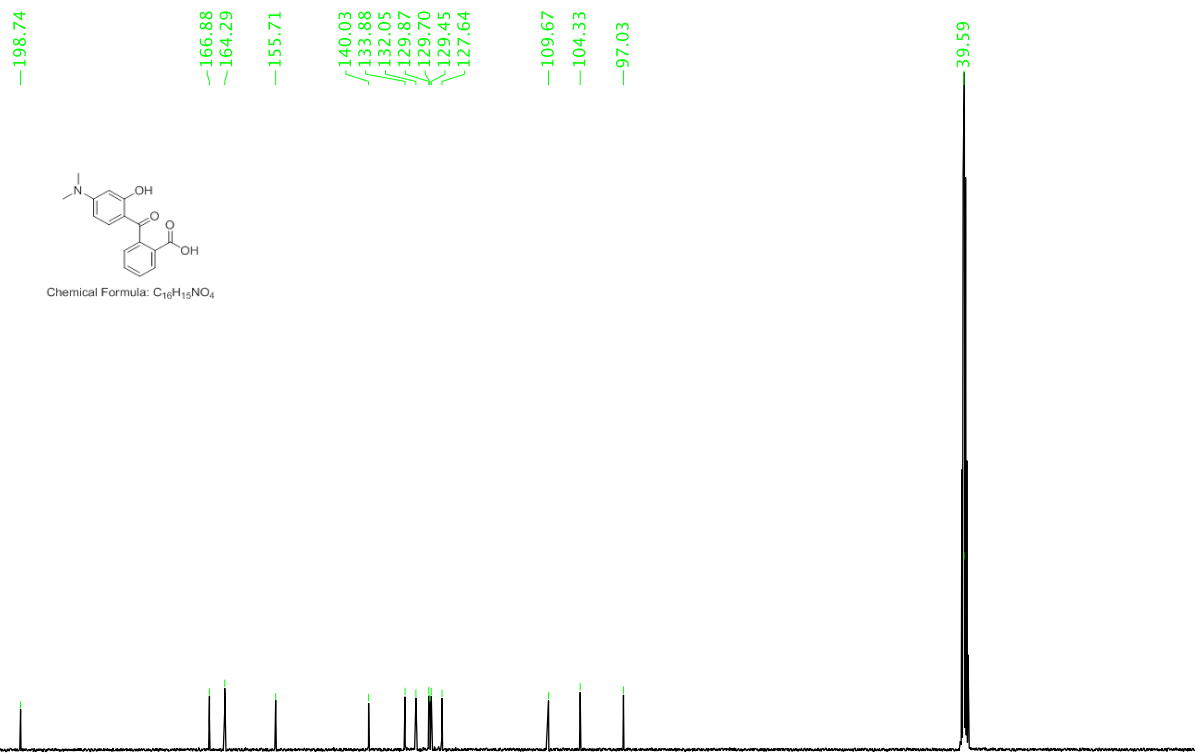

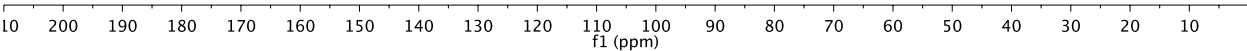

Figure A13. ${ }^{13} \mathrm{C}$ NMR spectrum of compound 20.

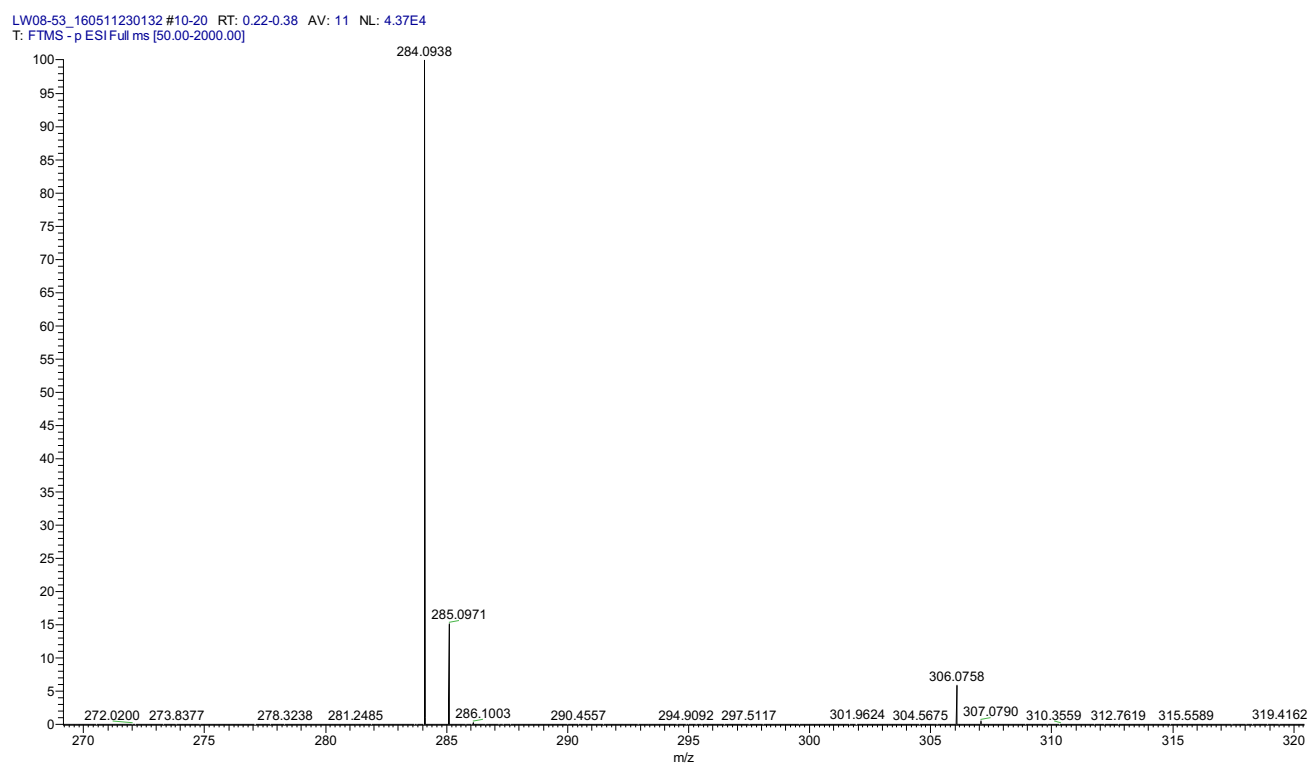

Figure A14. HR ESI positive mode spectrum of compound 20. 


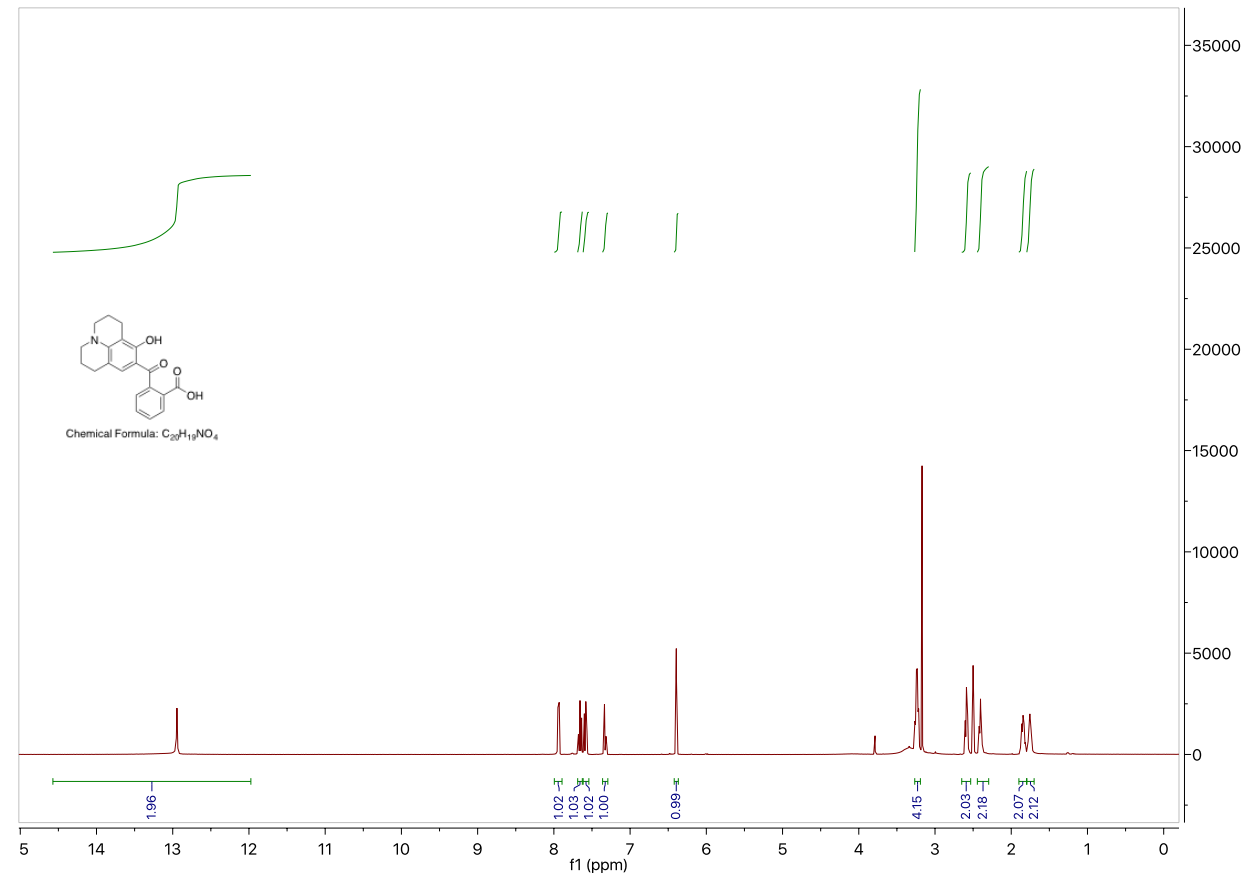

Figure A15. ${ }^{1} \mathrm{H}$ NMR spectrum of compound 25. 


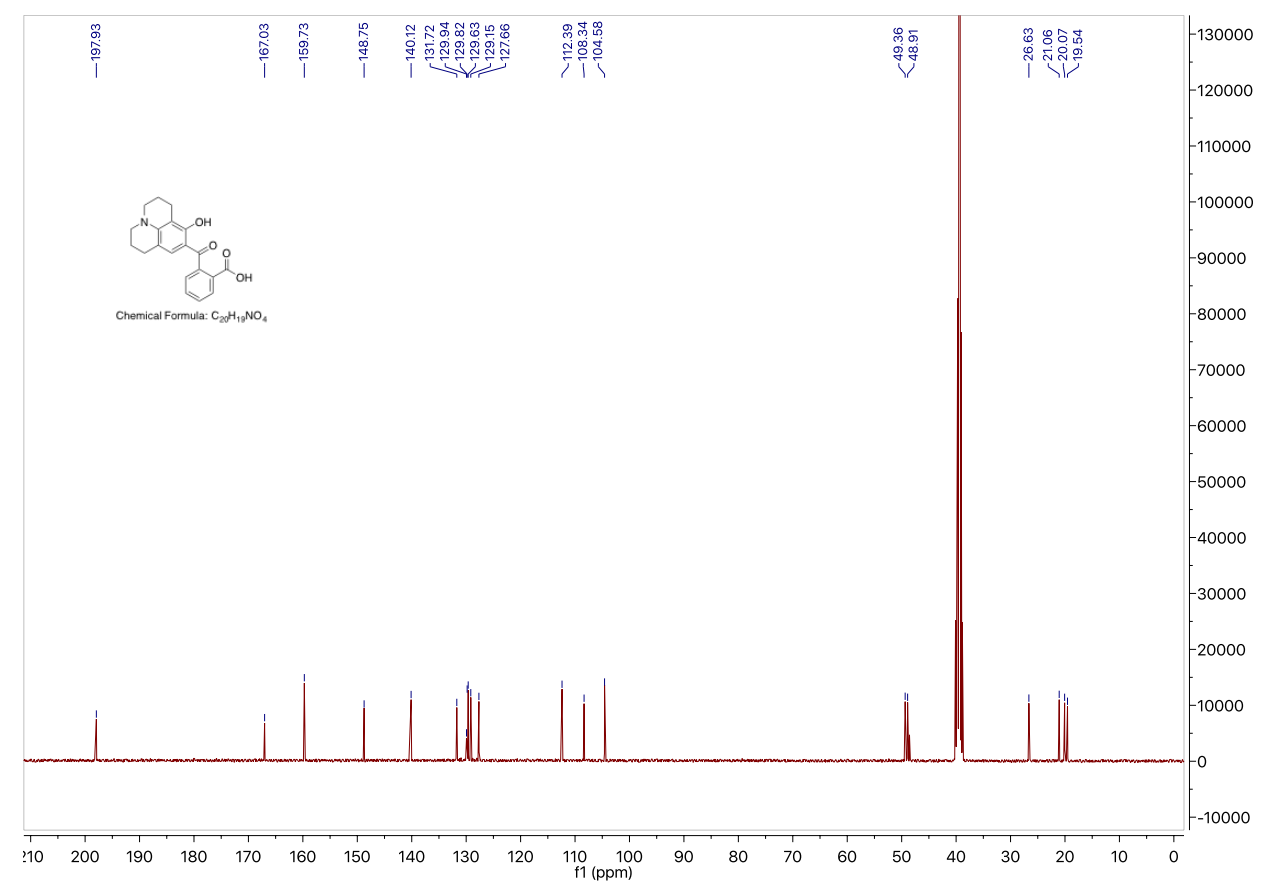

Figure A6. ${ }^{13} \mathrm{C}$ NMR spectrum of compound 25.

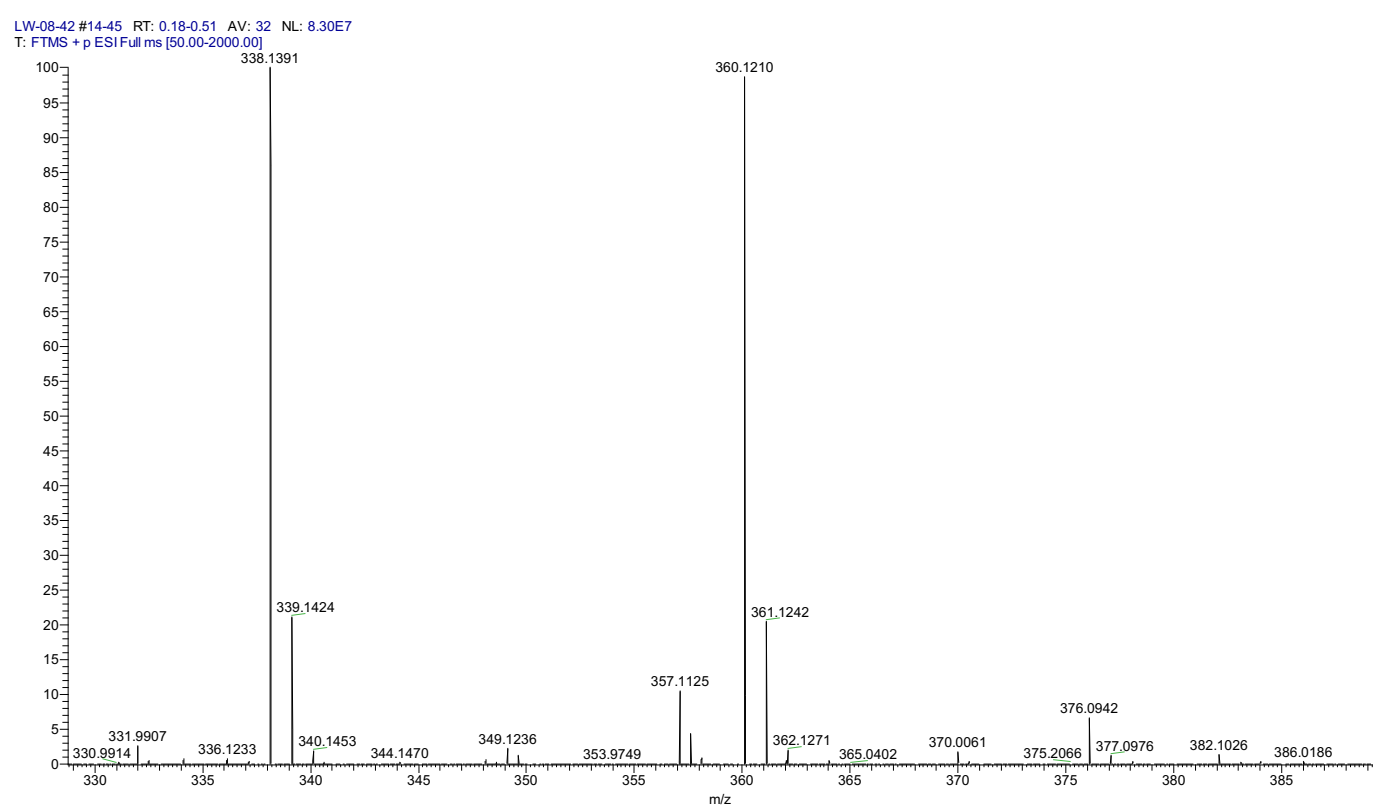

Figure A17. HR ESI positive mode spectrum of compound 25. 


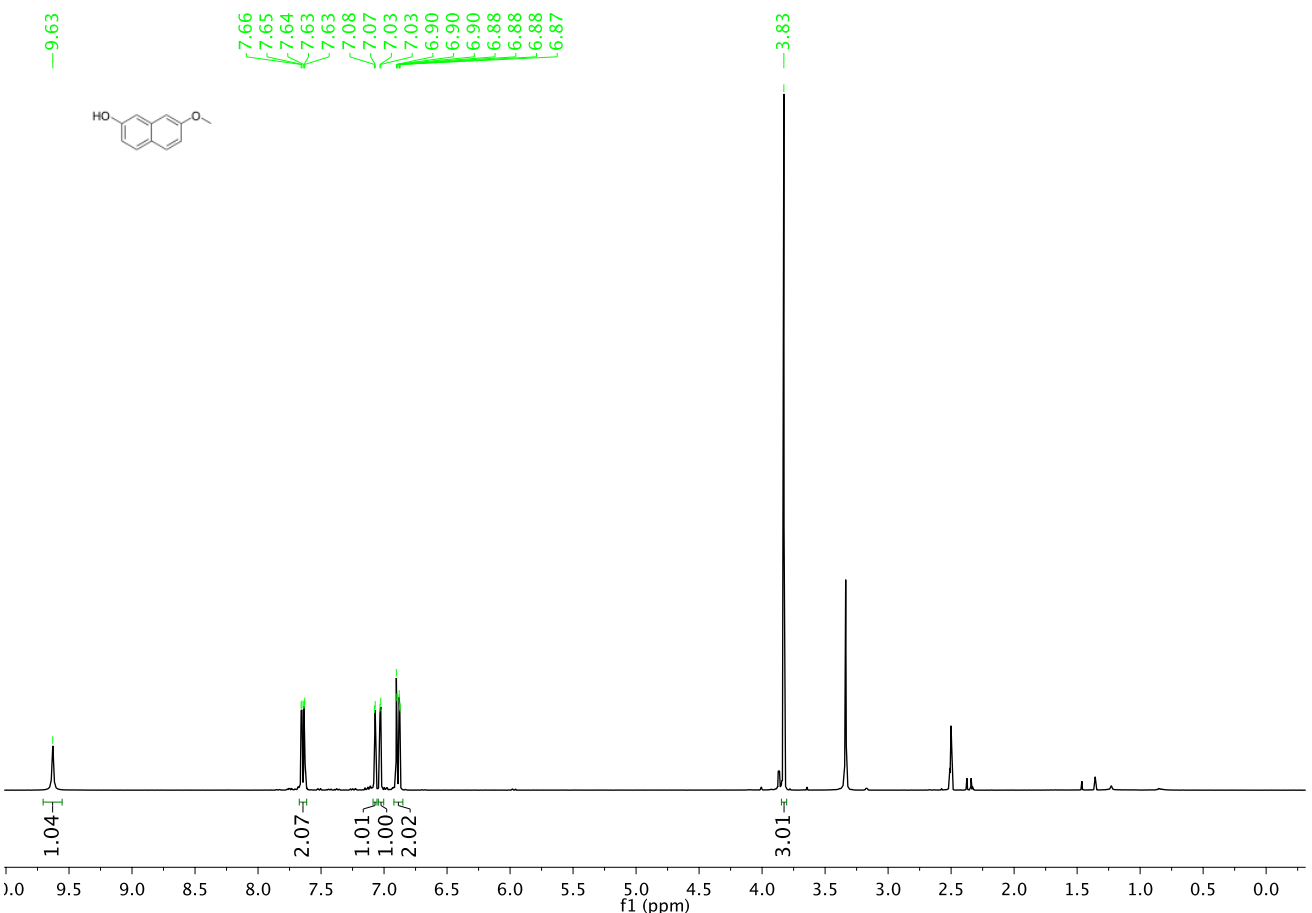

Figure A18. ${ }^{1} \mathrm{H}$ NMR spectrum of compound 13 . 


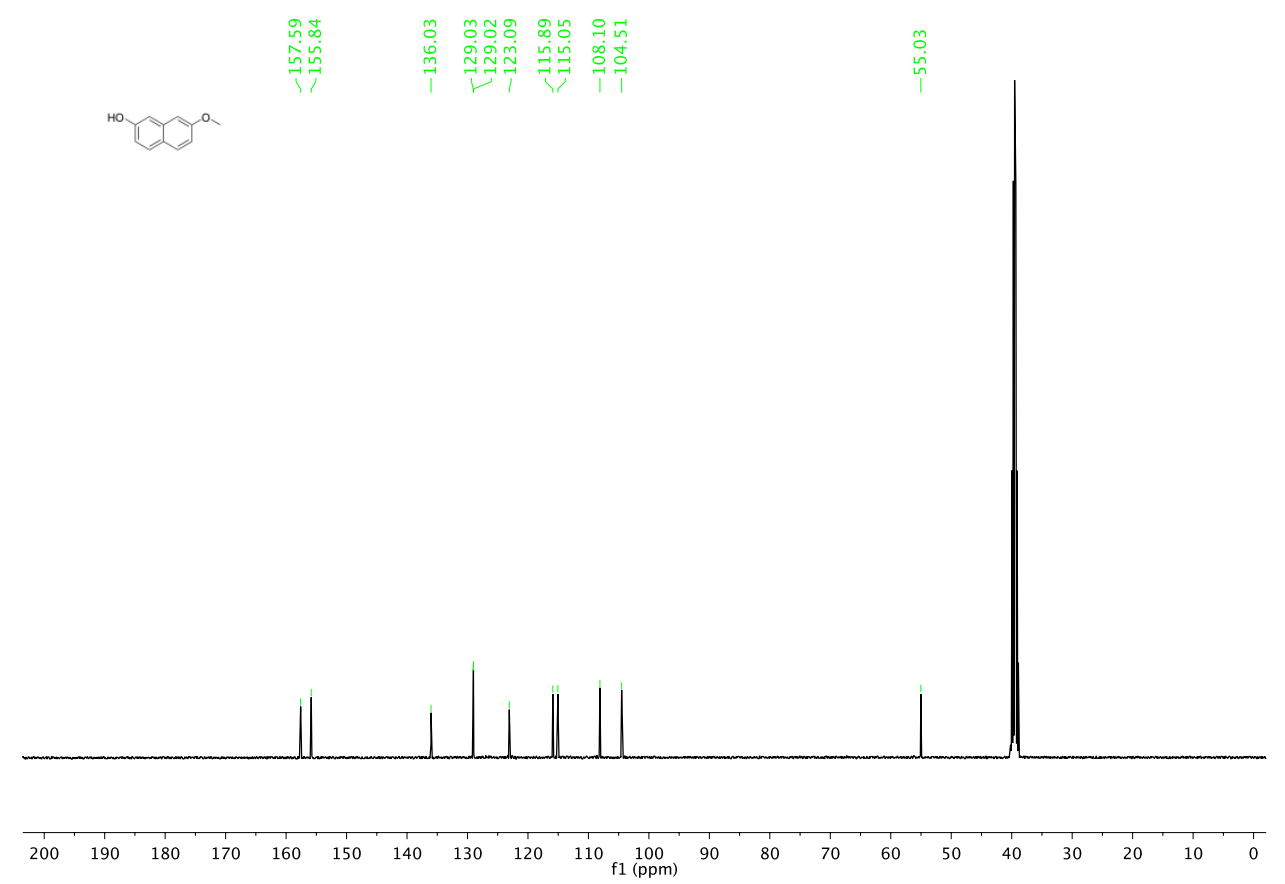

Figure A19. ${ }^{13} \mathrm{C}$ NMR spectrum of compound 13.

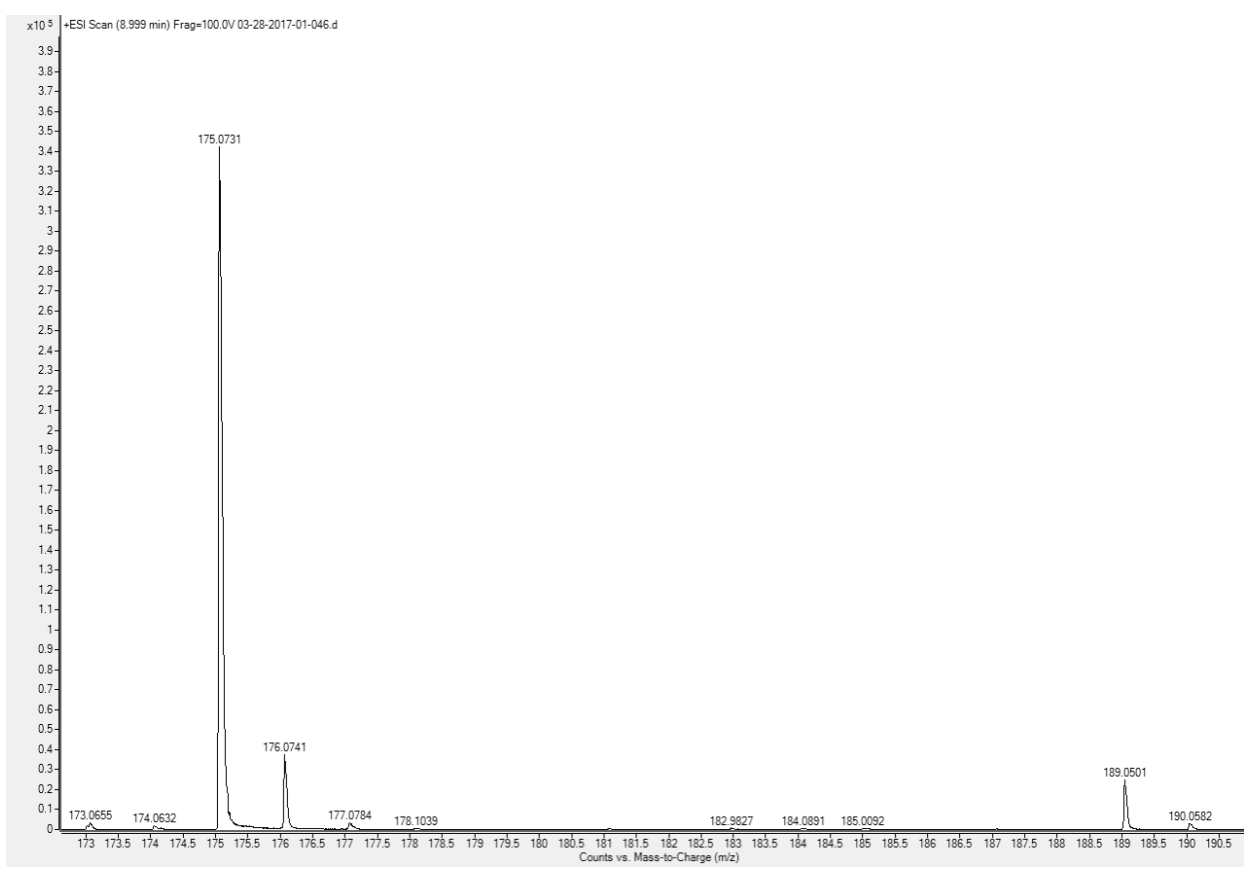

Figure A20. HR ESI positive mode spectrum of compound 13. 


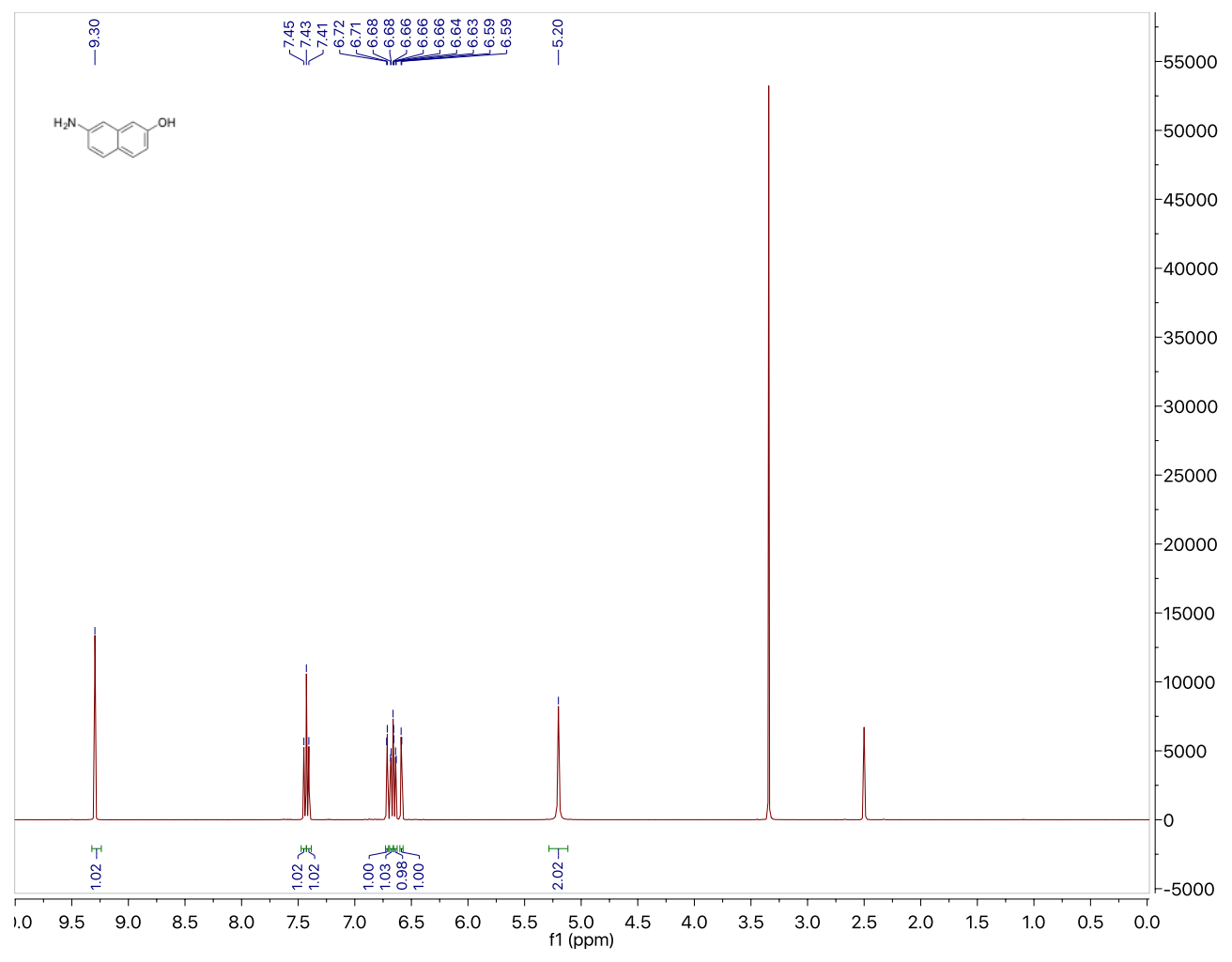

Figure A21. ${ }^{1} \mathrm{H}$ NMR spectrum of compound 14. 


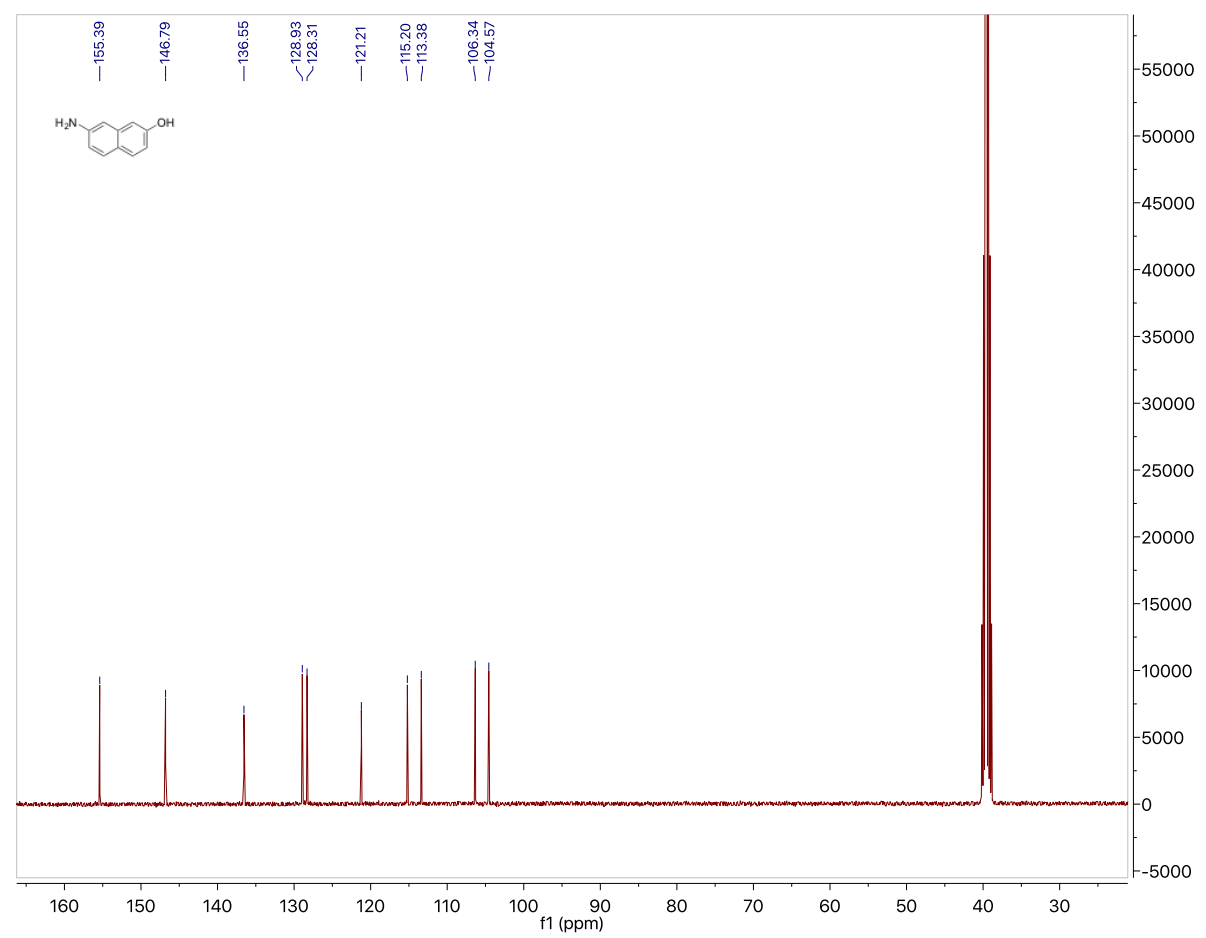

Figure A22. ${ }^{13} \mathrm{C}$ NMR spectrum of compound 14.

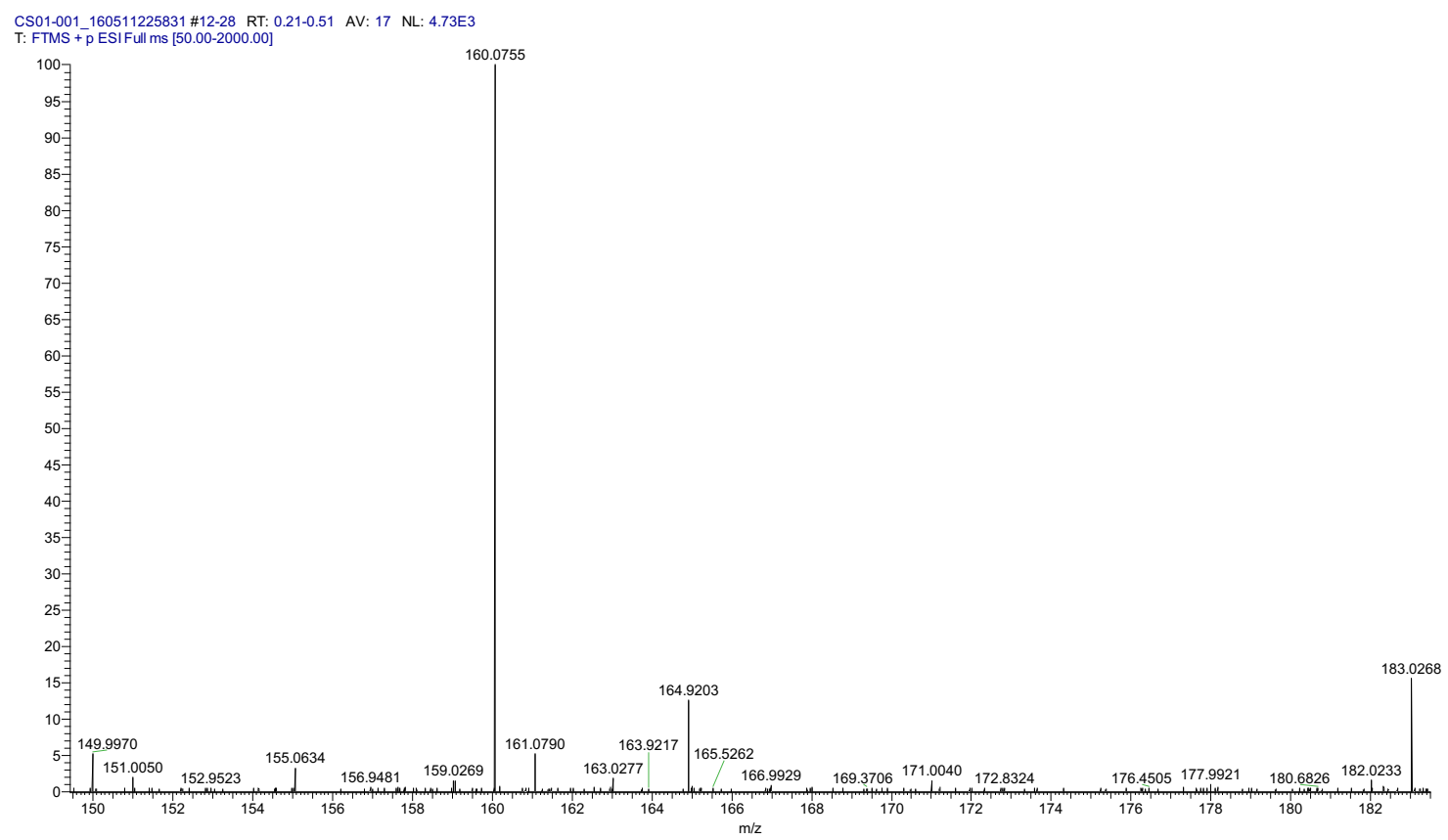

Figure A23. HR ESI positive mode spectrum of compound 14. 


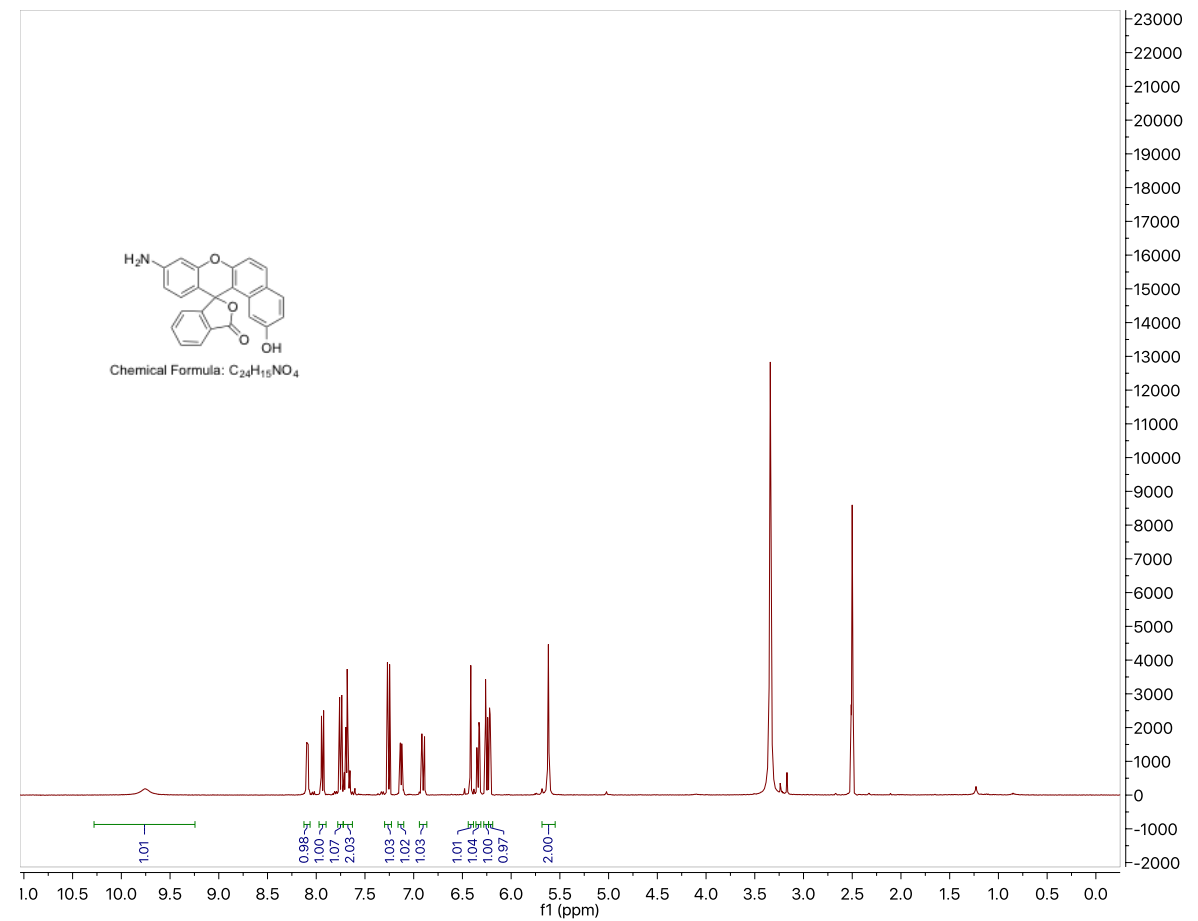

Figure A24. ${ }^{1} \mathrm{H}$ NMR spectrum of compound 15. 


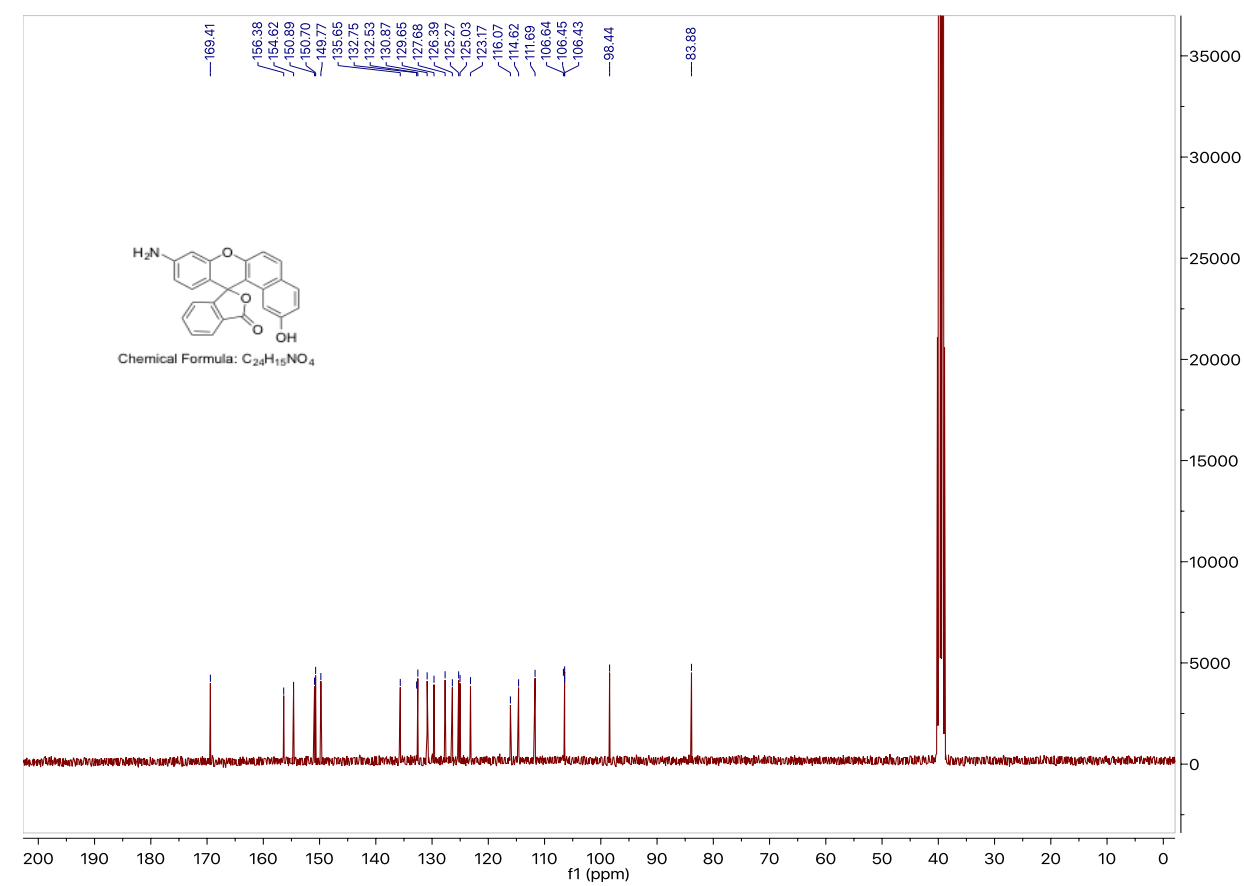

Figure A25. ${ }^{13} \mathrm{C}$ NMR spectrum of compound 15.

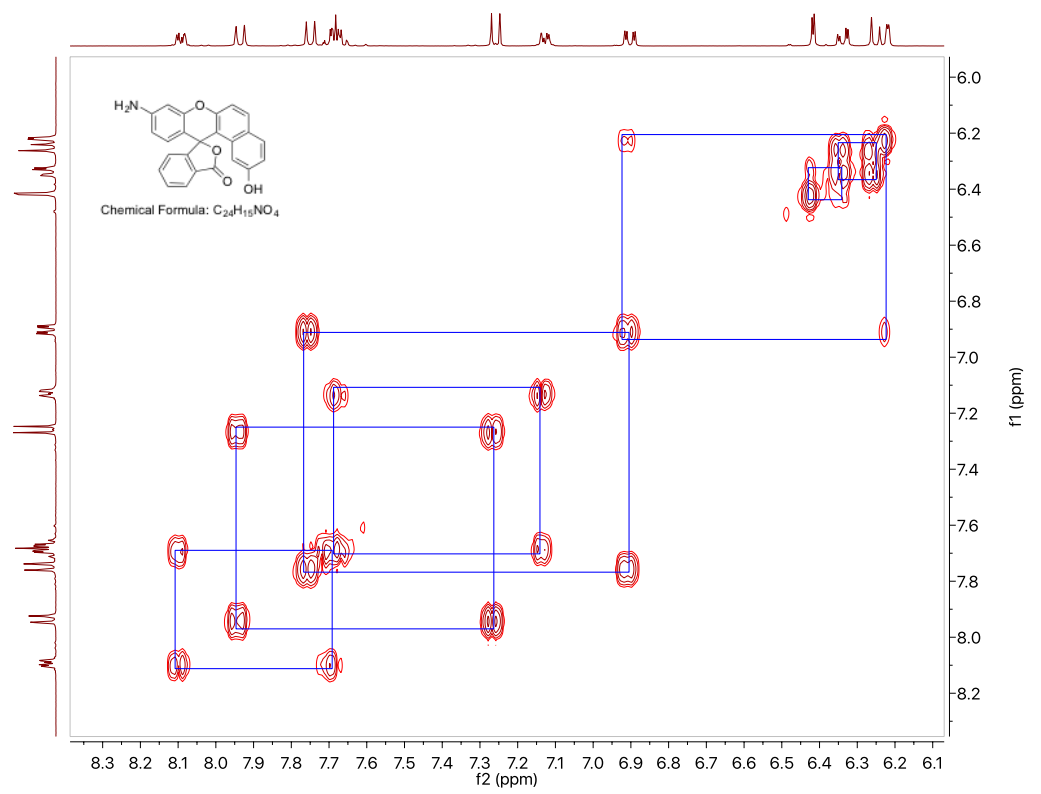

Figure A26. 2D COSY NMR spectrum for compound 15. 


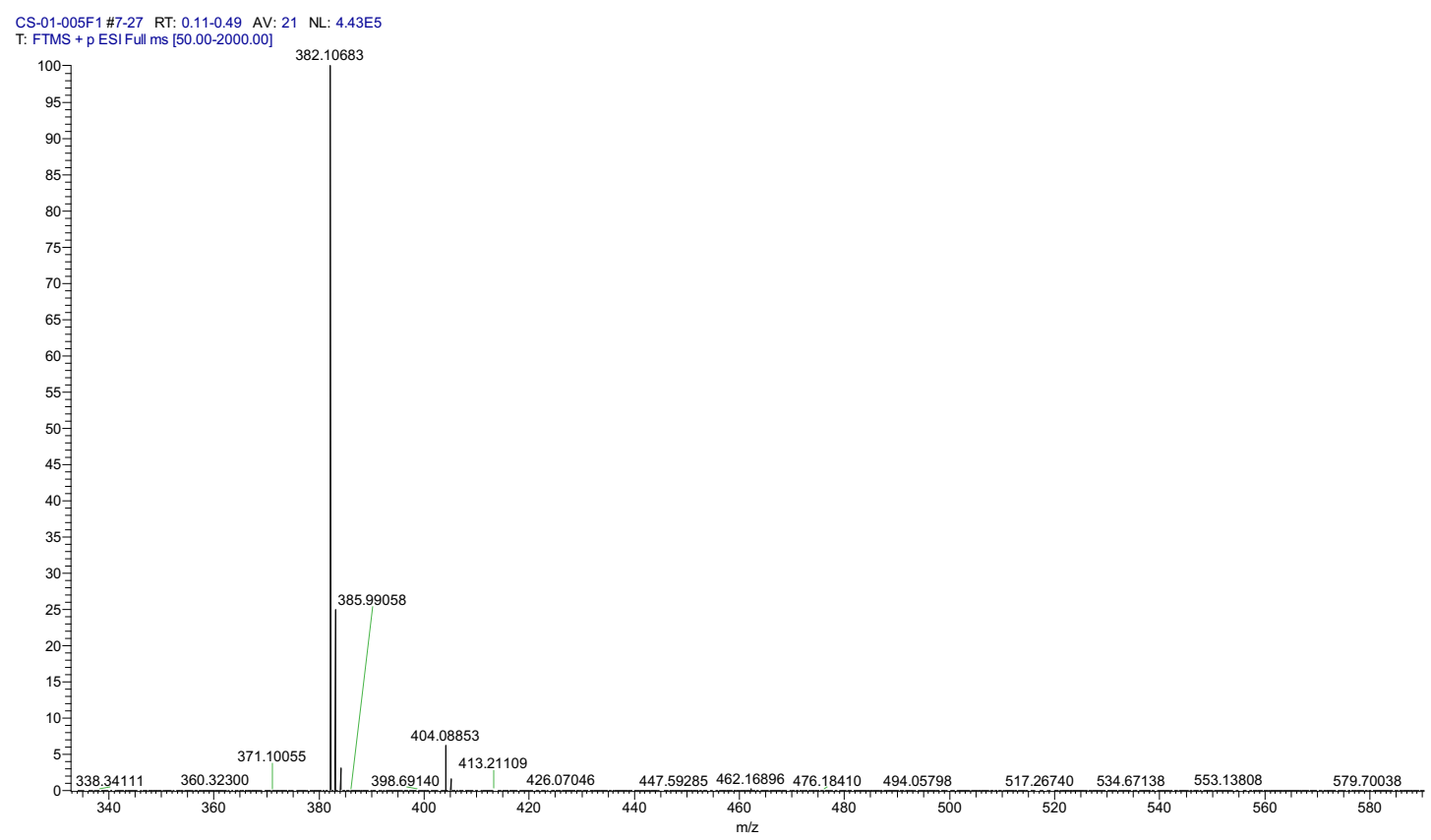

Figure A27. HR ESI positive mode spectrum of compound 15.

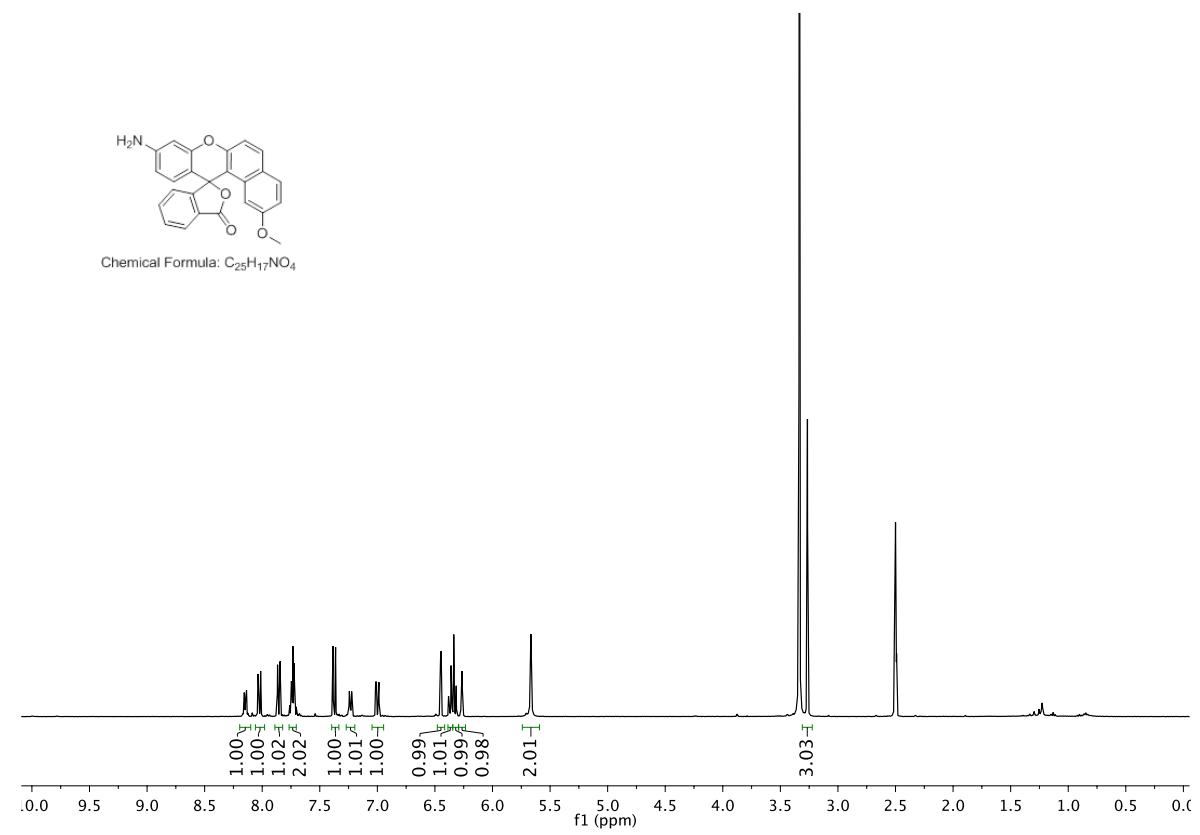

Figure A28. ${ }^{1} \mathrm{H}$ NMR spectrum of compound 16. 


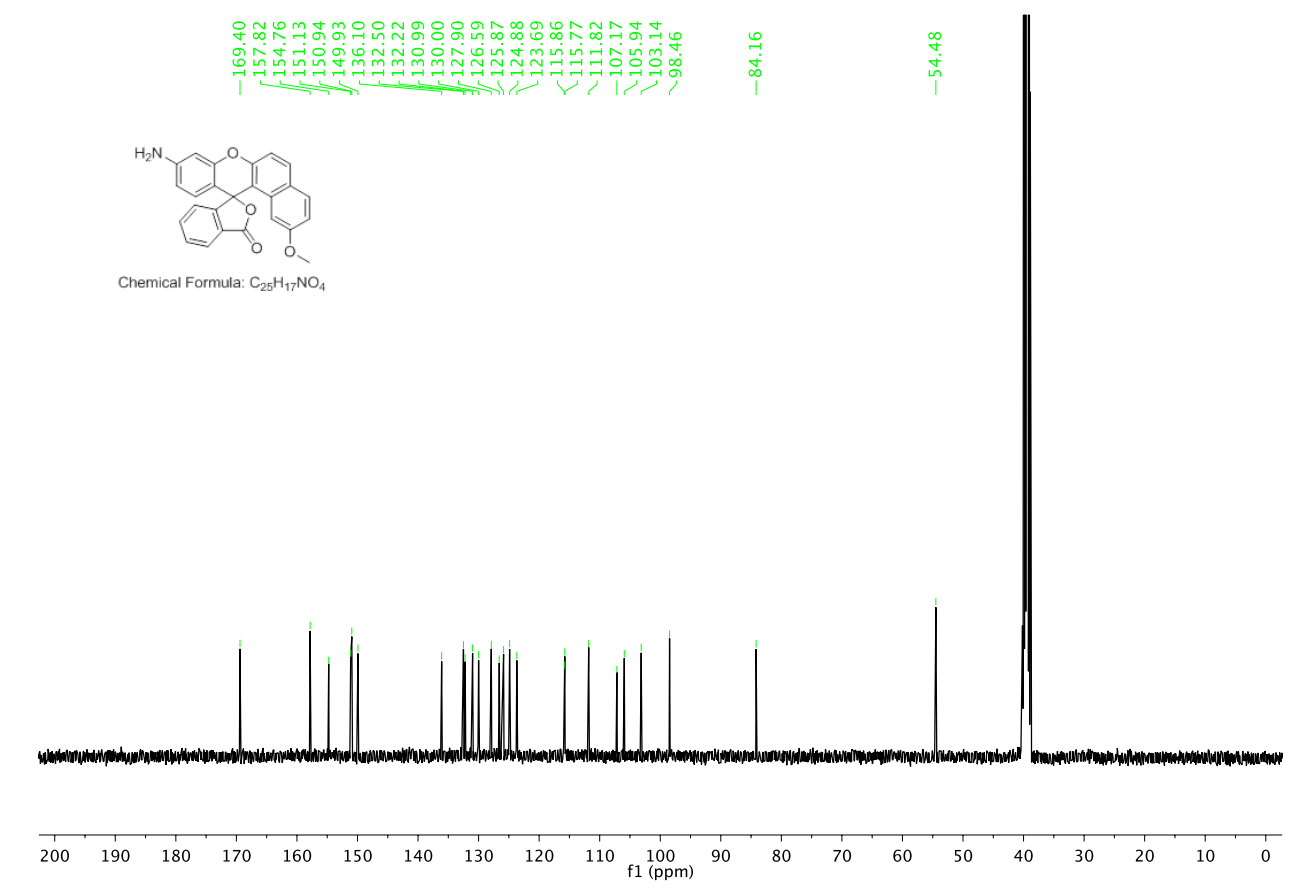

Figure A29. ${ }^{13} \mathrm{C}$ NMR spectrum of compound 16. 


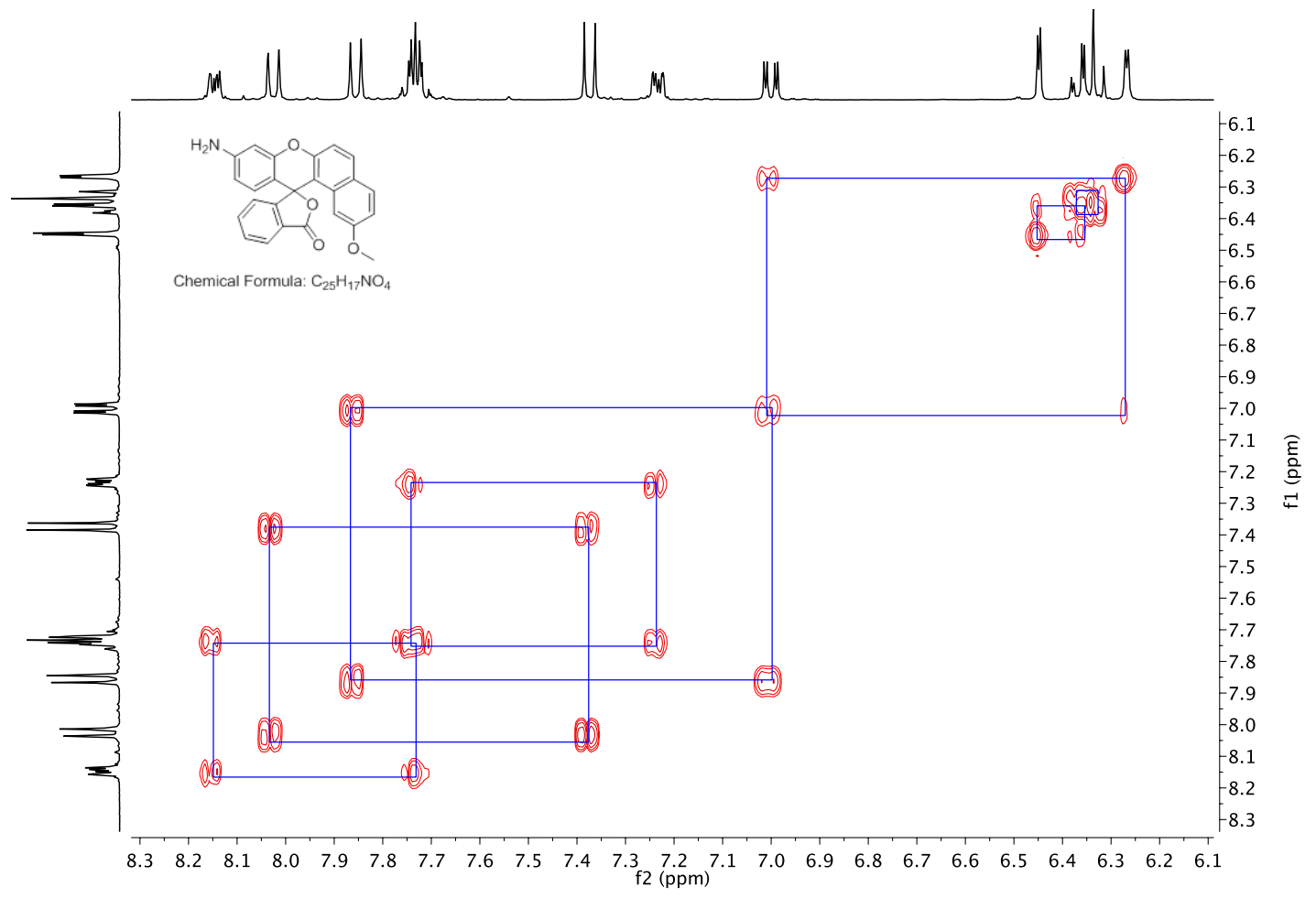

Figure A30. 2D COSY NMR spectrum for compound $\mathbf{1 6 .}$

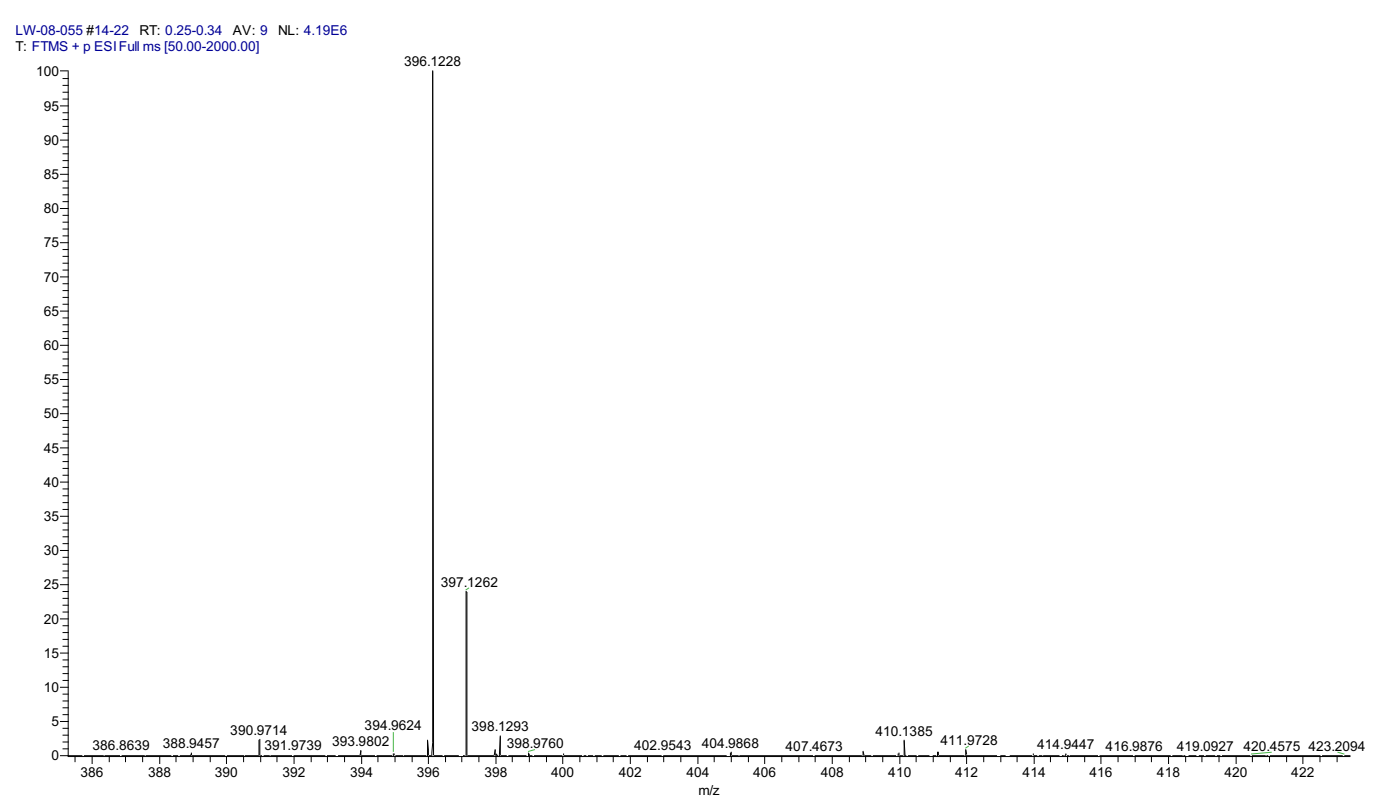

Figure A31. HR ESI positive mode spectrum of compound 16. 


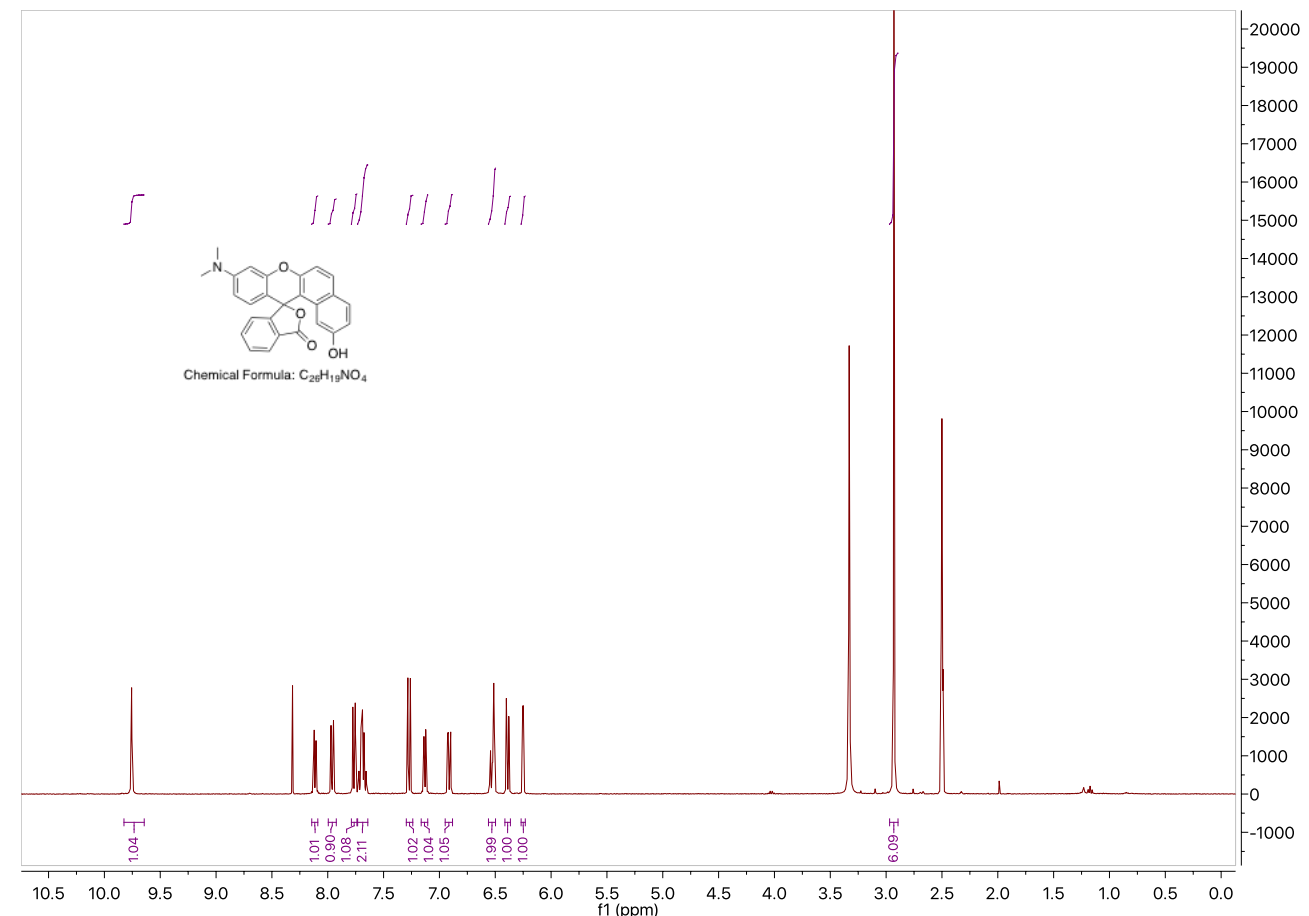

Figure A32. ${ }^{1} \mathrm{H}$ NMR spectrum of compound 21. 


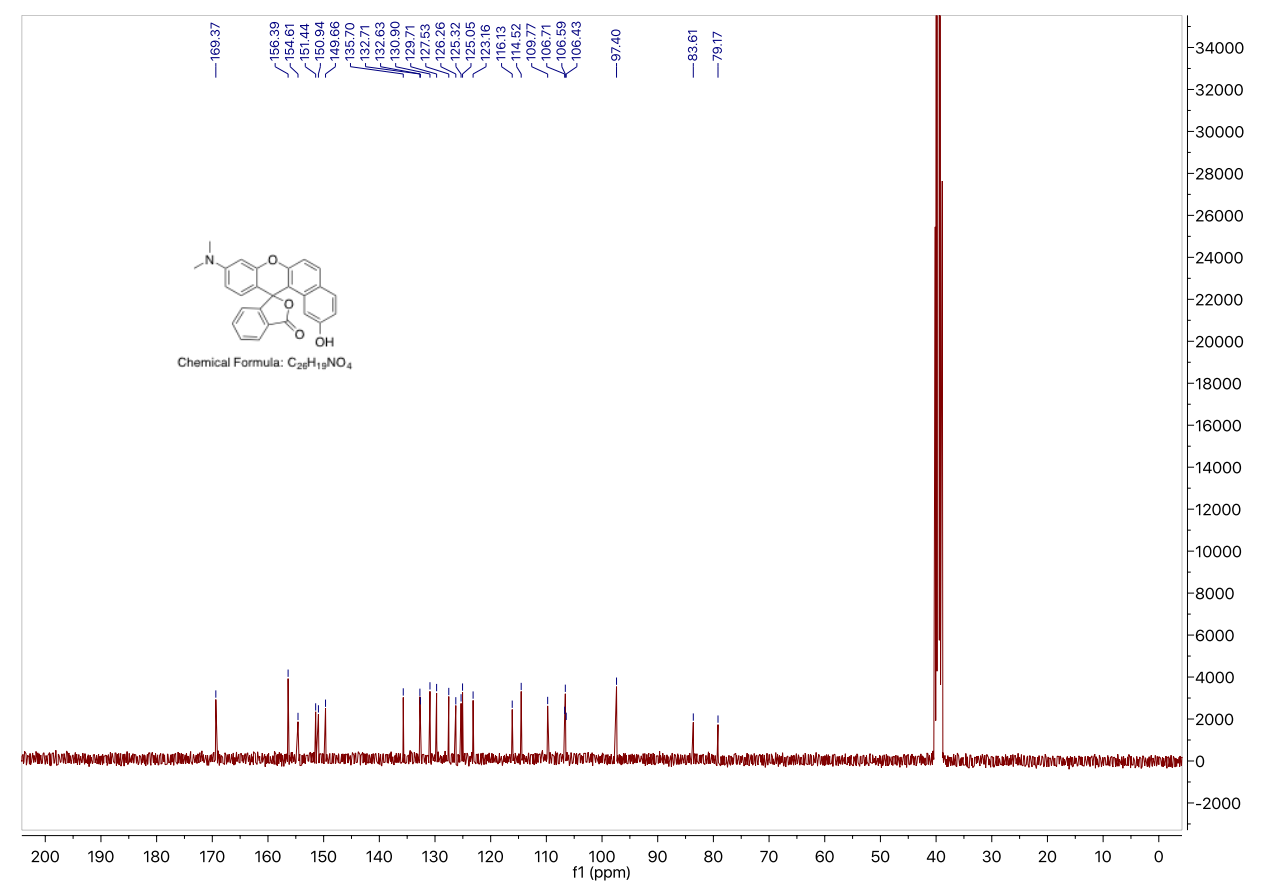

Figure A33. ${ }^{13} \mathrm{C}$ NMR spectrum of compound 21. 


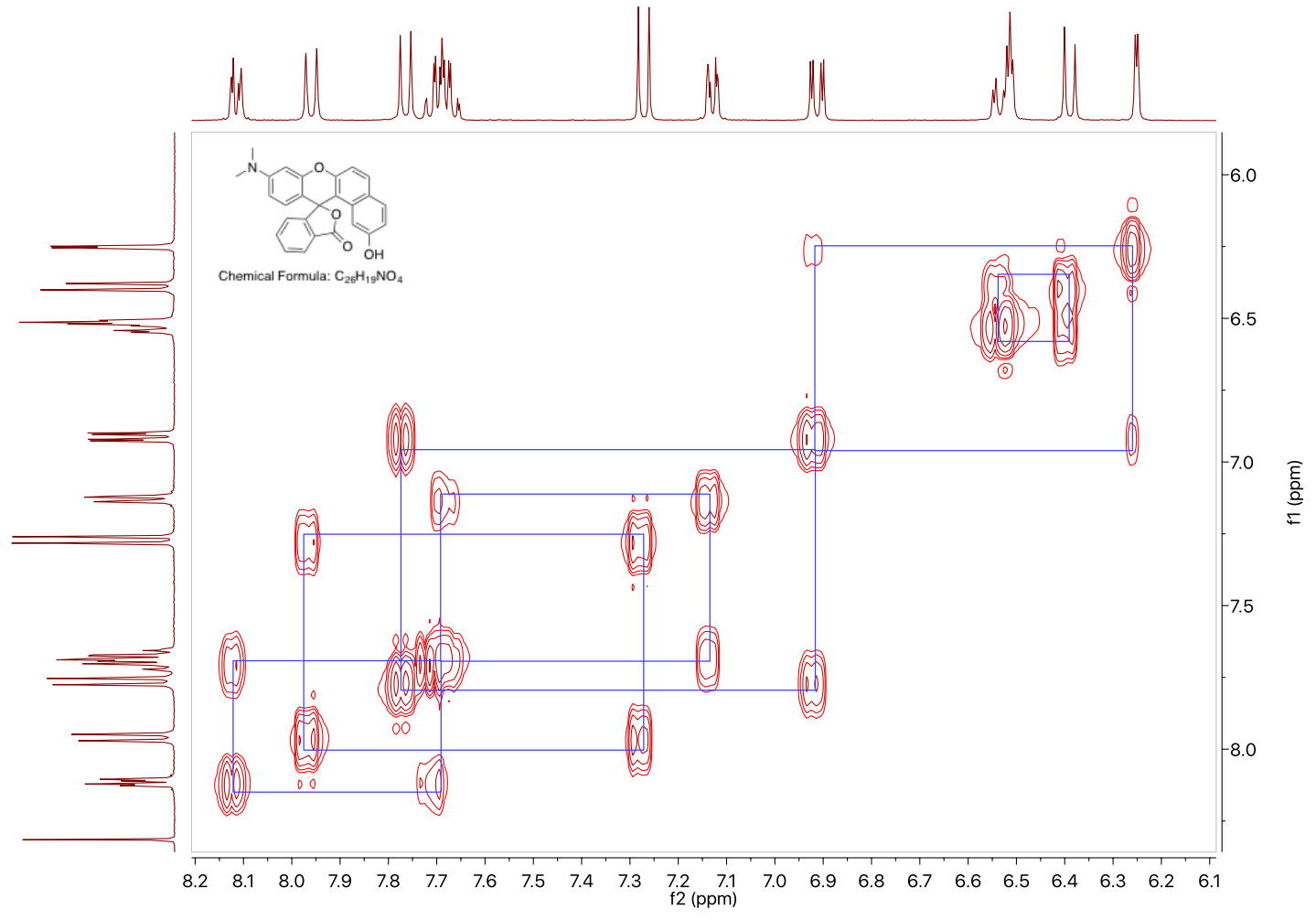

Figure A34. 2D COSY NMR spectrum for compound 21.

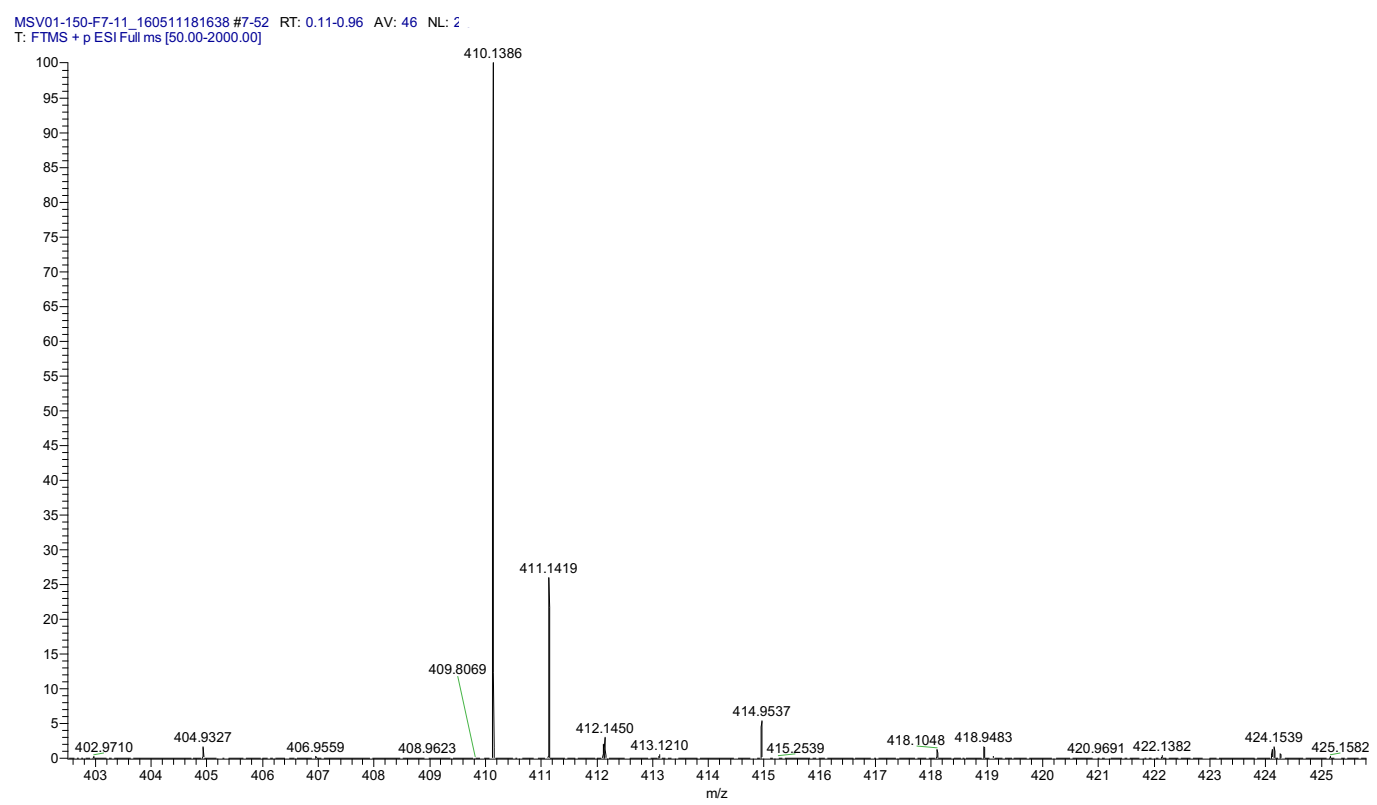

Figure A35. HR ESI positive mode spectrum of compound 21. 


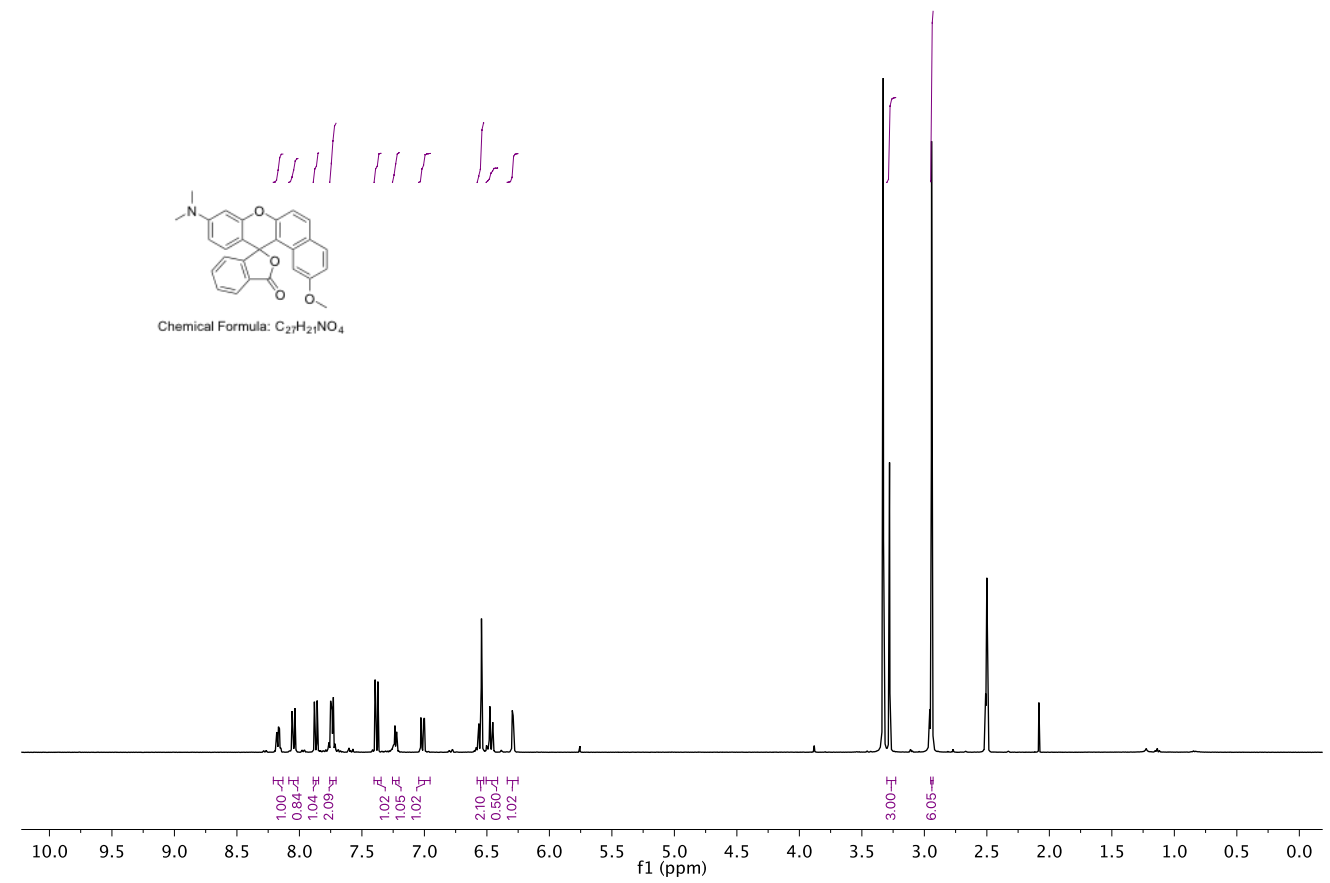

Figure A36. ${ }^{1} \mathrm{H}$ NMR spectrum of compound 22. 


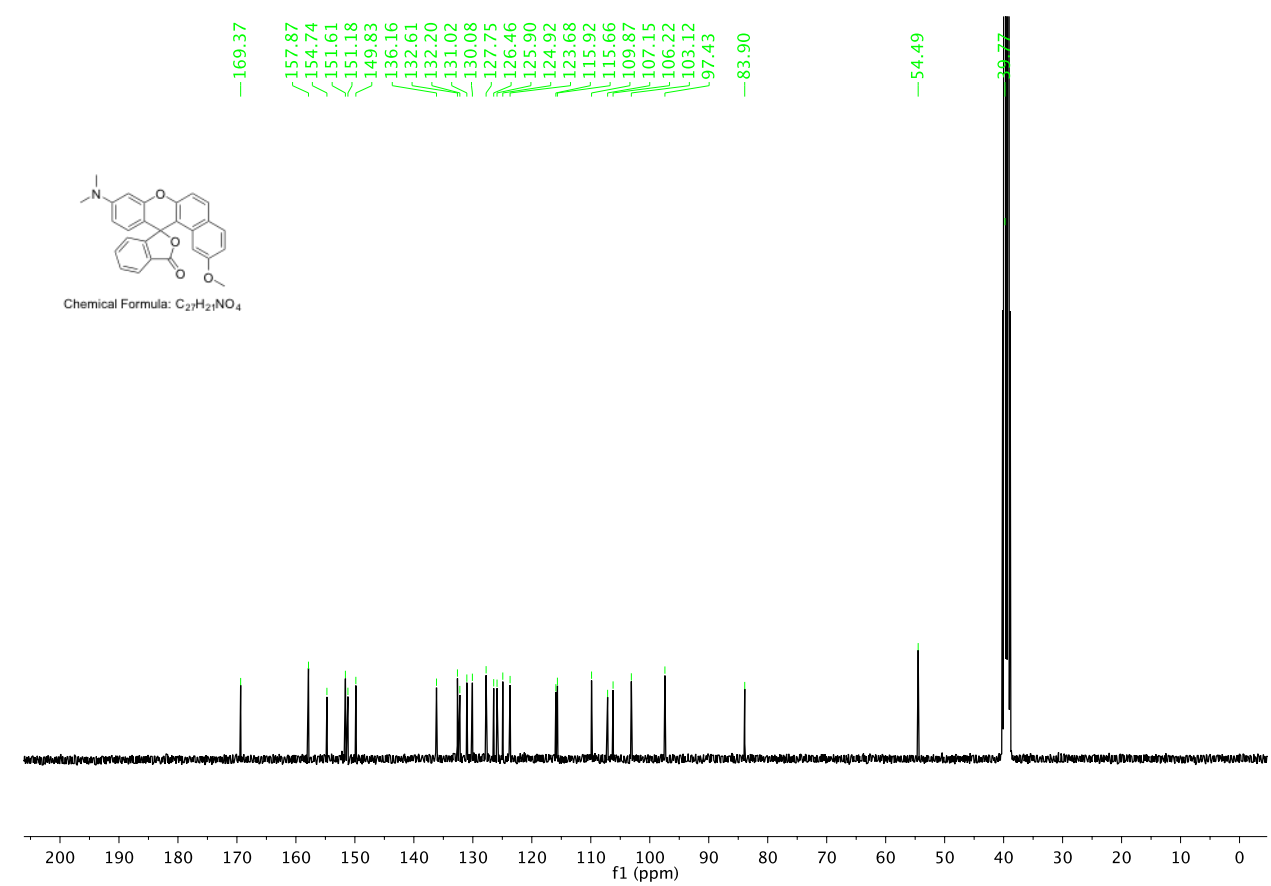

Figure A37. ${ }^{13} \mathrm{C}$ NMR spectrum of compound 22. 


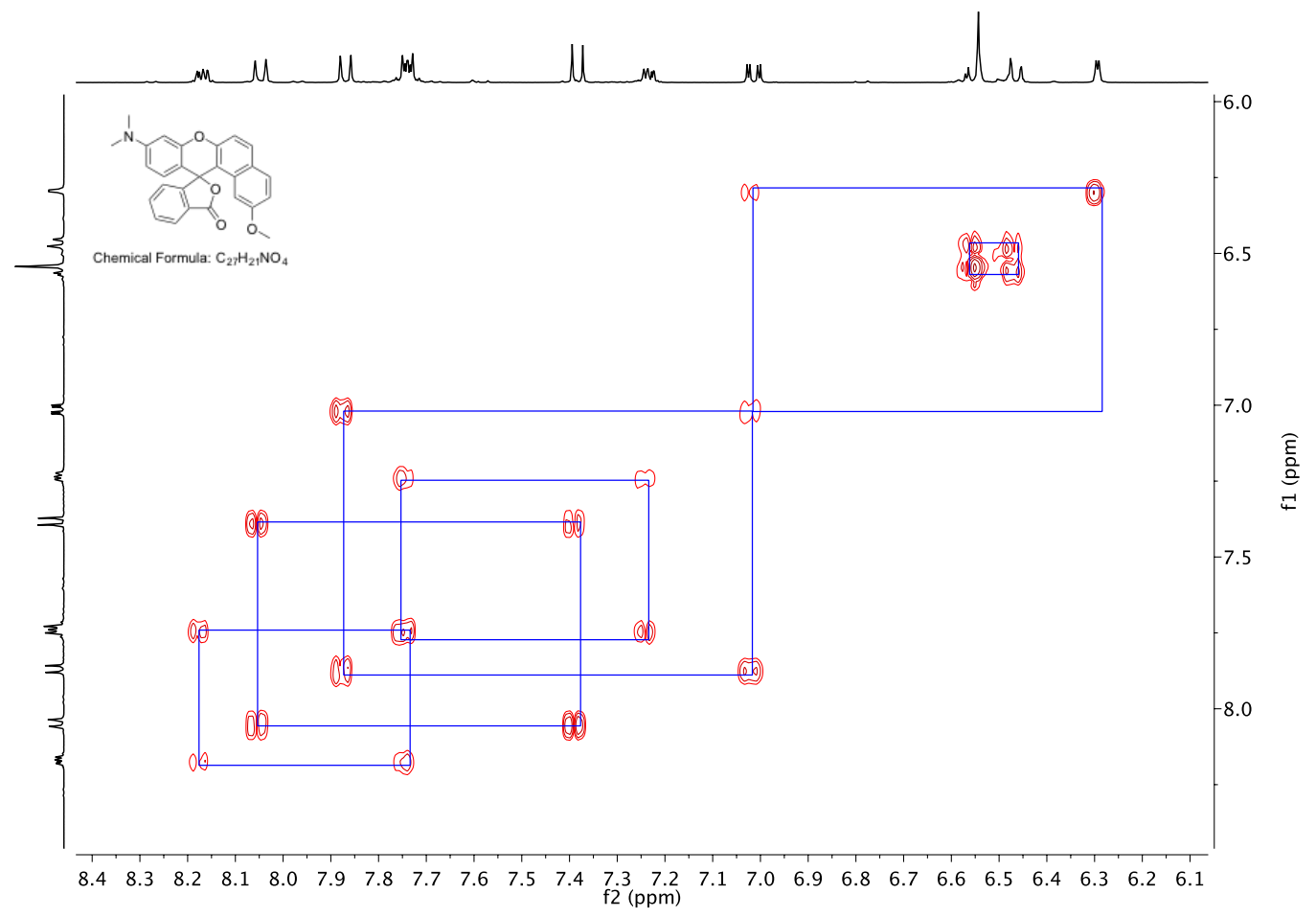

Figure A38. 2D COSY NMR spectrum for compound 22.

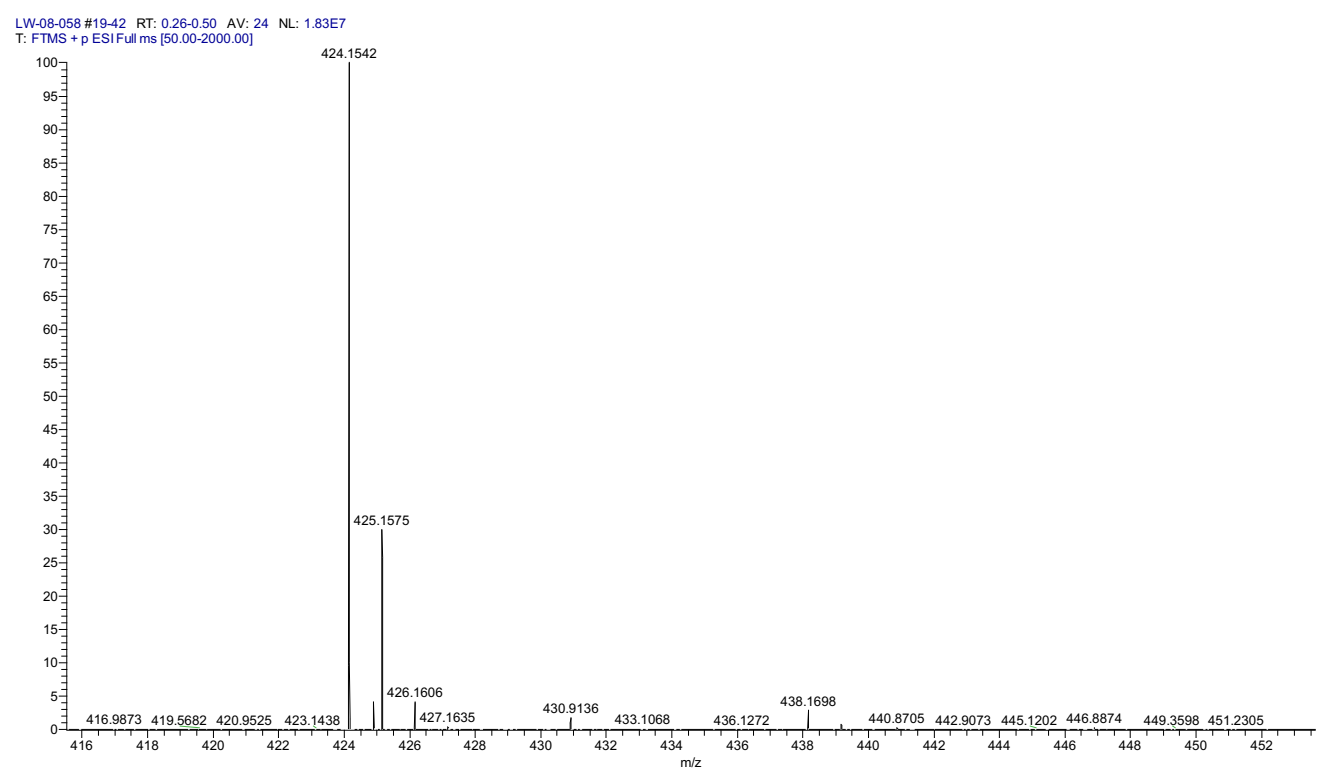

Figure A39. HR ESI positive mode spectrum of compound 22. 


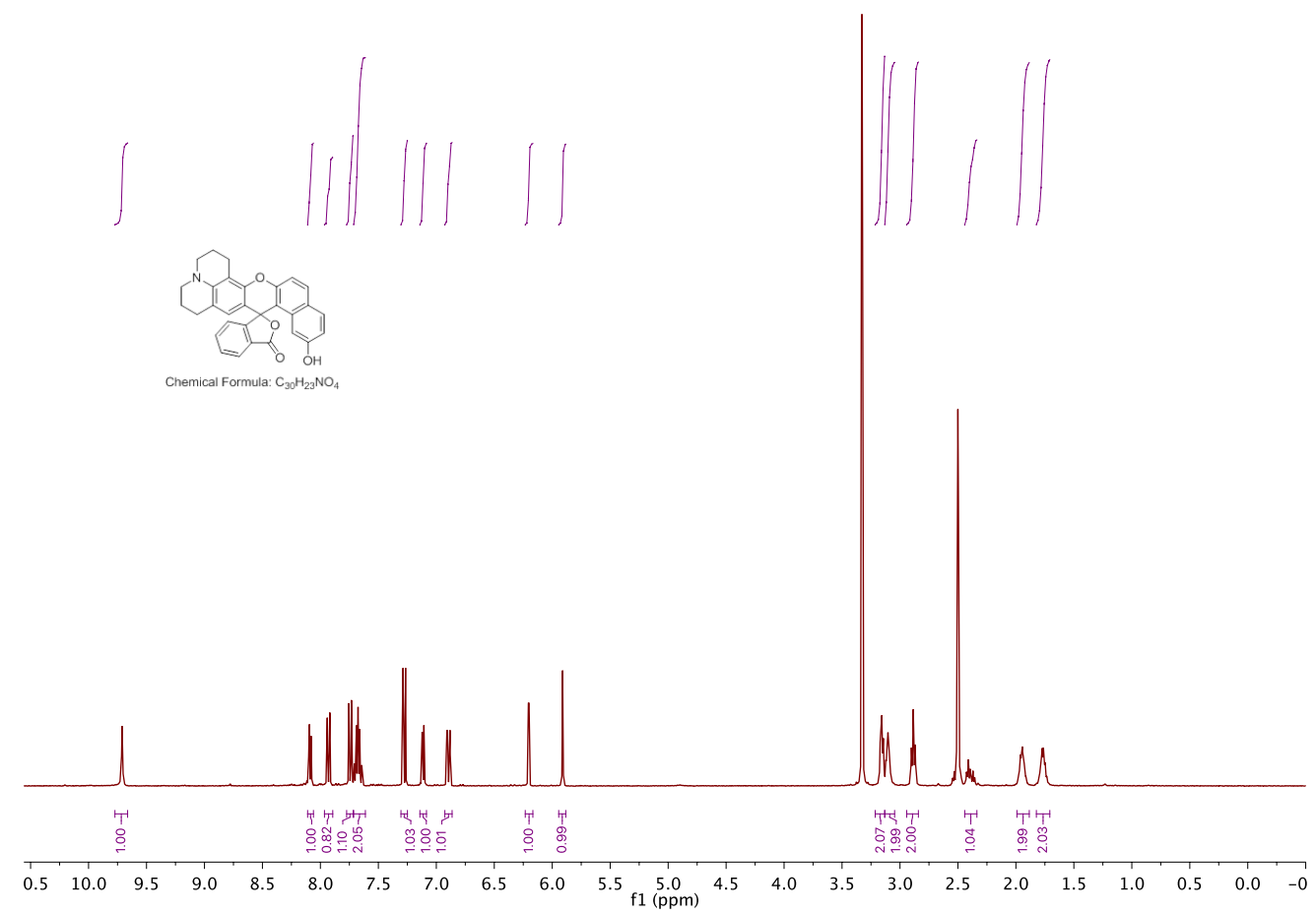

Figure A40. ${ }^{1} \mathrm{H}$ NMR spectrum of compound 26. 

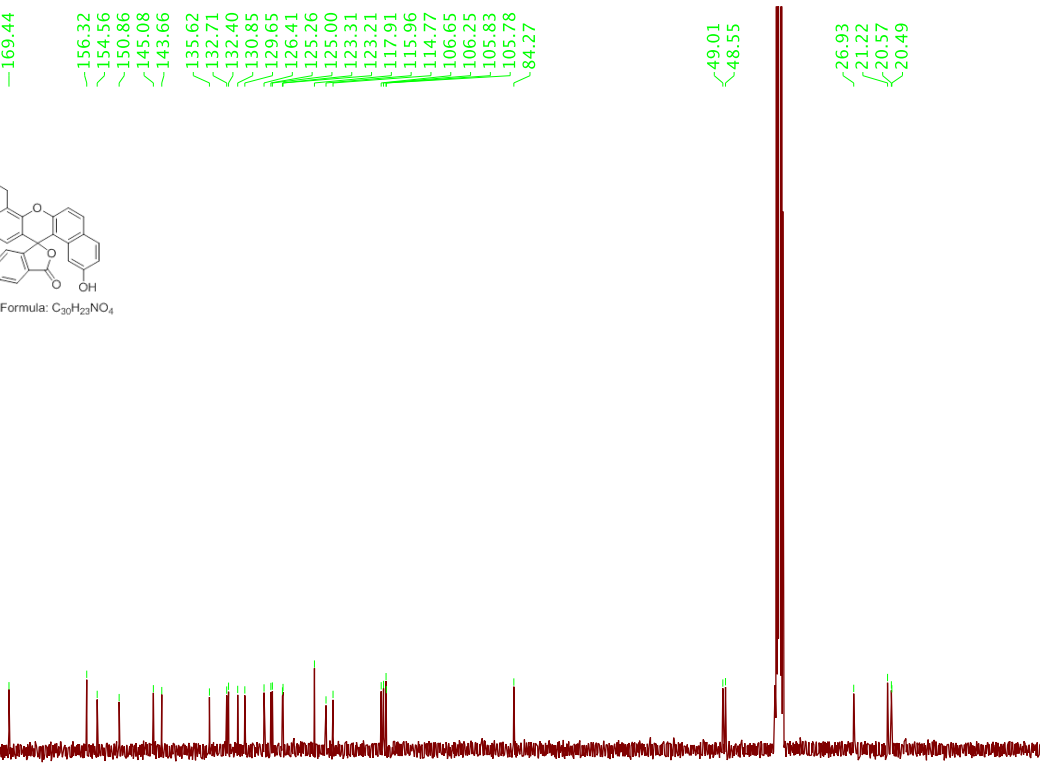

200
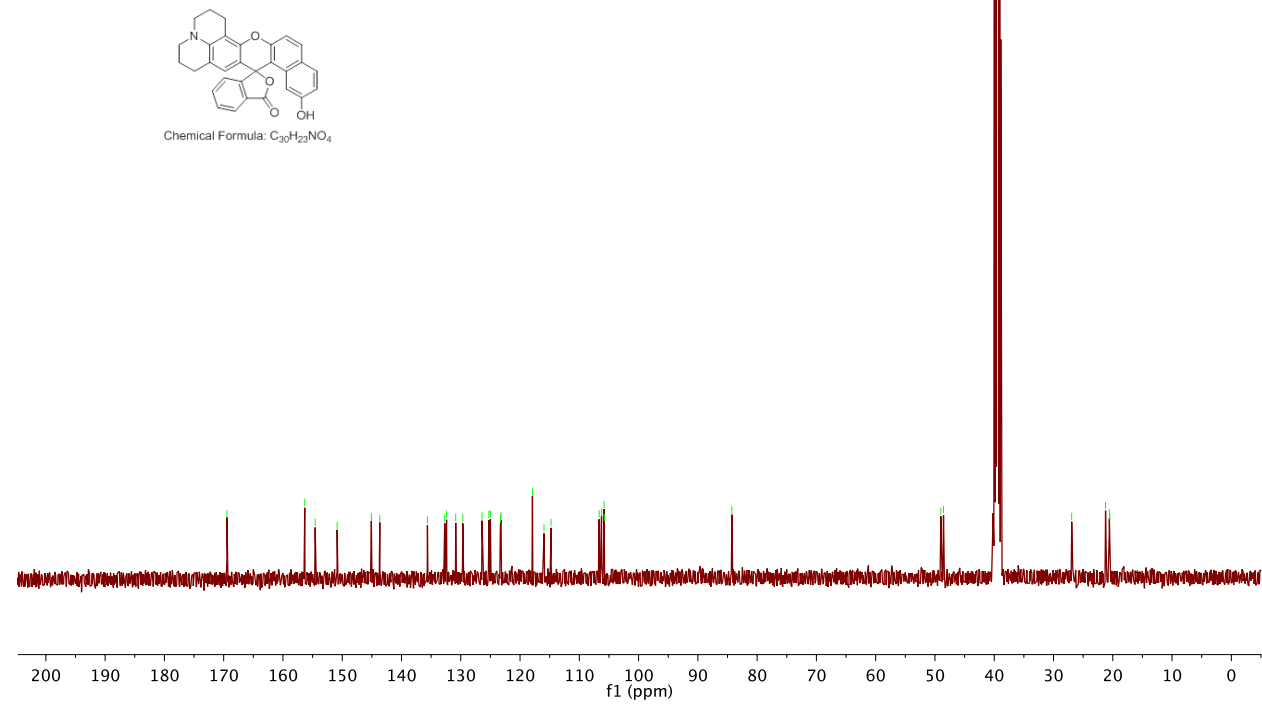

Figure A41. ${ }^{13} \mathrm{C}$ NMR spectrum of compound 26. 


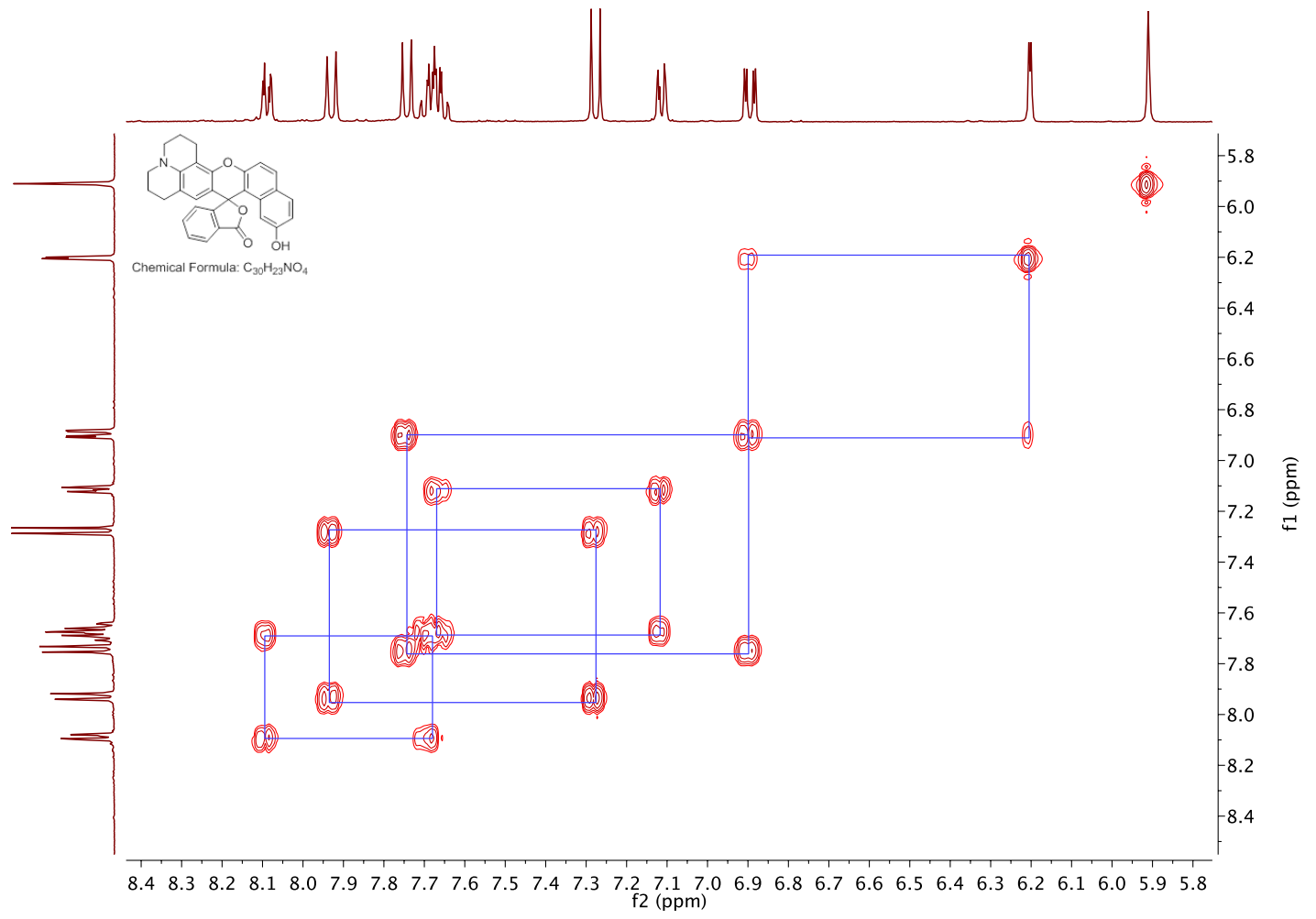

Figure A42. 2D COSY NMR spectrum for compound 26.

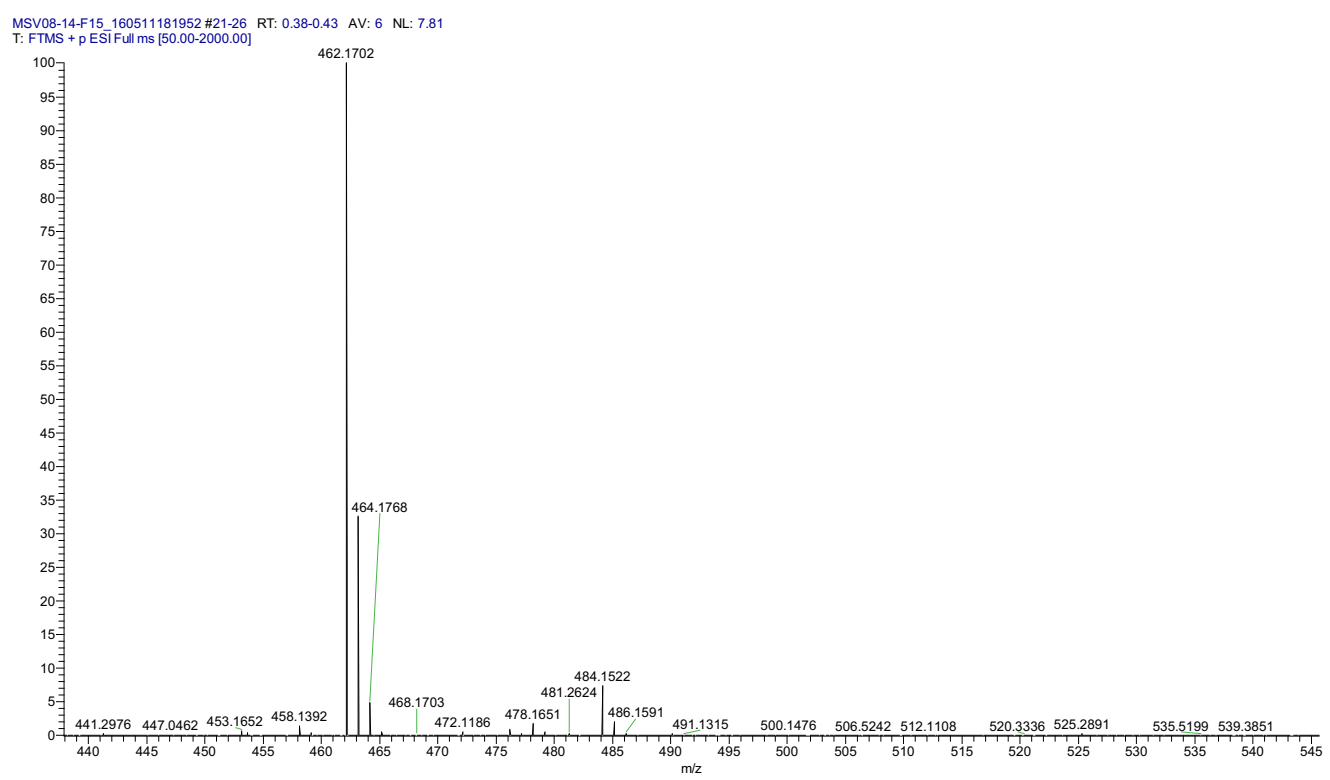

Figure A43. HR ESI positive mode spectrum of compound 26. 


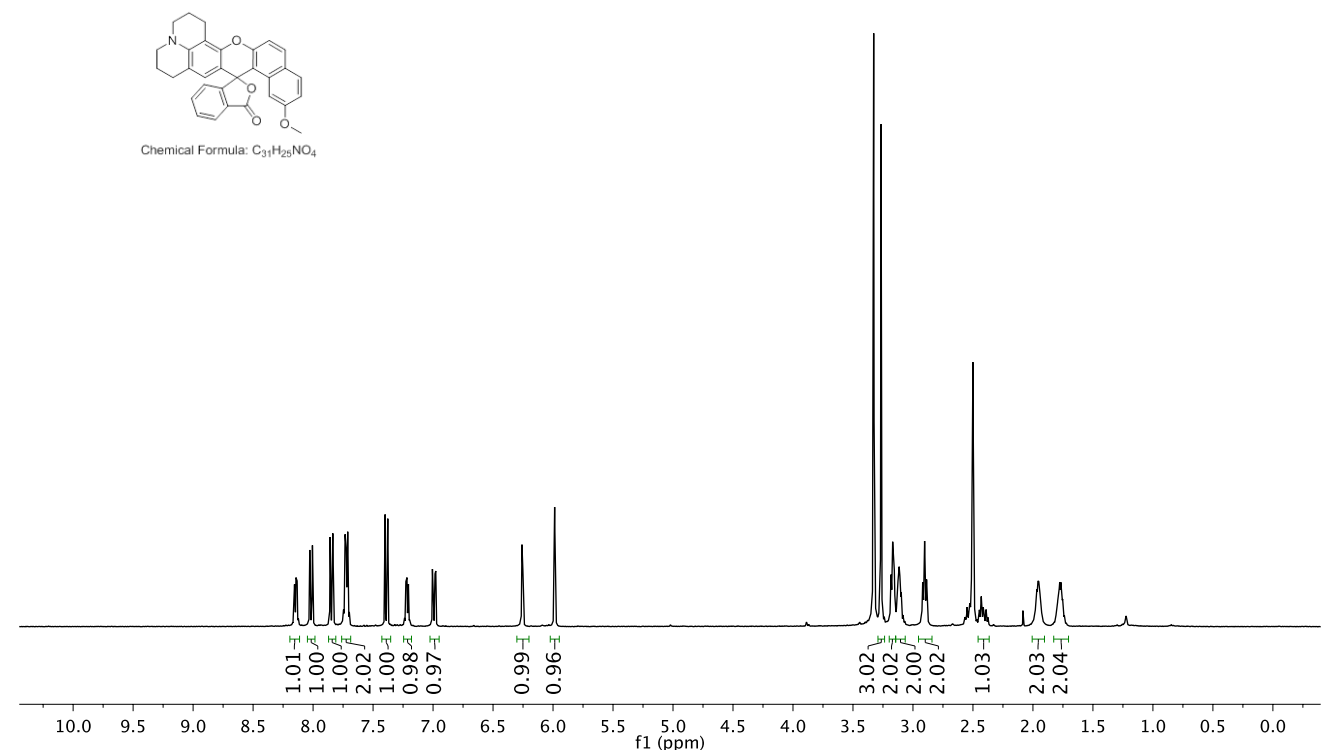

Figure A44. ${ }^{1} \mathrm{H}$ NMR spectrum of compound 27. 


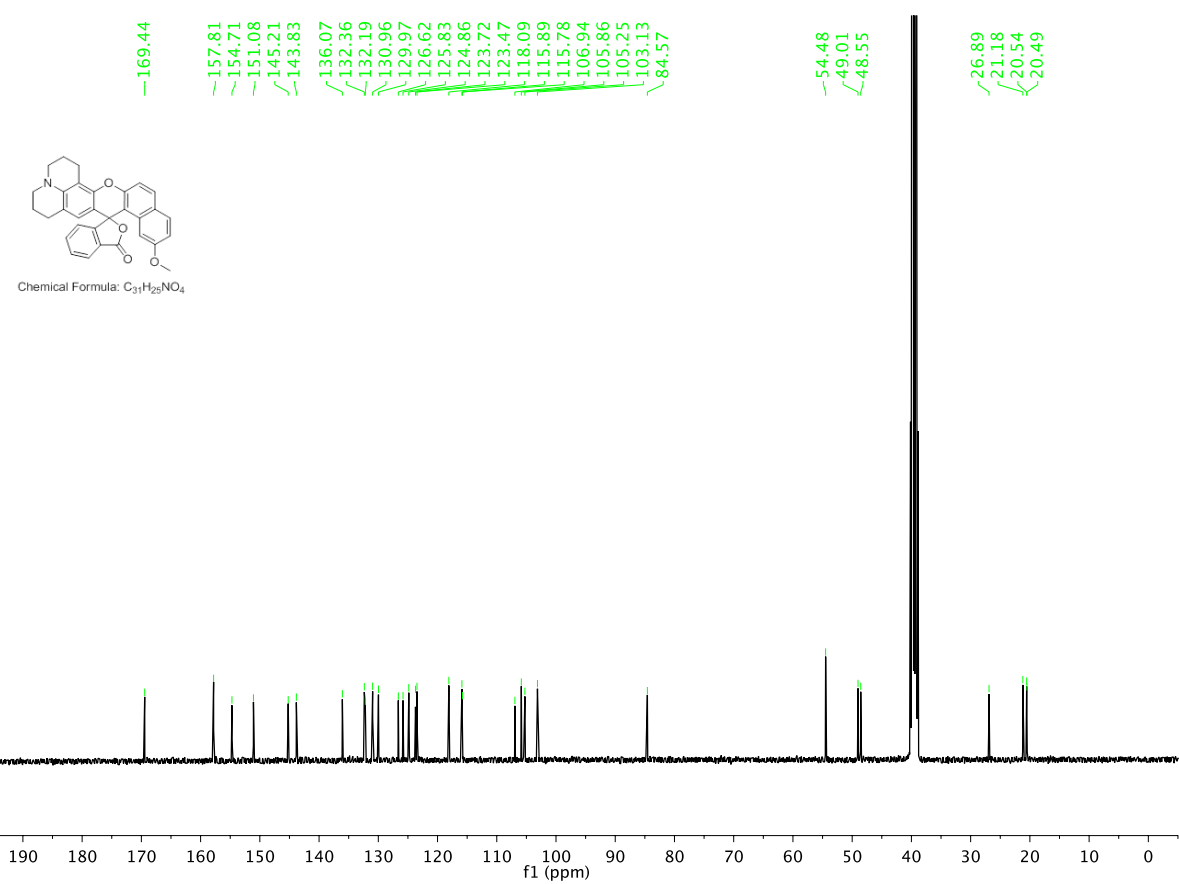

Figure A45. ${ }^{13} \mathrm{C}$ NMR spectrum of compound 27. 


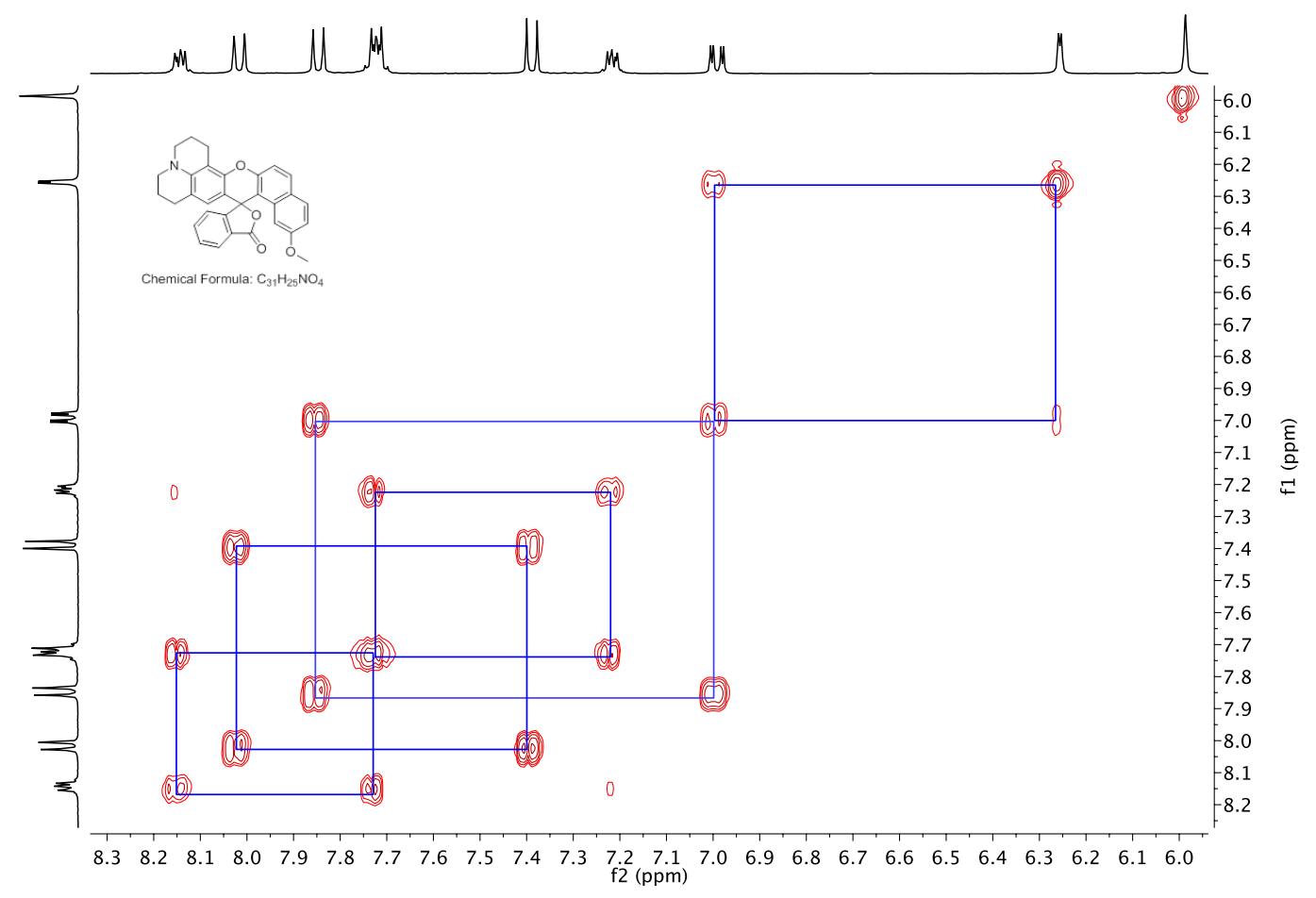

Figure A46. 2D COSY NMR spectrum for compound 27.

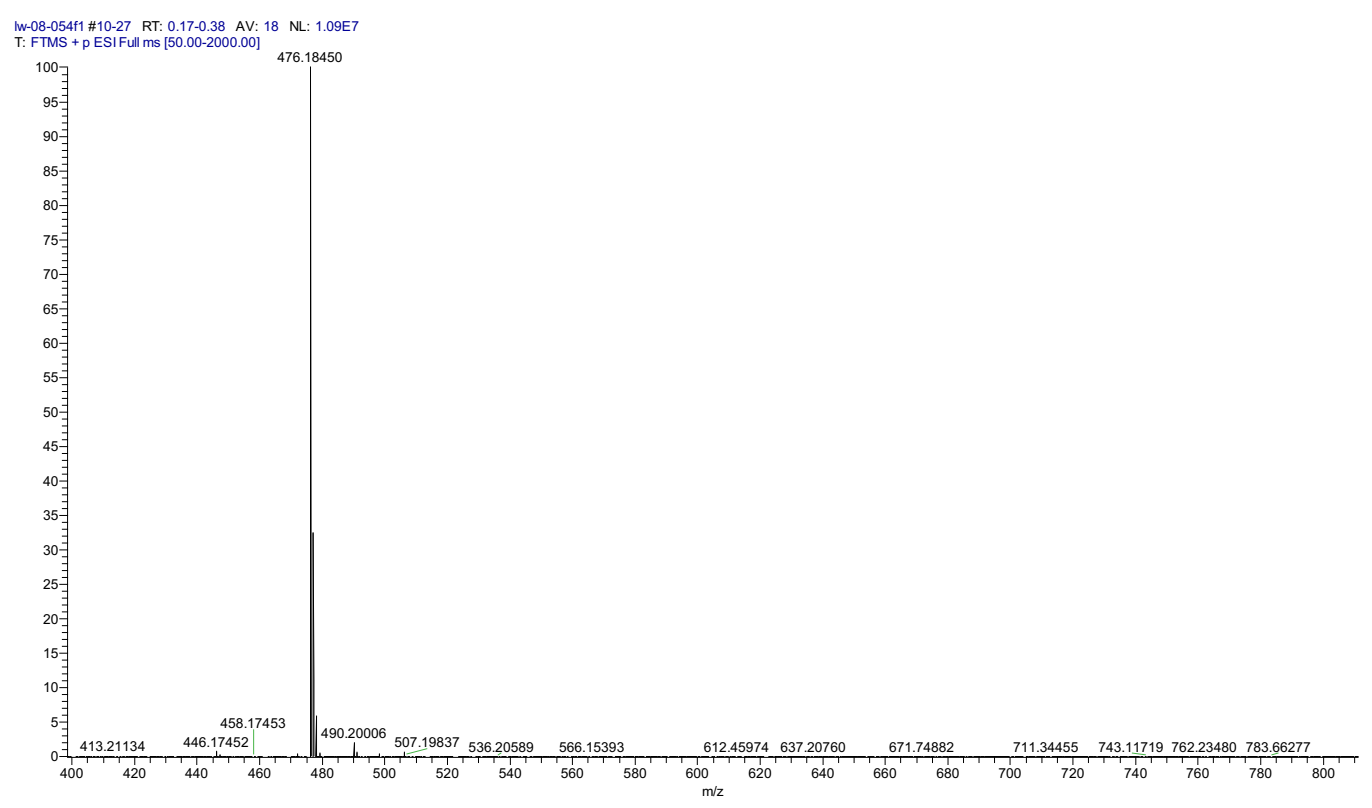

Figure A47. HR ESI positive mode spectrum of compound 27. 


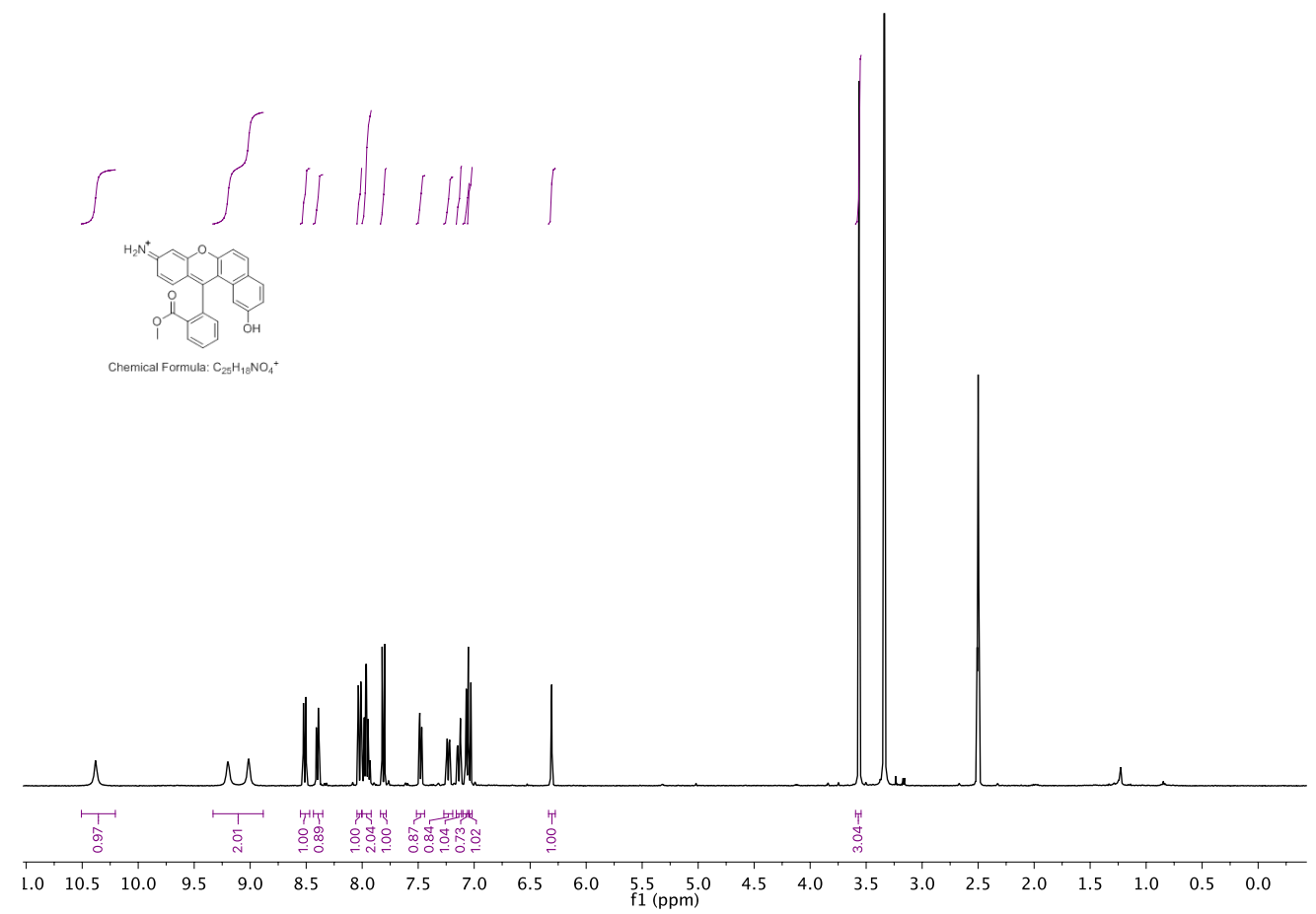

Figure A48. ${ }^{1} \mathrm{H}$ NMR spectrum of compound 1. 

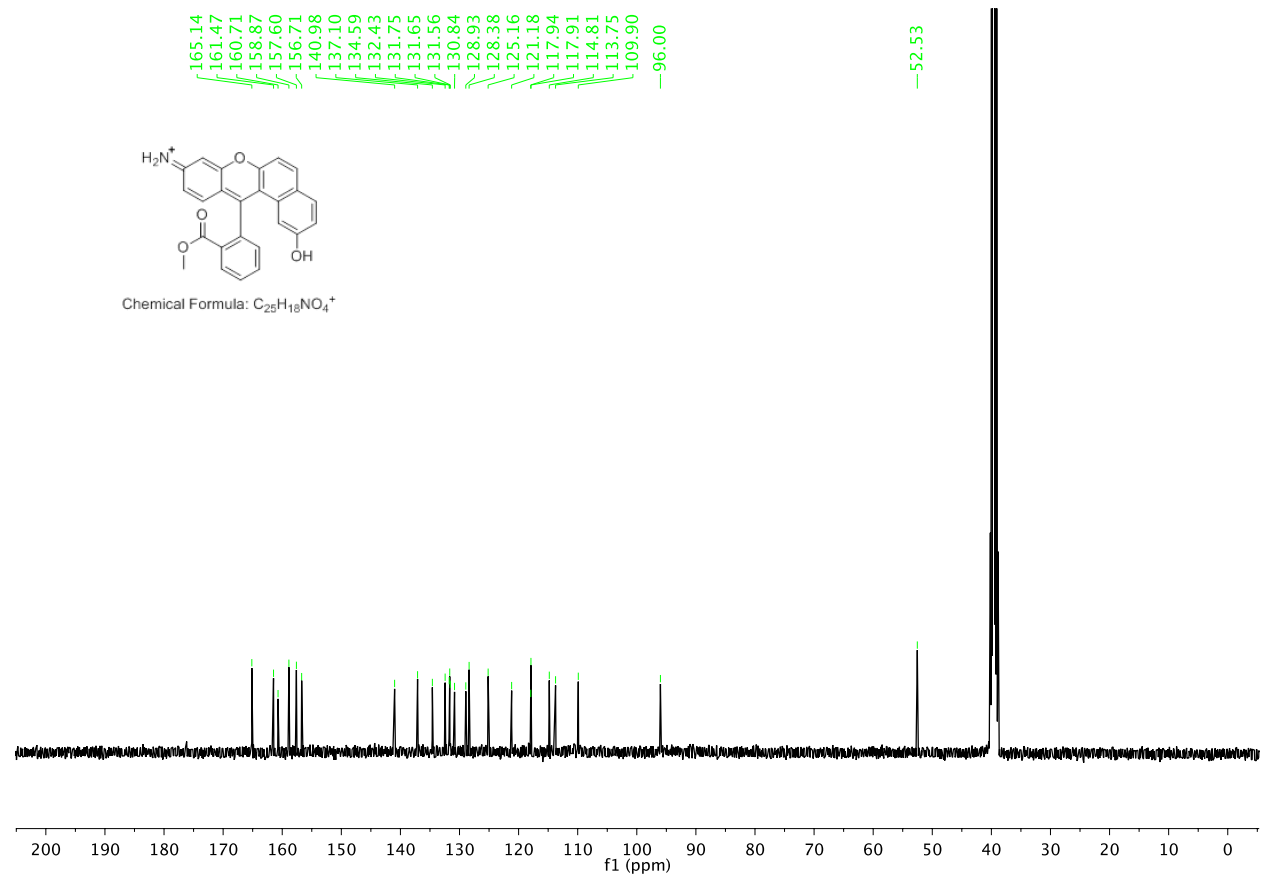

Figure A49. ${ }^{13} \mathrm{C}$ NMR spectrum of compound 1 . 


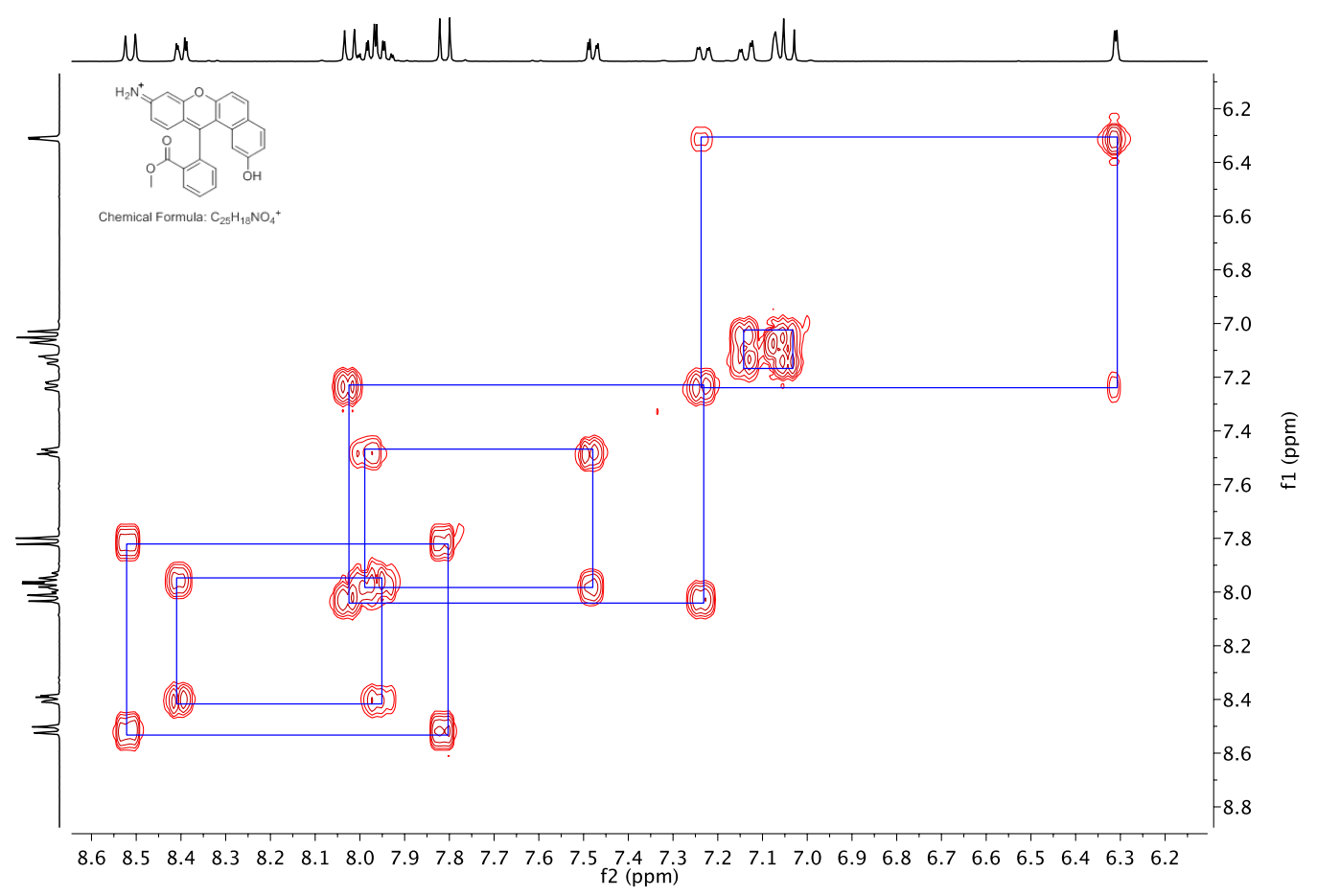

Figure A50. 2D COSY NMR spectrum for compound 1.

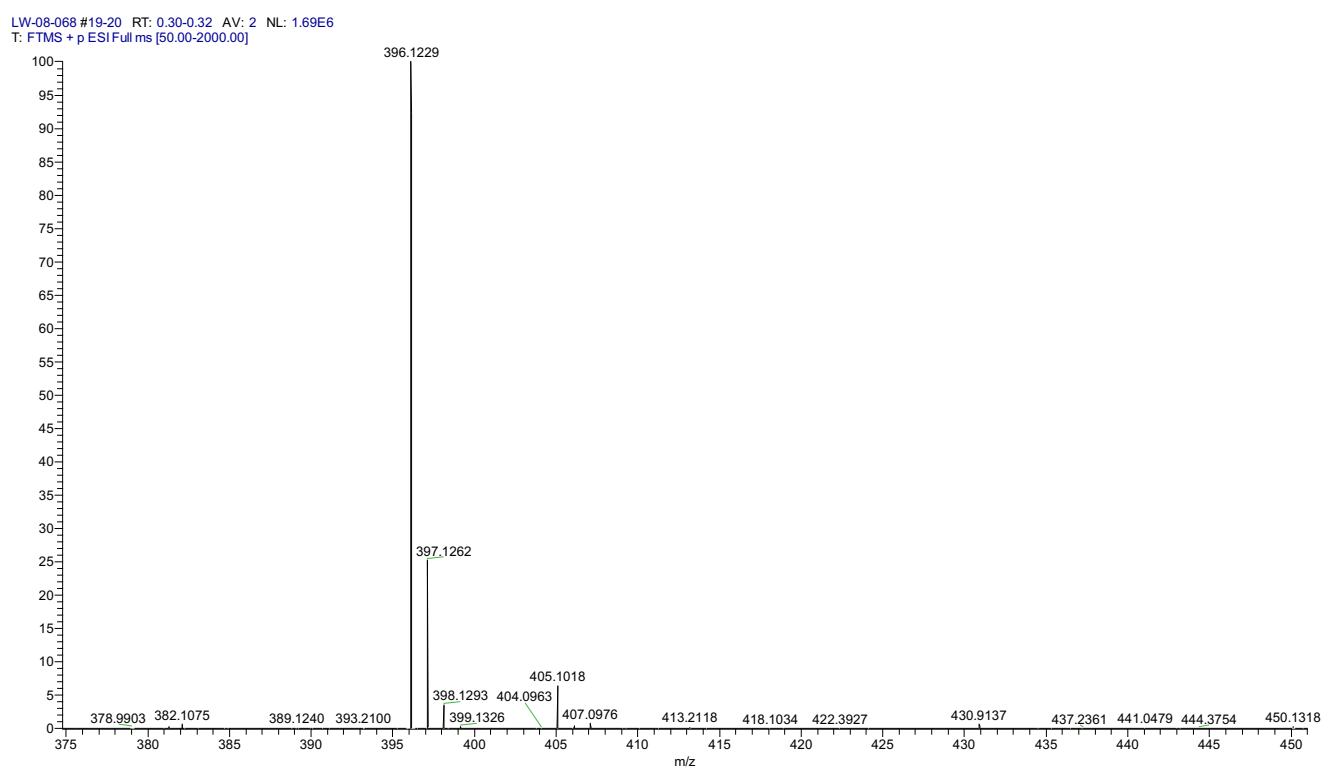

Figure A51. HR ESI positive mode spectrum of compound 1. 
LW-08-069-20160612

PROTON DMSO \{C.|Bruker\TOPSPIN\} Strongin-Lei 9

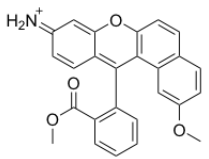

Chemical Formula: $\mathrm{C}_{26} \mathrm{H}_{20} \mathrm{NO}_{4}$

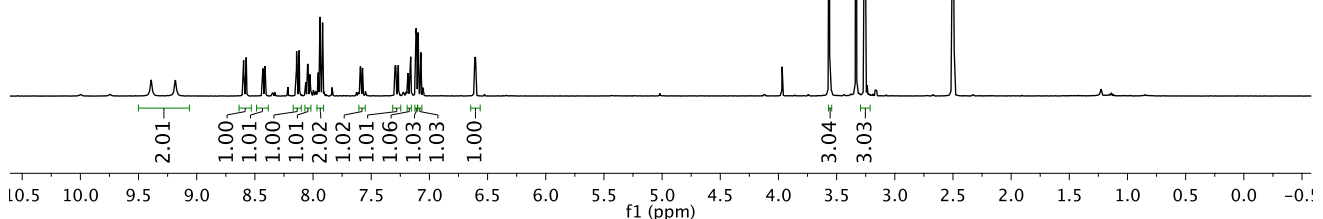

Figure A52. ${ }^{1} \mathrm{H}$ NMR spectrum of compound 2. 


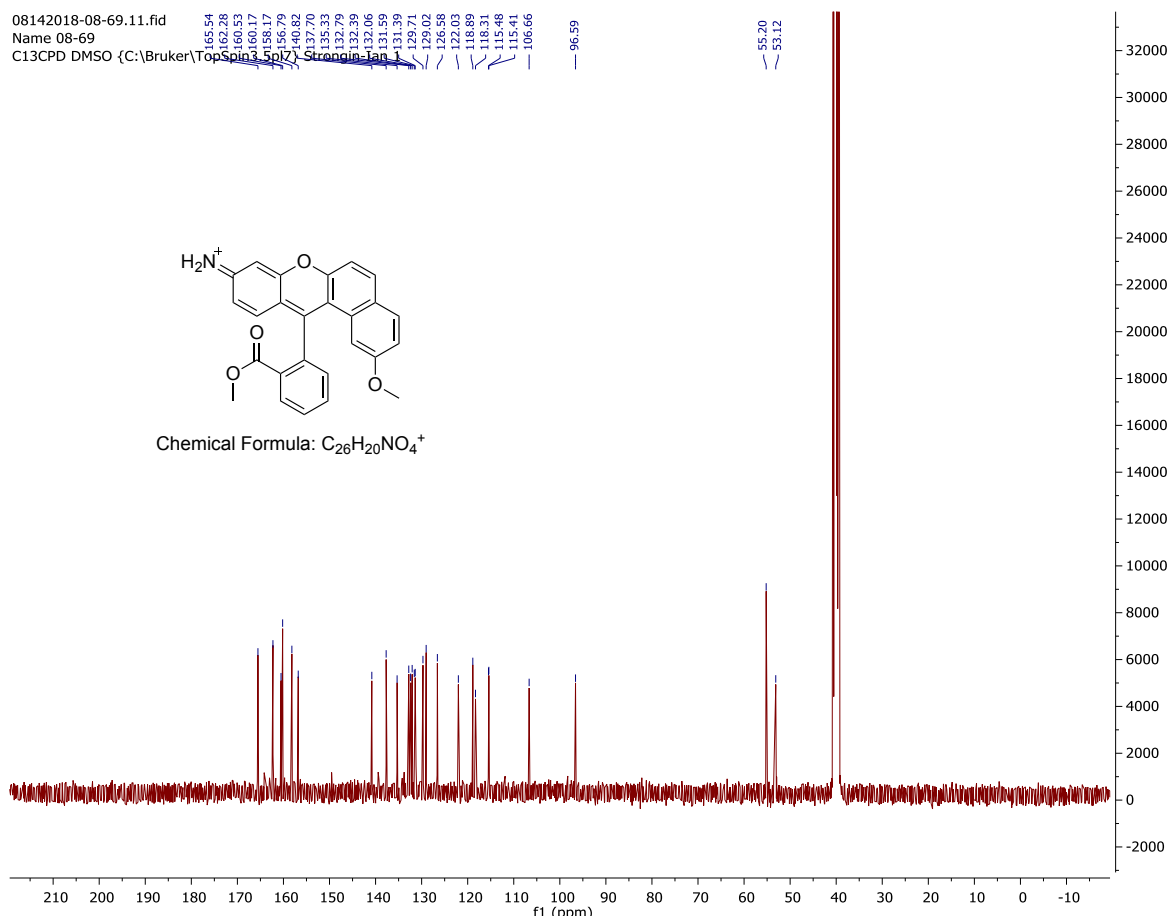

$\begin{array}{llllllllllll}210 & 200 & 190 & 180 & 170 & 160 & 150 & 140 & 130 & 120 & 110 & \begin{array}{l}100 \\ \mathrm{f} 1(\mathrm{ppm})\end{array}\end{array}$

Figure A53. ${ }^{13} \mathrm{C}$ NMR spectrum of compound 2. 


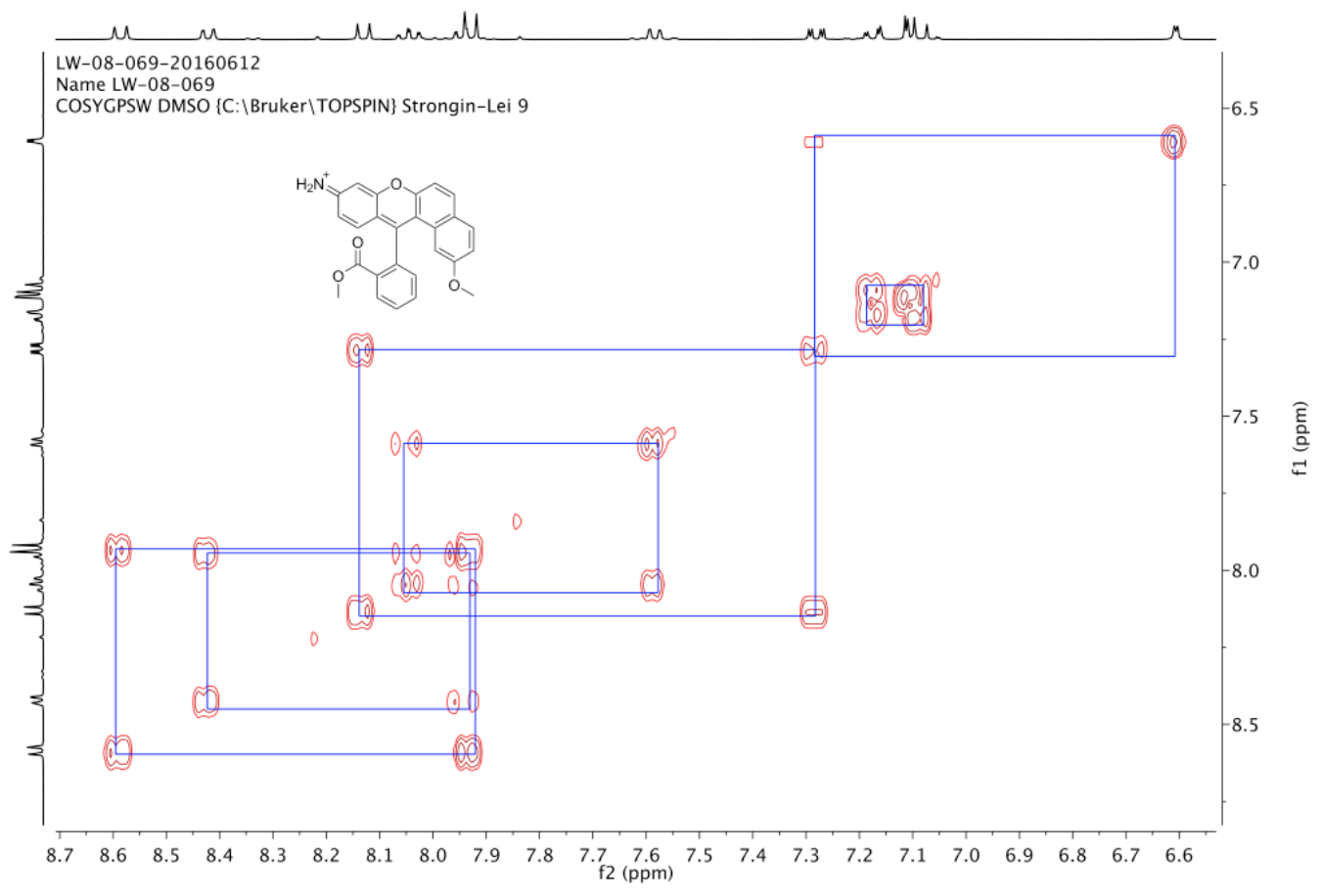

Figure A54. 2D COSY NMR spectrum for compound 2.

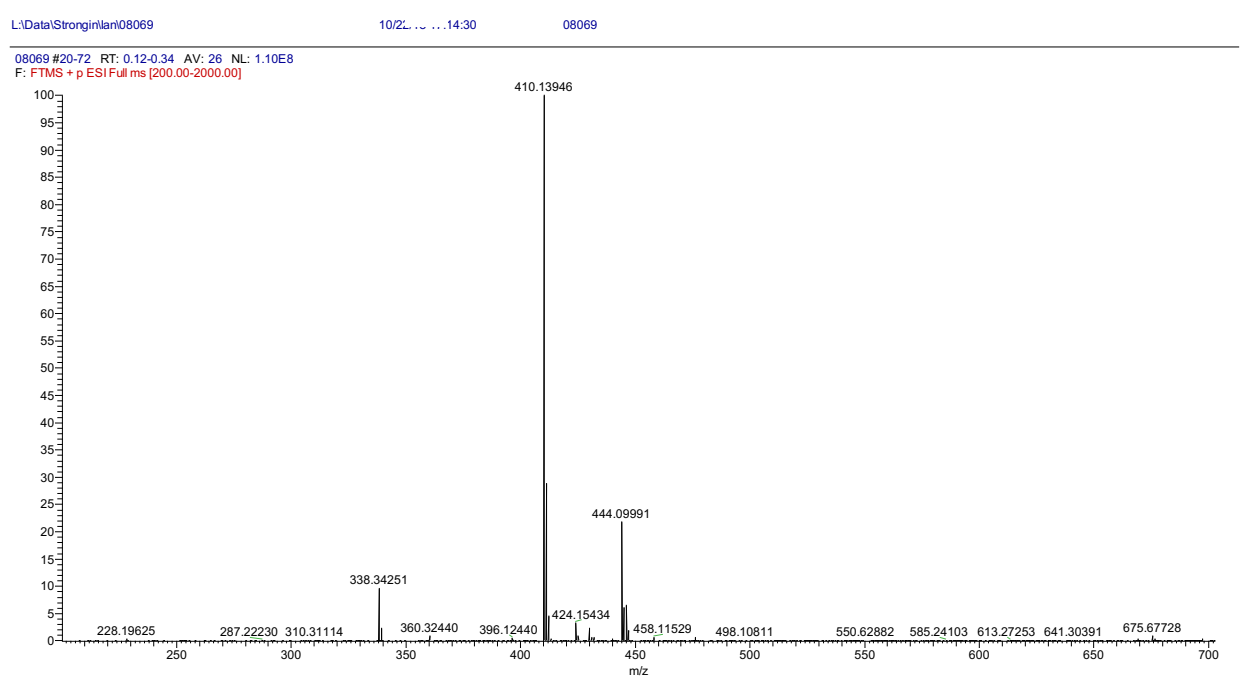

Figure A55. HR ESI positive mode spectrum of compound 2. 


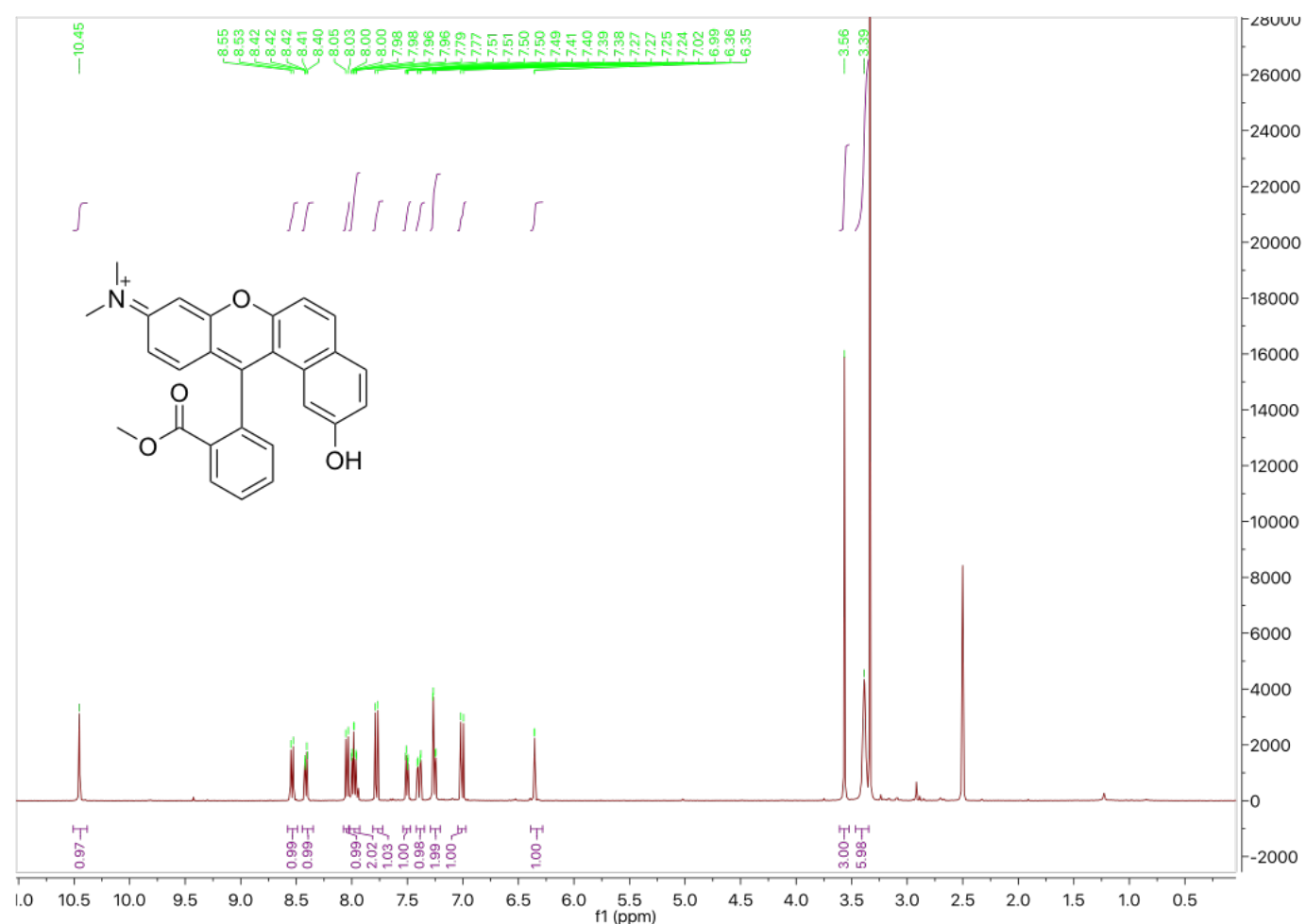

Figure A56. ${ }^{1} \mathrm{H}$ NMR spectrum of compound 4. 


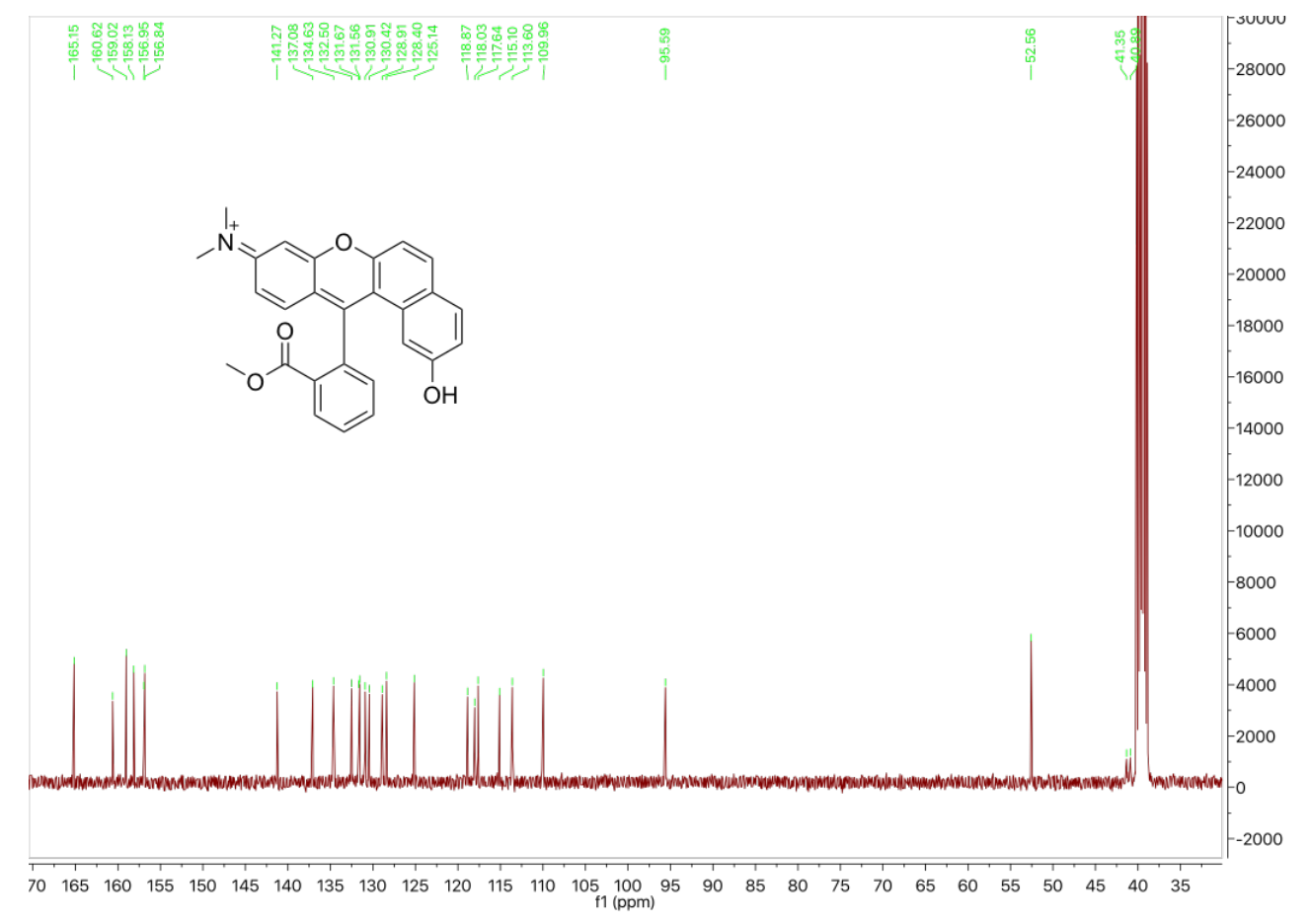

Figure A57. ${ }^{13} \mathrm{C}$ NMR spectrum of compound 4. 


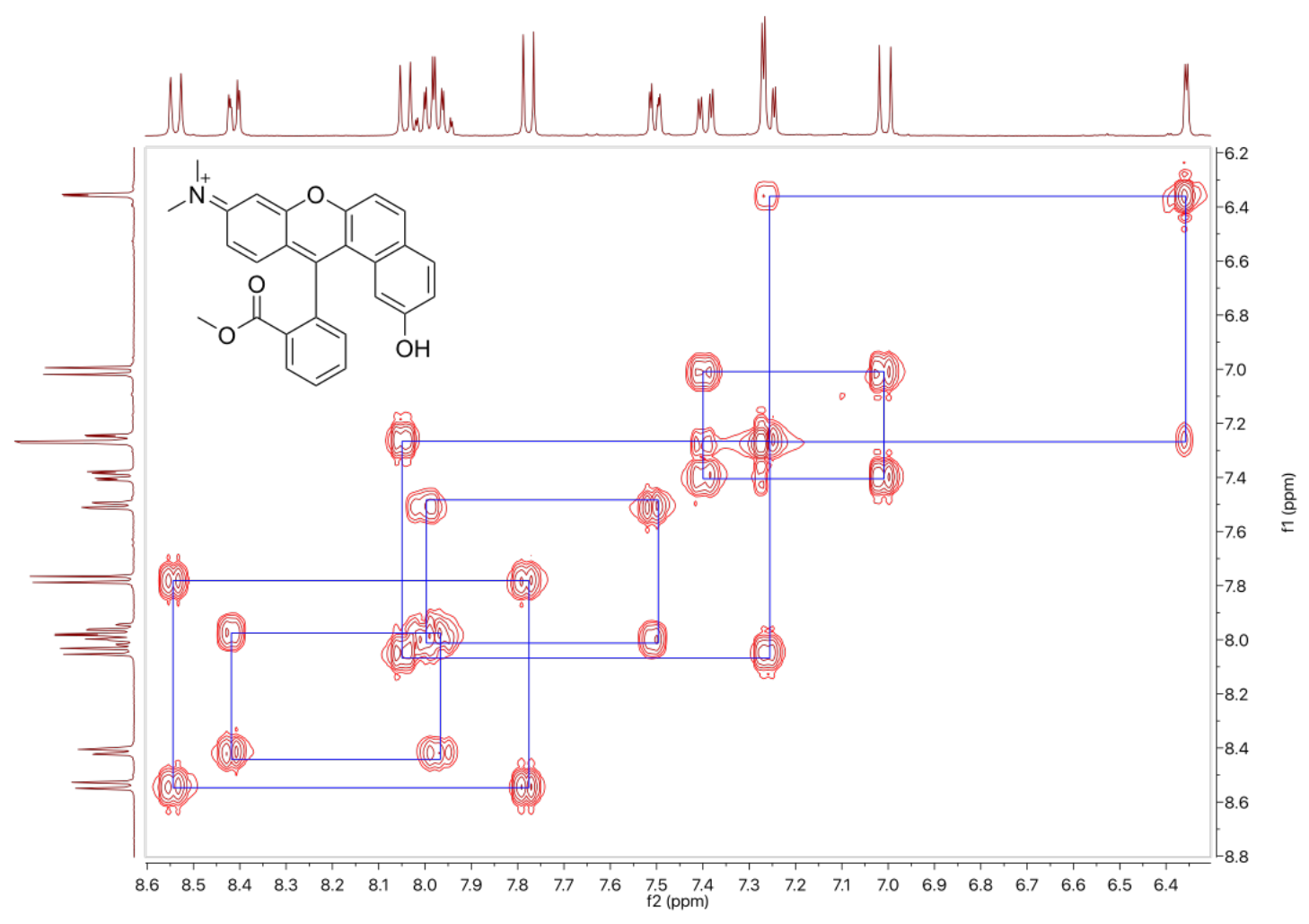

Figure A58. 2D COSY NMR spectrum for compound 4.

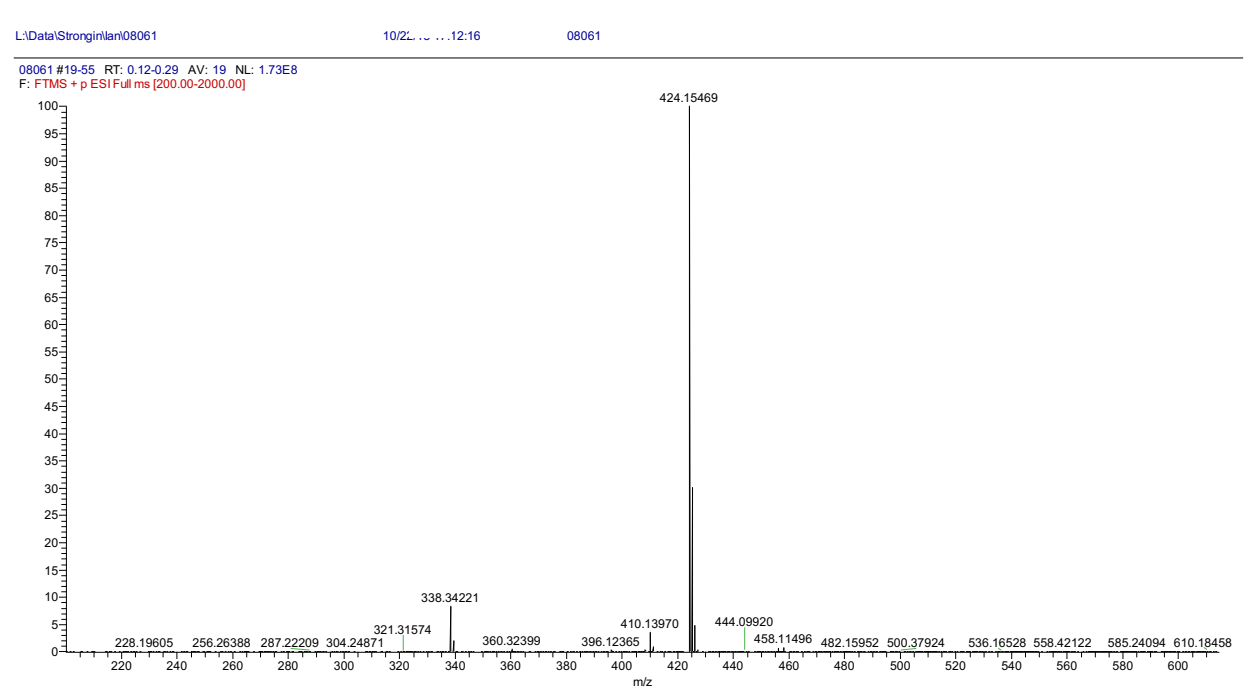

Figure A59. HR ESI positive mode spectrum of compound 4. 


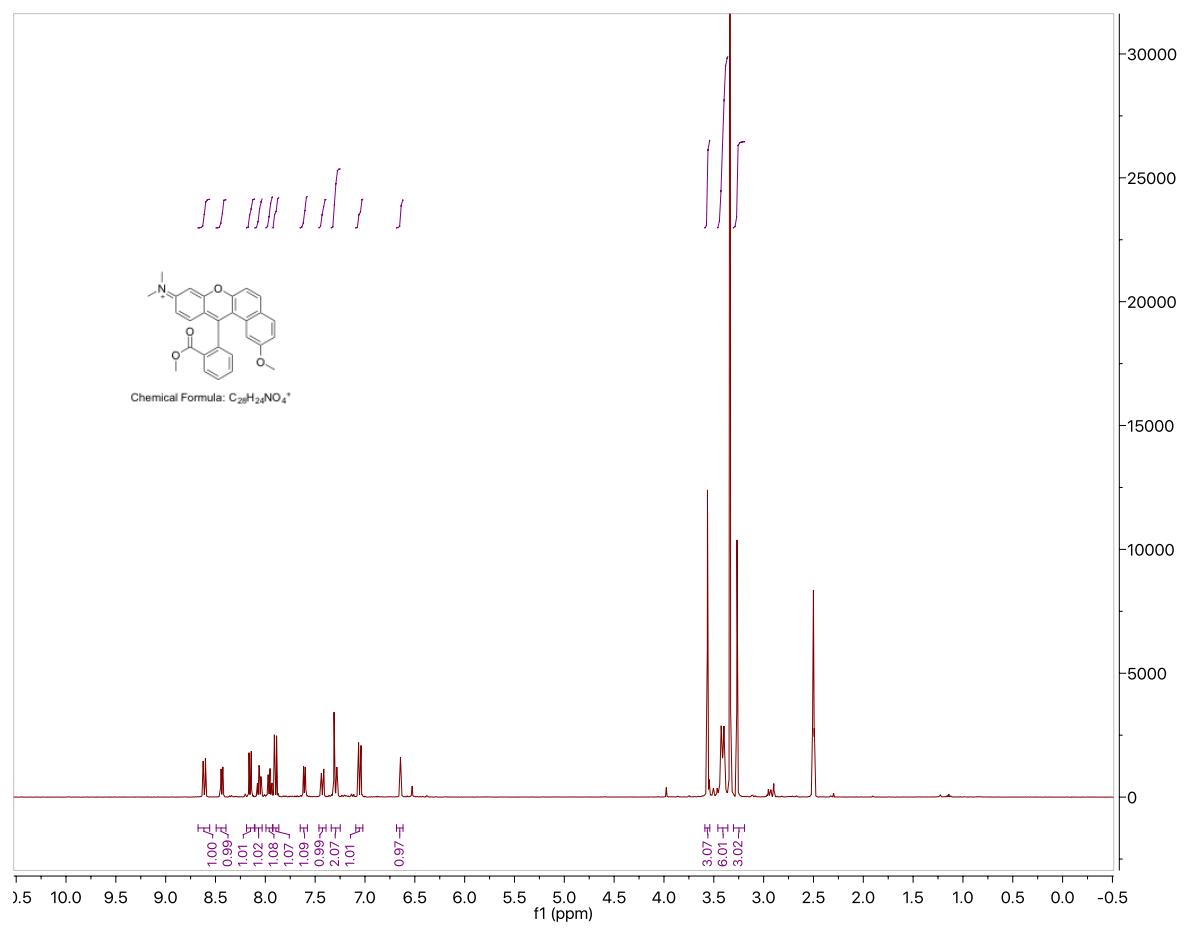

Figure A60. ${ }^{1} \mathrm{H}$ NMR spectrum of compound 5.

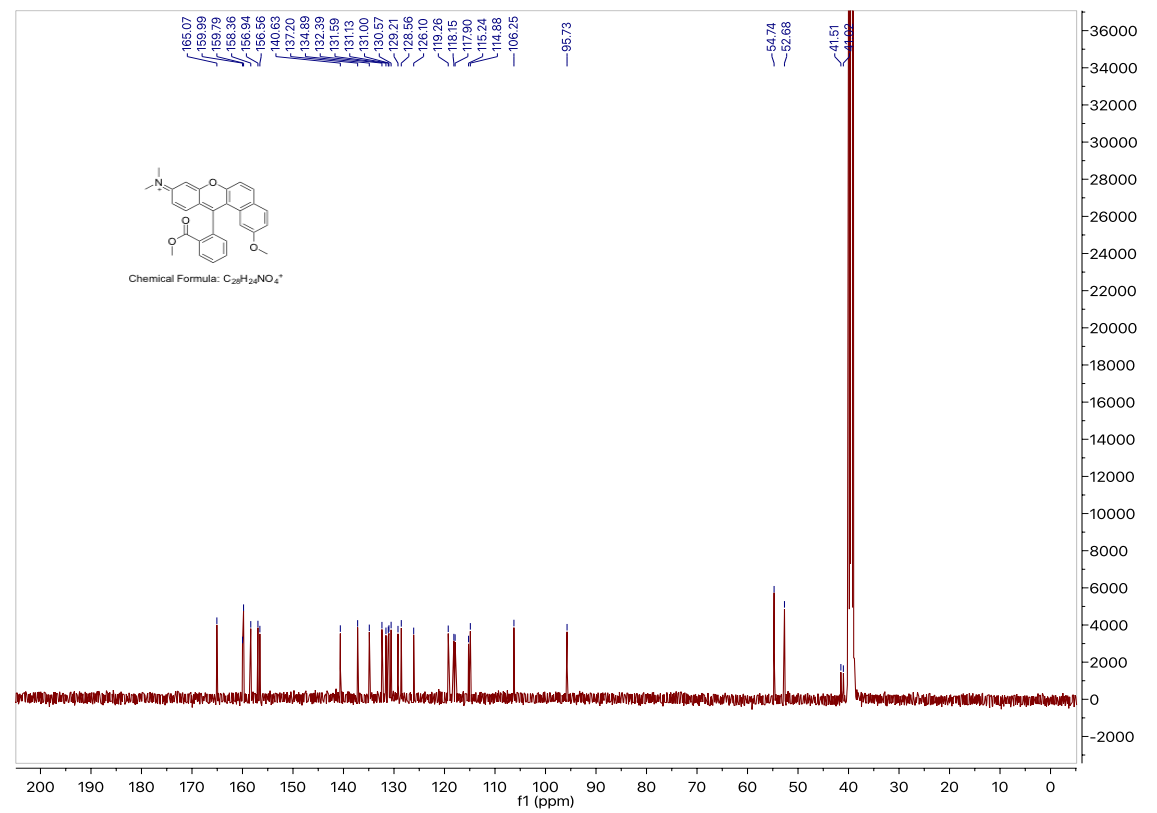

Figure A61. ${ }^{13} \mathrm{C}$ NMR spectrum of compound 5 . 


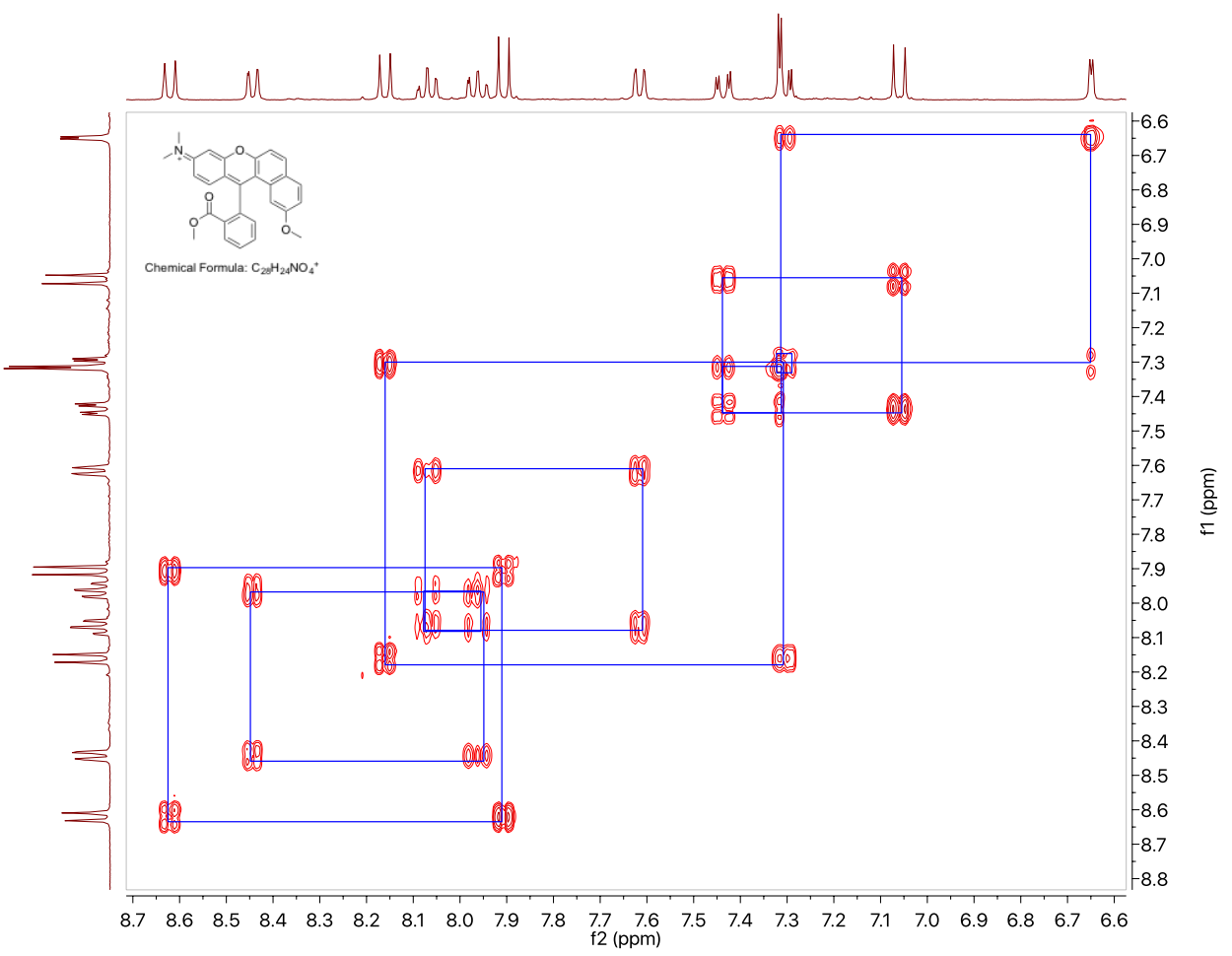

Figure A62. 2D COSY NMR spectrum for compound 5.

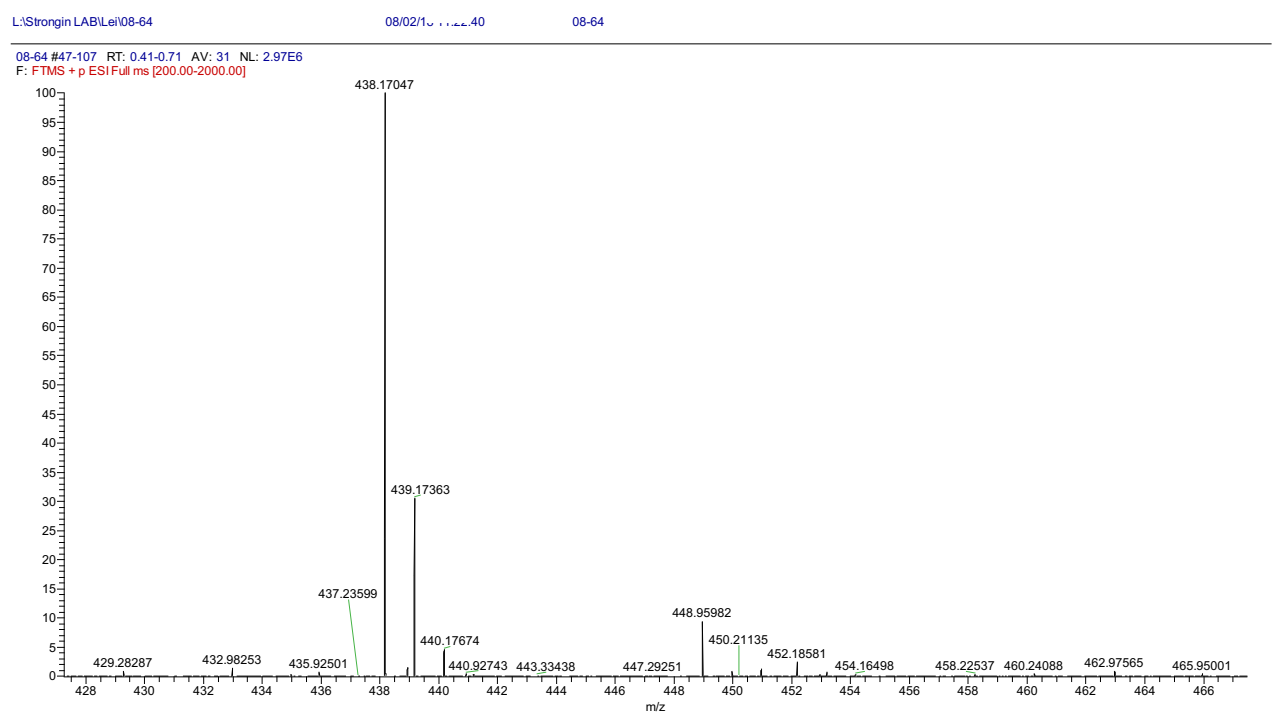

Figure A63. HR ESI positive mode spectrum of compound 5. 


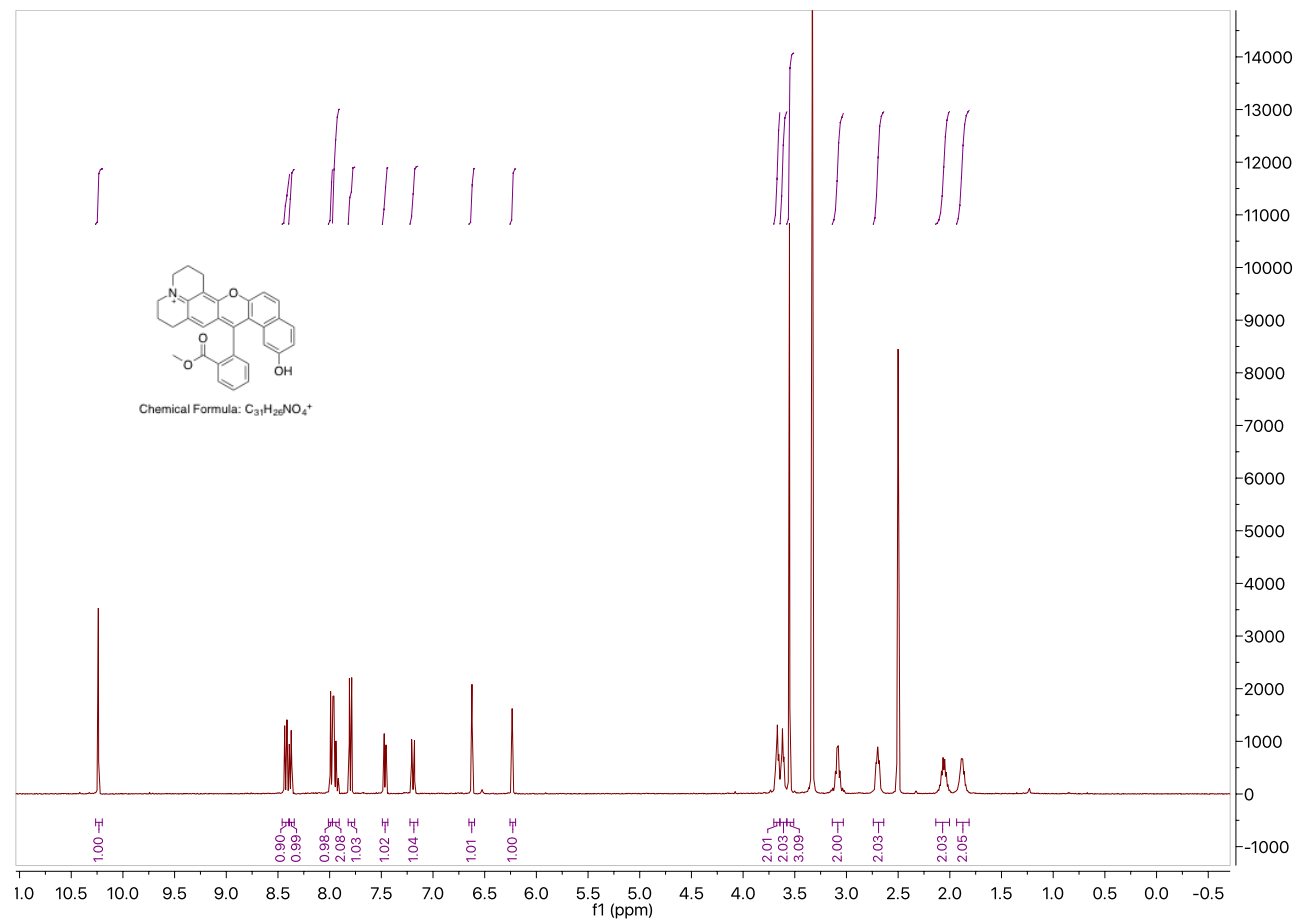

Figure A64. ${ }^{1} \mathrm{H}$ NMR spectrum of compound 7. 


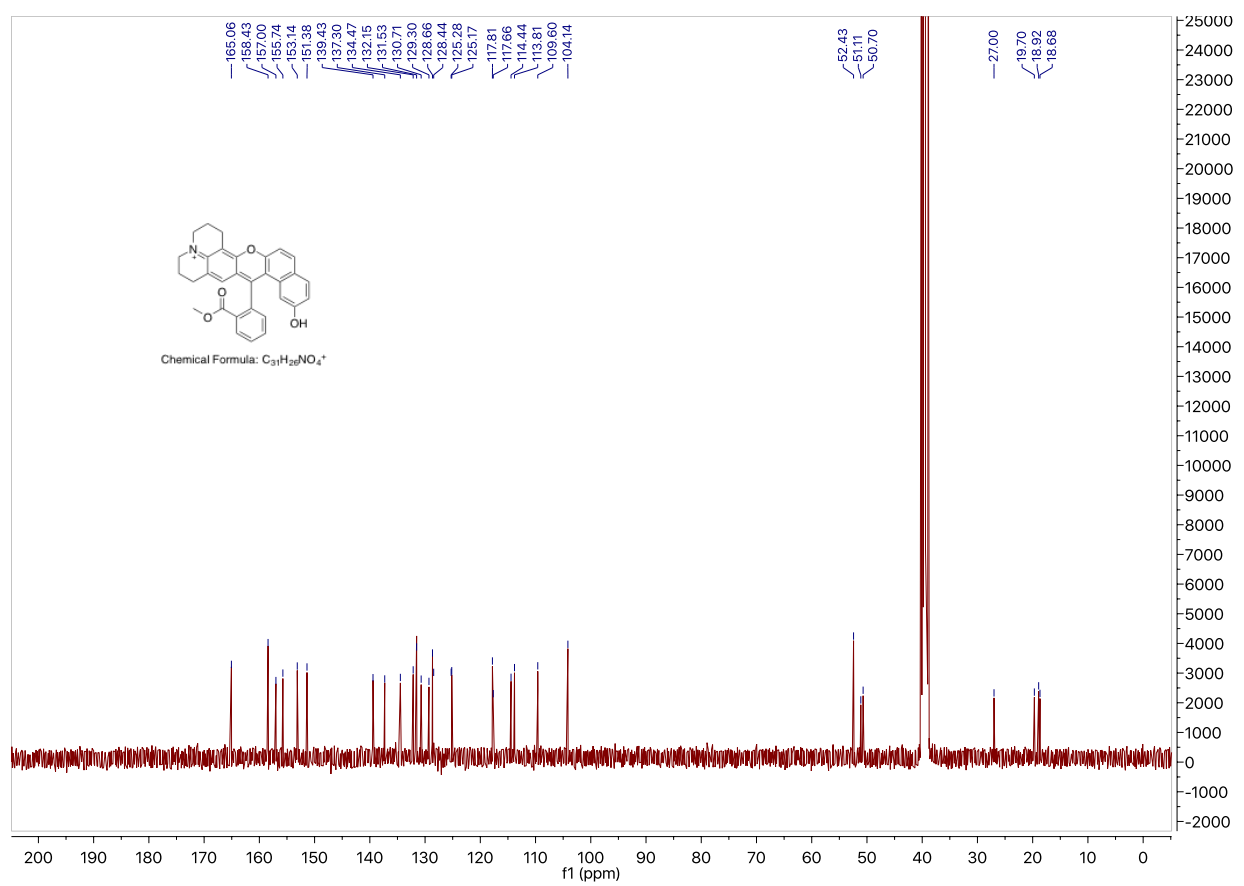

Figure A65. ${ }^{13} \mathrm{C}$ NMR spectrum of compound 7.

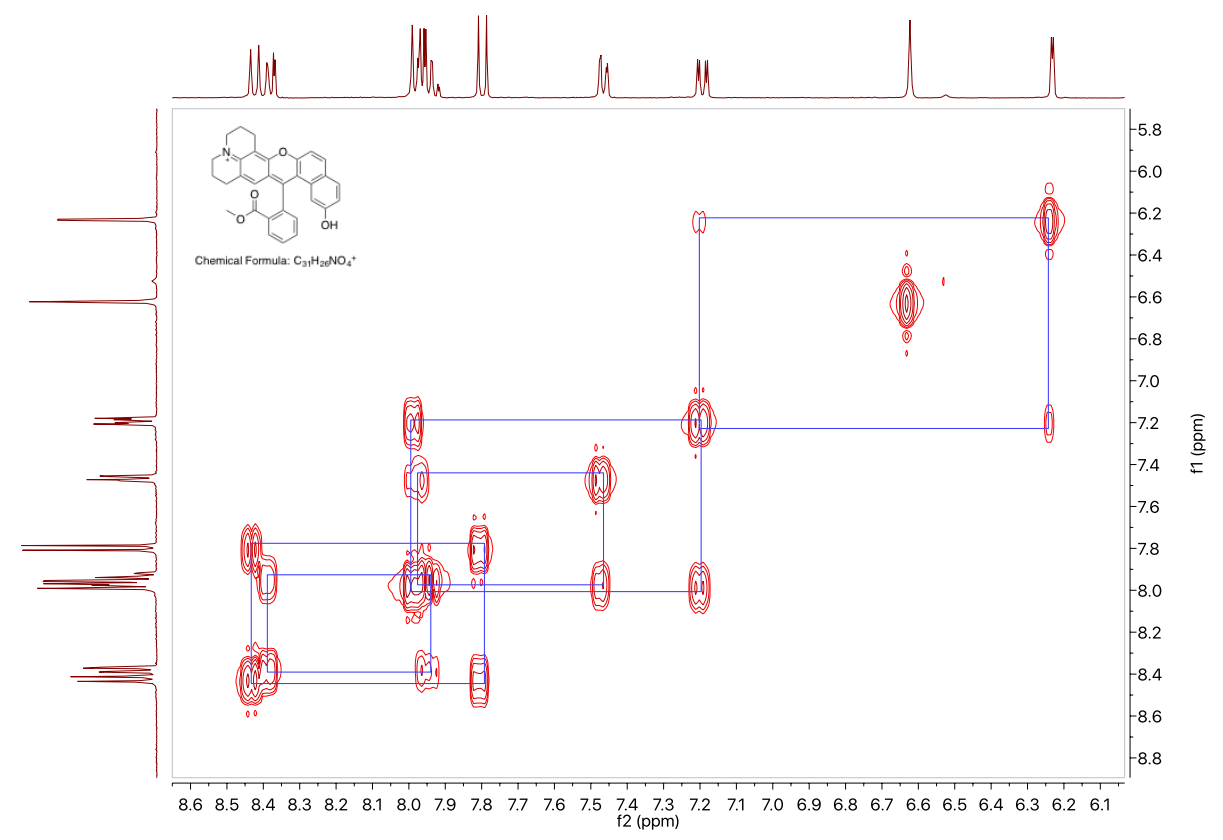

Figure A66. 2D COSY NMR spectrum for compound 7. 


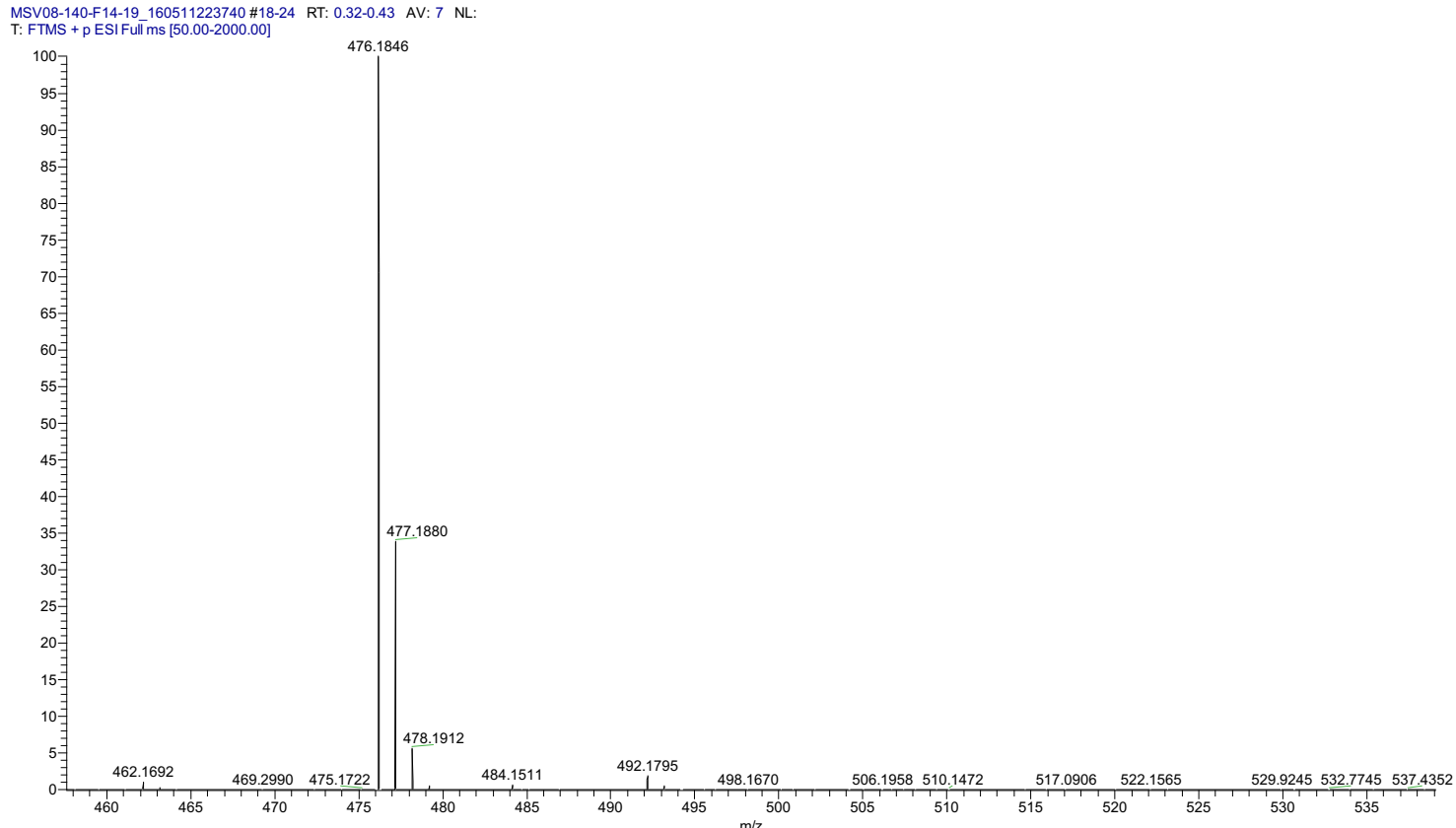

Figure A67. HR ESI positive mode spectrum of compound 7.

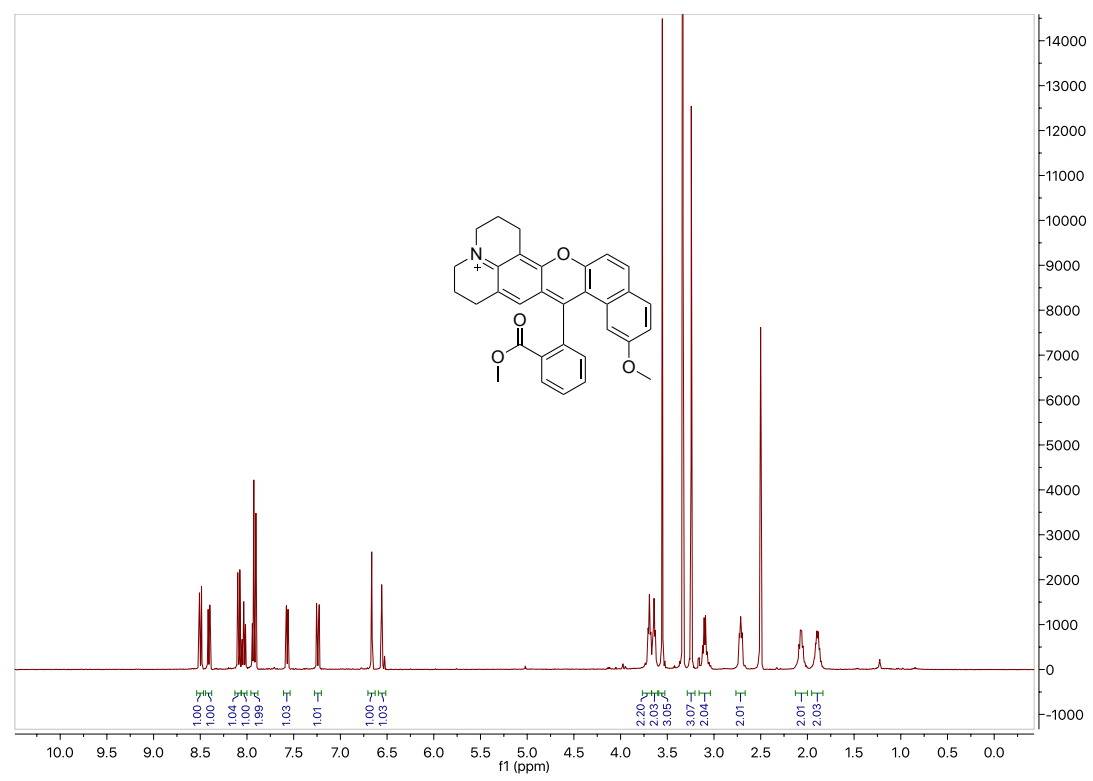

Figure A68. ${ }^{1} \mathrm{H}$ NMR spectrum of compound 8 . 


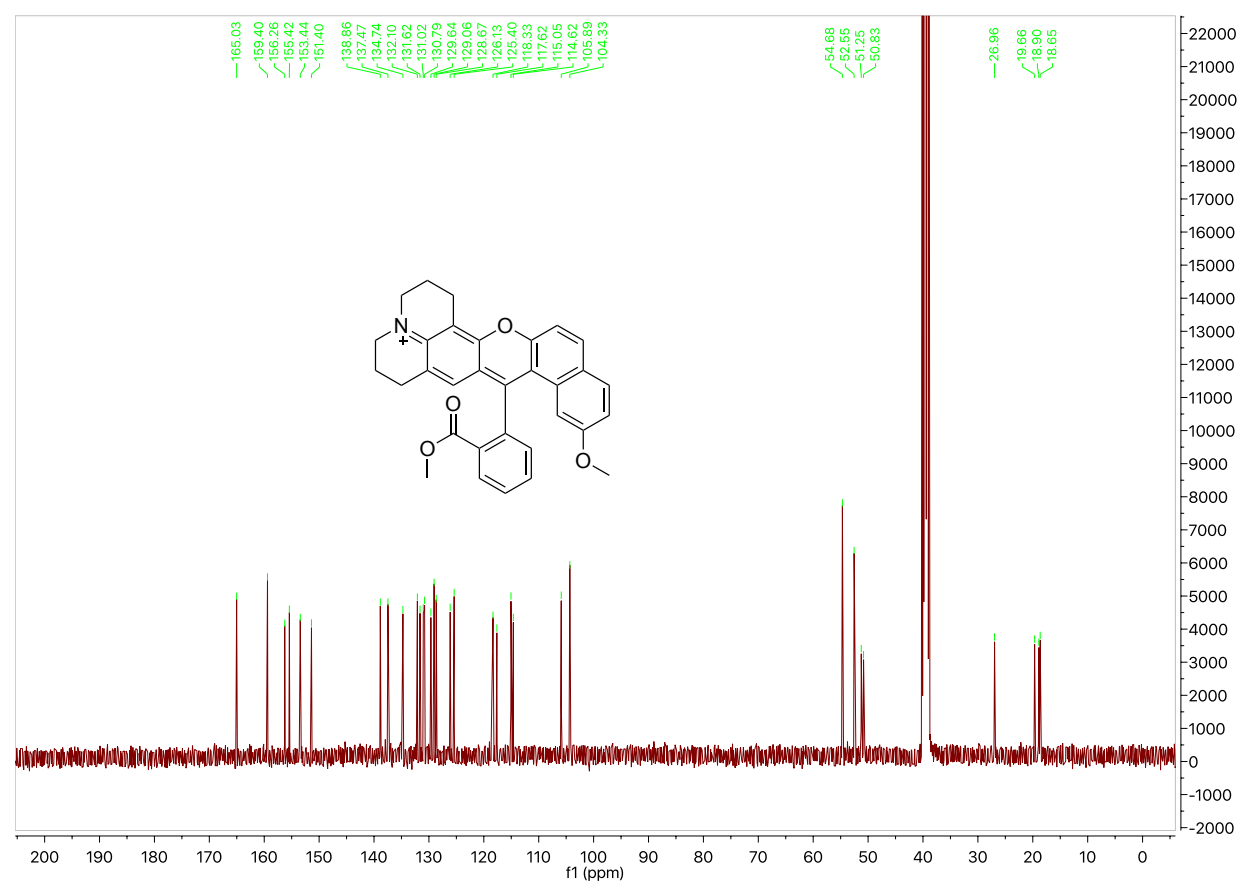

Figure A69. ${ }^{13} \mathrm{C}$ NMR spectrum of compound 8 . 


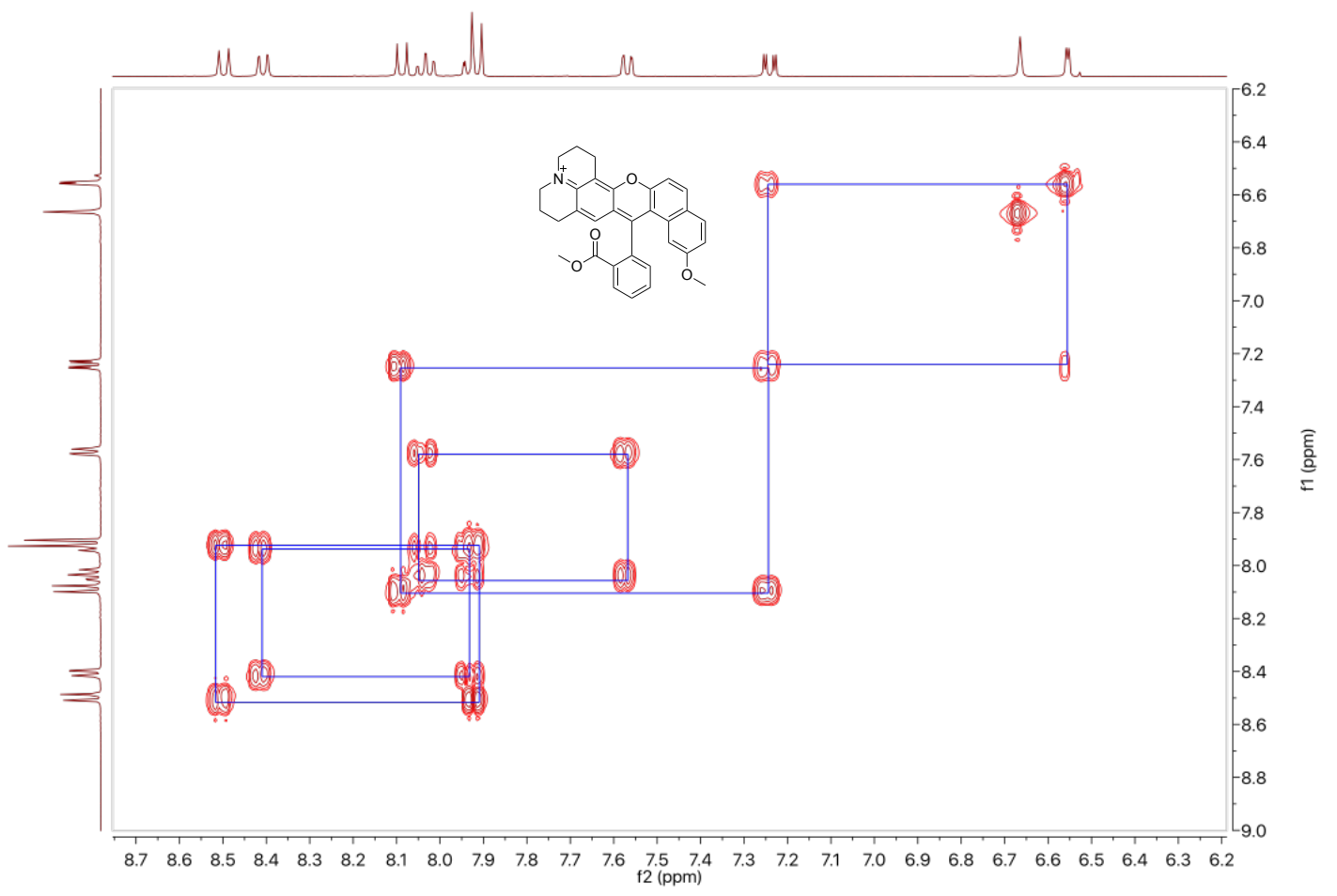

Figure A70. 2D COSY NMR spectrum for compound 8.

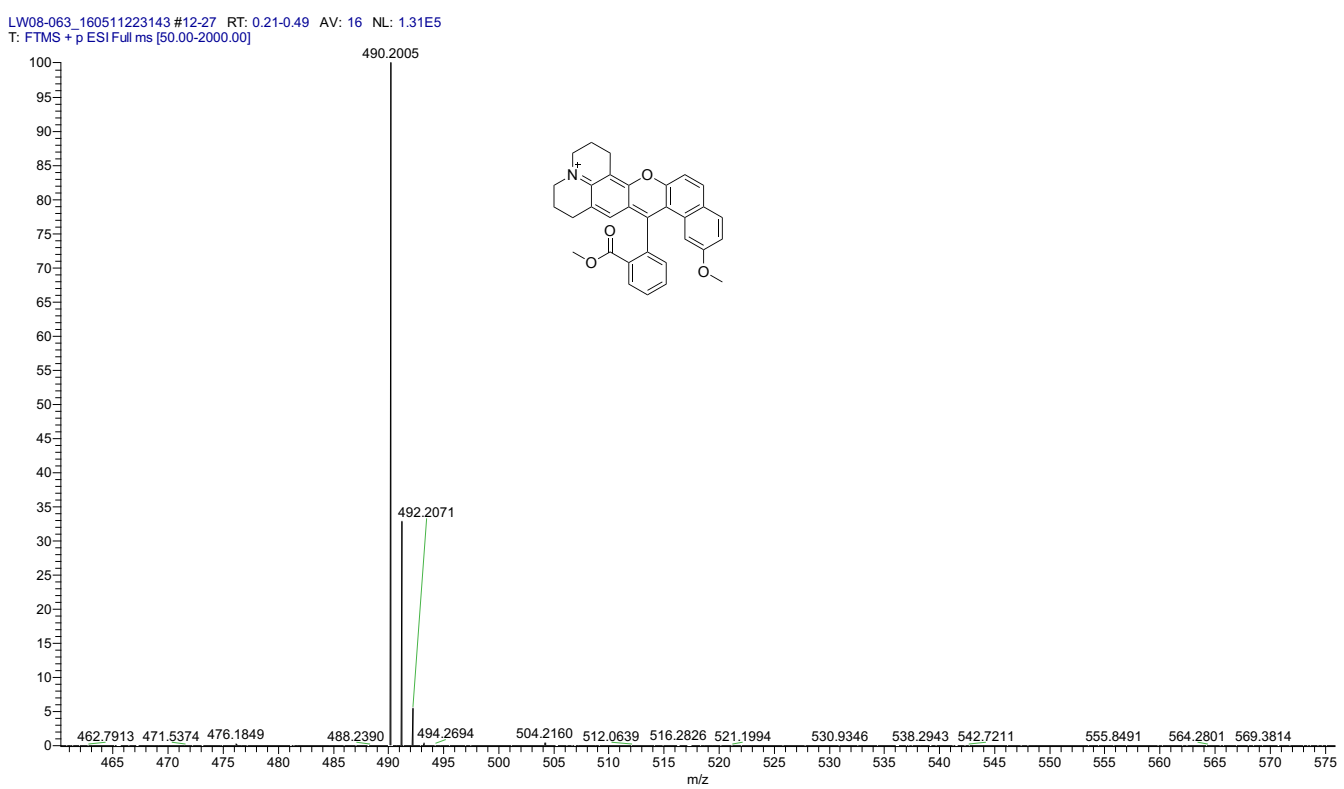

Figure A71. HR ESI positive mode spectrum of compound 8. 


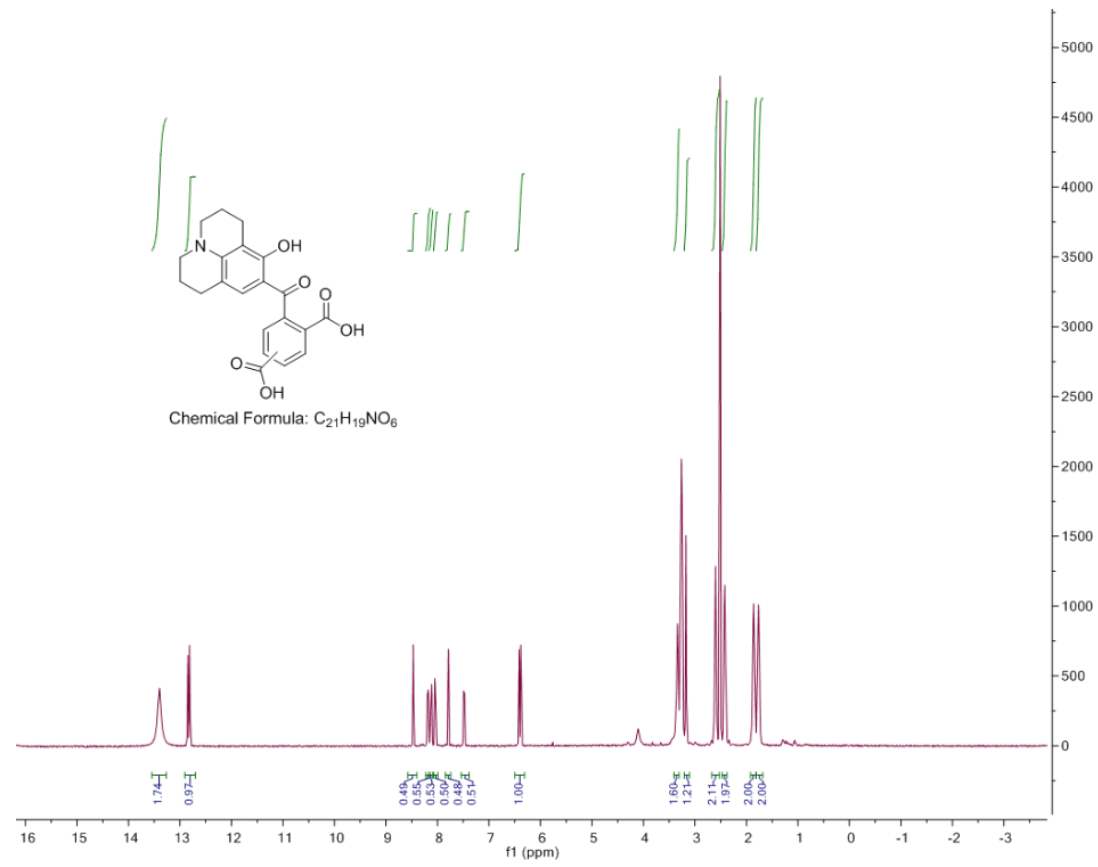

Figure A72. ${ }^{1} \mathrm{H}$ NMR spectrum of compound 29.

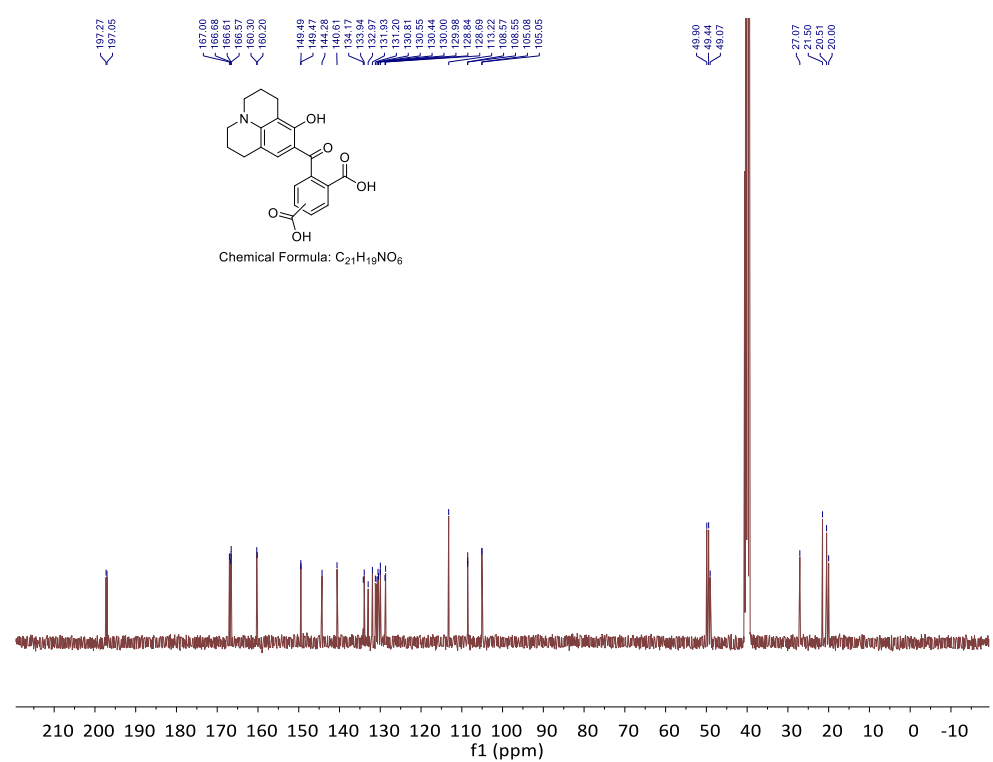

Figure A73. ${ }^{13} \mathrm{C}$ NMR spectrum of compound 29. 


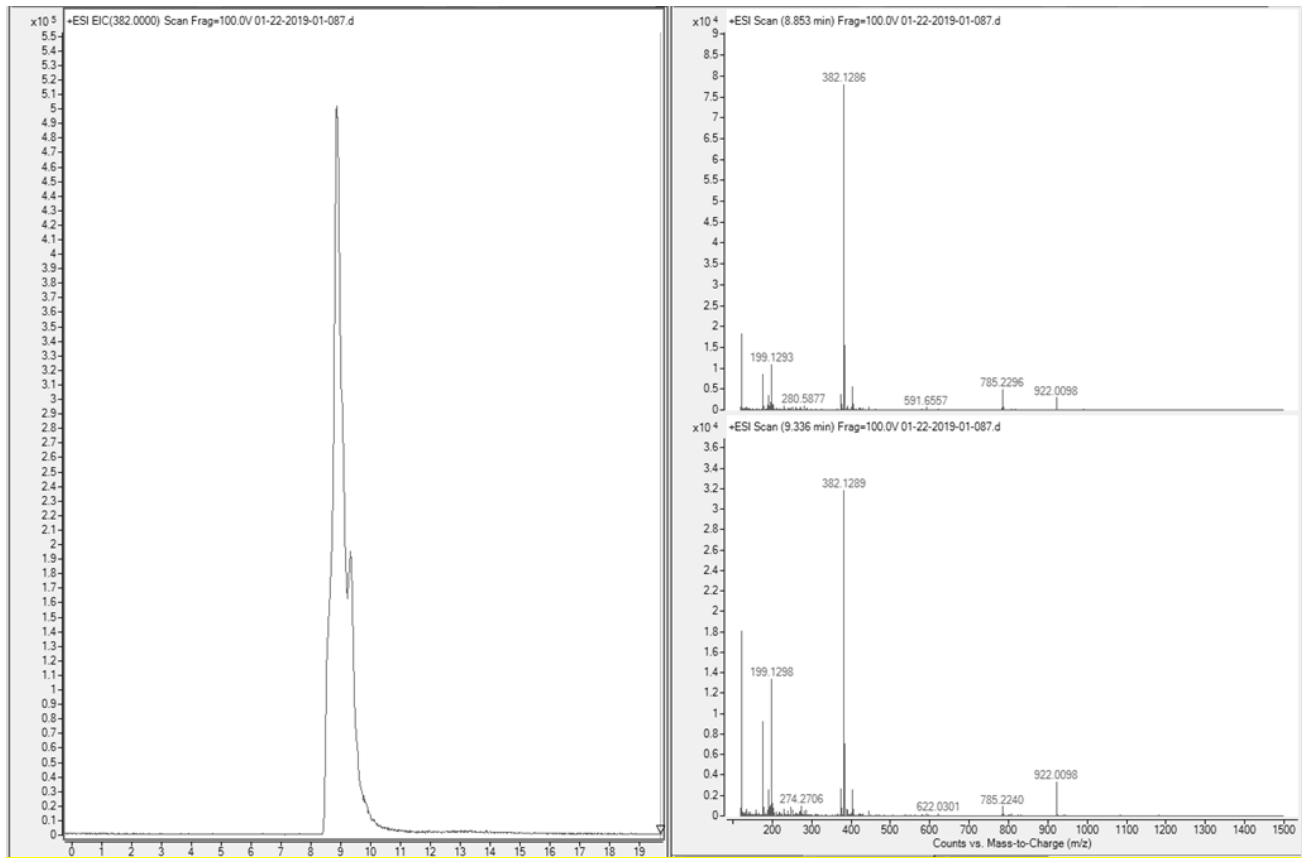

Figure A74. HR ESI positive mode spectrum of compound 29.

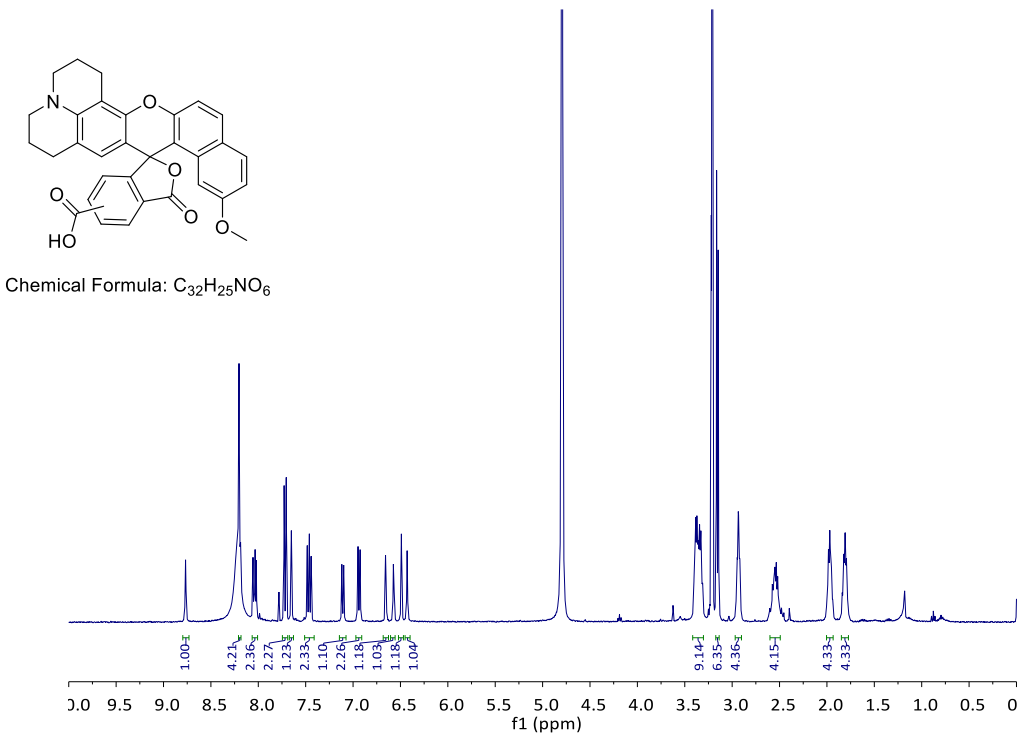

Figure A75. ${ }^{1} \mathrm{H}$ NMR spectrum of compound 30. 


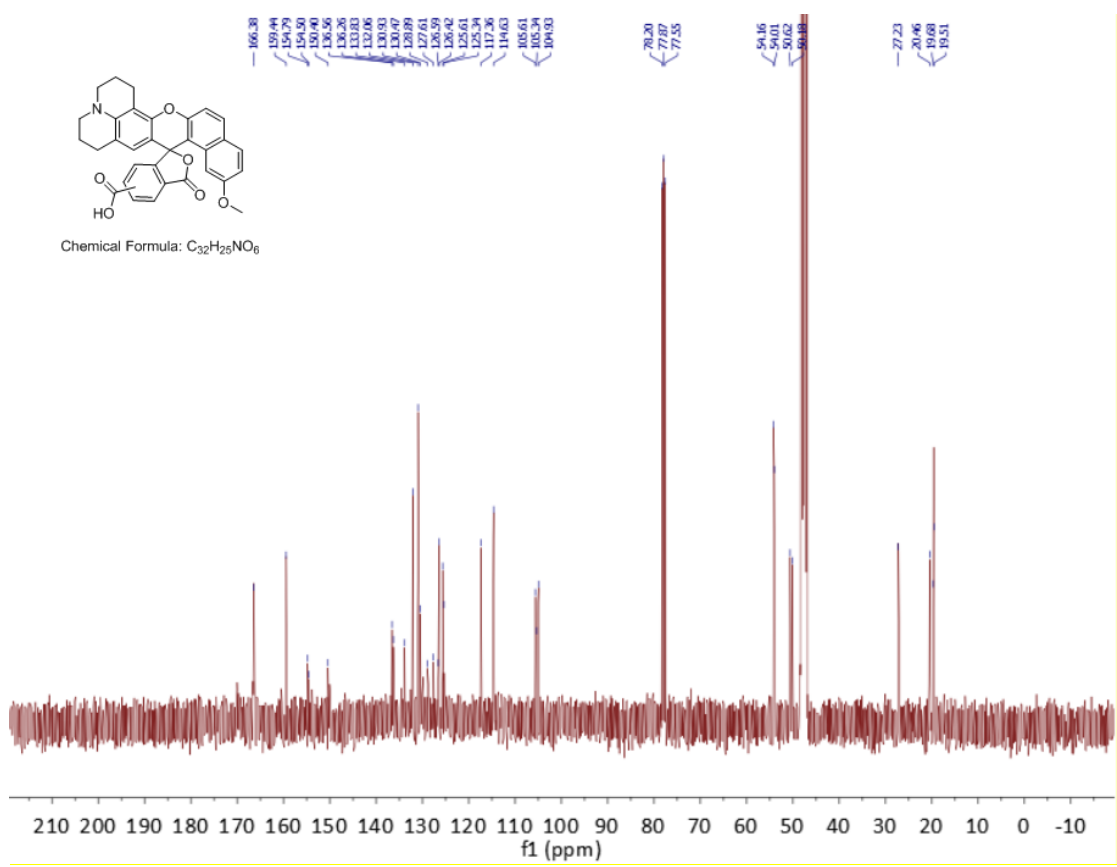

Figure A76. ${ }^{13} \mathrm{C}$ NMR spectrum of compound $\mathbf{3 0}$.
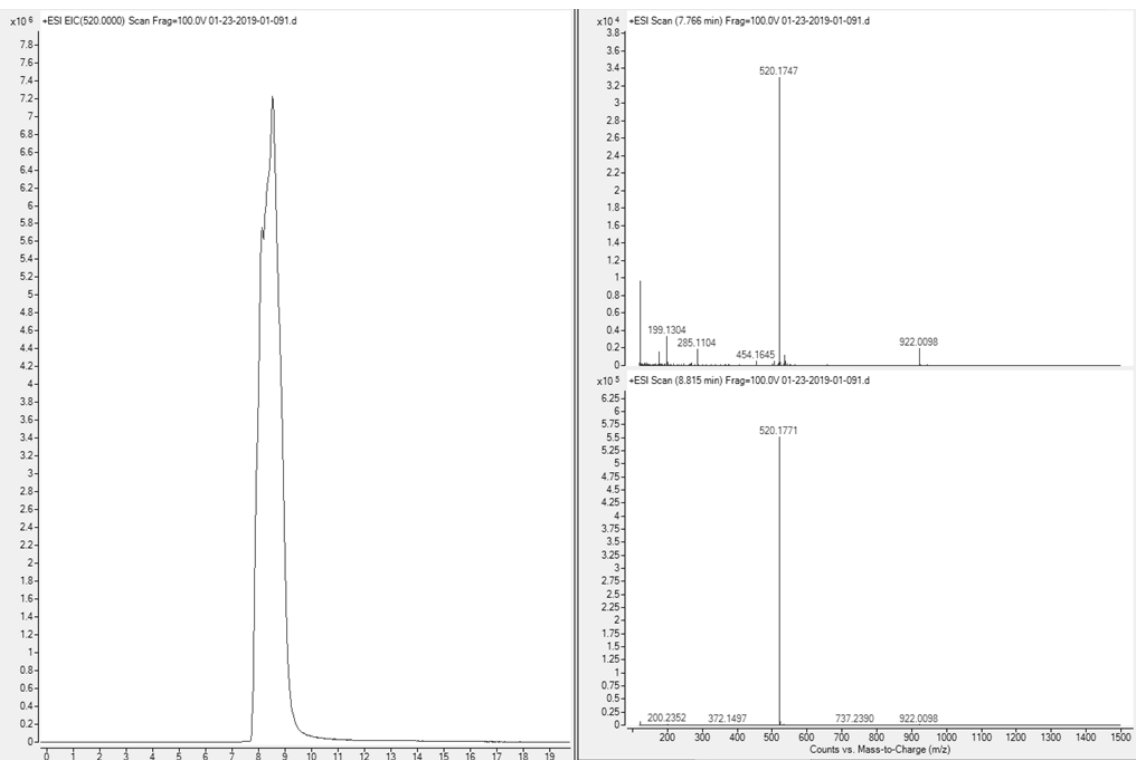

Figure A77. HR ESI positive mode spectrum of compound $\mathbf{3 0}$. 


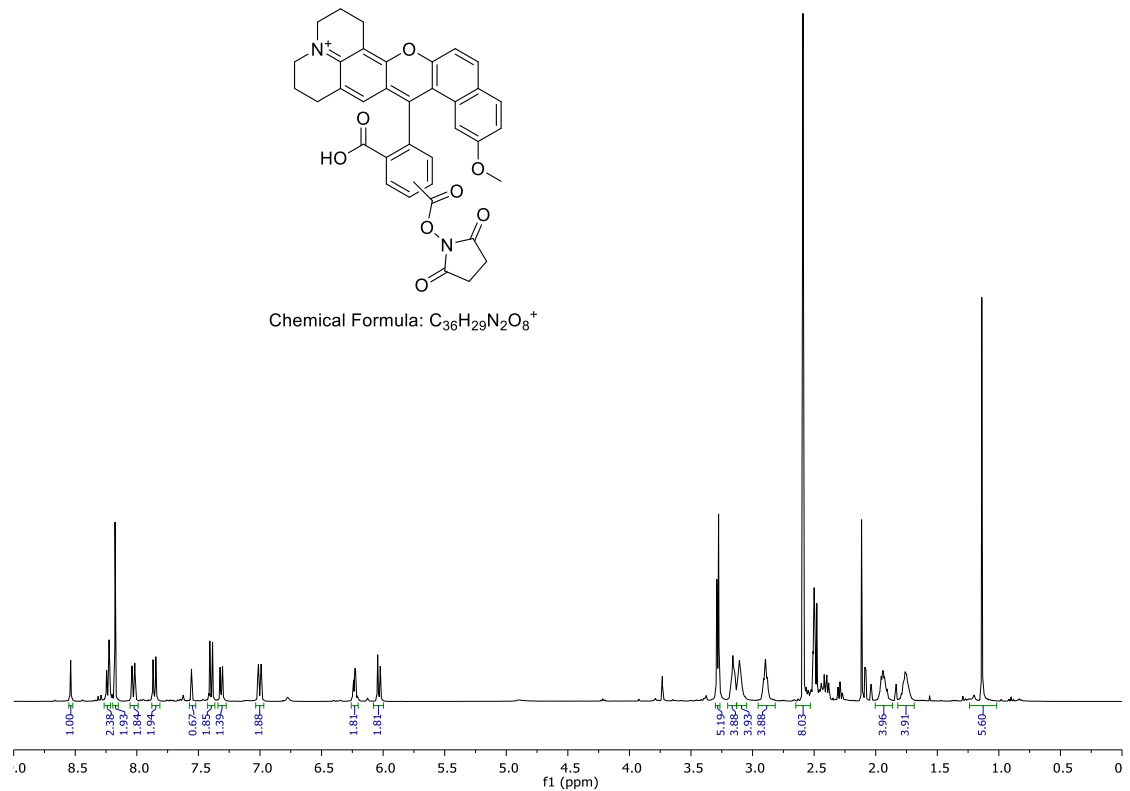

Figure A78. ${ }^{1} \mathrm{H}$ NMR spectrum of compound 8-NHS. 


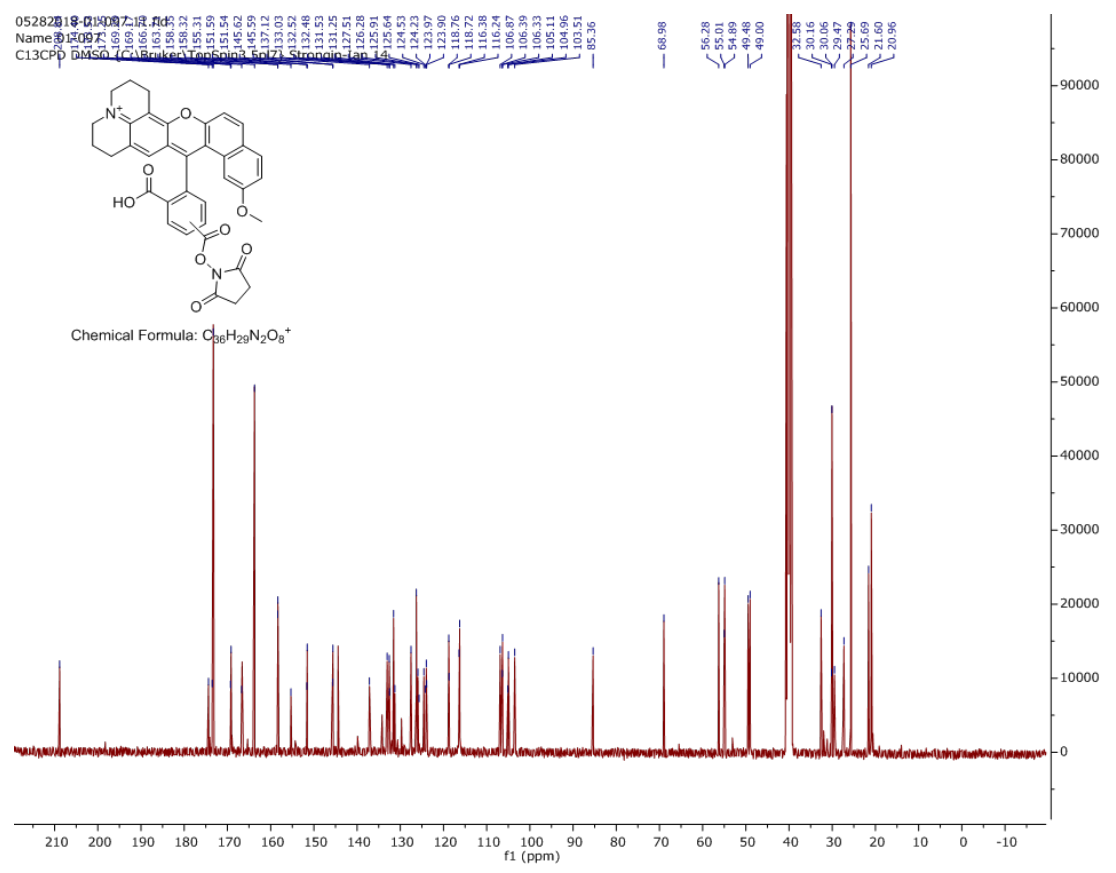

Figure A79. ${ }^{13} \mathrm{C}$ NMR spectrum of compound 8-NHS.
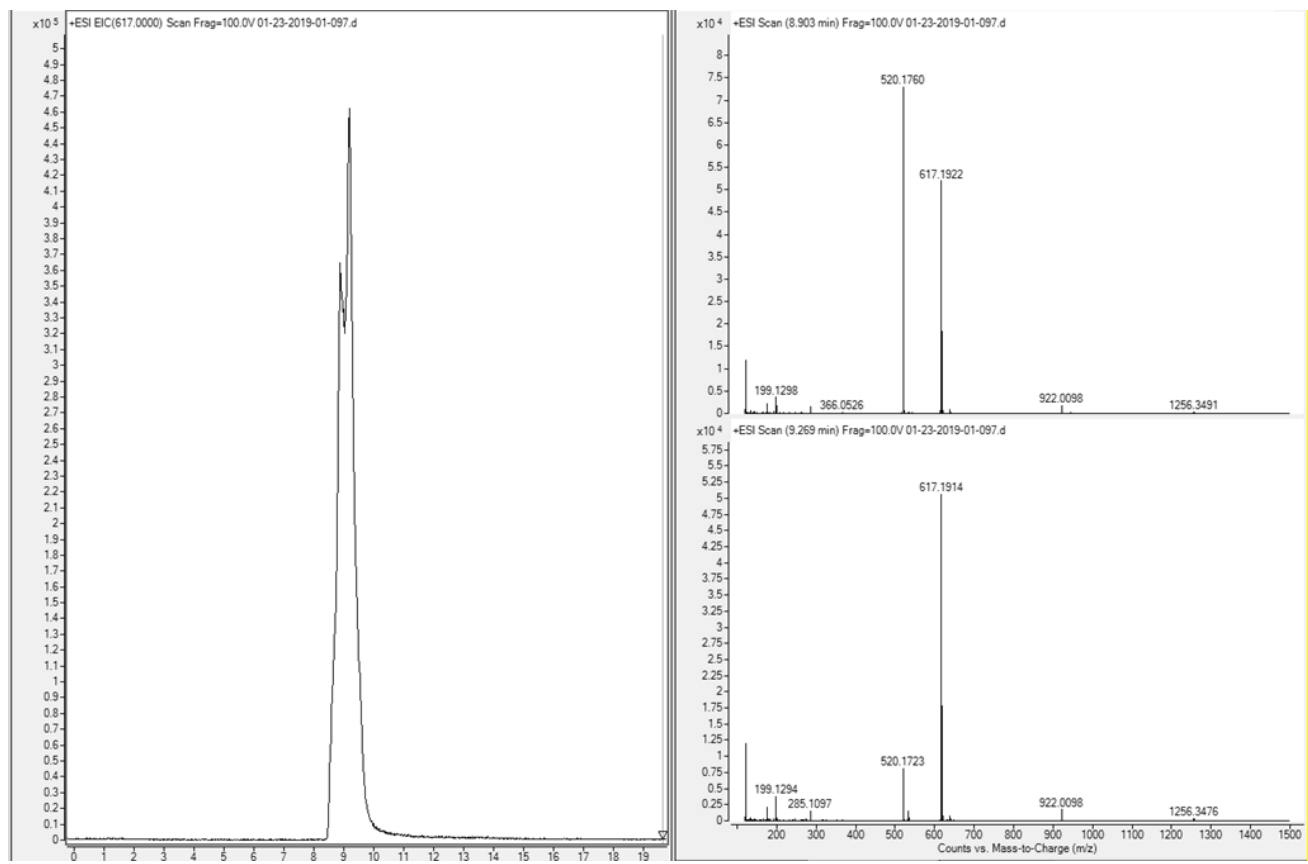

Figure A80. HR ESI positive mode spectrum of compound 8-NHS. 


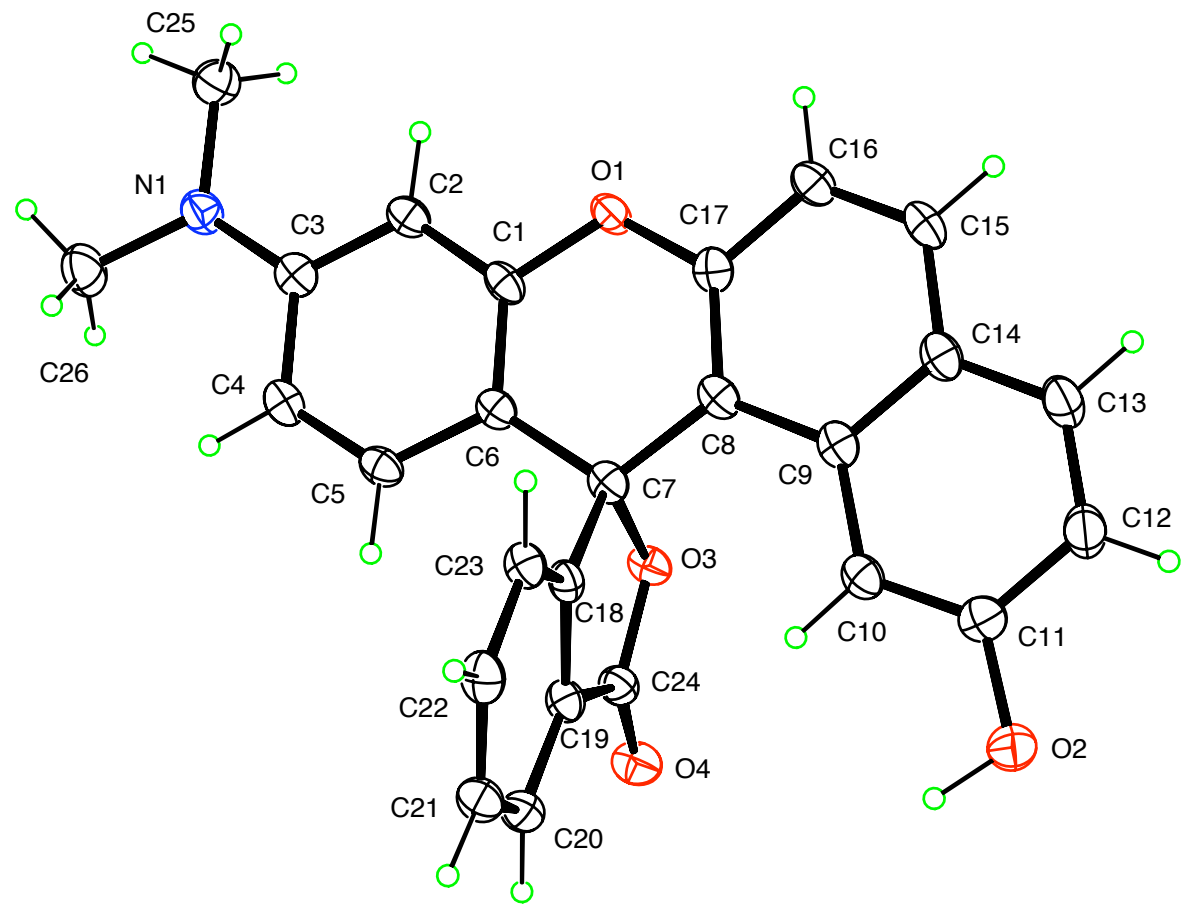

Figure A81. Crystal structure of compound 21. Ellipsoid contours are at the 50\% probability level.

\section{X-ray single-crystal experimental data for compound 21.}

Pink crystals of $\mathbf{2 1}$ were grown by solvent diffusion from chloroform, methanol and hexanes. The crystal structure was determined at $\mathrm{T}=90 \mathrm{~K}$ from data collected to $\theta_{\max }=68.4^{\circ}$ with $\mathrm{Cu} \mathrm{K \alpha}$ radiation on a Bruker Kappa Apex-II diffractometer. 13,611 measured reflections yielded 3585 unique data $\left(\mathrm{R}_{\mathrm{int}}=0.049\right)$, of which $2737 \mathrm{had} \mathrm{I}>2 \sigma(\mathrm{I}) . \mathrm{C}_{26} \mathrm{H}_{19} \mathrm{NO}_{4}$, $\mathrm{FW}=409.42$, monoclinic space group $\mathrm{P} 2{ }_{1} / \mathrm{c}, \mathrm{a}=13.6561(14), \mathrm{b}=7.5404(10), \mathrm{c}=20.070(2) \AA$, $\beta=106.046(5)^{\circ}, V=1986.1(4) \AA^{3}, Z=4$. Absorption corrections were by the multi-scan method. Nonhydrogen atoms were treated with anisotropic displacement parameters. All $\mathrm{H}$ atoms were visible in difference maps, but were placed in idealized positions except for that of the $\mathrm{OH}$ group, for which coordinates were refined. Refinement yielded $\mathrm{R}=0.039$ for the $\mathrm{I}>2 \sigma(\mathrm{I})$ data, $\mathrm{wR}\left(\mathrm{F}^{2}\right)=0.102$ for all data and 286 parameters. $\mathrm{GOF}=1.02$, 
$\Delta \rho_{\max }=0.25 \mathrm{e} \AA^{-3}, \Delta \rho_{\min }=-0.21 \mathrm{e} \AA^{-3}$. The CIF has been deposited at the Cambridge Crystallographic Data Centre, CCDC 1417685. 
Appendix B: Supporting Information for Chapter 4
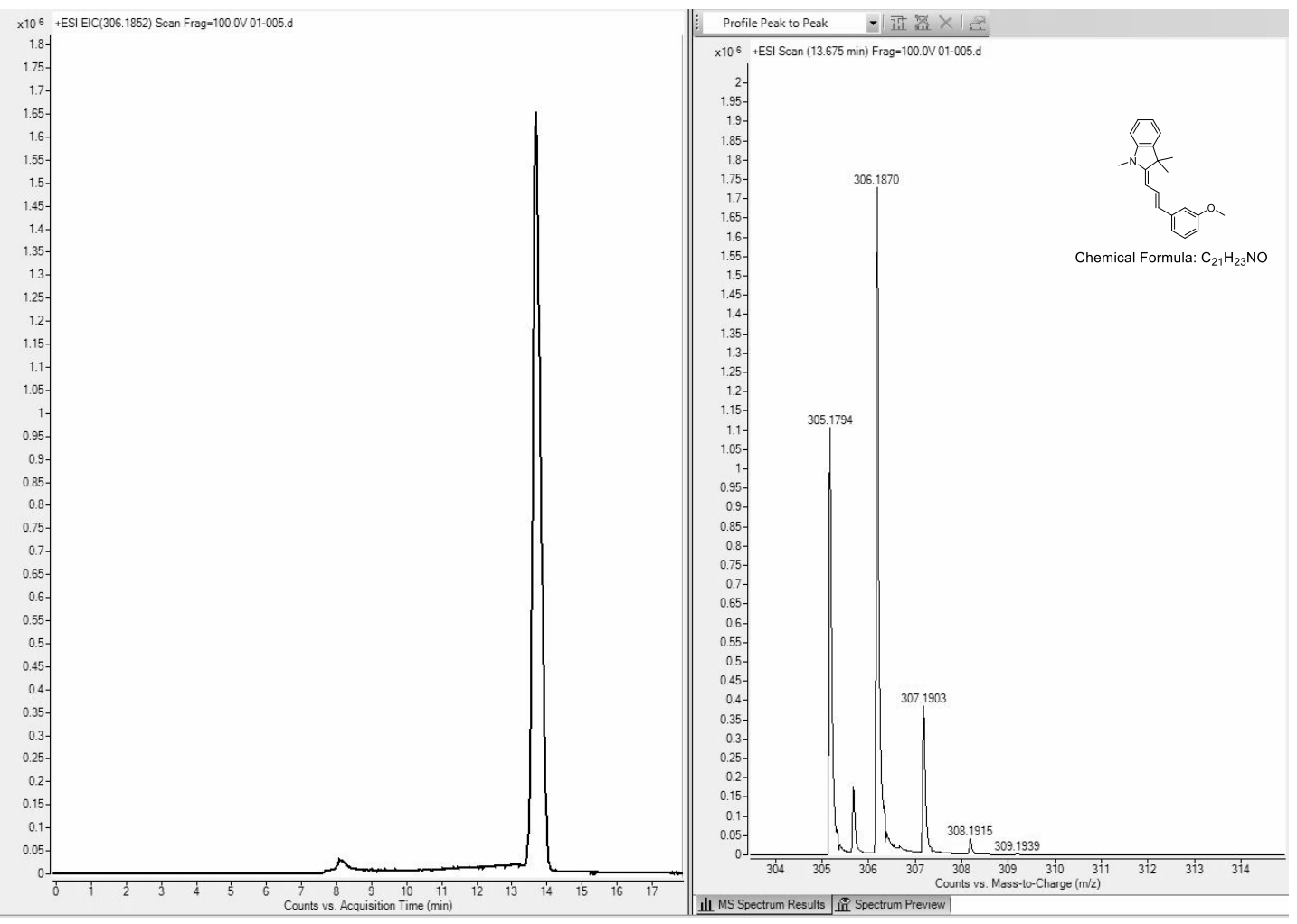

Figure B1. HR ESI positive mode spectrum of compound 14. 


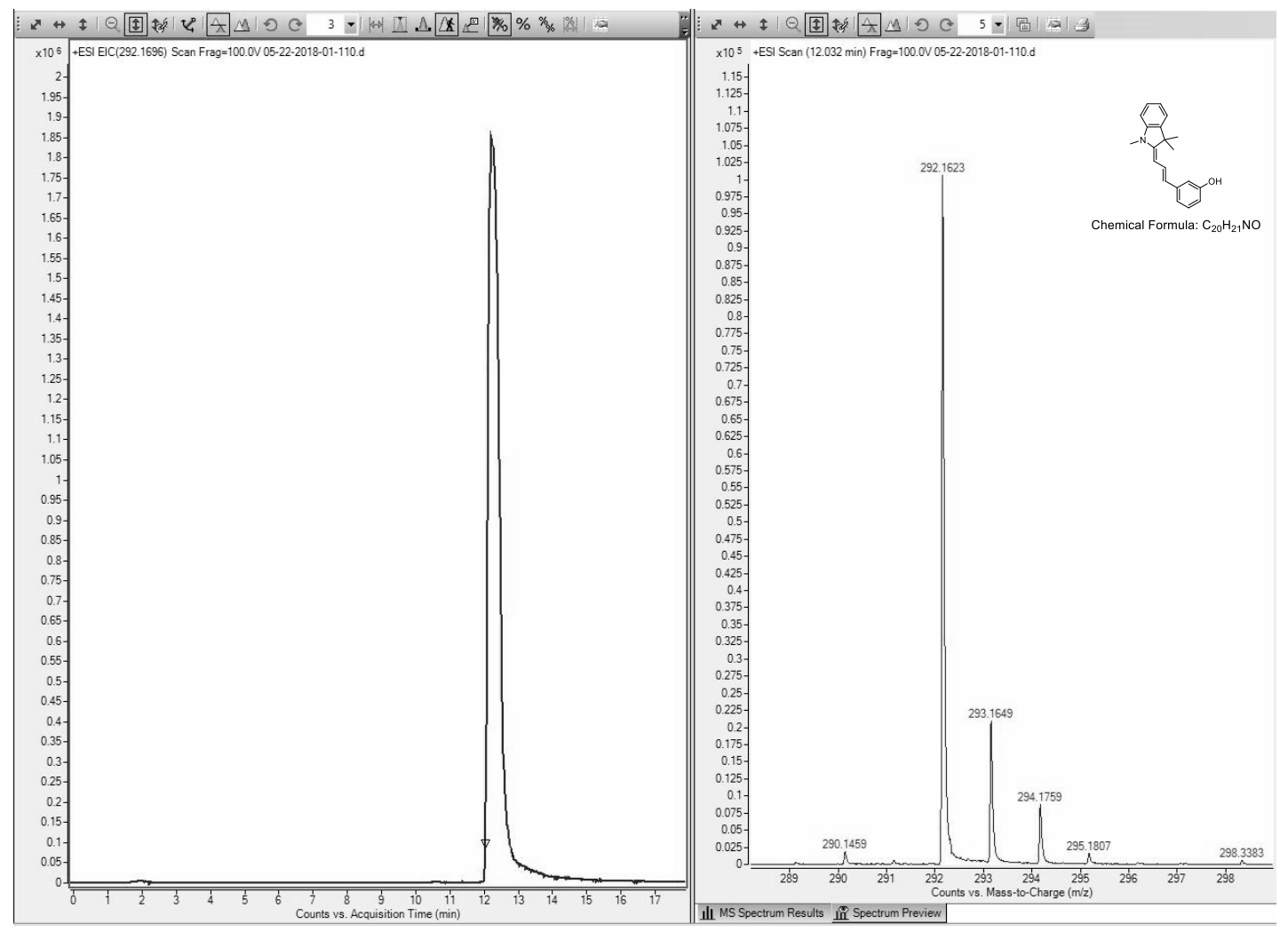

Figure B2. HR ESI positive mode spectrum of compound $\mathbf{1 5 .}$ 


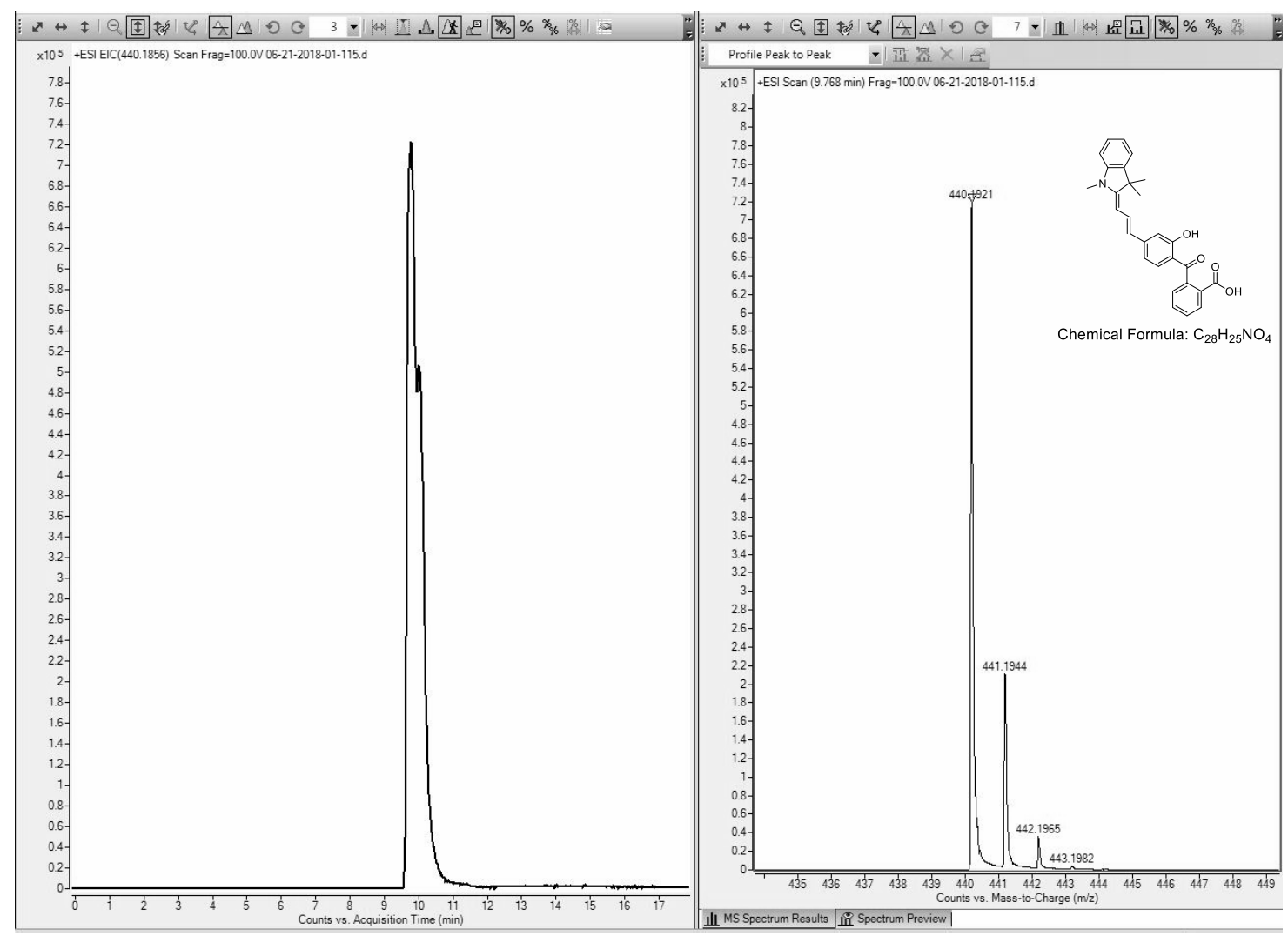

Figure B3. HR ESI positive mode spectrum of compound 17. 


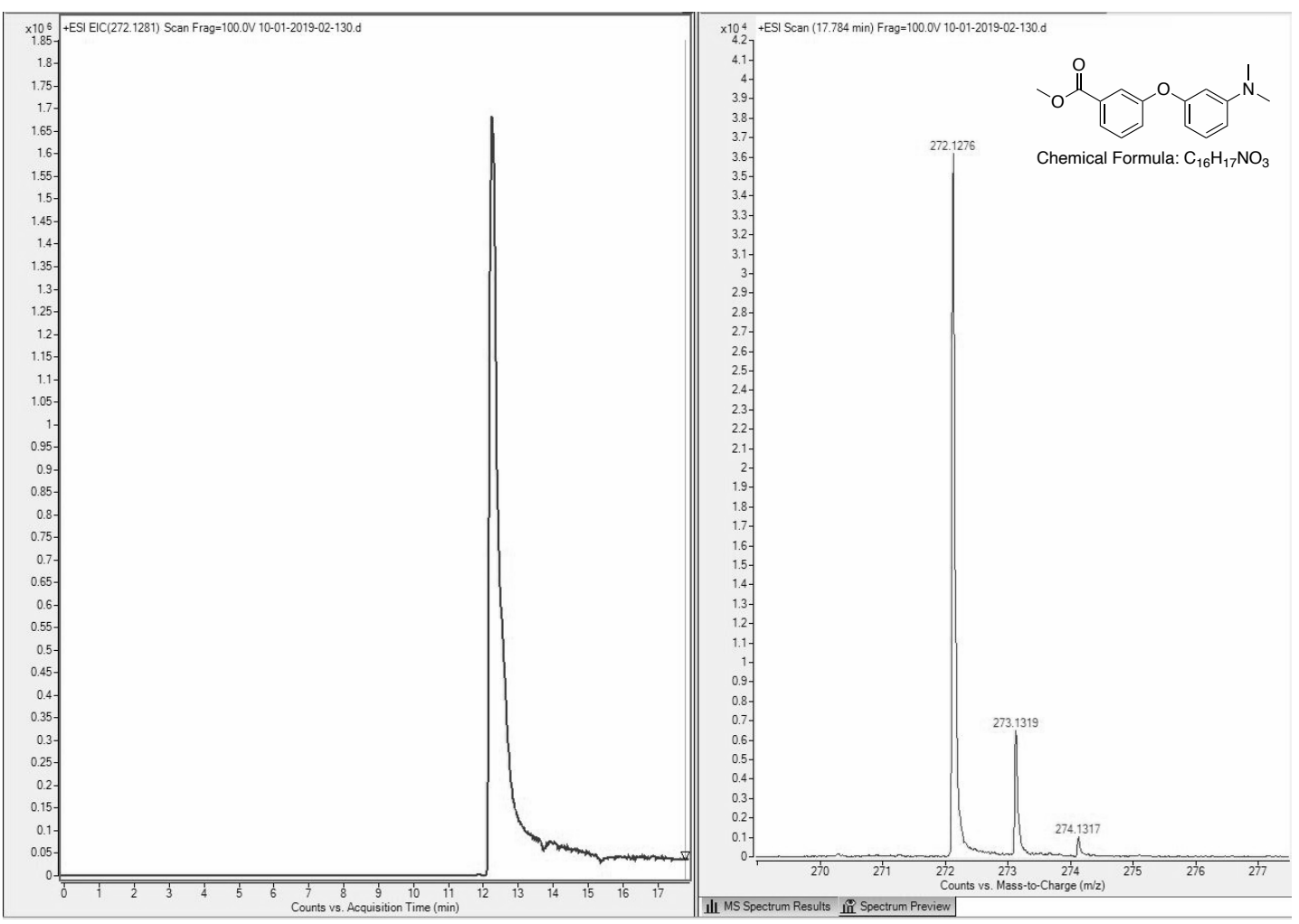

Figure B4. HR ESI positive mode spectrum of compound 22. 


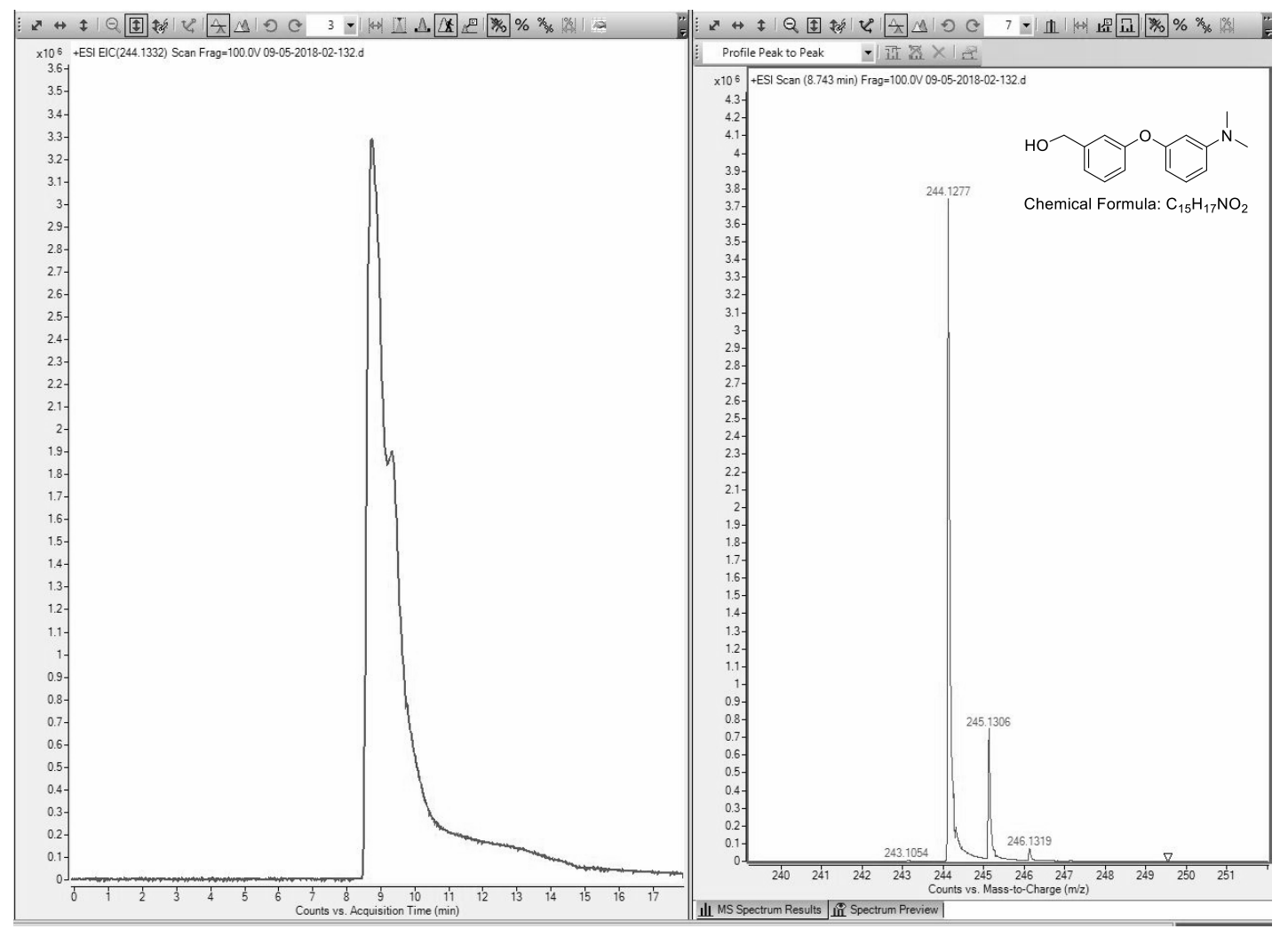

Figure B5. HR ESI positive mode spectrum of compound 23. 


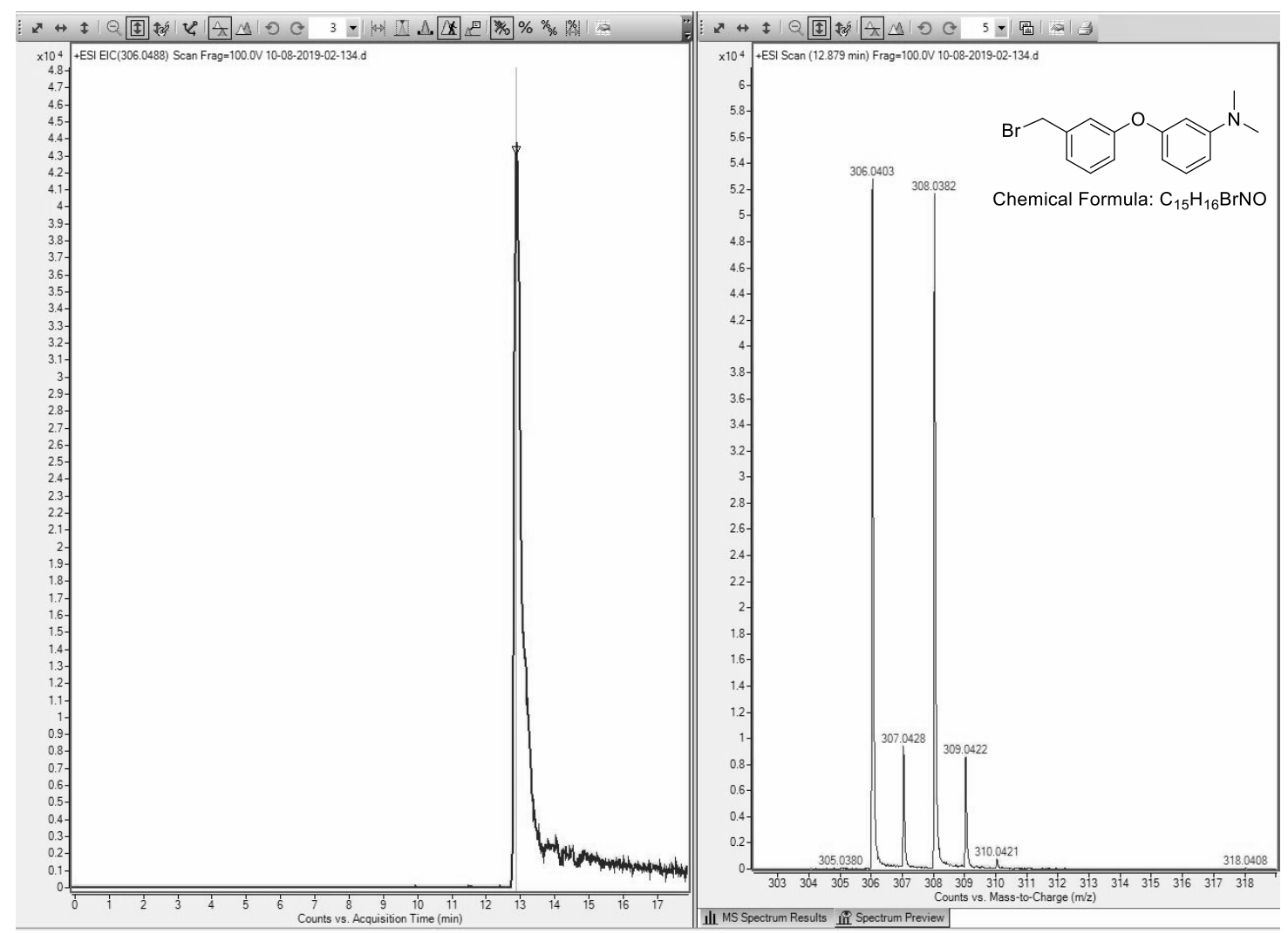

Figure B6. HR ESI positive mode spectrum of compound 24. 


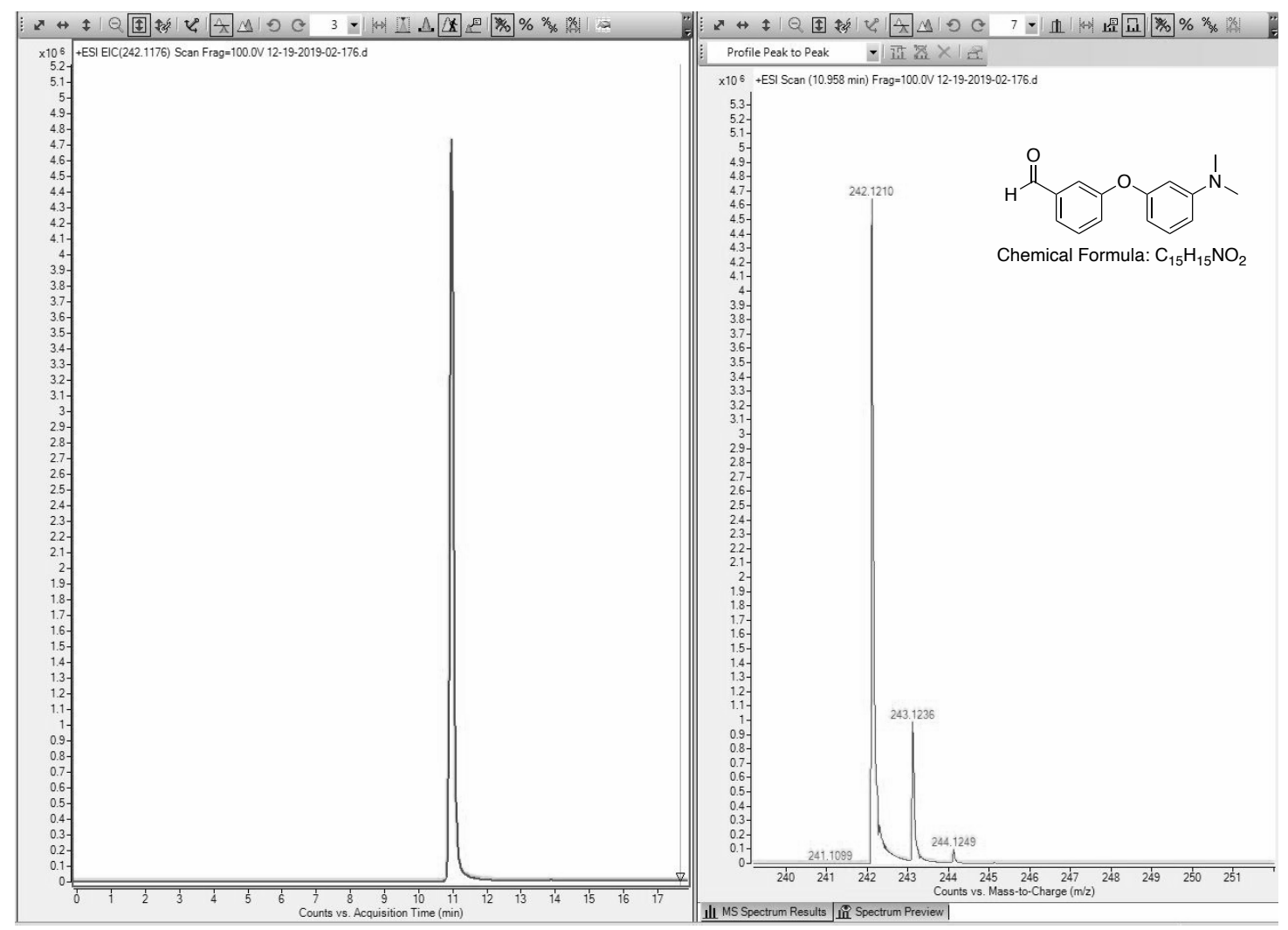

Figure B7. HR ESI positive mode spectrum of compound 25. 


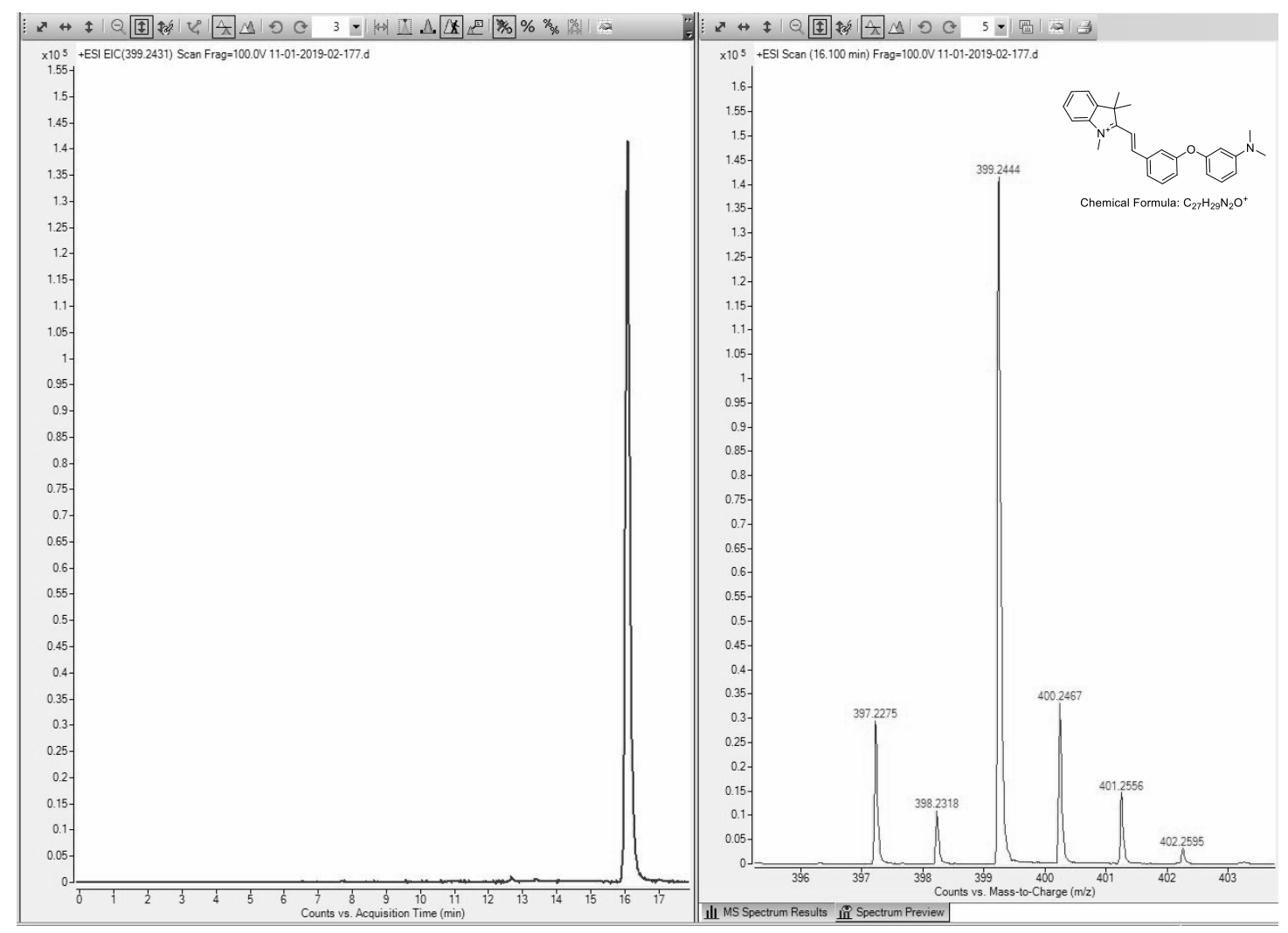

Figure B8. HR ESI positive mode spectrum of compound 27. 


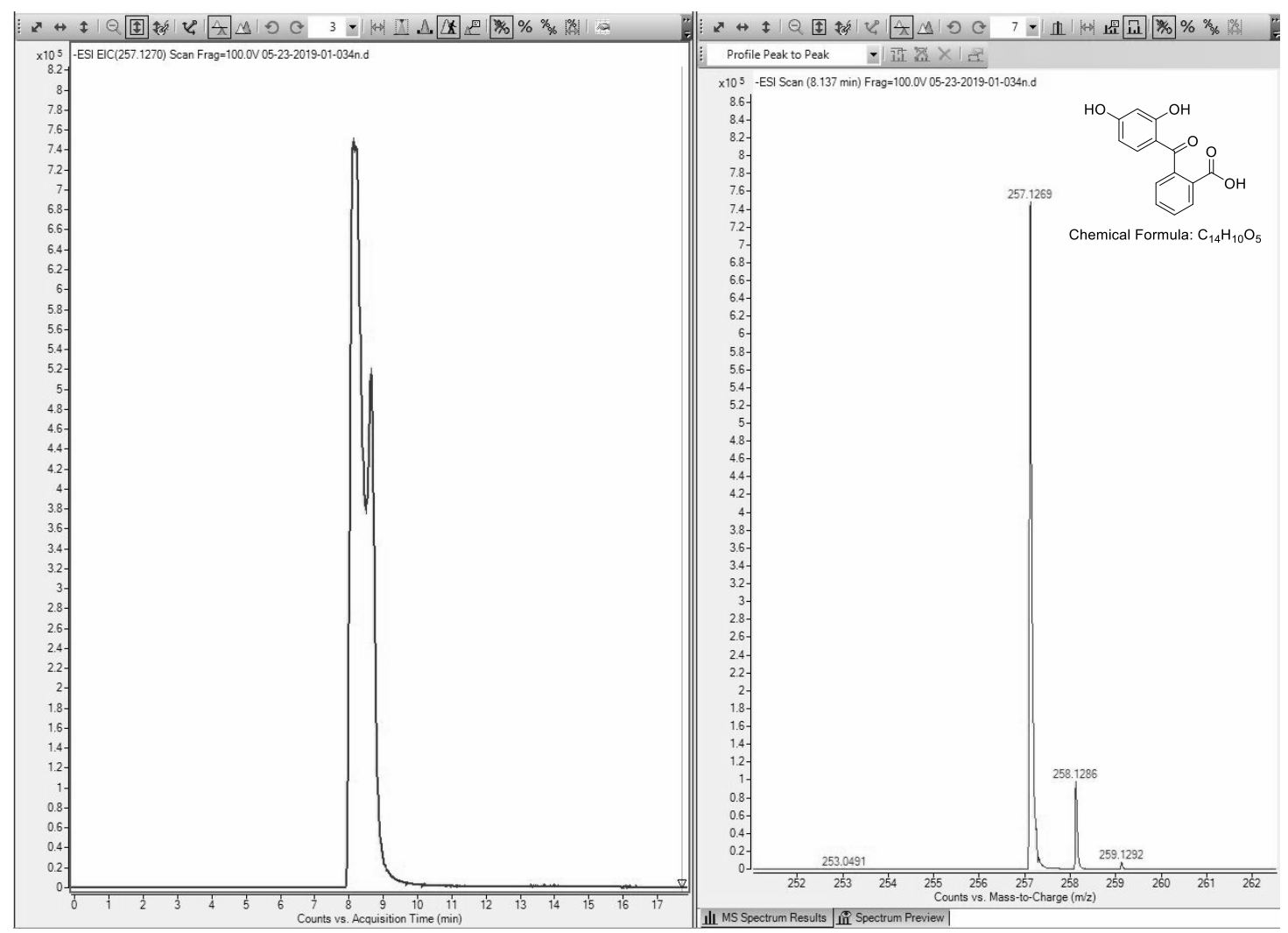

Figure B9. HR ESI positive mode spectrum of compound $\mathbf{3 0}$. 


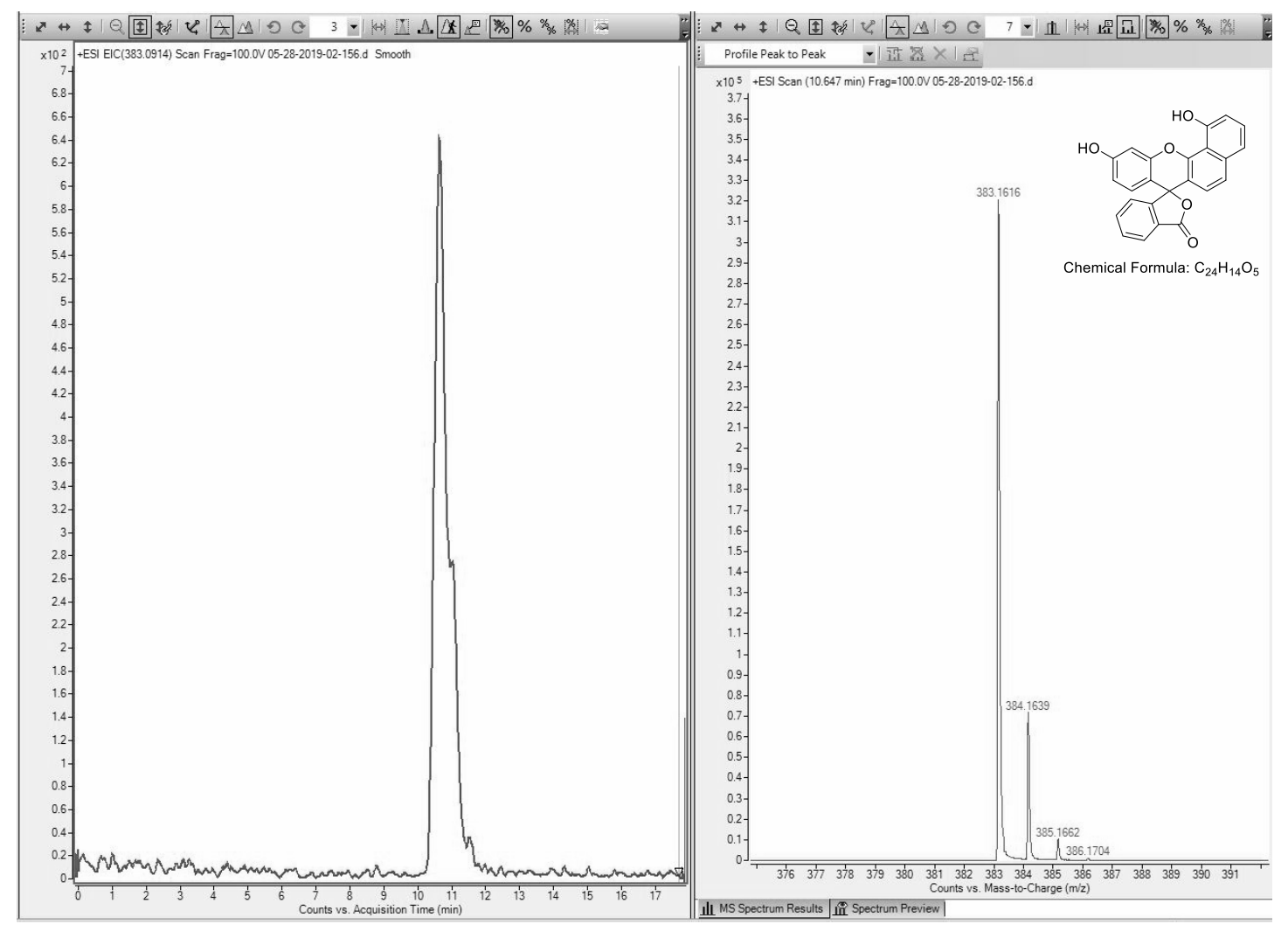

Figure B10. HR ESI positive mode spectrum of compound 31 . 


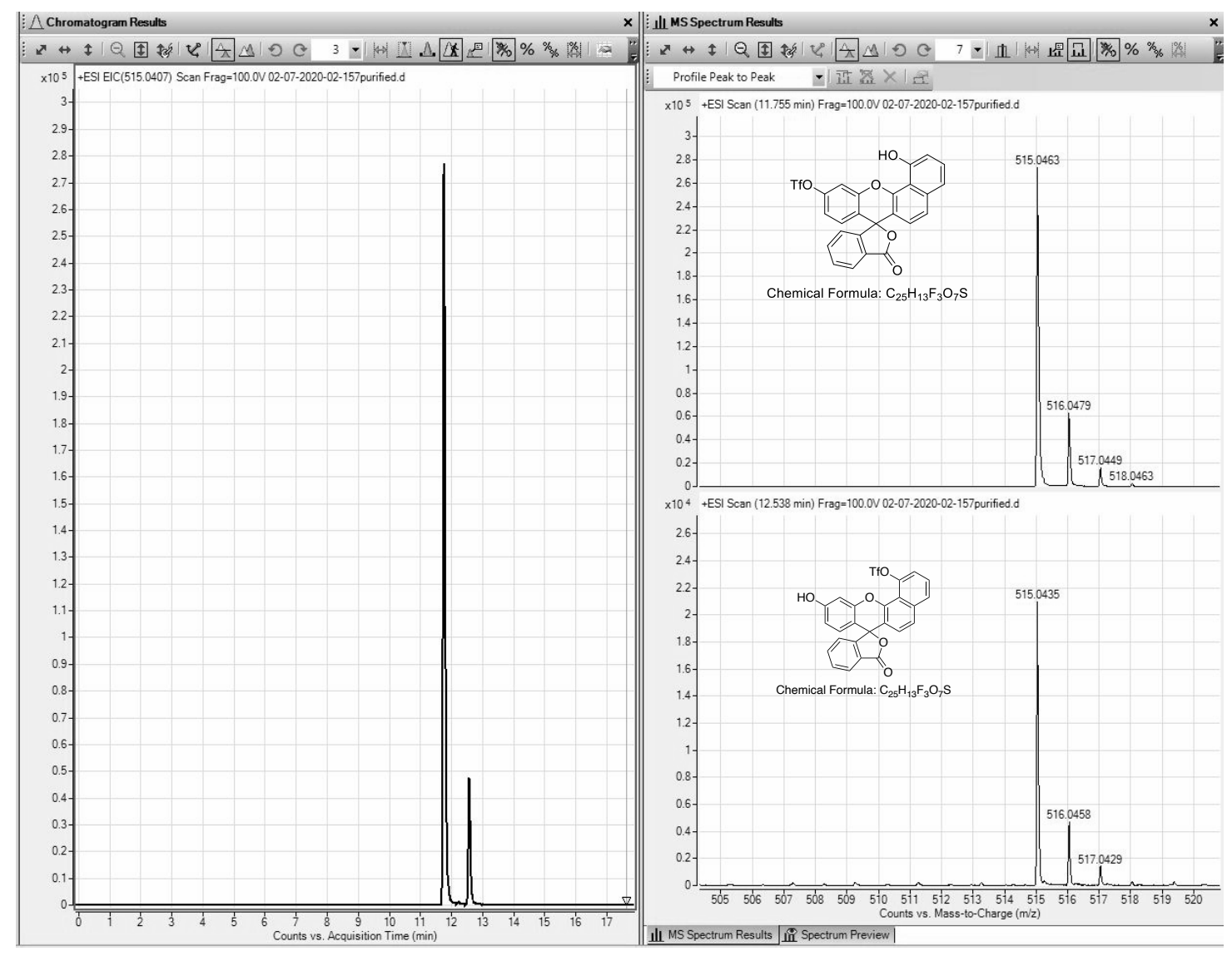

Figure B11. HR ESI positive mode spectrum of compound 32. 


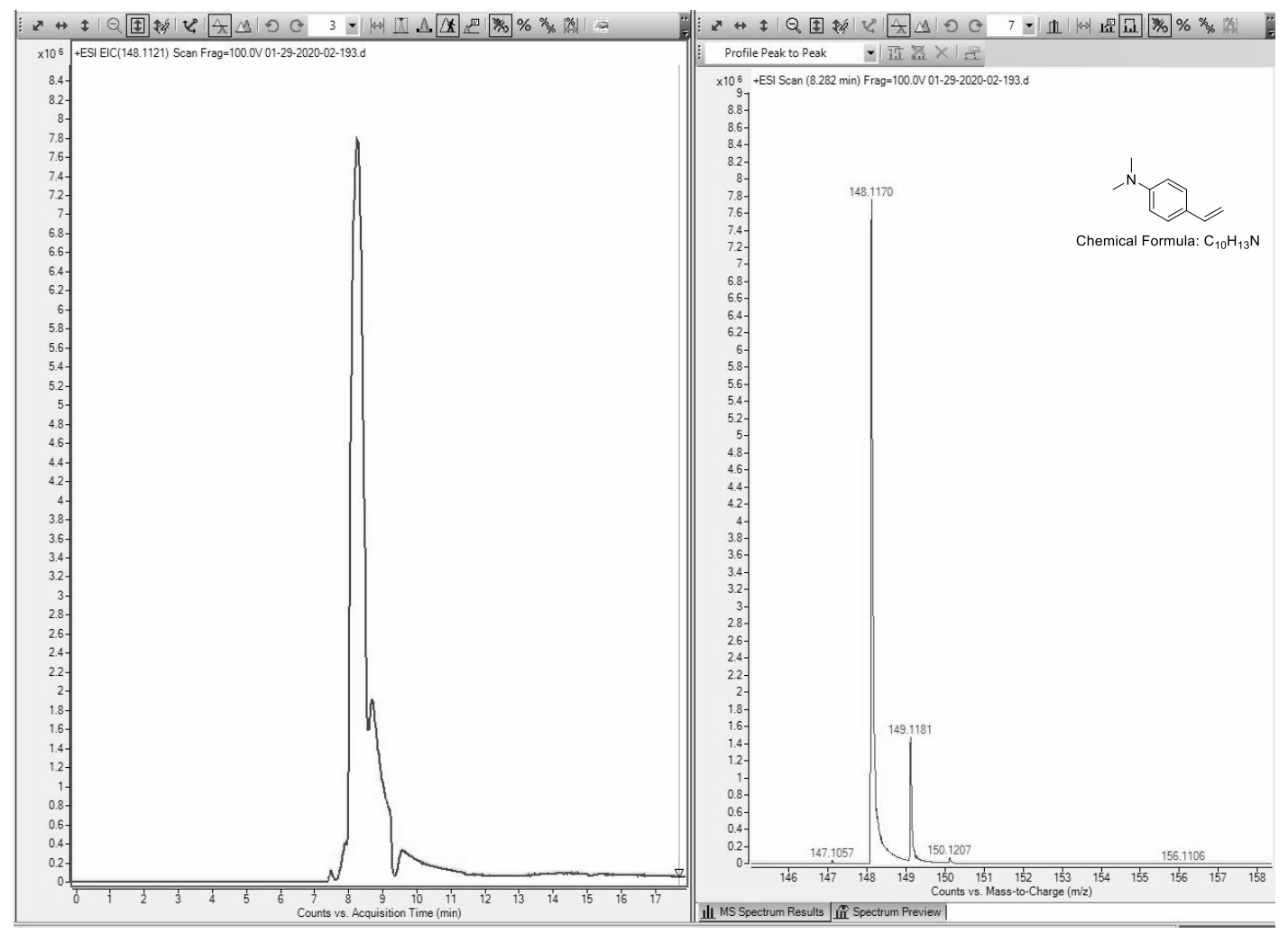

Figure B12. HR ESI positive mode spectrum of compound 33 . 


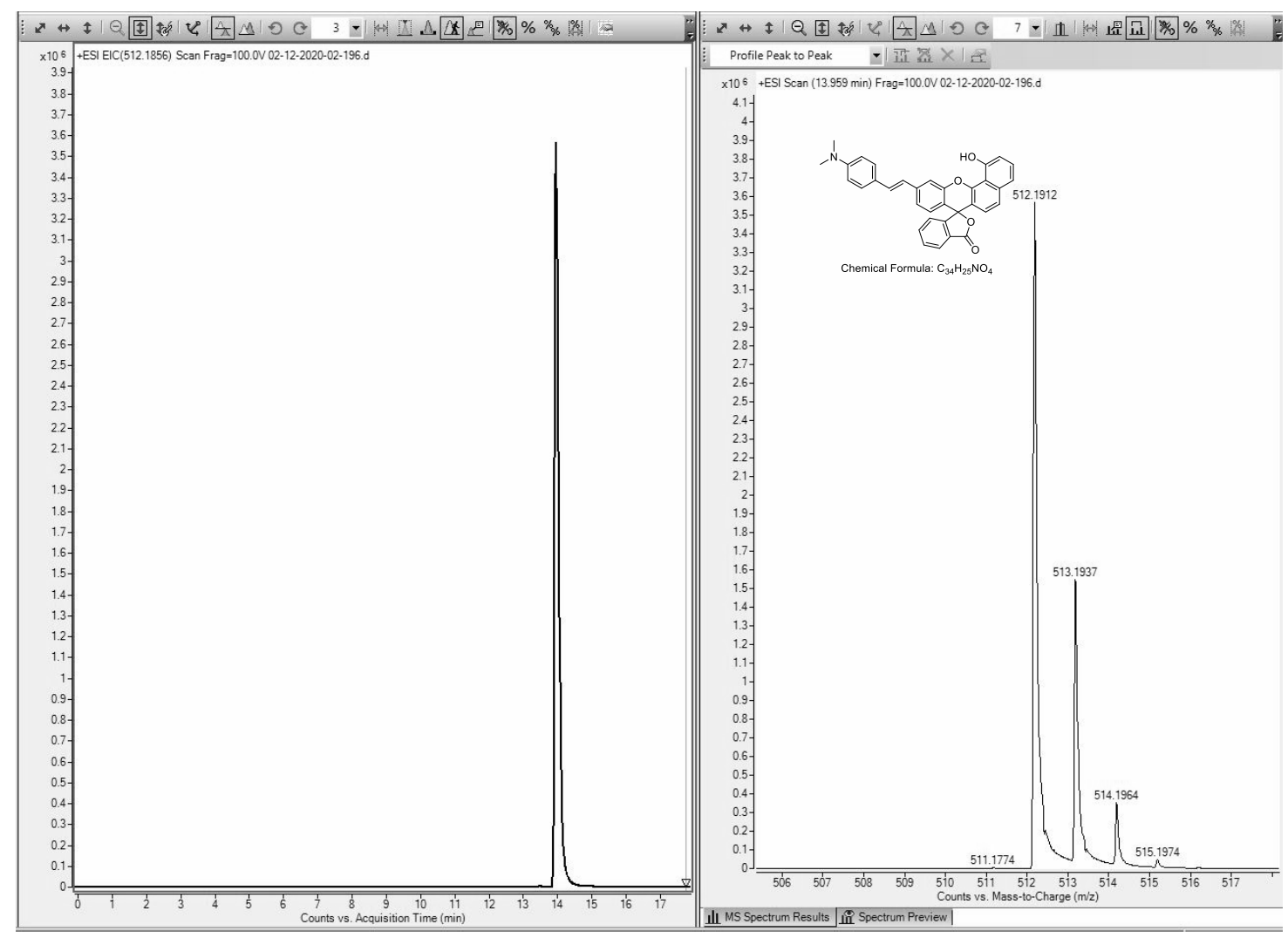

Figure B13. HR ESI positive mode spectrum of compound 34. 